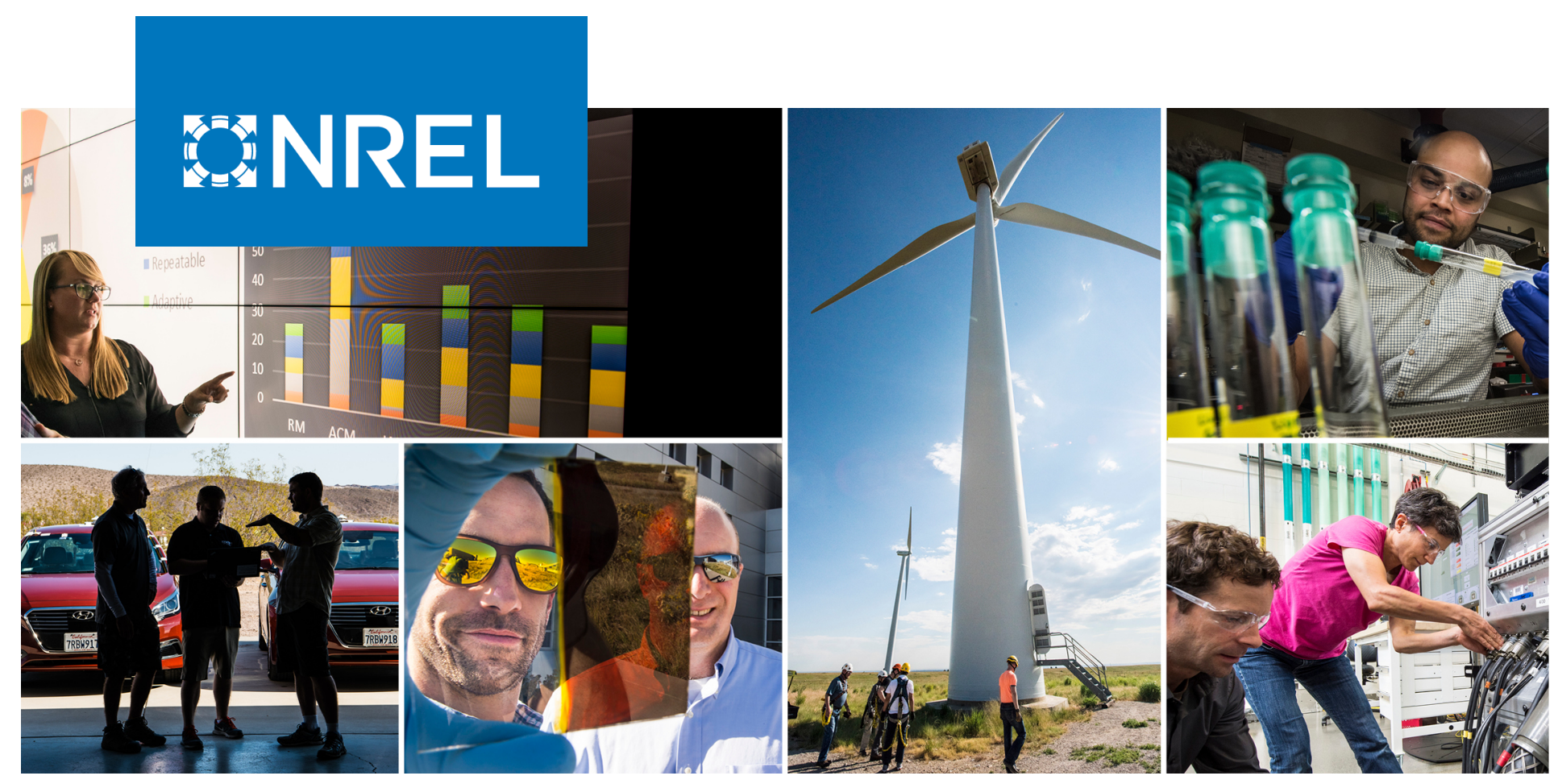

\title{
The Technical and Economic Potential of the H2@Scale Concept within the United States
}

Mark F. Ruth, ${ }^{1}$ Paige Jadun, ${ }^{1}$ Nicholas Gilroy, ${ }^{1}$

Elizabeth Connelly, ${ }^{1}$ Richard Boardman, ${ }^{2}$ A.J. Simon, ${ }^{3}$ Amgad Elgowainy, ${ }^{4}$ and Jarett Zuboy ${ }^{5}$

1 National Renewable Energy Laboratory

2 Idaho National Laboratory

3 Lawrence Livermore National Laboratory

4 Argonne National Laboratory

5 Independent Contractor

NREL is a national laboratory of the U.S. Department of Energy Office of Energy Efficiency \& Renewable Energy

Operated by the Alliance for Sustainable Energy, LLC

This report is available at no cost from the National Renewable Energy Laboratory (NREL) at www.nrel.gov/publications.
Technical Report

NREL/TP-6A20-77610

October 2020 


\section{GNREL}

\section{The Technical and Economic Potential of the H2@Scale Concept within the United States}

Mark F. Ruth, ${ }^{1}$ Paige Jadun, ${ }^{1}$ Nicholas Gilroy, ${ }^{1}$

Elizabeth Connelly, ${ }^{1}$ Richard Boardman, ${ }^{2}$ A.J. Simon, ${ }^{3}$ Amgad Elgowainy, ${ }^{4}$ and Jarett Zuboy ${ }^{5}$

1 National Renewable Energy Laboratory

2 Idaho National Laboratory

3 Lawrence Livermore National Laboratory

4 Argonne National Laboratory

5 Independent Contractor

\section{Suggested Citation}

Ruth, Mark, Paige Jadun, Nicholas Gilroy, Elizabeth Connelly, Richard Boardman, A.J. Simon, Amgad Elgowainy, and Jarett Zuboy. 2020. The Technical and Economic Potential of the H2@Scale Concept within the United States. Golden, CO: National Renewable Energy Laboratory. NREL/TP-6A20-77610. https://www.nrel.gov/docs/fy21osti/77610.pdf.

NREL is a national laboratory of the U.S. Department of Energy Office of Energy Efficiency \& Renewable Energy Operated by the Alliance for Sustainable Energy, LLC

This report is available at no cost from the National Renewable Energy Laboratory (NREL) at www.nrel.gov/publications.

Contract No. DE-AC36-08GO28308
Technical Report NREL/TP-6A20-77610 October 2020

National Renewable Energy Laboratory 15013 Denver West Parkway Golden, CO 80401 303-275-3000 • www.nrel.gov 


\section{NOTICE}

This work was authored by the National Renewable Energy Laboratory, operated by Alliance for Sustainable Energy, LLC, for the U.S. Department of Energy (DOE) under Contract No. DE-AC36-08GO28308. Funding provided by U.S. Department of Energy Office of Energy Efficiency and Renewable Energy Hydrogen and Fuel Cell Technologies Office. The views expressed herein do not necessarily represent the views of the DOE or the U.S. Government.

This report is available at no cost from the National Renewable Energy Laboratory (NREL) at www.nrel.gov/publications.

U.S. Department of Energy (DOE) reports produced after 1991 and a growing number of pre-1991 documents are available free via www.OSTI.gov.

Cover Photos by Dennis Schroeder: (clockwise, left to right) NREL 51934, NREL 45897, NREL 42160, NREL 45891, NREL 48097, NREL 46526.

NREL prints on paper that contains recycled content. 


\section{Acknowledgments}

The authors acknowledge the support and input we have received from many people; without them, this report would not be all it has become. First, we acknowledge the Hydrogen and Fuel Cell Technologies Office, part of the U.S. Department of Energy's (DOE) Office of Energy Efficiency and Renewable Energy (EERE), which leads the H2@Scale initiative within DOE and supported this work with funding and valuable insights. In that office, we acknowledge especially Sunita Satyapal, Fred Joseck, Neha Rustagi, Jason Marcinkoski, Jesse Adams, Zeric Hulvey, and Eric Miller. Michael Berube, as acting Deputy Assistant Secretary for Transportation within EERE, provided valuable insights and guidance that we greatly appreciate. EERE's Bioenergy Technologies Office provided valuable support in understanding and characterizing both biofuel technologies and technologies that convert carbon dioxide to products; we especially appreciate the support provided by Jonathan Male, Zia Haq, and Alicia Lindauer. We also acknowledge the support we received from the Office of Nuclear Energy, especially from Melissa Bates, Martha Shields, and Carl Sink. Other researchers and analysts provided valuable insights and support as well. They include Bryan Pivovar, Josh Eichman, Keith Wipke, Shannon Bragg-Sitton, Max Wei, Karen Studarus, Suzanne Singer, Darlene Steward, Chad Hunter, Todd Ramsden, and John Stevens.

We also recognize the national laboratory team that initially developed the H2@Scale concept and has pushed it to evolve. That team is led by Bryan Pivovar and includes many members across the national laboratory system, including Keith Wipke, Jennifer Kurtz, Josh Eichman, Jamie Holladay, Andrew Weber, Chris Moen, Ted Krause, John Kopasz, Don Anton, David Cullen, Scott McWhorter, Jonathan Zimmerman, and Rod Borup.

Finally, we recognize all those who provided valuable insights as reviewers. Their input improved this report immensely. In addition to those listed above, the reviewers include Matt Pellow, Ron Kent, Andrew Martinez, Ugi Otgonbaatar, Joe Powell, Bryan Chapman, Jeongwoo Han, Ian Sutherland, Trevor Brown, Scott Swartz, Brad Williams, Mark O’Malley, and Mary Biddy. 


\section{List of Acronyms}

\begin{tabular}{|c|c|}
\hline $\mathrm{AEO}$ & Annual Energy Outlook \\
\hline API & American Petroleum Institute \\
\hline BTS & Billion Ton Study \\
\hline $\mathrm{CCS}$ & carbon dioxide capture and sequestration \\
\hline $\mathrm{CO}$ & carbon monoxide \\
\hline $\mathrm{CO}_{2}$ & carbon dioxide \\
\hline $\mathrm{CO}_{2} \mathrm{e}$ & carbon dioxide equivalent \\
\hline CSP & concentrating solar power \\
\hline DOE & U.S. Department of Energy \\
\hline DRI & direct reduction of iron \\
\hline EERE & Office of Energy Efficiency and Renewable Energy \\
\hline EIA & U.S. Energy Information Administration \\
\hline EJ & exajoule \\
\hline EPA & U.S. Environmental Protection Agency \\
\hline FCEV & fuel cell electric vehicle \\
\hline FOGs & fats, oils, and greases \\
\hline GGE & gasoline gallon equivalent \\
\hline GREET & $\begin{array}{l}\text { Greenhouse Gases, Regulated Emissions, and Energy Use in } \\
\text { Transportation (model) }\end{array}$ \\
\hline $\mathrm{H}_{2}$ & hydrogen \\
\hline $\mathrm{H} 2 \mathrm{~A}$ & Hydrogen Analysis (model) \\
\hline $\mathrm{H}_{2}-\mathrm{CT}$ & hydrogen combustion turbine \\
\hline $\mathrm{H}_{2}-\mathrm{FC}$ & hydrogen fuel cell \\
\hline $\mathrm{HC}$ & hydrocarbon(s) \\
\hline HDSAM & Hydrogen Delivery Scenario Analysis Model \\
\hline HDV & heavy-duty vehicle \\
\hline $\mathrm{HHV}$ & higher heating value \\
\hline HTE & high-temperature electrolysis \\
\hline LCOE & levelized cost of energy \\
\hline $\mathrm{LDE}$ & low-cost, dispatch-constrained electricity \\
\hline LDV & light-duty vehicle \\
\hline LHV & lower heating value \\
\hline LOGR & Low Oil and Gas Resource and Technology \\
\hline LTE & low-temperature electrolysis \\
\hline MDV & medium-duty vehicle \\
\hline MHK & marine and hydrokinetic \\
\hline mmBtu & million British thermal units \\
\hline MMT & million metric tons \\
\hline mpgge & miles per gallon gasoline equivalent \\
\hline MT & metric ton \\
\hline MTG & methanol-to-gasoline \\
\hline $\mathrm{MWh}_{\mathrm{e}}$ & MWh electric \\
\hline $\mathrm{MWh}_{\text {th }}$ & MWh thermal energy (heat) \\
\hline NETL & National Energy Technology Laboratory \\
\hline NG & natural gas \\
\hline
\end{tabular}


NGCC

NGCT

$\mathrm{NO}_{\mathrm{x}}$

NREL

PEC

PEM

PEV

$\mathrm{PM}_{10}$

PV

R\&D

RE

ReEDS

RPS

SMR

$\mathrm{SOEC}$

$\mathrm{SO}_{\mathrm{x}}$

STCH

Tcf

TWh

VMT

VRE

ZEV natural gas combined cycle

natural gas combustion turbine

nitrogen oxides

National Renewable Energy Laboratory

photoelectrochemical

polymer electrolyte membrane

plug-in electric vehicle

particles with diameters 10 micrometers and smaller

photovoltaics

research and development

renewable energy

Regional Energy Deployment System (model)

renewable portfolio standard

steam methane reforming

solid oxide electrolysis

sulfur oxides

solar thermochemical

trillion cubic feet

terawatt-hours

vehicle miles traveled

variable renewable energy

zero-emission vehicle 


\section{Executive Summary}

The U.S. energy system is evolving as society and technologies change. Renewable electricity generation - especially from wind and solar - is growing rapidly, and alternative energy sources are being developed and implemented across the residential, commercial, transportation, and industrial sectors to take advantage of their cost, security, and health benefits. Systemic changes present numerous challenges to grid resiliency and energy affordability, creating a need for synergistic solutions that satisfy multiple applications while yielding system-wide cost and emissions benefits. One such solution is an integrated hydrogen energy system (Figure ES-1). ${ }^{1}$ This is the focus of H2@Scale-a U.S. Department of Energy (DOE) initiative led by the Office of Energy Efficiency and Renewable Energy's Hydrogen and Fuel Technologies Office. H2@Scale brings together stakeholders to advance affordable hydrogen production, transport, storage, and utilization in multiple energy sectors.

The H2@Scale concept involves hydrogen as an energy intermediate. Hydrogen can be produced from various conventional and renewable energy sources including as a responsive load on the electric grid. Hydrogen has many current applications and many more potential applications, such as energy for transportation - used directly in fuel cell electric vehicles (FCEVs), as a feedstock for synthetic fuels, and to upgrade oil and biomass-feedstock for industry (e.g., for ammonia production, metals refining, and other end uses), heat for industry and buildings, and electricity storage. Owing to its flexibility and fungibility, a hydrogen intermediate could link energy sources that have surplus availability to markets that require energy or chemical feedstocks, benefiting both.

This document builds upon a growing body of analyses of hydrogen as an energy intermediate by reporting the results from our initial analysis of the potential impacts of the H2@Scale concept by the mid- $21^{\text {st }}$ century for the 48 contiguous U.S. states. ${ }^{2}$ Previous estimates have been based on expert elicitation and focused on hydrogen demands. We build upon them, first, by estimating hydrogen's serviceable consumption potential for possible hydrogen applications and the technical potential for producing hydrogen from various resources. We define the serviceable consumption potential as the quantity of hydrogen that would be consumed to serve the portion of the market that could be captured without considering economics (i.e., if the price of hydrogen were $\$ 0 / \mathrm{kg}$ over an extended period); thus, it can be considered an upper bound for the size of the market. We define the technical potential as the resource potential constrained by real-world geography and system performance, but not by economics. We then compare the cumulative serviceable consumption potential with the technical potential of a number of possible sources.

Second, we estimate economic potential: the quantity of hydrogen at an equilibrium price at which suppliers are willing to sell and consumers are willing to buy the same quantity of hydrogen. We believe this method provides a deeper understanding than was available in the previous analyses. We develop economic potentials for multiple scenarios across various market and technology-advancement assumptions.

\footnotetext{
${ }^{1}$ See the H2@Scale website (https://www.energy.gov/eere/fuelcells/h2-scale) for more information.

${ }^{2}$ We use projected 2050 market sizes. For FCEVs, we use a 2050 market size, but, because the vehicle choice model is not at equilibrium in 2050, we use vehicle shares from a later date (2075) when they have equilibrated.
} 
This work was performed according to the direction of the Spark M. Matsunaga Hydrogen Act of 2005 (U.S. Congress 2005). The Act directed the Secretary of Energy to conduct research activities "to address production of hydrogen from diverse energy resources including - fossil fuels, which may include carbon capture and sequestration; hydrogen-carrier fuels (including ethanol and methanol); renewable energy resources, including biomass; and nuclear energy." Additionally, in 2017 the Hydrogen Technical Advisory Committee recommended that DOE take action to support "the potential for fuel shortages. For example, in Southern California where FCEV purchases have been strong, hydrogen fuel capacity is being outpaced by demand. Sustained investments in additional production capacity buildout are needed" (Hydrogen and Fuel Cell Technical Advisory Committee 2017).

This report addresses the technical potential of hydrogen production from fossil fuels, renewable resources, and nuclear energy to supply diverse applications, including transportation.

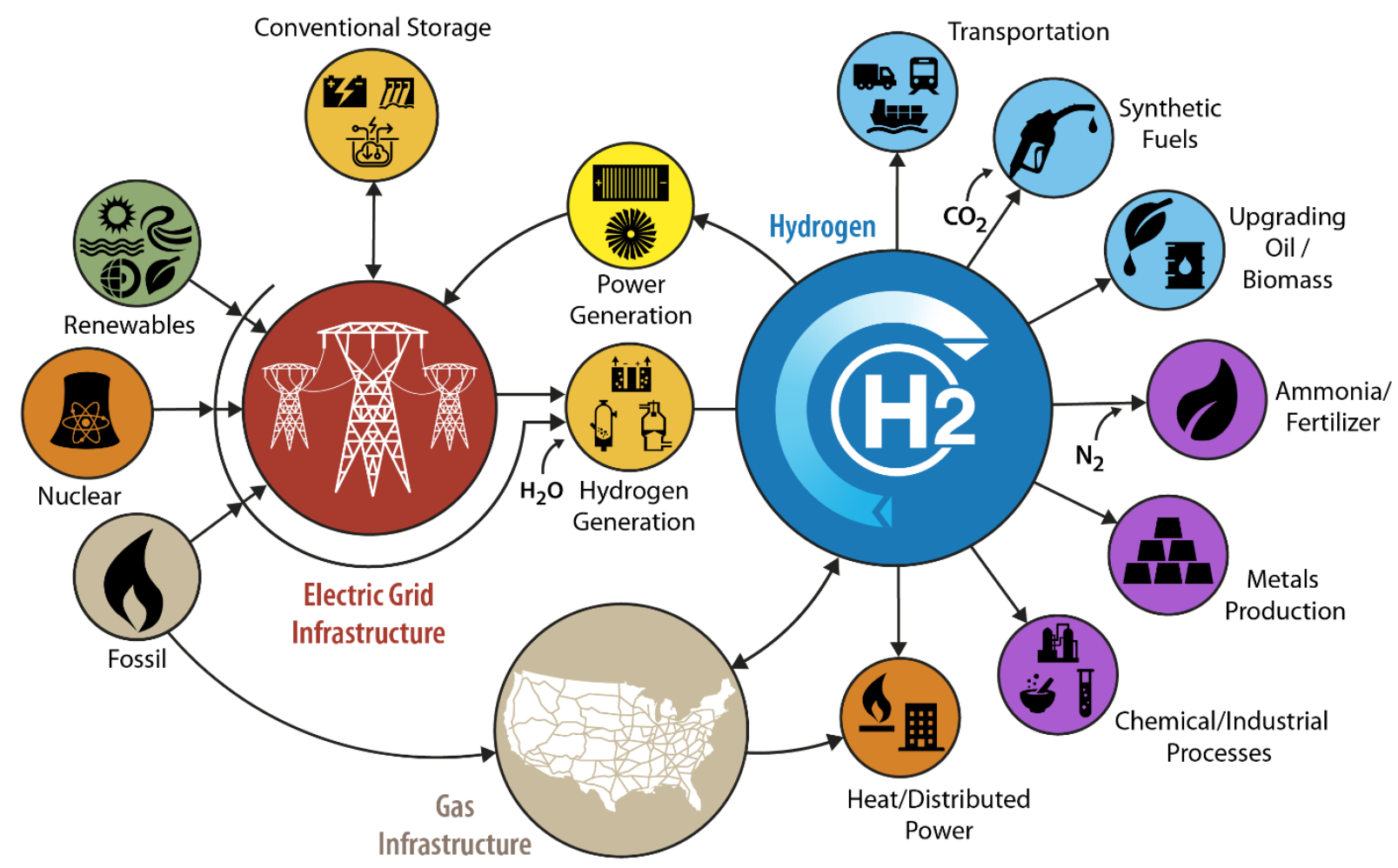

Figure ES-1. Schematic illustration of the H2@Scale concept (not comprehensive) (Pivovar, Rustagi, and Satyapal 2018)

\section{Serviceable Consumption Potential and Technical Potential}

We use the latest research and expert consultation to estimate the serviceable consumption potential of hydrogen as well as the technical potential for producing hydrogen from various resources. This initial analysis estimates a serviceable consumption potential of 106 million metric tons per year (MMT/yr) across nine applications (Table ES-1) - approximately 11 times larger than the 2015 U.S. on-purpose hydrogen production of $10 \mathrm{MMT} / \mathrm{yr}$ of hydrogen, which is used primarily for oil refining and ammonia production. The hydrogen demand for those two applications is expected to grow owing to the need to refine heavier crude oils and increased 
demands for fertilizer. Almost half of the potential market is for industrial processes, including synthetic hydrocarbon production (14 MMT/yr), metals refining (12), oil refining (7), ammonia production (4), and biofuels production (9). FCEVs accounts for over a quarter of the serviceable consumption potential (29 MMT/yr). The final quarter is for hydrogen that supports other energy systems: seasonal electricity storage (15 MMT/yr) and injection into the natural gas system (16). Other applications for hydrogen could evolve in the future to increase the serviceable consumption potential.

Table ES-1. Serviceable Consumption Potential for Hydrogen Applications

\begin{tabular}{lcc}
\hline Application & $\begin{array}{c}\text { Serviceable } \\
\text { Consumption Potential } \\
\text { (MMT/yr) }\end{array}$ & $\begin{array}{c}\text { 2015 Market for } \\
\text { On-Purpose } \mathbf{H}_{2} \\
\text { (MMT/yr) }\end{array}$ \\
\hline Oil refining & 7 & 6 \\
Metals refining & 12 & 0 \\
Ammonia & 4 & 3 \\
Biofuels & 9 & 0 \\
Synthetic hydrocarbons & 14 & 1 \\
Natural gas supplementation & 16 & 0 \\
Seasonal energy storage for the electric grid & 15 & 0 \\
\hline Industry and Storage Subtotal & $\mathbf{7 7}$ & $\mathbf{1 0}$ \\
\hline Light-duty FCEVs & 21 & 0 \\
Medium- and heavy-duty FCEVs & 8 & 0 \\
\hline Transportation Fuel Subtotal & $\mathbf{2 9}$ & $\mathbf{0}$ \\
\hline Total & $\mathbf{1 0 6}$ & $\mathbf{1 0}$ \\
\hline
\end{tabular}

Oil refining is rounded from 7.5 MMT/yr to $7 \mathrm{MMT} / \mathrm{yr}$ in this table so that the total and subtotals match the sum of the rounded values.

a "On-purpose hydrogen" considers consumption of captive hydrogen (produced intentionally by the consuming industry) and merchant hydrogen (produced intentionally for sale), but not consumption of captive byproduct hydrogen production.

We calculate the technical potentials of hydrogen-production technologies based on the availability of their feedstocks. Production technologies considered include steam methane reforming (SMR) using natural gas, coal gasification, high-temperature electrolysis (HTE) using nuclear power, low-temperature electrolysis (LTE), and biomass gasification. Hydrogen can also be produced by other methods that are outside the scope of this effort, including photoelectrochemical, biochemical, high-temperature thermochemical, and hybrid methods such 
as HTE with other sources of heat. Key conclusions regarding maximum serviceable consumption potential (not including considerations of economics) include the following ${ }^{3}$ :

- The full serviceable hydrogen consumption potential of $106 \mathrm{MMT} / \mathrm{yr}$ could be produced from only $2.1 \%$ of the annual technical potential of U.S. solar electricity, assuming that other domestic uses of solar resource continue at 2017 levels.

- The full serviceable hydrogen consumption potential could be produced from only $15 \%$ of the annual technical potential of electricity from combined U.S. onshore and offshore wind resources, assuming that other domestic uses of wind resource continue at 2017 levels.

- The full serviceable hydrogen consumption potential could be produced from only $22 \%$ of the annual technical potential of U.S. geothermal electricity, assuming that other domestic uses of geothermal resource continue at 2017 levels.

- The full serviceable hydrogen consumption potential could not be produced exclusively from the annual technical potential of U.S. biomass resources, assuming that other uses for biomass continue at 2017 levels. Production of the entire maximum potential of hydrogen demand from biomass alone would require $160 \%$ of the annual technical potential of U.S. biomass resources.

- The full serviceable consumption potential could not be produced exclusively from the annual technical potential of U.S. hydropower resources, assuming that other uses for hydropower continue at 2017 levels. Using electrolysis, $820 \%$ of the conventional hydropower resource or $300 \%$ of the advanced hydropower resource would be required. Thus, $230 \%$ of the total hydropower resource would be required.

- We do not anticipate uranium resources to limit the nuclear HTE potential, because of the potential for advancements in uranium recovery technology to enable access to unconventional resources (e.g., seawater).

- Proven and unproven U.S. natural gas reserves can generate sufficient hydrogen to supply the full serviceable hydrogen consumption potential of $106 \mathrm{MMT} / \mathrm{yr}$ for about 55 years, assuming other current demands for natural gas also continue and that the carbon dioxide emissions are not sequestered. If carbon sequestration is desired, impacts on efficiency and availability of geologic formations suitable for carbon sequestration could constrain natural gas use and thus reduce potential hydrogen production from the natural gas resource. Further analysis would be needed to quantify that impact.

- The demonstrated U.S. coal reserve base can generate sufficient hydrogen to supply the full serviceable hydrogen consumption potential for 260 years, assuming that conventional demands for coal also continue and that the carbon dioxide emissions are not sequestered. If carbon sequestration is desired, impacts on efficiency and availability of geologic formations suitable for carbon sequestration could constrain coal use and thus reduce potential hydrogen production from the coal resource. Further analysis would be needed to quantify that impact.

\footnotetext{
${ }^{3}$ For fossil and nuclear resources, we estimate the number of years that reserves could meet current demands and also serve as the single source for $106 \mathrm{MMT} / \mathrm{yr}$ of hydrogen. For renewables, we estimate the percentage of annual technical potential to meet current demand and serve as the single source for $106 \mathrm{MMT} / \mathrm{yr}$ of hydrogen.
} 
Even in the unlikely event of the hydrogen market reaching its serviceable consumption potential size, the United States has more than enough resources to meet all foreseeable demands and make hydrogen a key component of its energy system.

\section{Economic Potential}

We developed this initial estimate of hydrogen's economic potential by developing supply and demand curves for hydrogen production and use. The demand curves are based on the threshold price (i.e., our estimate of the maximum price customers are willing to pay) for various quantities of hydrogen in each market, which is affected by projected prices for alternatives that could provide the same service (e.g., fuel for vehicles, feedstock for metals refining). The supply curves are for hydrogen produced via natural gas SMR, nuclear HTE, biomass gasification, and LTE using low-cost, dispatch-constrained electricity (LDE) — electricity (particularly from wind, solar, and nuclear generation) that may be available at low costs for supplementary demand such as LTE.

We estimate hydrogen's economic potential to be 22-41 MMT/yr in the contiguous United States depending on resource prices, market conditions, hydrogen technology R\&D and fueling infrastructure availability, and the prices various users will pay for hydrogen, which depend on the cost of other technologies that provide the same services without changes to the current federal and state policy. The range is based on five scenarios with varying assumptions across those key factors as reported in Table ES-2. Specific variations across the scenarios include natural gas prices, hydrogen market assumptions for metals refining, hydrogen fueling infrastructure R\&D success and availability, R\&D-driven reductions in LTE costs, and the financial incentives for LTE providing grid support. These estimates are based on markets reaching equilibrium as well as our assumptions regarding technology improvements, hydrogen markets, and competition within those markets. They also include simple hydrogen transport and storage cost assumptions. They do not include potential economic feedback such as rebound effects where prices for resources and competing technologies change owing to hydrogen impacts on their market sizes. Additional analysis would be necessary to understand regional issues, estimate transport and storage costs rigorously, and identify key factors in economic transitions. Those transition analyses could quantify differences between likely market equilibria and our estimates as well as whether equilibrium might be reached and when that might occur. In addition, detailed regional analyses may identify additional hydrogen opportunities, but they are outside the scope of this effort. To provide some insights, we analyze the sensitivity of each scenario to changes in various parameters (see Section 6.8).

Figure ES-2 shows the economic potentials for each scenario by hydrogen demand application and production technology.

Table ES-2. Five Scenarios Used to Estimate Economic Potential

\begin{tabular}{ll}
\hline Scenario Name & Description \\
\hline Reference & $\begin{array}{l}\text { Current status of hydrogen technologies. Relatively low natural } \\
\text { gas prices }\end{array}$ \\
$\begin{array}{l}\text { R\&D Advances + } \\
\text { Infrastructure }\end{array}$ & $\begin{array}{l}\text { Same as Reference scenario except with expected cross-sector } \\
\text { hydrogen technology improvement and demand growth, fueling } \\
\text { infrastructure availability, and robust hydrogen demand for metals }\end{array}$
\end{tabular}




\begin{tabular}{ll}
\hline Scenario Name & Description \\
\hline $\begin{array}{l}\text { Low NG Resource/High } \\
\text { NG Price }\end{array}$ & $\begin{array}{l}\text { Same as R\&D Advances + Infrastructure scenario except with higher } \\
\text { natural gas prices }\end{array}$ \\
$\begin{array}{l}\text { Aggressive Electrolysis } \\
\text { R\&D }\end{array}$ & $\begin{array}{l}\text { Same as Low NG Resource/High NG Price scenario except LTE } \\
\text { purchase cost reduced to \$200/kW, and LTE receives some } \\
\text { compensation for grid support }\end{array}$ \\
Lowest-Cost Electrolysis & $\begin{array}{l}\text { Same as Aggressive Electrolysis R\&D scenario except LTE purchase } \\
\text { costs are reduced to \$100/kW and wholesale electricity selling prices } \\
\text { can be accessed for LTE }\end{array}$ \\
\hline
\end{tabular}

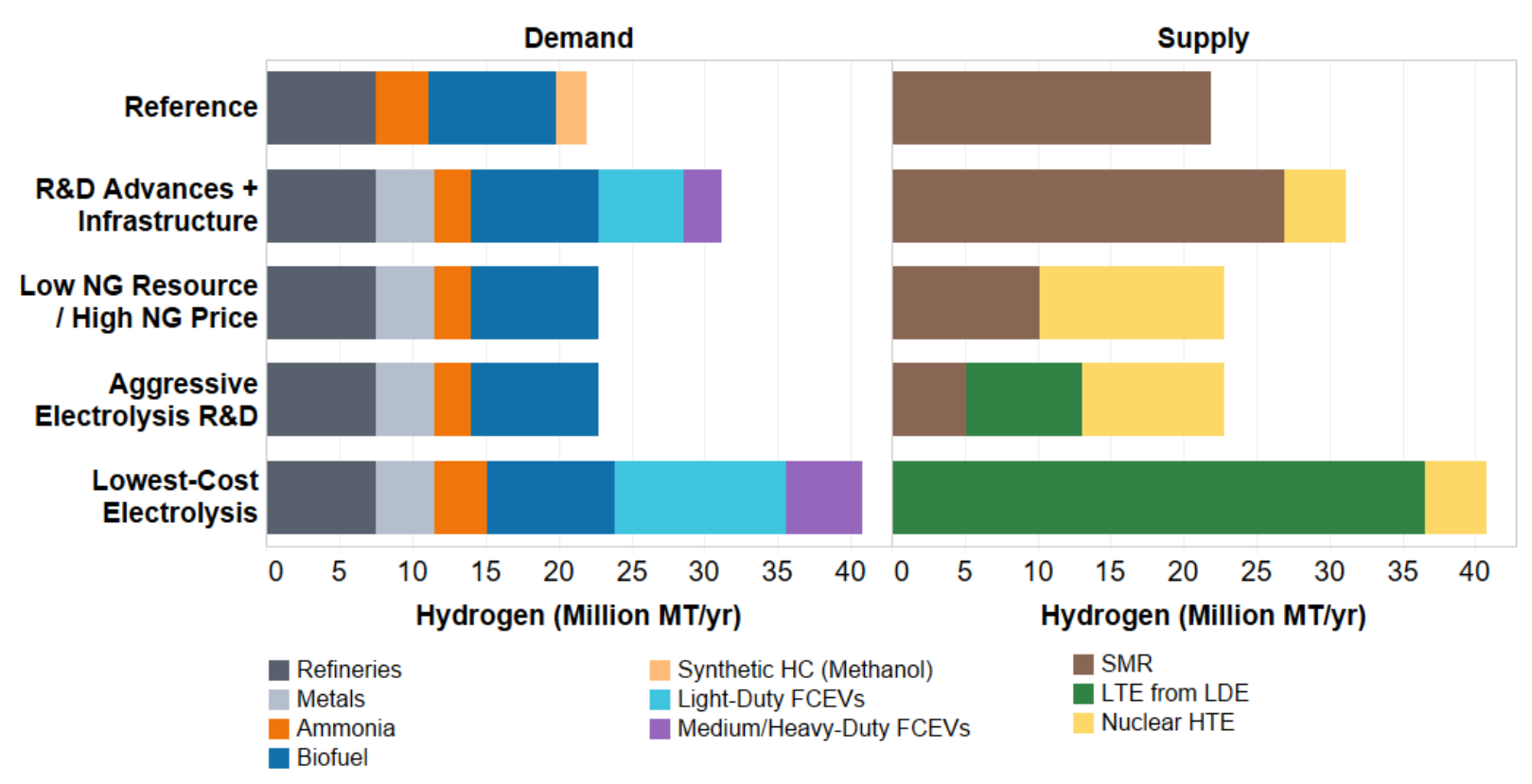

Figure ES-2. Hydrogen supply sources and demand applications for each H2@Scale scenario

The Reference scenario has a hydrogen market size of $22 \mathrm{MMT} / \mathrm{yr}$. It is based on the current status of hydrogen technologies and expected hydrogen demand growth across all sectors. It assumes U.S. Energy Information Administration Annual Energy Outlook Reference scenario natural gas prices and electrolysis costs based on current technology with robust supply chains, but it does not include fueling infrastructure development for FCEVs or compensation for grid support (i.e., LDE is available at retail price). All hydrogen production is from natural gas via SMR, because the cost of nuclear- and LTE-generated hydrogen is too high to compete with SMR. The current hydrogen markets (oil refining, ammonia, and methanol) and biofuel production are the primary demands in this scenario owing to the lack of alternatives for hydrogen for those processes.

The R\&D Advances + Infrastructure scenario has a larger market size of $31 \mathrm{MMT} / \mathrm{yr}$, because it includes increased hydrogen demands for metals refining and FCEVs (light-duty and medium/heavy-duty). The FCEV demand is driven by achieving the threshold hydrogen price of $\$ 5.00$ at the fueling station $(\$ 2.20 / \mathrm{kg}$ at the terminal) and in the price of FCEVs. This and following scenarios include assumptions that delivery and dispensing technologies meet targets and the infrastructure develops. However, the demand from FCEVs squeezes out some demand 
growth for ammonia and methanol by driving the hydrogen price up. As in the Reference scenario, the vast majority of hydrogen production is from natural gas via SMR, with a fraction produced via nuclear HTE. Just under half of the hydrogen is used for oil refining, metals refining, and ammonia production; the other half is used for biofuels production and FCEVs.

At $23 \mathrm{MMT} / \mathrm{yr}$, the Low NG Resource/High NG Price scenario has a smaller market than the R\&D Advancements + Infrastructure scenario, because higher natural gas prices drive higher hydrogen prices. Demands for oil refining, metals refining, ammonia, and biofuels are the same as in the R\&D Advances + Infrastructure Scenario, but insufficient low-cost hydrogen is available for any FCEV use. Higher natural gas prices also result in a larger market share for nuclear HTE-generated hydrogen (approximately 55\%).

The Aggressive Electrolysis R\&D scenario includes lower-cost LTE than the first three scenarios and retains the demand assumptions in the R\&D Advances + Infrastructure and Low NG Resource/High NG Price scenario. The resulting market size of $23 \mathrm{MMT} / \mathrm{yr}$ is the same as in the Low NG Resource/High NG Price scenario, but the market shares for generation change. Owing to the more aggressive LTE technology and electricity price assumptions, LTE-generated hydrogen is more competitive and takes about one third of the market, while SMR falls to about $22 \%$ and nuclear HTE to about $43 \%$.

The Lowest-Cost Electrolysis scenario has the largest market (41 MMT/yr) owing to its combination of high demand and low hydrogen prices enabled by low-cost LTE technologies and access to wholesale LDE prices. Approximately 90\% (37 MMT/yr) of the hydrogen is produced using LTE, with the remaining $4 \mathrm{MMT} / \mathrm{yr}$ from nuclear HTE. The larger ammonia market requiring $4 \mathrm{MMT} / \mathrm{yr}$ appears in this scenario as it does in the Reference scenario. In addition, this scenario has the highest FCEV demand (17 MMT/yr) because it has the lowest hydrogen price.

\section{Conclusions}

By comparing these results to the impacts of scenarios that do not have integrated hydrogen energy systems, we draw several key conclusions about the potential of the H2@Scale concept:

The domestic hydrogen market could increase 2 - to 4-fold if $R \& D$ targets are met and market and transition barriers are overcome. At those market sizes, hydrogen production is $4-17 \%$ of primary energy use. If the requisite conditions are achieved, hydrogen could provide energy and feedstock options that cost less than competing alternatives. In the Reference scenario, the hydrogen market size is $22 \mathrm{MMT} / \mathrm{yr}$ which is double the current market and equivalent to 3.0 quad/yr (2.6\% of primary energy). At $41 \mathrm{MMT} / \mathrm{yr}$ ( 8 quad/yr), the hydrogen market in the Lowest-Cost Electrolysis scenario is $6.4 \%$ of primary energy. Total energy input for hydrogen production is $17 \%$ of primary energy when calculated using an avoided fossil energy generation method. ${ }^{4}$

\footnotetext{
4 The avoided fossil energy generation method is used to provide an equivalent comparison between energy resources in the Annual Energy Outlook (EIA 2017a). It involves dividing the electricity generated using renewable resources by the average fossil-electricity generation efficiency $(37 \%)$.
} 
Conditions shown to maximize that increase include reducing the purchase price of LTEs to at most $\$ 200 / \mathrm{kW}$ (as in the Aggressive Electrolysis R\&D scenario) but more beneficially to $\$ 100 / \mathrm{kW}$ (as in the Lowest-Cost Electrolysis scenario) and giving electrolyzers access to at least some compensation for providing grid services (as in the Aggressive Electrolysis R\&D scenario) but more beneficially access to wholesale LDE prices (as in the Lowest-Cost Electrolysis scenario). The combination of lower capital cost and access to lower-cost electricity allows the LTE to use low-priced electricity when available. While using only low-priced electricity results in lower capacity factors than using electricity at all times, it also results in lower cost hydrogen supply. Although the combination of lower capital cost and wholesale LDE prices is required for substantial expansion, electricity price has a somewhat stronger impact on market size than the electrolyzer capital cost does. Very low capital costs provide little market expansion without wholesale LDE prices. Similarly, market expansion is modest in the absence of capital cost reductions, even when wholesale LDE prices are available.

An increased hydrogen market size can be realized even if low-cost LTE is not available as long as other hydrogen production options are available, including the following:

- SMR with low-cost natural gas - The low cost of natural gas in the R\&D Advances + Infrastructure scenario results in a large hydrogen market owing to cost-competitive FCEVs and fueling infrastructure, which is not observed in the scenarios with higher natural gas costs and without the lowest-cost LTE options (the Low NG Resource/High NG Price and Aggressive Electrolysis R\&D scenarios). We assume the quantity of natural gas reforming growth is capped at three times current values to approximate the potential natural gas price increases that would occur due to increased demand for hydrogen production. If LTE or LDE costs are high and the quantity of natural gas reforming were not capped, a larger hydrogen market would be possible.

- Low-cost HTE, even when constrained to use nuclear energy only-Our constraining of HTE technologies to be attached to nuclear plants limits their production to $13 \mathrm{MMT} / \mathrm{yr}$ or less in the scenarios we consider, depending on the cost of hydrogen from other sources. If HTE technology could employ additional cost-competitive energy sources (e.g., LDE or grid electricity coupled with natural gas-generated heat), the hydrogen market size might increase.

- Biomass - If the biomass resource is available for hydrogen production (because other potential applications do not outcompete for it), it supplies $22 \mathrm{MMT} / \mathrm{yr}$ of the hydrogen in a $34 \mathrm{MMT} / \mathrm{yr}$ market owing to its price competitiveness with natural gas, LTE, and HTE technologies.

Transportation is the largest new hydrogen market opportunity. Light-, medium-, and heavy-duty FCEV fuel constitutes 29 MMT/yr (27\%) of the serviceable consumption potential. That hydrogen demand could reduce petroleum use by up to $15 \%$. Among our economic potential scenarios, the Lowest-Cost Electrolysis scenario yields the largest reduction in petroleum use (15\%), because it has the highest FCEV penetration: $12 \mathrm{MMT} / \mathrm{yr}$ of hydrogen fuels $18 \%$ of cars and $26 \%$ of light-duty trucks, and $5 \mathrm{MMT} / \mathrm{yr}$ fuels $22 \%$ of the medium- and heavy-duty vehicle fleet.

Other new hydrogen markets are also possible. Biofuel production is consistently a growth market for hydrogen based on our assumptions that biofuels will have a significant share in the aviation fuels market and that hydrotreating and hydrogenation will be important in producing 
those fuels. Additional analysis on biofuel markets and process designs would improve the quantification of that opportunity. Metals refining is a growth opportunity across most of our scenarios; however, we assume market support to increase U.S. steel production using hydrogen. Additional R\&D is needed for steel production using hydrogen to meet our hydrogen demand target for this application. Synthetic methanol production for a methanol-to-gasoline (MTG) fuel does not appear in our core scenarios, but sensitivities indicate that technology R\&D and market opportunities such as a desire for non-fossil liquid fuels would result in growth of that market. Likewise, injection into natural gas pipelines and seasonal electricity storage do not appear in our core scenarios, because, within this national-scale analysis, hydrogen is not cost-competitive for these applications under our assumptions. However, this analysis does not capture the full variability of electricity net loads or potential policy/cost drivers of $100 \%$ or near- $100 \%$ renewable energy targets, emission reductions, and other factors that could impact those results.

LTE could boost renewable electricity generation deployment and utilization. When LTE contributes to hydrogen production in our scenarios, the capacity of renewable energy generation technologies increases because of additional demand for LDE. In addition, utilization of renewable electricity generators increases, because generation that exceeds the non-LTE load would be curtailed without the LTE. These two effects amplify the benefits of the integrated system. The renewable generators supply the grid when grid electricity is required, and they supply LTE hydrogen production with LDE when grid electricity is not required. In the LowestCost Electrolysis scenario, renewable electricity generation increases by more than $60 \%$ over the ReEDS High Curtailment scenario, and natural gas use for electricity decreases by $27 \%$.

The impacts of an integrated hydrogen system could be larger. We calculate a serviceable consumption potential hydrogen market size of $106 \mathrm{MMT} / \mathrm{yr}$ in the contiguous 48 states, more than 2.5 times as large as our largest estimate of economic potential (under the Lowest-Cost Electrolysis scenario), and we identify ample U.S. resources for satisfying this higher demand. However, non-economic drivers or economic conditions outside the scope of this analysis would be necessary to realize this demand. For example, higher-than-estimated prices for liquid fuels could increase the demand for hydrogen to fuel FCEVs more than our economic potential estimates indicate. Sensitivity analysis shows that - if drivers outside the scope of this analysis increase the demands for nonpetroleum fuel, hydrogen injection into the natural gas system, and seasonal electricity storage - the market size in the Lowest-Cost Electrolysis scenario could increase by over 100\% (from 41 to $94 \mathrm{MMT} / \mathrm{yr}$ ).

Growth in the H2@Scale concept will require delivery and storage infrastructure. In general, modeled hydrogen demand is projected to be near population centers, because most current oil refineries and ammonia plants are relatively close to population centers, and demand growth is dominated by FCEVs operating primarily in these areas. However, demands for metals refining, biofuel production, and possibly methanol production could be in rural areas. Production locations are highly technology dependent. SMR is close to demand locations, because the natural gas system is ubiquitous and SMR plants can be built to the size needed. HTE is likely to be far from most demand sites, because heat cannot be transmitted well over long distances. LTE is also likely to be located far from demand centers to align with high wind and solar generation; however, if transmission is available, it could be closer to the application and farther from the electricity source. Biomass conversion is close to the resource because of the cost of transporting biomass. Hence, if non-SMR alternatives for hydrogen production are to be developed, improved 
technology and infrastructure for transporting hydrogen from production areas to demand centers likely will be needed. Our analysis does not address those issues in detail; thus, additional analysis is warranted on optimal infrastructure and the requirements for and impacts of infrastructure costs while markets are emerging.

In conclusion, this initial analysis shows that hydrogen has potential to provide technical and economic synergies when integrated across multiple sectors of the U.S. energy system. To realize the potential of the H2@Scale concept, continued R\&D and deployment are required, particularly with regard to electrolyzer technology. Also, continuing evolution of electricity markets that would allow electrolyzers to monetize the energy and grid services that they can provide would enable considerable opportunities. 


\section{Table of Contents}

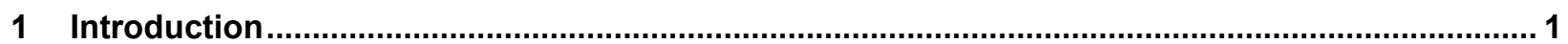

1.1 Hydrogen's Potential Roles in the U.S. Energy System ...................................................2

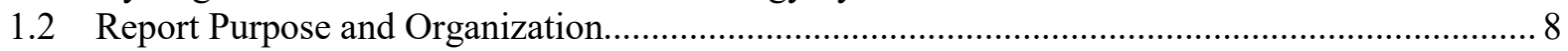

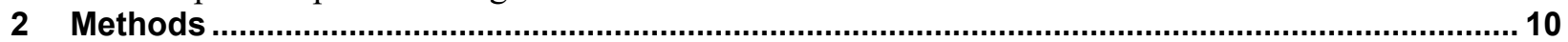

2.1 Estimating Technical Potential and Serviceable Consumption Potential................................. 10

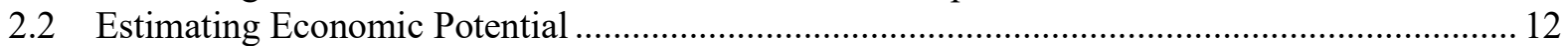

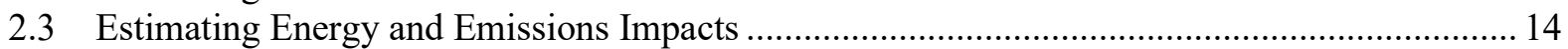

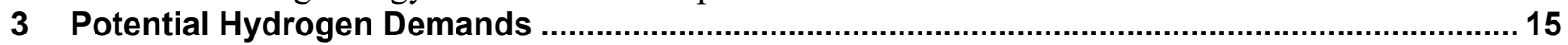

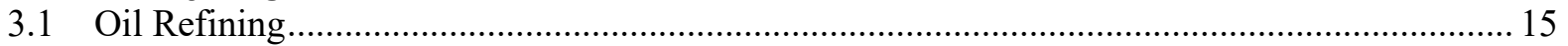

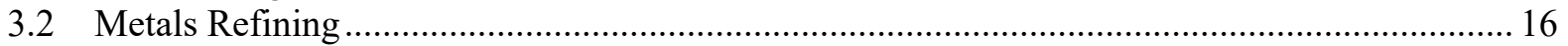

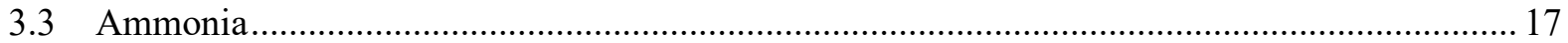

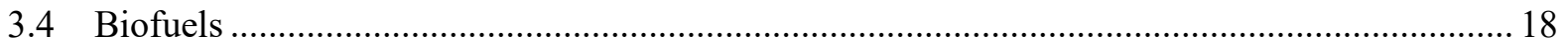

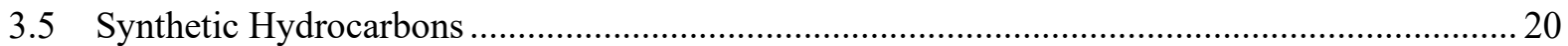

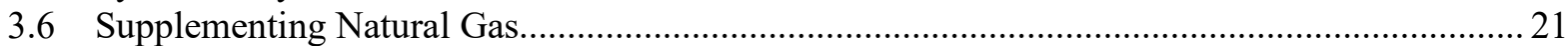

3.7 Seasonal Energy Storage for the Electric Grid............................................................. 22

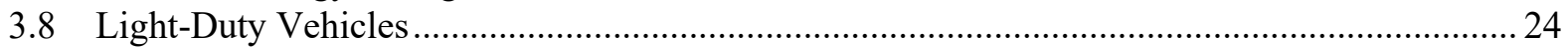

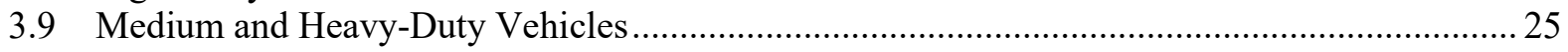

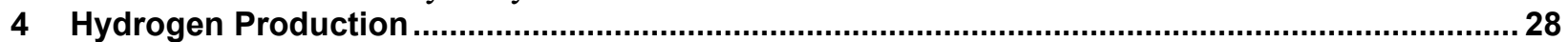

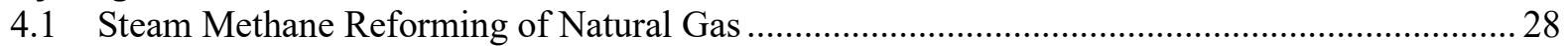

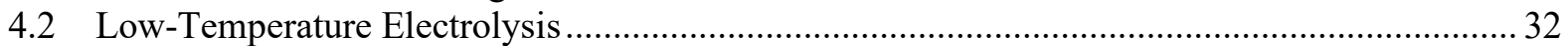

4.3 High-Temperature Electrolysis Using Nuclear-Generated Heat .............................................. 40

4.4 Production from Biomass Resources ........................................................................ 44

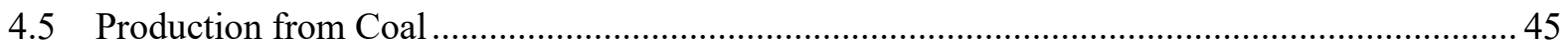

4.6 Other Production Technologies.................................................................................................. 46

5 Serviceable Consumption Potential and Technical Potential................................................. 48

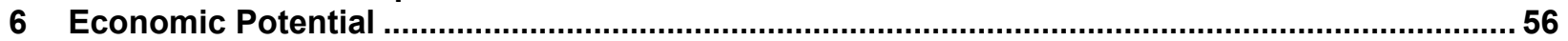

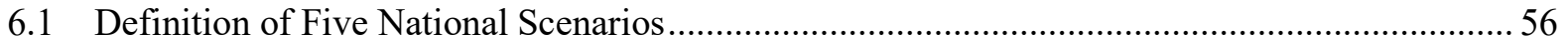

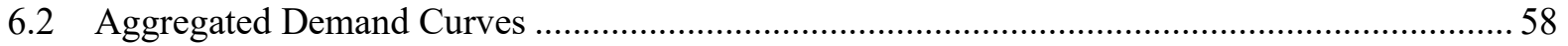

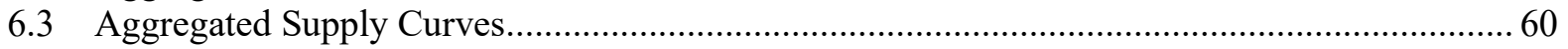

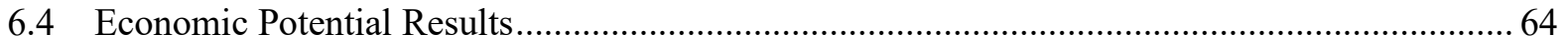

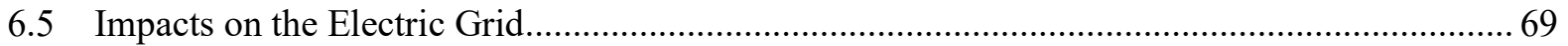

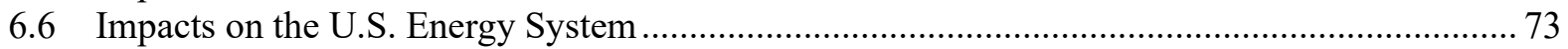

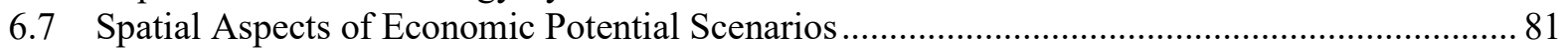

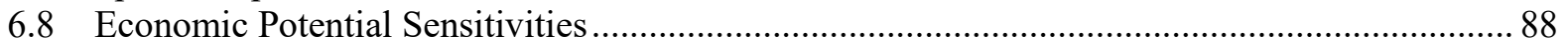

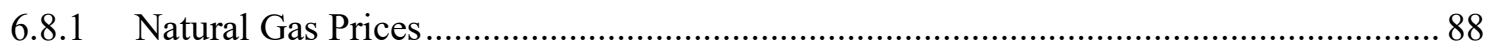

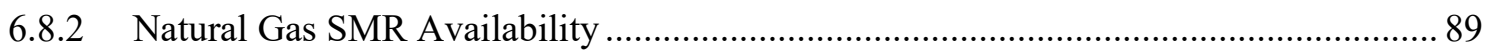

6.8.3 LTE Cost and Electricity Market Access .............................................................. 92

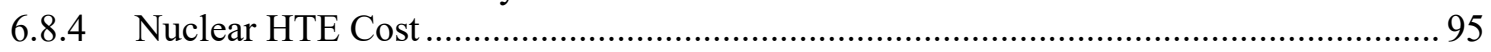

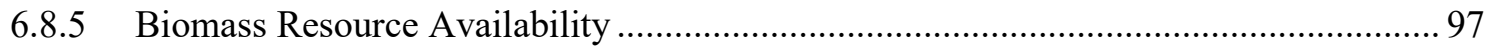

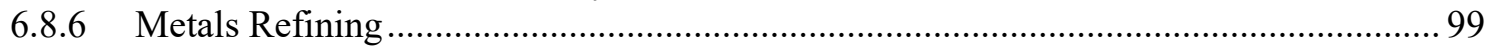

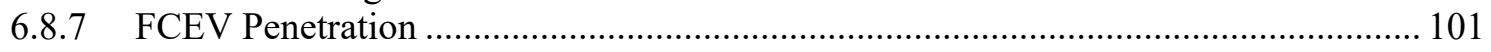

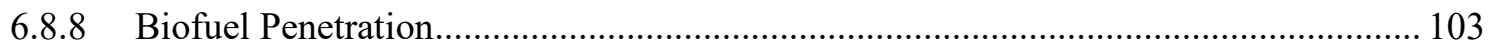

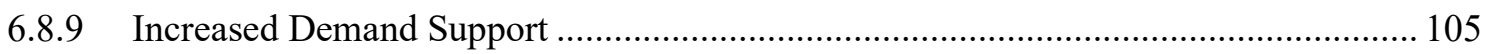

6.8.10 Summary of Economic Potential Sensitivities .................................................... 107

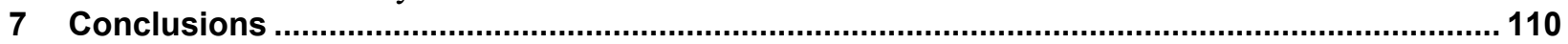

8 Analysis Limitations and Additional Analysis Needs ......................................................115

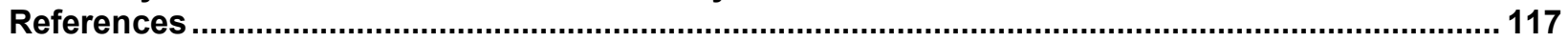

Appendix A. Summary of Economic Potential Assumptions .................................................. 128

Appendix B. Methodology and Data for Estimating U.S. Energy Use and Emissions Impacts 137 
Appendix C. Estimate of Serviceable Consumption Potential and Economic Potential for Seasonal Electricity Storage .................................................................................................. 142
Appendix D. Summary of Methods for Serviceable Consumption Potential, Technical Potential,

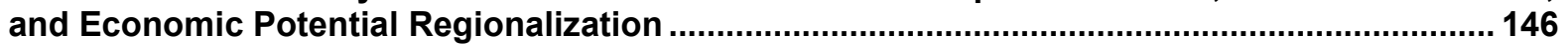

Appendix E. Maps of Hydrogen Serviceable Consumption Potentials and Hydrogen Production Technical Potentials 149

Appendix F. Serviceable Consumption Potential and Economic Potential Scenario Results in

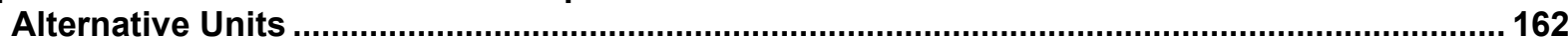

Appendix G. Scenario Electricity Generation and Capacity ................................................... 163

Appendix H. Energy Use Sankey Diagrams....................................................................... 165

Appendix I. Biomass Heating Value Assumptions................................................................... 172 


\section{List of Figures}

Figure ES-1. Schematic illustration of the H2@Scale concept (not comprehensive) (Pivovar, Rustagi, and Satyapal 2018).............................................................................................................. vii

Figure ES-2. Hydrogen supply sources and demand applications for each H2@Scale scenario.................xi

Figure 1. Illustrative example of an integrated hydrogen energy system (not comprehensive) ................... 2

Figure 2. Total U.S. energy consumption by source, 2019 (EIA 2020a) ............................................... 3

Figure 3. Total U.S. energy consumption by sector, 2019 (EIA 2020b) .............................................. 3

Figure 4. Net U.S. electricity generation (all sectors), 2000-2019 (EIA 2020c) ..................................... 4

Figure 5. Optimal power and discharge-duration characteristics of energy storage technologies............... 5

Figure 6. U.S. transportation energy sources (based on energy content), 2019 (EIA 2020d)..................... 7

Figure 7. Criteria used to determine different types of resource potentials (A. Brown et al. 2016) ........... 10

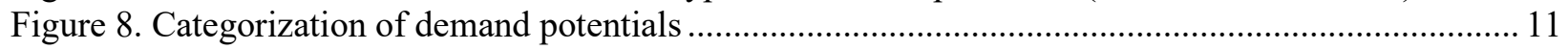

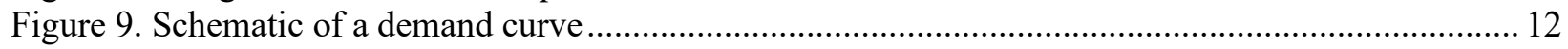

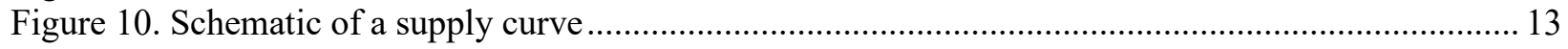

Figure 11. Schematic of supply and demand curves showing the equilibrium point where the curves cross

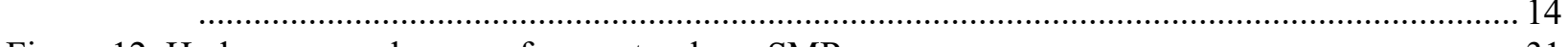

Figure 12. Hydrogen supply curve from natural gas SMR .............................................................. 31

Figure 13. LTE hydrogen production cost for varying electricity price, capacity factor, and installed

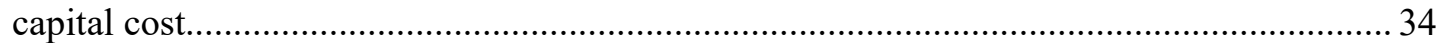

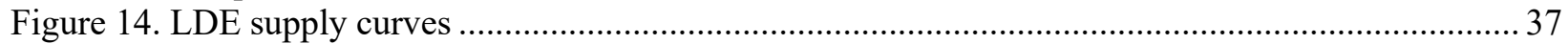

Figure 15. Hydrogen supply curve from LTE for the ReEDS Low RE Cost (top) and High Curtailment

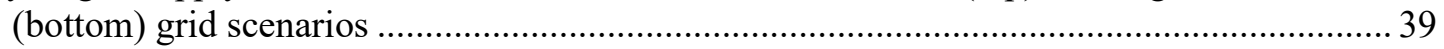

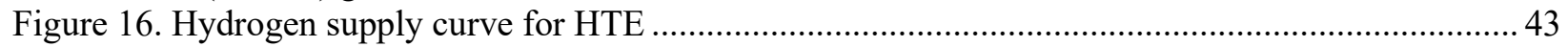

Figure 17. Hydrogen supply curve for biomass gasification ................................................................ 45

Figure 18. Locations of aggregated serviceable consumption potentials for industrial hydrogen

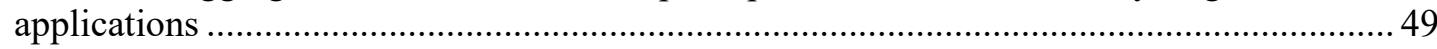

Figure 19. Locations of aggregated serviceable consumption potentials for industrial hydrogen

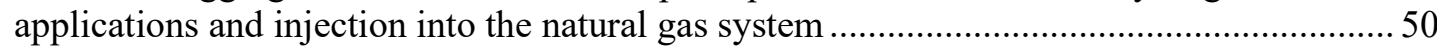

Figure 20. Locations of aggregated serviceable consumption potentials for industrial hydrogen applications, injection into the natural gas system, and transportation ................................51

Figure 21. Locations of aggregated serviceable consumption potentials for all hydrogen applications..... 52

Figure 22. County-by-county differences between the technical potential for hydrogen production from onshore wind and PV resources and serviceable consumption potential for all hydrogen

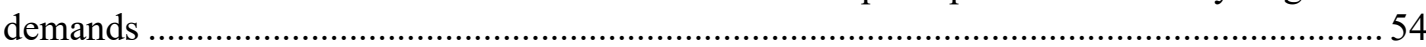

Figure 23. Impact of generating the serviceable hydrogen consumption potential on fossil and nuclear resource consumption (bars, left axis) and years to resource depletion for natural gas

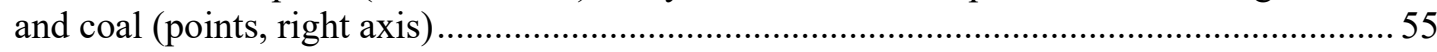

Figure 24. Aggregated demand curves for H2@Scale scenarios ............................................................ 60

Figure 25. Aggregated supply curves for Reference and R\&D Advances + Infrastructure scenarios (top), and Low NG Resource/High NG Price, Aggressive Electrolysis R\&D, and Lowest-Cost Electrolysis scenarios (bottom).

Figure 26. Supply and demand curves for the (a) Reference, (b) R\&D Advances + Infrastructure, (c) Low NG Resource/High NG Price, (d) Aggressive Electrolysis R\&D, and (e) Lowest-Cost

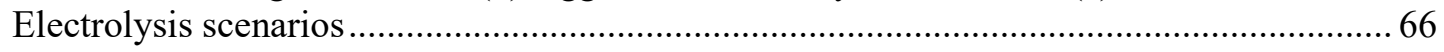

Figure 27. Electricity generation capacities for each scenario........................................................ 72

Figure 28. PV and wind generation for each scenario, broken out by load, hydrogen production, and

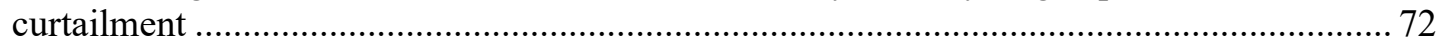

Figure 29. Energy-use Sankey diagram for the ReEDS Low RE Cost scenario..................................... 74

Figure 30. Energy-use Sankey diagram for the Reference scenario .................................................... 75 
Figure 31. Difference in energy use between the ReEDS Low RE Cost and Reference scenarios, showing reduced petroleum demand due to increased biofuel use...

Figure 32. Difference in energy use between the ReEDS Low RE Cost and R\&D Advances + Infrastructure scenarios, showing reduced petroleum demand due to increased FCEV penetrations and increased biofuel use.... 76

Figure 33. Energy-use Sankey diagram for the ReEDS High Curtailment scenario ............................... 78

Figure 34. Difference in energy use between the ReEDS High Curtailment and Low NG Resource/High

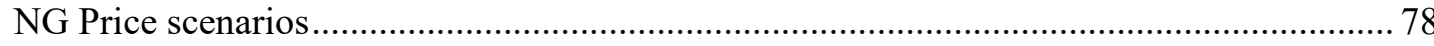

Figure 35. Difference in energy use between the ReEDS High Curtailment and Aggressive Electrolysis R\&D scenarios, showing increased wind and nuclear generation for grid energy and hydrogen production and decreased petroleum use due to biofuels........................................ 79

Figure 36. Energy-use Sankey diagram for the Lowest-Cost Electrolysis scenario .................................. 79

Figure 37. Difference in energy use between the ReEDS High Curtailment and Lowest-Cost Electrolysis scenarios, showing increased wind and solar to produce grid electricity and hydrogen, reduced natural gas for electricity and hydrogen, and petroleum displaced by hydrogen and

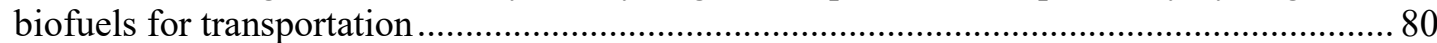

Figure 38. Supply and demand locations for the Reference scenario .............................................. 83

Figure 39. Supply and demand locations for the R\&D Advances + Infrastructure scenario ...................... 84

Figure 40. Supply and demand locations for the Low NG Resource/High NG Price scenario .................. 85

Figure 41. Supply and demand locations for the Aggressive Electrolysis R\&D scenario....................... 86

Figure 42. Supply and demand locations for the Lowest-Cost Electrolysis scenario ............................... 87

Figure 43. Supply and demand curves assuming higher (AEO LOGR) natural gas prices in core scenarios versus lower (AEO Reference) natural gas prices in sensitivity scenarios ............................. 89

Figure 44. Supply and demand applications assuming higher (AEO LOGR) natural gas prices in core scenarios versus lower (AEO Reference) natural gas prices in sensitivity scenarios ............ 89

Figure 45. Supply and demand curves for core and SMR availability sensitivity scenarios ..................... 91

Figure 46. Supply and demand applications for core and SMR availability sensitivity scenarios ............ 92

Figure 47. Supply and demand curves (left) and applications (right) for LDE market access and LTE capital cost sensitivity scenarios, with supply and demand curves based on higher natural gas

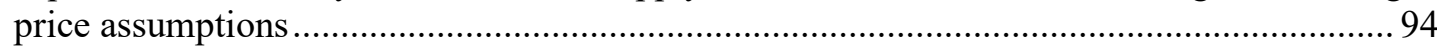

Figure 48. Supply and demand curves for core and HTE sensitivity scenarios.......................................96

Figure 49. Supply and demand applications for core and HTE sensitivity scenarios ............................... 97

Figure 50. Supply and demand curves for core and biomass resource availability sensitivity scenarios ... 98

Figure 51. Supply and demand applications for core and biomass resource availability sensitivity

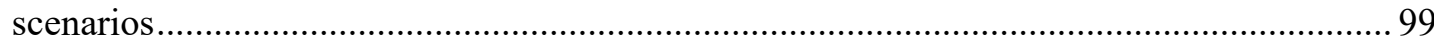

Figure 52. Supply and demand curves for core and metals refining sensitivity scenarios ...................... 100

Figure 53. Supply and demand applications for core and metals refining sensitivity scenarios............... 101

Figure 54. Supply and demand curves for core and FCEV penetration sensitivity scenarios ................. 102

Figure 55. Supply and demand applications for core and FCEV penetration sensitivity scenarios.......... 102

Figure 56. Supply and demand curves for core and biofuel penetration sensitivity scenarios ................ 104

Figure 57. Supply and demand applications for core and biofuel penetration sensitivity scenarios ........ 105

Figure 58. Supply and demand curves for core and demand support sensitivity scenarios.................... 106

Figure 59. Supply and demand applications for core and demand support sensitivity scenarios ............ 107

Figure 60. Summary of scenario settings and supply and demand applications for core and supply-related

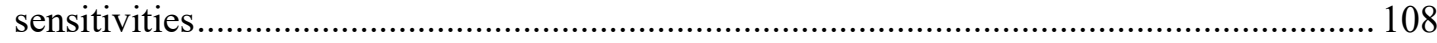

Figure 61. Summary of scenario settings and supply and demand applications for core and demand-

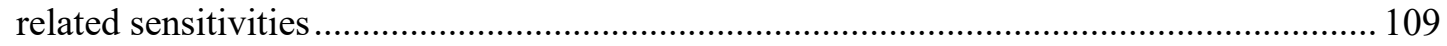

Figure 62. Hydrogen supply sources and demand applications for each H2@.Scale scenario................. 111

Figure A-1. Capital expenditures trajectory for land-based wind from the 2017 ATB (NREL 2017a).... 134

Figure A-2. Capacity factor trajectory for land-based wind from the 2017 ATB (NREL 2017a) ........... 134

Figure A-3. Capital expenditures trajectory for utility-scale PV from the 2017 ATB (NREL 2017a)..... 135 
Figure A-4. Capital expenditures trajectory for utility-scale PV from the 2017 ATB (NREL 2017a)..... 135

Figure C-1. Locations of aggregated serviceable consumption potentials for seasonal energy storage for

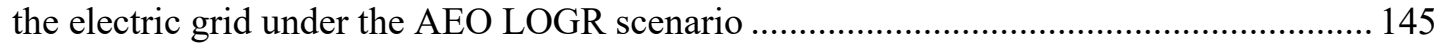

Figure E-1. Geographic distribution of the top 100 U.S. natural gas fields.......................................... 149

Figure E-2. Geographic distribution of U.S. continuous unconventional natural gas resources .............. 150

Figure E-3. Hydrogen production potential from utility-scale PV resources, by county land area .......... 150

Figure E-4. Hydrogen production potential from onshore wind resources, by county land area ............. 151

Figure E-5. Hydrogen production potential from offshore wind resources, by county land area............. 151

Figure E-6. Hydrogen production potential from solid biomass resources, by county land area ............ 152

Figure E-7. Hydrogen production potential from biogas resources, by county land area....................... 152

Figure E-8. Serviceable consumption potential of hydrogen for oil refining ....................................... 153

Figure E-9. Serviceable consumption potential of hydrogen for metals production................................. 154

Figure E-10. Serviceable consumption potential of hydrogen for ammonia ......................................... 155

Figure E-11. Serviceable consumption potential of hydrogen for biofuels ........................................... 156

Figure E-12. Serviceable consumption potential of hydrogen for synthetic HC ................................... 157

Figure E-13. Serviceable consumption potential of hydrogen for injection into the natural gas

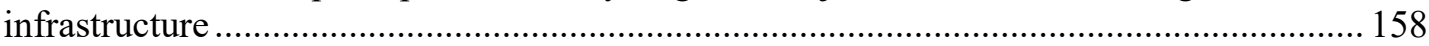

Figure E-14. Serviceable consumption potential of hydrogen for light-duty FCEVs and medium- and

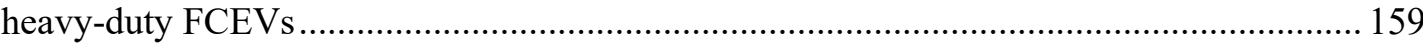

Figure E-15. Serviceable consumption potential of hydrogen for seasonal energy storage for the electricy grid....

Figure E-16. County-by-county comparison between the technical potential for hydrogen production from onshore wind and PV resources and serviceable consumption potential for all demands, with current nuclear plants

161

Figure G-1. Electricity generation capacity from ReEDS for H2@Scale scenarios............................... 163

Figure G-2. Electricity generation from ReEDS for H2@Scale scenarios by technology ...................... 164

Figure H-1. Energy-use Sankey diagram for the ReEDS Low RE Cost scenario .................................. 165

Figure H-2. Energy-use Sankey diagram for the Reference scenario ................................................. 166

Figure H-3. Energy-use Sankey diagram for the R\&D Advances + Infrastructure scenario................... 166

Figure H-4. Difference in energy use between the ReEDS Low RE Cost and Reference scenarios ........ 167

Figure H-5. Difference in energy use between the ReEDS Low RE Cost and R\&D Advances +

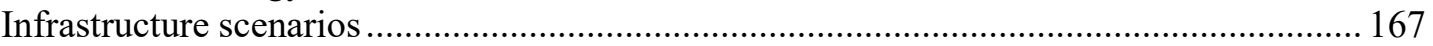

Figure H-6. Energy-use Sankey diagram for the ReEDS High Curtailment scenario .............................. 168

Figure H-7. Energy-use Sankey diagram for the Low NG Resource/High NG Price scenario ................ 169

Figure H-8. Energy-use Sankey diagram for the Aggressive Electrolysis R\&D scenario....................... 169

Figure H-9. Energy-use Sankey diagram for the Lowest-Cost Electrolysis scenario .............................. 170

Figure H-10. Difference in energy use between the ReEDS High Curtailment and Low NG

Resource/High NG Price scenarios...

Figure H-11. Difference in energy use between the ReEDS High Curtailment and Aggressive Electrolysis R\&D scenarios

Figure H-12. Difference in energy use between the ReEDS High Curtailment and Lowest-Cost Electrolysis scenarios 


\section{List of Tables}

Table ES-1. Serviceable Consumption Potential for Hydrogen Applications ..........................................viii

Table ES-2. Five Scenarios Used to Estimate Economic Potential ............................................................

Table 1. Hydrogen Demand and Threshold Price for Oil Refining (Elgowainy et al. 2020).................... 16

Table 2. Hydrogen Demand and Threshold Prices for Metals Refining under the AEO Reference Scenario

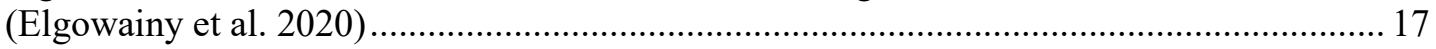

Table 3. Hydrogen Demand and Threshold Prices for Metals Refining under the AEO LOGR Scenario

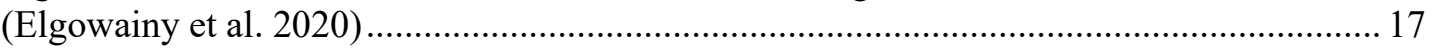

Table 4. Hydrogen Demand and Threshold Prices for Ammonia Production (Elgowainy et al. 2020)...... 18

Table 5. Hydrogen Demand and Threshold Price for Biofuels.............................................................. 19

Table 6. Hydrogen Demand and Threshold Prices for Synthetic HC (Elgowainy et al. 2020) .................. 21

Table 7. Hydrogen Demand and Threshold Price for Injection into the Natural Gas Pipeline System under the AEO Reference Scenario (Elgowainy et al. 2020) .......................................................... 22

Table 8. Hydrogen Demand and Threshold Price for Injection into the Natural Gas Pipeline System under the AEO LOGR Scenario (Elgowainy et al. 2020) .............................................................. 22

Table 9. Hydrogen Demand and Required Threshold Prices for Seasonal Electricity Storage under the ReEDS High Curtailment Grid Scenario (Using the AEO LOGR Costs) ............................. 23

Table 10. Hydrogen Demand and Required Threshold Prices for Seasonal Electricity Storage under the ReEDS Low RE Cost Grid Scenario (Using the AEO Reference Costs) .............................. 23

Table 11. Projected LDV Stock Penetration by Powertrain from MA3T (Elgowainy et al. 2020) ............ 25

Table 12. Hydrogen Demand and Threshold Prices for Light-Duty FCEVs (Elgowainy et al. 2020) ....... 25

Table 13. Hydrogen Demand and Threshold Prices for Medium- and Heavy-Duty FCEVs (Elgowainy et

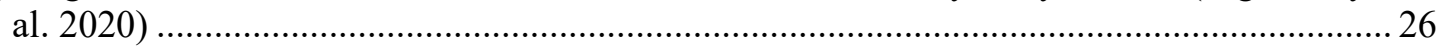

Table 14. Hydrogen Production Costs for Natural Gas SMR by Census Division.................................... 30

Table 15. Industrial Natural Gas Prices in 2050 from AEO 2017 (EIA 2017a) ...................................... 30

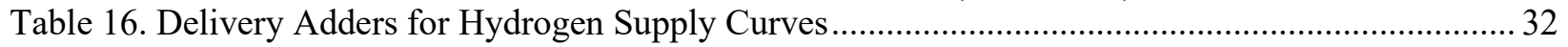

Table 17. Central Hydrogen Production Costs for Emerging Technologies........................................... 47

Table 18. Serviceable Consumption Potential for Hydrogen Demands................................................... 48

Table 19. Impact of Generating the Serviceable Consumption Potential for Hydrogen on Technical

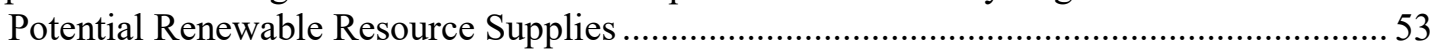

Table 20. Five Scenarios Used for Economic Potential Estimates ........................................................ 57

Table 21. Summary of Hydrogen Demand Price Points and Cumulative Annual Quantities for H2@Scale

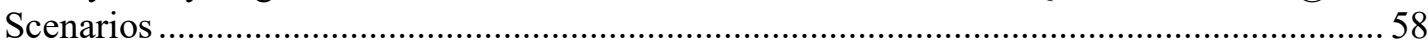

Table 22. Summary of Hydrogen Maximum Supply Price Points and Corresponding Annual Cumulative

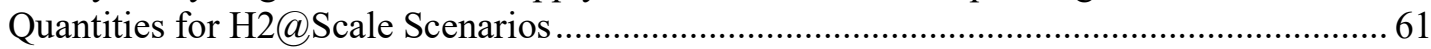

Table 23. Hydrogen Supply Sources and Demand Applications for Each Scenario (MMT/yr)................ 67

Table 24. Comparison of Hydrogen Market Sizes (MMT/yr) between the Roadmap to a U.S. Hydrogen

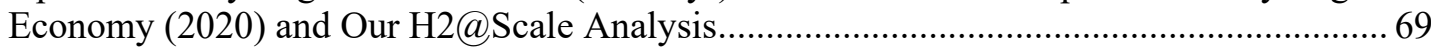

Table 25. Impacts of H2@Scale Scenarios on the Electric Grid ........................................................... 71

Table 26. Emissions and Fuel-Use Reductions due to Estimated Changes in Power Sector without

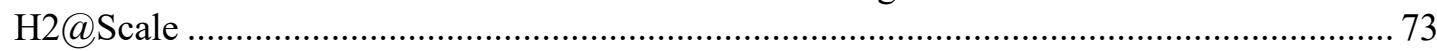

Table 27. Emissions and Petroleum-Use Reductions for H2@Scale Scenarios ....................................... 81

Table 28. Demand Price Points for Increased Demand Support Sensitivity Scenarios ........................... 106

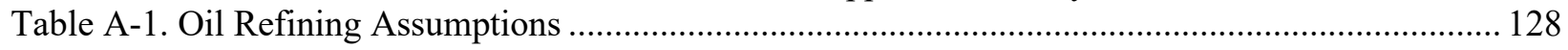

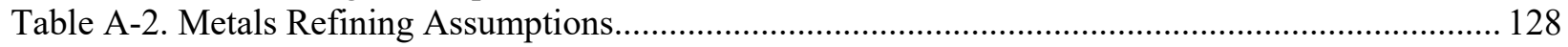

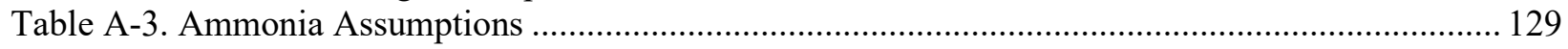

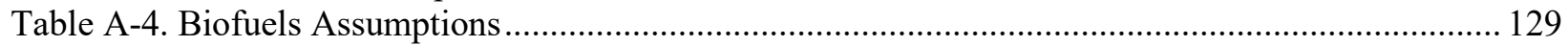

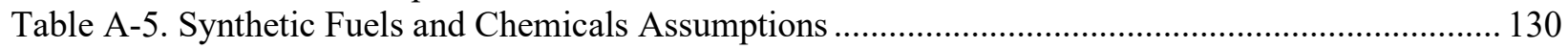

Table A-6. Seasonal Energy Storage Assumptions ....................................................................... 130

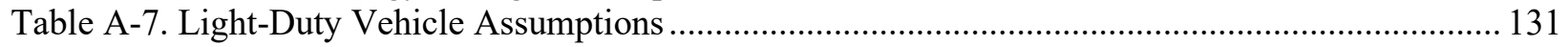


Table A-8. Medium- and Heavy-Duty Vehicle Assumptions

Table A-9. Steam Methane Reforming of Natural Gas Assumptions................................................... 132

Table A-10. Low-Temperature Electrolysis Assumptions.

Table A-11. High-Temperature Electrolysis Using Nuclear-Generated Heat Assumptions..................... 136

Table B-1. Energy Use Required for Hydrogen Production .............................................................. 138

Table B-2. Fuel Economy and VMT Estimates for 2075 (Elgowainy et al. 2020)................................ 139

Table B-3. Energy Displacement from Each Hydrogen Demand Application ....................................... 140

Table B-4. Emissions Factors Used to Estimate Emissions Impacts (ANL 2017) ................................ 140

Table B-5. Grid Electricity Emissions Factors Used to Estimate Emissions Impacts ............................ 141

Table C-1. Stationary Hydrogen Fuel Cell and Combustion Turbine Assumptions and References ....... 143

Table C-2. Hydrogen Prices Necessary to Compete with Fossil Generation for Seasonal Dispatch under

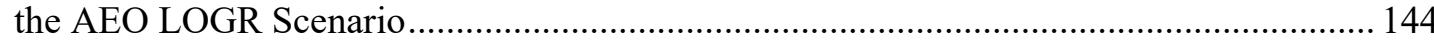

Table C-3. Hydrogen Prices Necessary to Compete with Fossil Generation for Seasonal Dispatch under

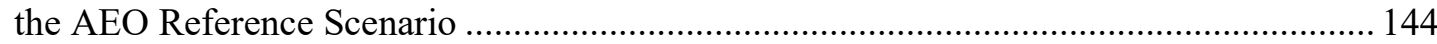

Table D-1. Summary of Methods Used to Determine Demand and Production Locations for Serviceable Consumption Potential, Technical Potential, and Economic Potential Estimates ............... 146

Table F-1. Annual Hydrogen Market Sizes for Serviceable Consumption Potential and Economic Potential Scenarios in Alternative Units ................................................................................. 162

Table G-1. Electricity Generation Capacity (GW) from ReEDS for H2@Scale Scenarios ..................... 163

Table G-2. Electricity Generation (TWh) from ReEDS for H2@Scale Scenarios by Technology.......... 164

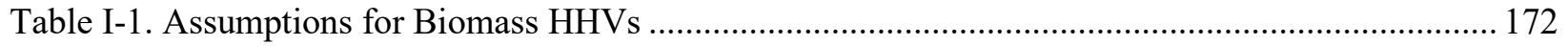




\section{Introduction}

The U.S. energy system is multifaceted, with a diverse mix of generators and end uses, and it is evolving as society and technologies change. Electricity generation from renewable sources, especially wind and solar photovoltaics (PV), is growing. Alternative energy sources applicable across the residential, commercial, transportation, and industrial sectors are also being investigated to increase economic competitiveness, improve energy security, and reduce human health impacts. The systemic changes present numerous challenges. Although solutions exist for addressing each challenge individually, viewing the energy system as an interrelated whole suggests opportunities for synergistic solutions that satisfy multiple needs while yielding systemwide efficiency and cost benefits. Systemic solutions also reduce unintended consequences that may occur when solutions in one area create or exacerbate issues in other areas.

One such synergistic solution is an integrated hydrogen energy system, which is the focus of H2@Scale (Figure 1). ${ }^{5}$ H2@Scale is a U.S. Department of Energy (DOE) initiative led by the Office of Energy Efficiency and Renewable Energy's Hydrogen and Fuel Cell Technologies Office. H2@Scale brings together stakeholders to advance affordable hydrogen production, transport, storage, and utilization to increase revenue opportunities in multiple energy sectors. The focus of this report is technoeconomic modeling and analysis to characterize the overall potential of the H2@Scale concept, given evolutions in the U.S. energy system and future research and development $(\mathrm{R} \& \mathrm{D})$ advances.

As shown in Figure 1, hydrogen is proposed as a third energy infrastructure, joining the electric grid and the natural gas infrastructure. On the generation side, hydrogen can be produced from various conventional and renewable energy sources. One example is when electricity is used to generate hydrogen: electrolysis can serve as a form of responsive load on the electric grid, which enhances grid stability, reduces curtailment, and creates a revenue stream for generators. On the application side, hydrogen has many current applications and many more potential applications. In the transportation sector, hydrogen can be used to power fuel cell electric vehicles (FCEVs) directly or to produce or upgrade fuels made from renewable or fossil sources. In the industrial sector, hydrogen is essential to fertilizer manufacturing, oil refining, metals refining, and the production of various plastics and chemicals. In the future, hydrogen also has a potential role as a means of energy storage. Hydrogen can be produced using low-cost, intermittently available electricity, stored in bulk, and then used in power generation. Using hydrogen in power generation has a value proposition in power-intensive industries, such as data centers, and in regions with high levels of curtailment and interest in zero-emission peak demand technologies. Similarly, hydrogen can be mixed into the natural gas pipeline system to add renewable gas content.

\footnotetext{
${ }^{5}$ See the H2@Scale website (https://www.energy.gov/eere/fuelcells/h2-scale) for more information.
} 


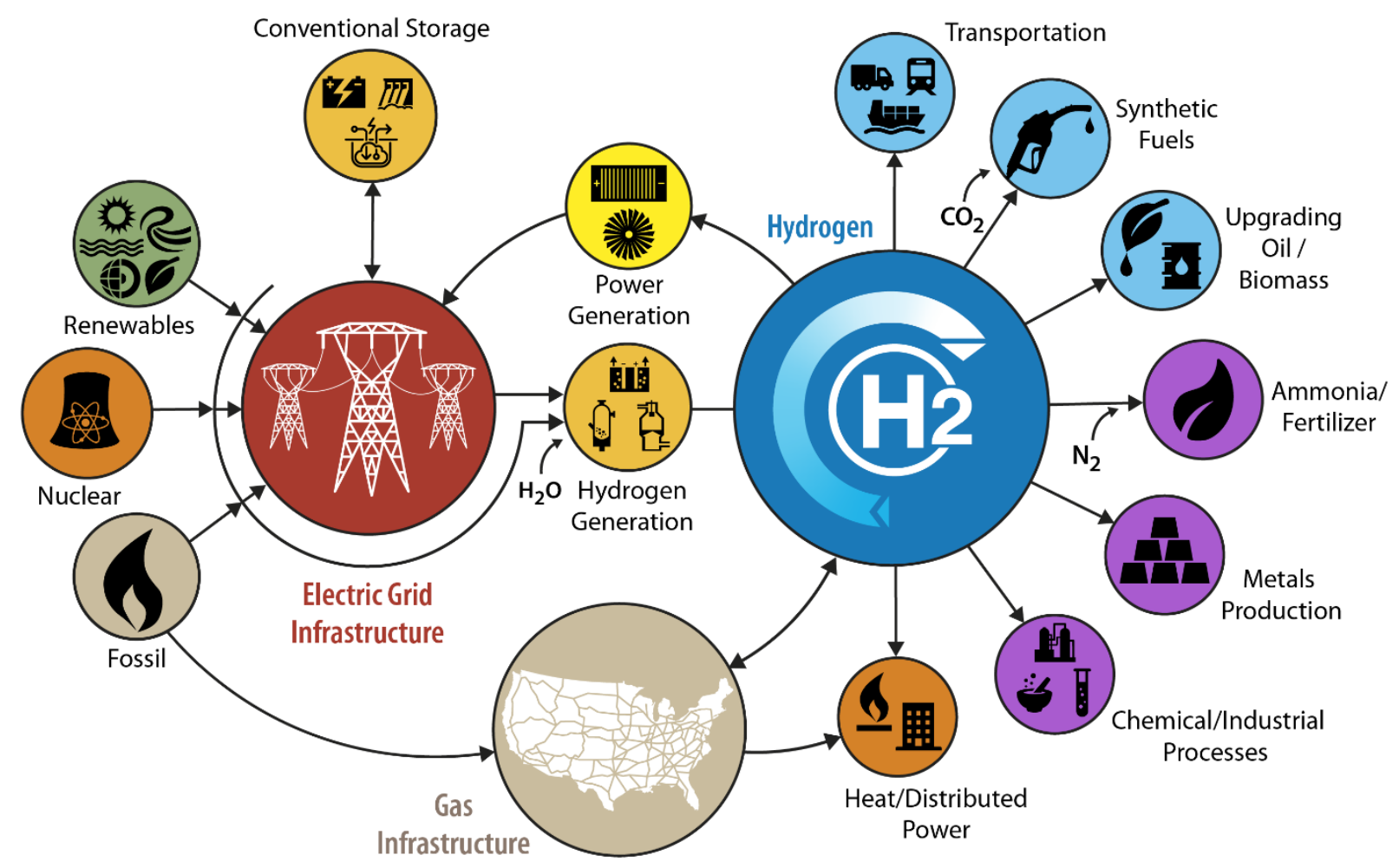

Figure 1. Illustrative example of an integrated hydrogen energy system (not comprehensive)

The Spark M. Matsunaga Hydrogen Act of 2005 (U.S. Congress 2005) directed the Secretary of Energy to conduct research activities "to address production of hydrogen from diverse energy resources including - fossil fuels, which may include carbon capture and sequestration; hydrogen-carrier fuels (including ethanol and methanol); renewable energy resources, including biomass; and nuclear energy." This report addresses the technical potential of hydrogen production from fossil fuels, renewable resources, and nuclear energy. In addition, the Hydrogen Technical Advisory Committee recommended that DOE take action to address "the potential for fuel shortages. For example, in Southern California where FCEV purchases have been strong, hydrogen fuel capacity is being outpaced by demand. Sustained investments in additional production capacity buildout are needed" (Hydrogen and Fuel Cell Technical Advisory Committee 2017). This report identifies the potential for diverse methods of hydrogen production to address multiple FCEV fuel demand scenarios as well as other hydrogen demands.

\subsection{Hydrogen's Potential Roles in the U.S. Energy System}

The H2@Scale concept could enhance today's U.S. energy system by monetizing low-cost energy, creating an additional revenue stream for baseload generators, supplying emerging/advanced transportation technologies (such as FCEVs and synthetic fuels), and reducing domestic dependence on fossil fuels, freeing up these resources for higher-value markets. Fossil fuels currently satisfy most U.S. energy demands, and they likely will continue to play an important role in the coming decades (EIA 2018a). Coal, natural gas, and petroleum constituted about $80 \%$ of all U.S. energy consumed in 2019 , with nuclear and renewable sources accounting for the rest at about $10 \%$ each (Figure 2). The top energy-consuming sectors are industry and transportation, followed by the residential and commercial sectors (Figure 3 ). 
Although fossil fuels are primarily used to provide energy, they also serve as industrial feedstocks. Natural gas is used to produce chemicals, fertilizer, and hydrogen (EIA 2017c). Petroleum is used to make plastics, polyurethane, solvents, and numerous other products (EIA 2017d). Technologies are being developed to convert coal into synthetic gases and liquids, which can then be used as fuels or feedstocks for products including hydrogen (EIA 2017b). However, fossil fuel supplies are limited, and a significant amount of U.S. petroleum demand continues to be supplied by imports, which creates vulnerability to international supply disruptions (EIA 2018b).

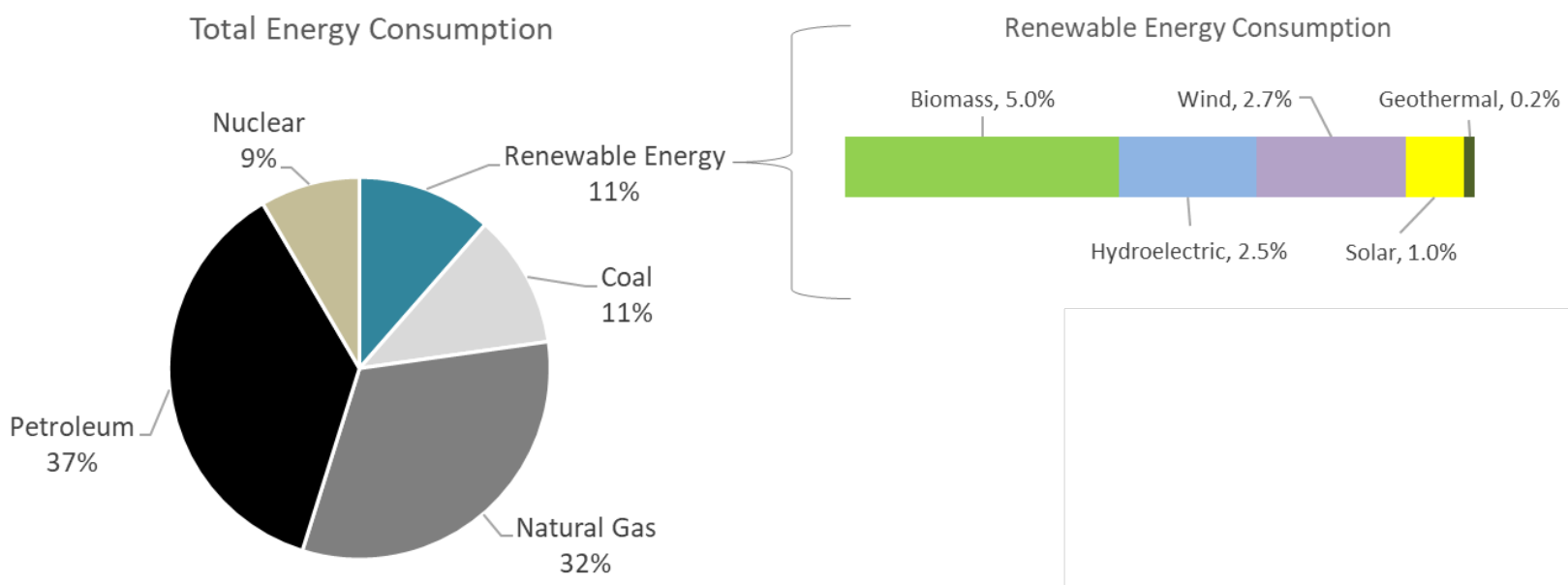

Figure 2. Total U.S. energy consumption by source, 2019 (EIA 2020a)

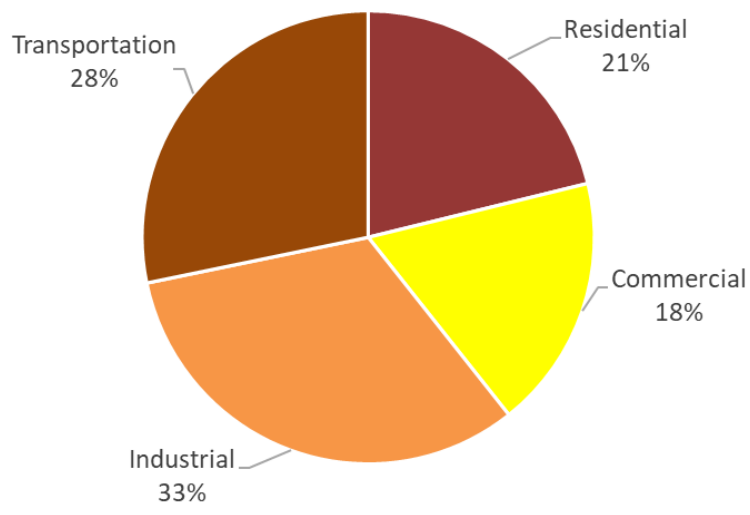

Figure 3. Total U.S. energy consumption by sector, 2019 (EIA 2020b)

The H2@Scale system can support the U.S. electricity sector by enhancing the affordability of renewable power and supporting critical baseload nuclear generation. The electric power sector accounts for about $40 \%$ of U.S. primary energy consumption (EIA 2020b), with the resulting electricity consumed by the industrial, residential, commercial, and transportation sectors. These electricity needs are increasingly being met by cost-competitive variable renewable energy (VRE) technologies, particularly wind and solar power (Figure 4). In 2019, wind provided about $7 \%$ of total U.S. electricity generation and solar about $2 \%$ (EIA 2020c). Some regions of the country are deploying renewable energy more rapidly than others. California, for example, reached $11 \%$ wind penetration and $11 \%$ solar penetration in 2018 , and its renewable portfolio 
standard (RPS) is targeting 60\% renewable electricity by 2030 (CEC 2019; CPUC n.d.). As of 2019, 29 states, Washington DC, and three U.S. territories had RPS policies requiring a portion of electricity needs be supplied by renewable sources, while another eight states and one territory had renewable portfolio goals (DSIRE 2019); however, renewable electricity growth is likely to depend on market, policy, and technology conditions. The National Renewable Energy Laboratory's (NREL's) Renewable Electricity Futures study identifies the potential for renewable electricity generation from technologies that are commercially available today to supply $80 \%$ of total U.S. electricity generation in 2050 - providing the flexibility of the U.S. electricity system is improved (NREL 2018b). Nuclear generation, on the other hand, currently provides about $20 \%$ of annual U.S. electricity generation (EIA 2020c). In addition to providing energy to the grid, nuclear power plants - by virtue of their synchronous rotational natureprovide real inertia that supports frequency regulation.

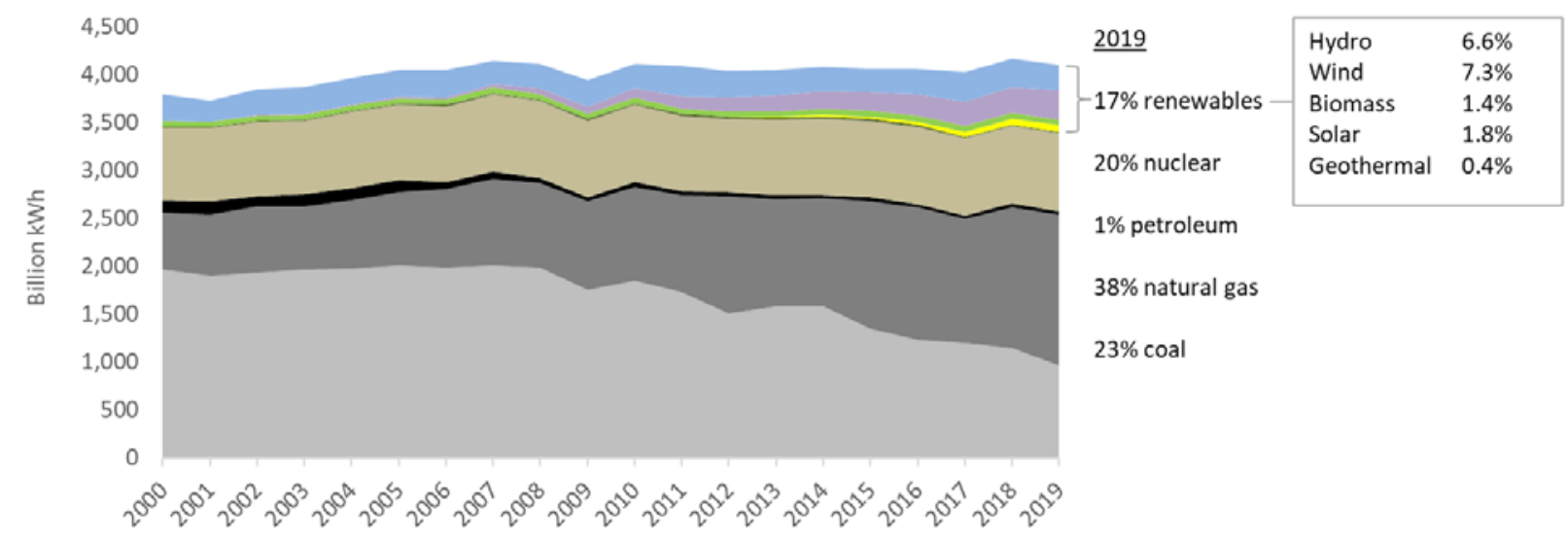

Figure 4. Net U.S. electricity generation (all sectors), 2000-2019 (EIA 2020c)

Renewable energy technologies draw from virtually limitless resources in some regions of the United States, yet - as they achieve high penetrations - the variable nature of their output can complicate the operation of relatively inflexible electric systems, resulting in substantial VRE curtailment, inefficient operation of conventional generation plants, and increased electricity costs (Denholm et al. 2015). Nuclear generation could have similar issues at high penetrations, because, although nuclear generators produce a constant amount of electricity, loads vary daily and seasonally.

Hydrogen production could provide a flexible load that supports higher VRE penetrations. In California, generation already exceeds loads during some hours of the year because of high levels of VRE generation, which is resulting in negative wholesale electricity prices during those hours (California ISO 2018). That electricity could be a low-cost resource for producing hydrogen, which in turn could supply other energy demands.

Energy storage technologies, such as batteries and hydrogen, could also help achieve high penetrations of renewable and nuclear resources (Denholm et al. 2016). A variety of storage scales and periods of stored energy discharge likely will be necessary to support the grid. Hydrogen offers unique benefits compared with other storage technologies, because it can be economically stored in large quantities for long periods with minimal energy loss, thus enabling the shifting of substantial renewable generation over time scales up to the seasonal level (Figure 5). Storage technologies can also provide short-term load and generation balancing (Denholm et 
al. 2013), if they have sufficient response rates. Low-temperature electrolyzers have been shown to meet the response-rate requirements (Mohanpurkar et al. 2017), as have batteries (Swierczynski et al. 2014).

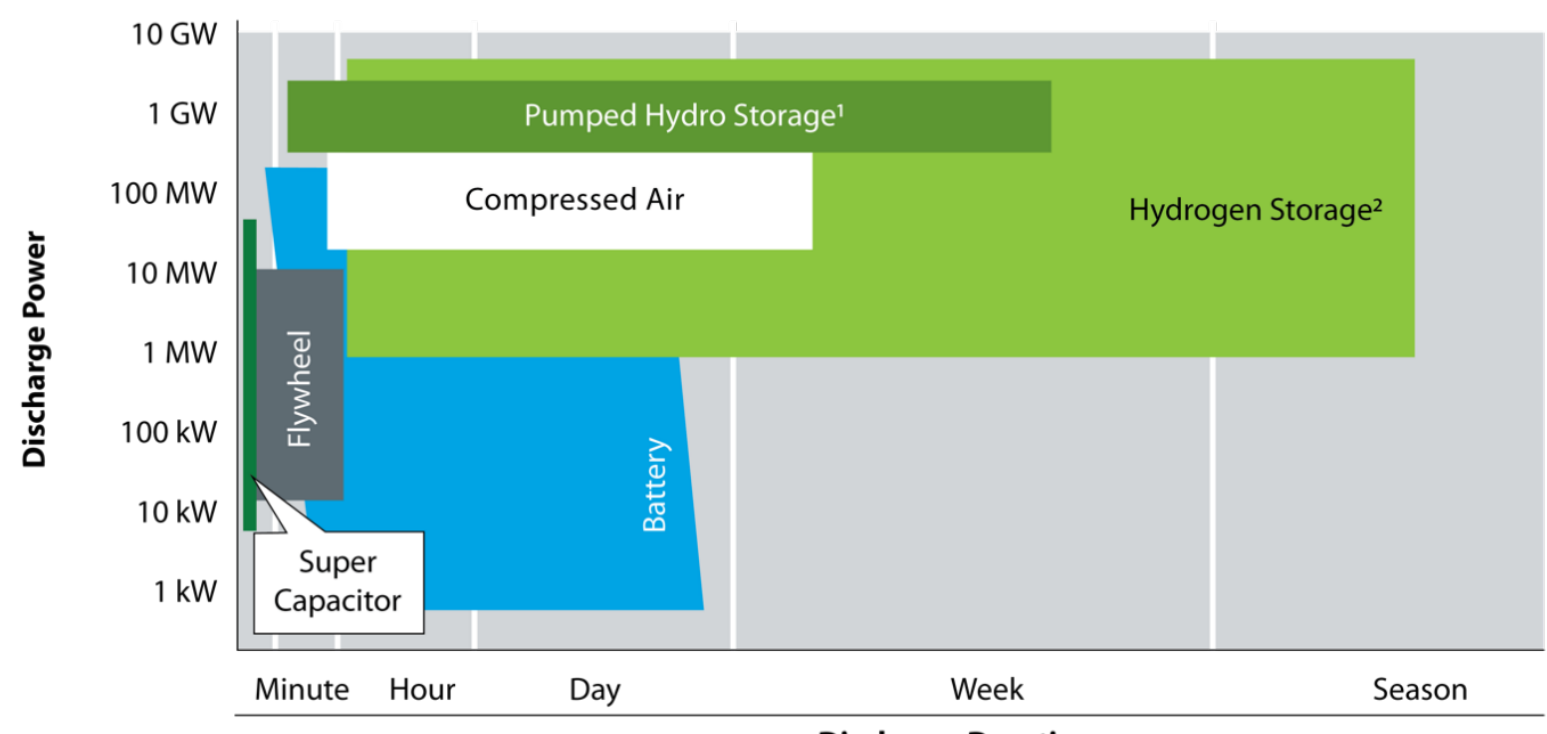

Discharge Duration

1 Pumped hydro capacity is limited due to geographic constraints. Estimated maximum potential is $<1 \%$ of U.S. electrical energy demand ${ }^{2}$ As hydrogen, ammonia, or synthetic natural gas

Figure 5. Optimal power and discharge-duration characteristics of energy storage technologies

Source: Adapted from Hydrogen Council (2017), based on IEA (2015)

Hydrogen production could potentially improve the economics of nuclear generators. Current U.S. nuclear generators are commonly challenged by their inability to economically vary their power output. As a result, many plants remain online and generate power even though they are selling it at a price lower than their operating costs in deregulated markets. If such plants could integrate with other technologies that monetize nuclear-generated heat, they might be able to improve their economics. In such hybrid systems, nuclear plants could alternate between using their heat for power generation and using their heat for other applications (e.g., water desalination, district heating). Such plants could therefore supply power to the grid for a fraction of the day and produce higher-value products at other times. Hydrogen production using nuclear heat is one such hybrid energy system currently being explored by utilities (Meeks et al. 2019).

In our analysis, the viability of high-temperature electrolysis (HTE) technologies in dedicated systems is analyzed. HTE uses heat and electricity to produce hydrogen from water. HTE can be integrated with newly constructed nuclear plants as well as existing reactors that are modified for the purpose. These plants could either produce hydrogen as a dedicated product or operate as hybrids that generate and sell electricity when its price is high and produce hydrogen when the electricity price is low. The hybrid strategy could increase capital costs owing to additional equipment or equipment capacity; however, under certain market conditions, using this strategy to optimize the products sold could be more profitable than using the dedicated option (Ruth et al. 2014; Rabiti et al. 2017). Because dedicated systems are more profitable unless there are 
many hours with high electricity prices, and because opportunity costs for hybrid systems are site specific, we analyze dedicated nuclear-HTE systems.

The H2@Scale system also could supply low-cost hydrogen to the growing numbers of lightand heavy-duty FCEVs. Although most U.S. transportation fuels are petroleum based (Figure 6) (EIA 2017d; 2017g), the sector is evolving to include advanced, high-efficiency powertrains. Automakers introduced FCEVs in 2014, and several models are available today in select markets (H2USA 2018a; AFDC 2016). California's Zero Emission Vehicle (ZEV) Action Plan targets deployment of 1.5 million ZEVs in the state by 2025 and 5 million ZEVs by 2030, including plug-in electric vehicle (PEVs) and FCEVs (Governor's Interagency Working Group on ZeroEmission Vehicles 2018). Ten additional states have adopted California's ZEV regulationsrequiring ZEVs to constitute $7 \%-10 \%$ of light-duty vehicle (LDV) sales by 2025 -including Colorado, Connecticut, Maine, Maryland, Massachusetts, New Jersey, New York, Oregon, Rhode Island, and Vermont (Auto Alliance n.d.). Throughout the United States, concrete plans have also been announced for use of fuel cells in medium- and heavy-duty transportation, including long-haul trucks and buses (DOE 2018b). More than 14,000 fuel cell trucks have been ordered in the United States (personal communication with Nikola Motor Company, May 20, 2019), and 30 fuel cell buses were in demonstrations throughout the United States as of May 2018 (Eudy and Post 2018). Internationally, fuel cells are even being deployed in trains and marine applications, such as ferries (Frihammer 2018; Braunsdorf 2018). The first fuel cell ferry in the United States is expected to be complete in 2020, in San Francisco (personal communication with Golden Gate Zero Emission Marine, June 11, 2020).

This ambitious ZEV scale-up presents various implementation challenges. Importantly, because the success of the initiatives ultimately relies on consumer choices, the ZEV products must compare favorably with conventional vehicles in terms of cost, performance, fueling convenience, and driving range. Four FCEVs were available as of early 2020 in select locations. They have combined city/highway fuel economies of 60-66 miles per kilogram of hydrogen, ${ }^{6}$ driving ranges of 312-380 miles (Fueleconomy.gov 2020), and the ability to fill up at hydrogen dispensers in less than 5 minutes (H2USA 2018b).

Hydrogen can also be used in the production of synthetic fuels or in blends with conventional fuels. In some U.S. regions, financial incentives exist for such blends. For example, California's Low Carbon Fuel Standard requires fuel producers and importers to achieve a 20\% reduction in the carbon intensity of transportation fuels by 2030 (CARB 2018). This can be achieved through sale of fuels including bio-based and fossil natural gas, electricity, hydrogen, ethanol, and biodiesel (AFDC 2018; CARB 2016a). Another California policy (SB 1383) promotes use of renewable fuels by requiring a $40 \%-50 \%$ reduction in emissions of short-lived climate pollutants including black carbon, fluorinated gases, and methane (State of California 2016). In addition to being used as a fuel directly, hydrogen can be reacted with carbon dioxide (in a process called methanation), be mixed with natural gas, or be used to convert biomass into a variety of renewable liquid fuels (McMillan et al. 2016). A benefit of the latter three approaches is that the resulting fuels can be used in conventional methods of energy generation (e.g., combustion turbines) with engineering modifications. Many such "power to gas" demonstration projects are

\footnotetext{
${ }^{6}$ One kilogram of hydrogen has approximately the same amount of energy as 1 gallon of gasoline.
} 
underway in Europe, with some in the United States as well (SoCalGas 2018; EIA 2015c; European Power to Gas 2018).

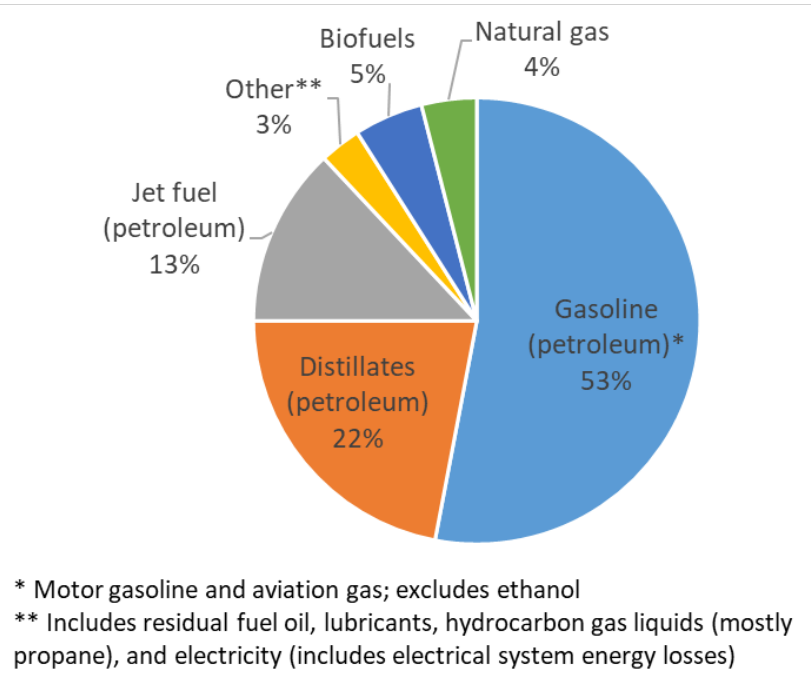

Figure 6. U.S. transportation energy sources (based on energy content), 2019 (EIA 2020d)

Hydrogen has many existing and potential new applications specific to the industrial sector. In some of these applications, such as oil refining, hydrogen is an essential feedstock. In others, such as iron refining, its use can improve process efficiency (Green 2018). Oil refineries consume - for processes including heavy oil hydrocracking and hydrotreating and desulfurization of sour crude - about two thirds of the approximately 10 million metric tons (MMT) of on-purpose feedstock hydrogen produced and consumed in the United States each year (see Section 3.1). The remainder is used for ammonia, methanol and other alcohol production, the food industry, metals refining, glass production, and electronics fabrication, with a small amount used in industrial vehicles such as fuel cell powered forklifts. Potential new applications include small ammonia plants that are based on alternatives to the Haber-Bosch process, biofuel upgrading, hydrogenation of carbon dioxide for chemical and fuel synthesis, iron ore reduction for steel processing, and combustion for its heating value (e.g., in power generation). Hydrogen demand as a feedstock for ammonia could also grow owing to expansion of energy-crop agriculture and the use of ammonia and amides in combustion emission control systems for stationary and transportation applications.

Most previous studies of hydrogen futures have used expert elicitation to estimate the potential for hydrogen markets and focus on hydrogen markets without a deep analysis of resource limitations. The Hydrogen Council developed a vision that includes $550 \mathrm{MMT} / \mathrm{yr}$ (78 exajoules $[\mathrm{EJ}] / \mathrm{yr}$ ) of global hydrogen demand in 2050 , based on estimates from industry experts of market shares for hydrogen technologies in industrial feedstock and energy, building heating and power, transportation, and dispatchable power generation (Hydrogen Council 2017). Another Hydrogen Council report compares the total cost of ownership for hydrogen technologies with the cost of conventional and low-carbon alternatives, finding that 40 technologies in 35 applications could be cost-competitive by 2050 based on technology development and scaling for the application and for hydrogen production and delivery (Hydrogen Council 2020). Compared with the Hydrogen Council's estimate of $18 \%$ of final energy consumption, the International Renewable Energy Agency estimates a lower share: 6\% in 2050 of which is up from the current 4\% share 
(IRENA 2019). Bloomberg New Energy Finance estimates a theoretical global maximum demand for hydrogen in 2050 of 1,370 MMT/yr (195 EJ/yr) and a potential demand of 696 MMT/yr (99 EJ/yr) under a strong policy scenario (BNEF 2020). The Shell Sky scenario estimates that hydrogen demand does not start growing dramatically until 2040 but reaches 800 MMT/yr in 2070 (Shell 2018). The International Energy Agency recommends seven potential actions that would support growth of hydrogen markets and proposes follow-on analyses to better understand integration opportunities (IEA 2019). Using methods similar to those used in Hydrogen Council (2017), a U.S. analysis estimates 2050 hydrogen demand of $20 \mathrm{MMT} / \mathrm{yr}$ in a "base" scenario and $63 \mathrm{MMT} / \mathrm{yr}$ in an "ambitious" scenario, with the potential for an additional $11 \mathrm{MMT} / \mathrm{yr}$ for synthetic jet fuel and ammonia for use as a shipping fuel ("Roadmap to a US Hydrogen Economy" 2020).

\subsection{Report Purpose and Organization}

This document reports our initial analysis and quantifies the potential impacts on primary energy supplies and emissions if R\&D is successful and potential hydrogen markets develop within the 48 contiguous U.S. states. ${ }^{7}$ First, we estimate hydrogen's serviceable consumption potential and technical potential (i.e., the market and resource potential constrained by the services that society uses energy for today, real-world geography, and system performance, but not by economics). Those results can also be considered the serviceable consumption potential of a hydrogen sector without considering costs. We also examine potential regional and total resource constraints on hydrogen supply. Second, we estimate economic potential - the quantity and price of hydrogen at which suppliers are willing to sell and consumers are willing to buy - under five market scenarios. Finally, we estimate impacts of the modeled hydrogen energy system under each scenario in terms of reduced energy use and emissions for potential markets at equilibrium in 2050. This work extends previous work by addressing supply and demand curves simultaneously. Others have fixed one and solved for the other; for example, they have estimated demand potential assuming the full hydrogen demand can be served at a single hydrogen price.

Within the H2@Scale initiative, R\&D to improve the cost-effectiveness of associated technologies is underway. The scenarios detailed in this report are predicated upon successful completion of R\&D on multiple technologies, including metals refining that uses hydrogen in place of carbon-based reductants, ammonia production that uses hydrogen directly, production of synthetic hydrocarbons (HC) from hydrogen and carbon dioxide, production of third-generation biofuels, fuel cell component and system technologies for LDVs as well as medium- and heavyduty trucks, lower-cost low-temperature electrolysis (LTE) equipment, and lower-cost, higherdurability HTE equipment.

\footnotetext{
${ }^{7}$ We do not include imports/exports because of the difficulty in estimating a global market. Nor do we include Alaska or Hawaii, because these states are likely to have a higher fraction of hydrogen imported and/or exported. In addition, our simple storage and delivery cost assumptions are likely to be unrealistic for transmission between those states and the contiguous states.
} 
The report is organized as follows. Section 2 describes our methods for estimating hydrogen potentials as well as energy and emissions impacts. Sections 3 and 4 address the hydrogen demand and supply options that we consider in our analysis. Section 5 provides the results of the serviceable consumption potential and technical potential analyses. Section 6 provides the economic potential as well as energy and emissions results. Sections 7 and 8 offer conclusions and avenues for further analysis. 


\section{Methods}

This section describes our methods for calculating the serviceable consumption potential, technical potential of hydrogen-producing resources, and economic potential of hydrogen demand in the contiguous United States as well as the energy and emissions impacts of increased hydrogen use under various scenarios. Because resources and demands can be affected by changing land-use patterns, system performance, and demand for energy services (e.g., miles driven), the serviceable consumption potential varies with time and depends on many factors that are outside the scope of this analysis. To make the analysis possible, we chose a single target year: 2050. That year is near enough in the future to consider economic conditions as done in other analyses - e.g., EIA (2018a) - but it is likely far enough in the future to allow time for markets to develop. For technologies that need more development time to reach equilibrium (i.e., FCEVs), we chose a later year.

In this analysis, we report hydrogen market sizes on a mass basis (primarily in MMTs of hydrogen). For reference, Appendix F includes results for the serviceable consumption potential and economic potential in various other units.

\subsection{Estimating Technical Potential and Serviceable Consumption Potential}

In resource analysis, technical potential is the subset of available resource potential constrained by real-world geography and system performance, but not economics. Economic potential is a subset of the technical potential. These relationships are shown in Figure 7.

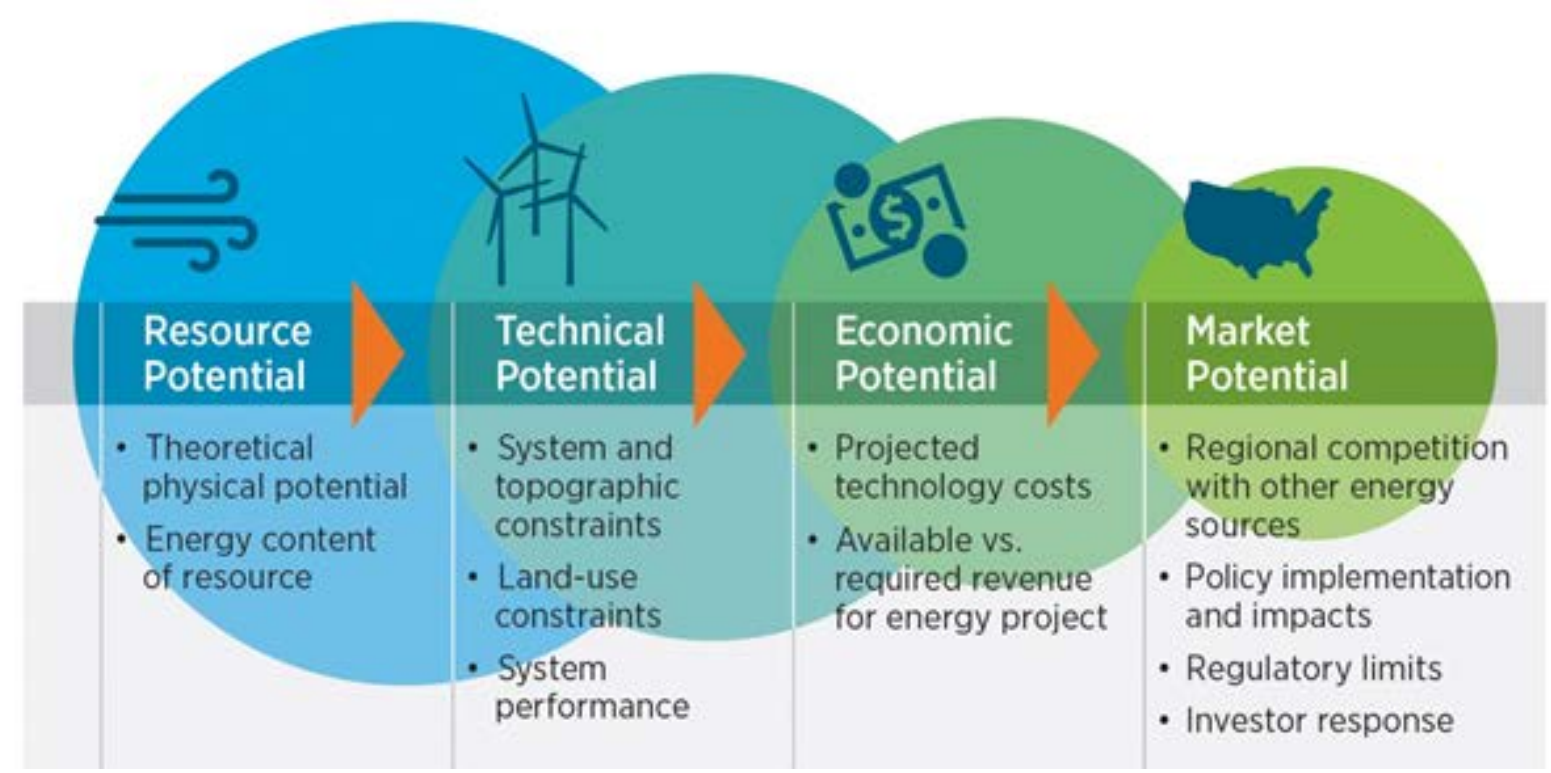

Figure 7. Criteria used to determine different types of resource potentials (A. Brown et al. 2016)

To estimate the technical potential for producing hydrogen from various resources, we use the methods from Connelly et al. (2020). We estimate wind, PV and concentrating solar power (CSP), and biomass technical potential using NREL resource data (Connelly et al. 2020; NREL 2017b; DOE 2016). We calculate impacts on fossil energy resources and greenhouse gas 
emissions using the Greenhouse Gases, Regulated Emissions, and Energy Use in Transportation $\left(\right.$ GREET $^{\circledR}$ ) model developed by Argonne National Laboratory (ANL 2017).

Figure 8 illustrates our categorization of potential hydrogen demands. Total consumption potential is the amount of hydrogen that would be consumed if all consumers in a given industry used hydrogen without considering competing sources for the services, costs, or economic competition. It could also be defined as the maximum theoretical consumption. The serviceable consumption potential is a subset of the total consumption potential. It is the quantity of hydrogen that would be consumed to serve the portion of the market that could be captured when considering competing sources for the same energy services but without considering economics (i.e., if the price of hydrogen were $\$ 0 / \mathrm{kg}$ over an extended period but considering non-economic drivers - for example, if hydrogen were free many LDV purchaser would not choose FCEVs due to preferences and other considerations). The economic potential is the amount of hydrogen that would be consumed by a sector when the hydrogen price and the price for competing alternatives are considered.

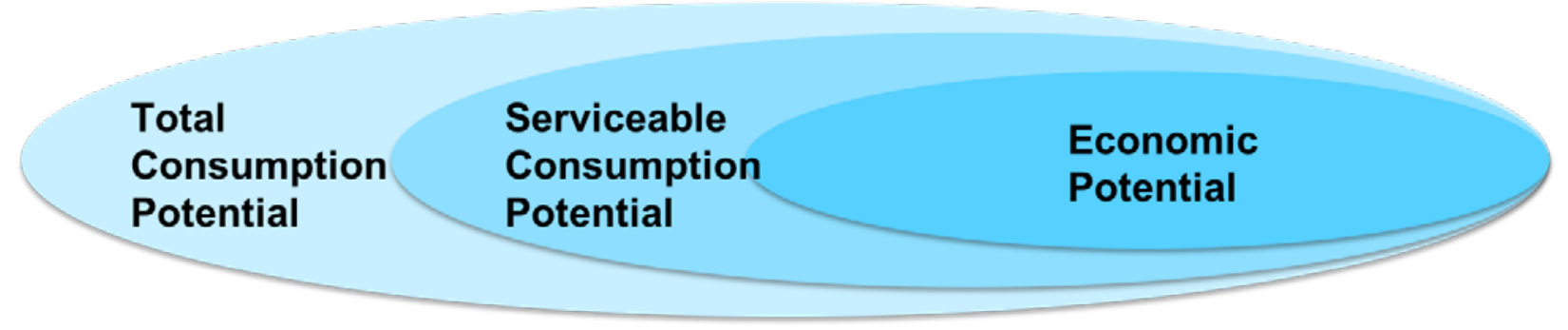

Figure 8. Categorization of demand potentials

We estimate the serviceable consumption potential for hydrogen as the quantity of hydrogen necessary to satisfy the potential markets that use hydrogen for its molecular properties (oil refining, metals, ammonia, biofuels, and synthetic $\mathrm{HC}$ ) and, for markets that use hydrogen primarily as an energy carrier (light-, medium-, and heavy-duty vehicles, and dispatchable power in the electricity sector), the energy requirements needed to serve the portion of the market that could be captured without considering economics. We draw on a literature review and expert consultations to estimate the potential for hydrogen use based on displacing the primary option for energy or feedstock in nine markets:

- Oil refining

- Metals refining (primarily steel production)

- Ammonia

- Biofuels

- Synthetic HC

- Natural gas supplementation

- Seasonal energy storage for the electric grid

- Light-duty FCEVs

- Medium- and heavy-duty FCEVs 


\subsection{Estimating Economic Potential}

In resource analysis, economic potential is a subset of serviceable consumption potential and technical potential, including only the resource that can be sold for more than it costs to produce (Figure 7). For our purposes, we define economic potential as the quantity of hydrogen expected to be available at prices lower than other options to meet each end-use requirement. We estimate the economic potential as the market equilibrium between supply and demand using traditional microeconomic analysis techniques (Brownlie and Lloyd Prichard 1963; Schwartz 2010). This method is based on a theory of mature, competitive markets, in which the price of a particular good will settle at a point where the quantity demanded at that price matches the quantity supplied at that price. At a higher price, more of the good would be supplied, but less demanded. At a lower price, more would be demanded, but less supplied. Hence, in both cases, the supply and demand quantities would differ, and the price would have to shift to a point where the quantities match.

We consider the national market for each hydrogen application and identify the threshold price at which hydrogen can compete with other options. Most of our estimates are based on potential mature markets in 2050 without considering market development rates. However, because the markets for FCEVs - as LDVs, medium-duty vehicles (MDVs), or heavy-duty vehicles (HDVs) - are unlikely to approach maturity in the 2050 timeframe, we use a later year for our FCEV potential estimates. Details of our assumptions and estimates are reported in Section 3. The prices in the demand curves are not necessarily the prices being paid for hydrogen today; rather, they are the hydrogen prices necessary to compete against the next-best option for providing the same service. For example, in the natural gas market, the value of hydrogen is the energy that can be produced when hydrogen is combusted, so the demand price of hydrogen is set equal to that of natural gas on a heating-value basis. Because alternatives to hydrogen in ammonia production and refining are limited, the hydrogen prices for those markets in the demand curve are set relatively high. Thus, the prices in the demand curves may be higher than prices actually paid.

To calculate the economic potential of hydrogen, we first construct demand curves for each hydrogen-consuming market, estimating the quantity of hydrogen each consumer would purchase over a range of prices (Figure 9). As the price increases, the quantity demanded declines, implying that fewer buyers are willing and/or able to purchase hydrogen at higher prices.

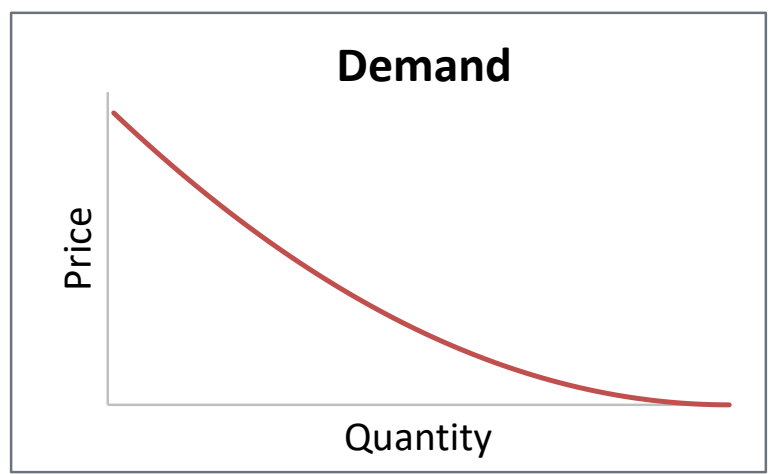

Figure 9. Schematic of a demand curve 
We also construct supply curves to estimate the quantity of hydrogen each producer would supply over a range of prices (Figure 10). As the price increases, production of hydrogen using higher-cost conversion technologies and/or feedstocks becomes profitable, more hydrogen is produced, and the total supply of hydrogen increases. Our supply curves are composed of the sum of production and delivery costs, so they can be considered supply prices at the industrial hydrogen user facility, or at the city-gate terminal for transportation demands.

We include four hydrogen-production methods: natural gas steam methane reforming (SMR) based on current production and future potential (including capital cost), LTE using low-cost, dispatch-constrained electricity (LDE) based on the Regional Energy Deployment System (ReEDS) model (Eurek et al. 2016), ${ }^{8}$ nuclear energy with HTE based on converting 20\%-60\% of the current nuclear power fleet to hydrogen production, and gasification of solid biomass based on resource availability from the Billion Ton Study (BTS) (DOE 2016). We also consider hydrogen production from coal and emerging technologies, but the hydrogen cost from these approaches precludes them from playing a role in the economic potential analysis. The production methods are described in Section 4.

Hydrogen production from reforming of biogas is not included, because biogas will likely be used in natural gas markets - potentially at a premium price. Because hydrogen production from natural gas is included in this analysis, and the price of biogas will be the same as or higher than the price of natural gas, biogas could be considered a fraction of the natural gas reported in the results. Photoelectrochemical (PEC), solar-thermal, photolytic biological, and dark fermentative hydrogen production technologies are not included, because they currently are far from commercial realization, and their costs and resource availabilities are highly speculative. Hydrogen imports and exports (as hydrogen or within a carrier like ammonia) are not included, because a global market assessment would be necessary to estimate international market activity.

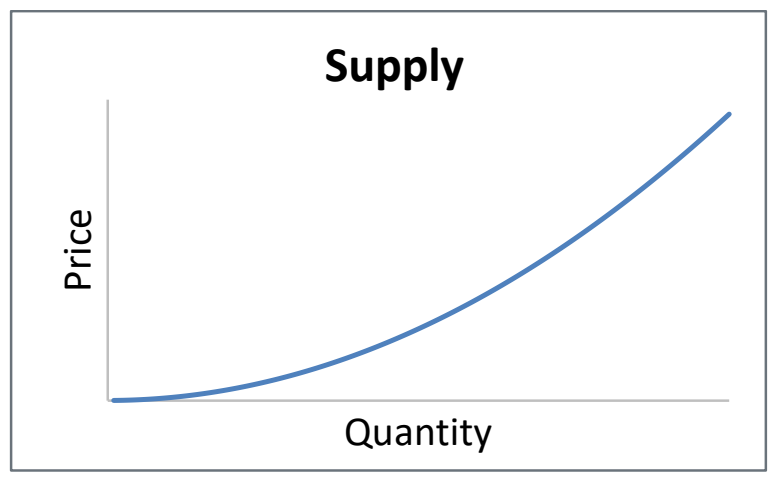

Figure 10. Schematic of a supply curve

We develop several scenarios using various combinations of the supply and demand curves. For each scenario, the supply and demand curves (aggregated across all markets) cross each other at an equilibrium point denoting the quantity of hydrogen at which the demand price is equal to the

\footnotetext{
${ }^{8}$ ReEDS is a capacity planning expansion and dispatch model for the North American power sector that uses system-wide least-cost optimization to estimate the future buildout of generation and transmission capacity.
} 
supply curve's price (Figure 11). The hydrogen quantities at each of these equilibrium points represent the economic potentials of hydrogen under the corresponding scenarios.

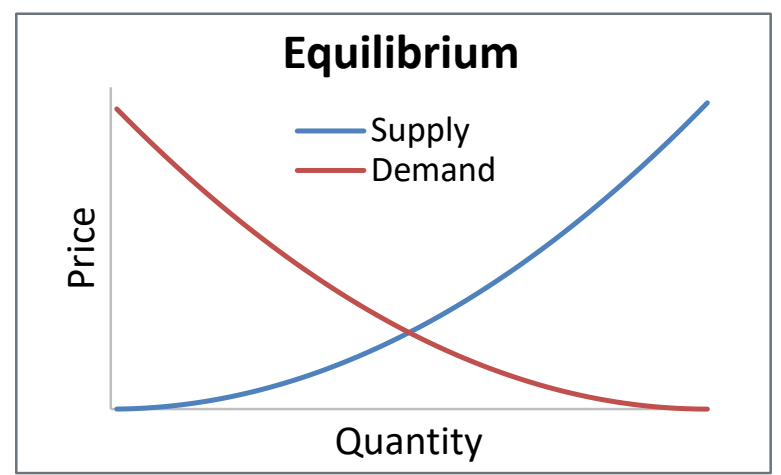

Figure 11. Schematic of supply and demand curves showing the equilibrium point where the curves cross

Unless otherwise noted, all costs presented in this analysis are in 2016 dollars. When cost estimates provided in Elgowainy et al. (2020) are in 2015 or 2017 dollars, we do not convert them to 2016 dollars, because the dollar-year difference is much smaller than the estimates' level of precision (rounded to $\$ 0.10$ increments).

We assume no economic impacts due to carbon policy either as costs for emissions or as impacts on costs to use fossil resources to produce hydrogen or competing alternatives. We also do not consider potential impacts due to caps on carbon emissions.

\subsection{Estimating Energy and Emissions Impacts}

To estimate the impacts associated with the H2@Scale technical and economic potentials, we calculate the change in energy use and emissions from a baseline due to the projected hydrogen production and demand. In our technical and economic potential analysis, we make assumptions regarding the evolution of the power sector (e.g., natural gas prices, renewable energy technology costs, nuclear retirements), which differ from an Annual Energy Outlook (AEO) reference scenario (EIA 2017a); our emissions and energy-use reduction results are meant to show only the effect of estimated hydrogen markets (e.g., energy reductions from increased efficiency of FCEVs), and not the effect of changes to the electric grid mix.

We calculate impacts based on the hydrogen production and demand mix in each scenario. For markets that currently use hydrogen (oil refining and ammonia production), the emissions reduction is based on displacing SMR hydrogen with hydrogen produced from the hydrogen supply mix for the respective scenarios. For markets where hydrogen is assumed to be an alternative fuel or feedstock (e.g., FCEVs), we calculate the energy use and emissions changes due to displacing the baseline fuel or feedstock. Emissions factors from GREET are used (ANL 2017). Appendix B includes more detailed information on the assumptions and methods used to estimate energy-use and emissions impacts. 


\section{Potential Hydrogen Demands}

Hydrogen can provide value across a multitude of industries and applications as an energy carrier for intermediate or end use. On-purpose hydrogen production (i.e., not byproduct) in the United States is $10 \mathrm{MMT} / \mathrm{yr}$ (Connelly, Elgowainy, and Ruth 2019), primarily for oil refining and ammonia production. In this analysis, we consider consumption of captive hydrogen (produced intentionally by the consuming industry) and merchant hydrogen (produced intentionally for sale), but we do not consider captive byproduct hydrogen production. Although we consider hydrogen demand in existing and emerging markets, we assume all market size estimates correspond to mature markets that have reached a state of equilibrium. ${ }^{9}$

The potential hydrogen demand varies for each application, as does the threshold price for hydrogen in each market. The viability of alternatives to hydrogen in various markets affects the estimated threshold price. For existing hydrogen markets, such as ammonia and oil refining, the prices in the demand curves estimated here are not necessarily the prices being paid for hydrogen today; rather, they are the hydrogen prices necessary to compete against the next-best option. This threshold price, or our estimate of the maximum price customers are willing to pay, may be higher than prices in current markets, representing the maximum price point hydrogen can reach before an alternative is selected. Each application's threshold price is at the location where the hydrogen would be purchased from wholesale markets in large quantities. For industrial demands, this location is at the industrial site. For transportation, this location is a city-edge terminal, so delivery and distribution costs would need to be added to the price-point estimate.

In this section, we estimate the serviceable consumption potential for each demand opportunity, competitive hydrogen price points, and demand locations for the following potential hydrogen demands: oil refining, metals refining, ammonia, biofuels, synthetic HC, natural gas supplementation, seasonal energy storage for the electrical grid, light-duty FCEVs, and mediumand heavy-duty FCEVs. The hydrogen demands presented here are primarily based on related H2@Scale analysis from Argonne National Laboratory (Elgowainy et al. 2020), but original analysis is conducted for seasonal energy storage.

\subsection{Oil Refining}

Currently, U.S. oil refining consumes about 10 MMT of hydrogen annually, ${ }^{10}$ making it the largest hydrogen market. Refining requires hydrogen for the hydrocracker to produce diesel from heavy crude; the fluid catalytic cracker feed hydrotreater that removes sulfur from heavy crude; the diesel hydrotreater that removes sulfur from various feed, intermediate, and product streams; and the naphtha hydrotreater (Elgowainy et al. 2014). Hydrogen requirements depend primarily on the heaviness of the feed crude (as measured by American Petroleum Institute [API] gravity),

\footnotetext{
${ }^{9}$ Because resources and demands can be affected by changing land-use patterns, system performance, and demand for energy services (e.g., miles driven), the maximum market size varies with time and depends on many factors that are outside the scope of this analysis. To make the analysis possible, we chose a single target year-2050. That year is near enough in the future to consider economic conditions as done in other analyses, e.g., EIA (2018a), but it is likely far enough in the future to allow time for markets to develop. For technologies that need more development time to reach equilibrium (i.e., FCEVs), we chose a later year.

${ }^{10}$ This includes about 4 MMT of byproduct hydrogen, which includes both byproduct hydrogen that is combusted and byproduct hydrogen recovered for internal or merchant use (D. Brown 2016).
} 
feed sulfur content, and the ratio of gasoline-to-diesel production. The hydrogen is sourced from natural gas SMR, purchases from merchant plants, and byproduct hydrogen produced during catalytic reforming of naphtha.

The total captive and merchant hydrogen demand (other than reformer-byproduct hydrogen) of U.S. refineries is projected to increase by $27 \%$ between 2017 and 2050 , from 5.9 to $7.5 \mathrm{MMT} / \mathrm{yr}$ (Elgowainy et al. 2020). This projected growth is primarily due to an increase in the estimated diesel-to-gasoline ratio as well as processing of lower-quality crude (lower API gravity and higher sulfur), which require higher hydrogen use.

For the H2@Scale analysis, we estimate the serviceable consumption potential for oil refining at 7.5 MMT/yr (Table 1), consistent with the projected demand in 2050. Because the oil refining process depends heavily on hydrogen and alternatives are very limited, we set a price point of $\$ 3.00 / \mathrm{kg}$ to reflect the need for hydrogen and lack of alternatives in this industry.

Table 1. Hydrogen Demand and Threshold Price for Oil Refining (Elgowainy et al. 2020)

\begin{tabular}{cc}
\hline Hydrogen Price (\$/kg) & Annual Hydrogen Demand (MMT) \\
\hline 3.00 & 7.5 \\
\hline
\end{tabular}

This is the assumed threshold price based on the lack of a low-cost alternative to hydrogen for oil refining. Hence, the prices in the demand curves may be higher than prices in current markets.

Locations for hydrogen demand from refineries are determined using 2017 refinery capacity data from the U.S. Energy Information Administration (EIA 2017e). We apportion the projected hydrogen demand by location using 2017 refinery capacities.

\subsection{Metals Refining}

Current steel production primarily uses blast furnace/coke oven technology to produce the required feed of pig iron from iron ore. Iron production via direct reduction of iron (DRI) using natural gas, synthesis gas, and/or hydrogen can decrease the energy use and emissions of steel production while improving steel quality compared with blast furnace/coke oven technology (Elgowainy et al. 2020). The DRI process can use mixtures of hydrogen and carbon monoxide or natural gas up to $100 \%$ hydrogen. Mixtures may be favorable both because they may reduce the operating cost (by mixing hydrogen with lower-cost natural gas) and because the presence of carbon monoxide can improve the quality of some steel products. Experts suggest that a 30\% mix of hydrogen with natural gas (by energy) is feasible without altering the production process (Chevrier 2018). Other approaches to iron reduction that use hydrogen exclusively for improvements in process efficiency, such as flash ironmaking technology, are currently in R\&D stages. In this analysis, we consider hydrogen use in metals refining for steel production as a potential emerging market.

Consistent with Elgowainy et al. (2020), we estimate hydrogen's serviceable consumption potential for metals refining based on the hydrogen that would be required for the total potential U.S. steel manufacturing industry to use the DRI process. The estimate includes the assumption that feasible growth in U.S. demand would be met by a corresponding growth in domestic iron refining. Thus, using hydrogen for metals refining does not reduce U.S. fossil energy use for refining. Instead it requires additional energy use but reduces expected growth in imported steel. Elgowainy et al. (2020) report that U.S. steel production is expected to increase to $120 \mathrm{MMT}$ 
annually in 2040 (compared with about 82 MMT in 2017). We estimate a serviceable hydrogen consumption potential of $12 \mathrm{MMT} / \mathrm{yr}$, corresponding to the hydrogen required if all projected steel production were converted to iron refining using $100 \%$ hydrogen. ${ }^{11}$ For this to be economical, hydrogen would need to be competitive with natural gas on a higher heating value (HHV) basis, resulting in a threshold price of $\$ 0.80 / \mathrm{kg}$ for the AEO Reference scenario and $\$ 1.40 / \mathrm{kg}$ for the AEO Low Oil and Gas Resource and Technology (LOGR) scenario (Elgowainy et al. 2020). Iron refining using 30\% hydrogen, which is considered a feasible mix, would use 4 MMT of hydrogen. Elgowainy et al. (2020) report that, at a 30\% hydrogen mixture, a hydrogen price of $\$ 1.70 / \mathrm{kg}$ is considered to be economically competitive. Thus, we estimate the threshold prices of hydrogen for metals refining shown in Table 2 and Table 3.

Table 2. Hydrogen Demand and Threshold Prices for Metals Refining under the AEO Reference Scenario (Elgowainy et al. 2020)

\begin{tabular}{cc}
\hline Hydrogen Price (\$/kg) & $\begin{array}{l}\text { Cumulative Annual Hydrogen } \\
\text { Demand (MMT) }\end{array}$ \\
\hline 1.70 & 4 \\
0.80 & 12 \\
\hline
\end{tabular}

These hydrogen threshold prices are the prices required for hydrogen processes to compete with alternative methods of refining metals.

Table 3. Hydrogen Demand and Threshold Prices for Metals Refining under the AEO LOGR Scenario (Elgowainy et al. 2020)

\begin{tabular}{cc}
\hline Hydrogen Price (\$/kg) & $\begin{array}{l}\text { Cumulative Annual Hydrogen } \\
\text { Demand (MMT) }\end{array}$ \\
\hline 1.70 & 4 \\
1.40 & 12 \\
\hline
\end{tabular}

These hydrogen threshold prices are the prices required for hydrogen processes to compete with alternative methods of refining metals.

We allocate hydrogen demand for metals refining to U.S. locations based on personal communication with experts from Idaho National Laboratory (January 25, 2017). Demand is split evenly between three primary regions for metals refining: Minnesota, Lake Michigan and Lake Erie, and Birmingham, Alabama. ${ }^{12}$

\subsection{Ammonia}

Ammonia as a nitrogen fertilizer facilitates food and energy crop production. Ammonia production is a major consumer of hydrogen, although that hydrogen is produced in an SMR

\footnotetext{
11 The hydrogen requirement ranges from $80-120 \mathrm{~kg}$ of hydrogen per metric ton of hot iron, depending on the technology employed, the reaction temperature, and the reaction off-gas available for hydrogen preheating; the value we use - $100 \mathrm{~kg}$ of hydrogen per metric ton of hot iron - is the midpoint of this range.

12 Demand for Minnesota is allocated to Minneapolis and Duluth. Demand for Lake Michigan and Lake Erie is distributed evenly to Gary, IN; Toledo, OH; Cleveland, OH; Erie, PA; Buffalo, NY; and Rochester, NY. Demand for Birmingham is distributed to the metro areas within a 250-mile radius of the city.
} 
process that is heat integrated with the Haber-Bosch ammonia production process. We estimate hydrogen demand for ammonia production based on existing and planned U.S. ammonia plants (T. Brown 2018), as analyzed by Elgowainy et al. (2020). ${ }^{13}$ Projected hydrogen demand from ammonia production is expected to grow at a rate of about $1 \%$ annually from 2018 through 2050, resulting in 3.6 MMT/yr of hydrogen demand.

Currently, domestic ammonia production is growing because of low-cost natural gas and the low-cost hydrogen that can be produced from it. We assume that low-cost hydrogen continues to be necessary for projected growth. We estimate the threshold price for hydrogen for current ammonia production at $\$ 3.00 / \mathrm{kg}$ (because, as with oil refining, the process is hydrogen dependent). The method used for this analysis does not distinguish between production technologies. Therefore, even though SMR of natural gas to be used for ammonia production should have a discounted production cost to account for the heat integration, that discount is not included in this analysis. The estimated growth in the ammonia market is based on a hydrogen price of $\$ 2.00 / \mathrm{kg}$ (Elgowainy et al. 2020); thus, we require that price for additional hydrogen demand. Table 4 shows our demand and threshold price assumptions for ammonia production.

Table 4. Hydrogen Demand and Threshold Prices for Ammonia Production (Elgowainy et al. 2020)

\begin{tabular}{cc}
\hline Hydrogen Price (\$/kg) & $\begin{array}{l}\text { Cumulative Annual Hydrogen } \\
\text { Demand (MMT) }\end{array}$ \\
\hline 3.00 & 2.5 \\
2.00 & 3.6 \\
\hline
\end{tabular}

For current ammonia production, this hydrogen threshold price is based on the lack of a low-cost alternative to hydrogen. Hence, the prices in the demand curves may be higher than prices in the current markets. The threshold price for future ammonia production is based on the economic competitiveness of the current production pathway of SMR hydrogen.

We project ammonia demand locations from planned and existing ammonia plants presented in Elgowainy et al. (2020), based on data from the ammonia industry (T. Brown 2018). Most facilities are located near natural gas pipelines, because ammonia production is highly reliant on natural gas feedstock. Our 2050 demand locations assume the same locations that are assumed for 2021, scaled to the 2050 demand estimate of 3.6 MMT/yr.

\subsection{Biofuels}

In the future, biofuels could be the primary option for applications needing energy-dense liquid fuels (e.g., aviation, marine transport). For many applications, cellulosic ethanol does not meet required performance specifications. In addition, a large fraction of the carbon in biomass is emitted as carbon dioxide during fermentation to produce ethanol. Thus, additional biofuel technologies are being developed. Many of those new technologies require hydrogen directlyfor conversion, hydroprocessing, and/or hydrotreating of the biofuels - and all require hydrogen

\footnotetext{
${ }^{13}$ Hydrogen demand is estimated using the stoichiometric ratio (3 moles of hydrogen for 2 moles of ammonia production) and an assumed plant capacity factor of $80 \%$.
} 
indirectly through the increased need for ammonia fertilizer in biomass production. Biofuel development and corresponding implementation would lead to increased hydrogen demand.

For the H2@Scale analysis, we rely on analysis from Elgowainy et al. (2020) projecting biofuel production to meet half of total projected jet fuel demand in 2050, which is $38.6 \mathrm{billion}$ gal $/ \mathrm{yr}$ per the 2017 AEO LOGR scenario (EIA 2017a). Thus, the projected biofuel demand is 19.3 billion gal/yr. The AEO projects 0.25 quad/yr utilization of "green liquids," and Elgowainy assumes those green liquids would be produced by hydrotreating fats, oils, and greases (FOGs) into diesel drop-in fuels. Thus, 1.8 billion gal/yr of biofuels are from hydrotreating FOGs. Hydrotreating FOGs requires $0.02-0.03 \mathrm{~g}$ of hydrogen per $1 \mathrm{~g}$ of biofuel; we use the midpoint ( $0.025 \mathrm{~g}$ of hydrogen), which is equivalent to $76 \mathrm{~g}$ of hydrogen per $1 \mathrm{gal}$ of biofuel and results in an annual hydrogen demand of 0.1 MMT/yr. Also following Elgowainy et al. (2020), we assume that the remaining 17.5 billion gal/yr of biofuels are produced using catalytic fast pyrolysis of lignocellulosic biomass. Catalytic fast pyrolysis requires $490 \mathrm{~g}$ of hydrogen per $1 \mathrm{gal}$ of biofuel, although almost all of that hydrogen is produced by reforming non-condensable products from the pyrolysis reactor (Dutta et al. 2020). We assume that hydrogen could instead be produced exogenously, and the non-condensable reactor products could be converted into higher-value chemicals. Further analysis is necessary to check that assumption and adjust as necessary. At a biofuel demand of $17.5 \mathrm{billion}$ gal $/ \mathrm{yr}$ and $490 \mathrm{~g}$ of hydrogen per $1 \mathrm{gal}$ of biofuel, the annual hydrogen demand is 8.6 MMT/yr. Including the hydrogen demand for FOG conversion, the serviceable consumption potential is $8.7 \mathrm{MMT} / \mathrm{yr}$. Because this growth of biofuel consumption is assumed to be driven primarily by other factors (e.g., biomass cost, conversion technology costs, mandates), we assume hydrogen price is not a key driver, and any price less than $\$ 3.00 / \mathrm{kg}$ would not impact hydrogen demand for biofuels production. Thus, we use a price point of $\$ 3.00 / \mathrm{kg}$ for the entire serviceable consumption potential. Table 5 summarizes these results.

Table 5. Hydrogen Demand and Threshold Price for Biofuels

\begin{tabular}{cc}
\hline Hydrogen Price $(\mathbf{\$} / \mathbf{k g})$ & Annual Hydrogen Demand (MMT) \\
\hline 3.00 & 8.7 \\
\hline
\end{tabular}

\begin{abstract}
We assume a high threshold price because the biofuels market is assumed to be driven by factors other than hydrogen price. Hence, the prices in the demand curves may be higher than prices in the current markets.
\end{abstract}

Estimated hydrogen demand for biofuels is distributed to locations with available biomass based on the BTS (DOE 2016). We allocate hydrogen demand according to the distribution of biomass resource availability by state (e.g., if a state has $10 \%$ of the biomass resource, we assume the state has $10 \%$ of demand for biofuel production). Owing to the lack of detail on biofuel production facilities from the BTS, we make assumptions regarding the biofuel locations within each state. We distribute regional biofuel production to locations with oil refining, ammonia production, metals refining, or SMR, as identified in the respective sections of this report, because those locations will likely have the industrial infrastructure to also support biofuel production. Hydrogen demand for biofuels is allocated evenly to the industrial locations within each state. 


\subsection{Synthetic Hydrocarbons}

Hydrogen can be used to produce various synthetic $\mathrm{HC}$ that compete in the fuels and chemical markets. Reacting hydrogen with carbon dioxide can produce HC that can be used as substitutes for fossil fuel-based HC. These products can serve as substitutes for liquid fuels (e.g., for use in long-haul trucks) and as feedstocks in petrochemical production (e.g., methanol production). Ethanol plants and SMR units for oil refining and ammonia production can provide high-purity carbon dioxide for potential synthetic $\mathrm{HC}$ production that requires carbon dioxide. Elgowainy et al. (2020) estimate about $100 \mathrm{MMT} / \mathrm{yr}$ of recoverable carbon dioxide are available from these sources. Additional sources of carbon dioxide include lower-purity sources from combustion (e.g., natural gas and coal power plants, industrial boilers) and direct capture from the air.

Here we estimate the serviceable consumption potential for hydrogen that could be used with carbon dioxide to produce synthetic $\mathrm{HC}$, as well as the threshold prices necessary for synthetic methanol for chemical markets and methanol for methanol-to-gasoline (MTG) markets. We assume all $100 \mathrm{MMT} / \mathrm{yr}$ of concentrated carbon dioxide sources are used (44 MMT/yr from ethanol plants, with the remainder from SMR for refining and ammonia production) and that hydrogen would be purchased to use with the carbon dioxide. Using all $100 \mathrm{MMT} / \mathrm{yr}$ of carbon dioxide and assuming a 3:1 hydrogen to carbon dioxide molar ratio would require $14 \mathrm{MMT} / \mathrm{yr}$ of hydrogen demand (6 MMT/yr at ethanol facilities, 5.9 MMT/yr at refinery SMR units, and 2.1 MMT/yr at ammonia SMR units) (Elgowainy et al. 2020). ${ }^{14}$

We estimate the hydrogen market size for methanol for the chemical market and a threshold price to enable it to compete against fossil sources based on Elgowainy et al. (2020). The current U.S. capacity for methanol production is $9.4 \mathrm{MMT} / \mathrm{yr}$, and planned and announced capacity additions of $25.5 \mathrm{MMT} / \mathrm{yr}$ by 2030 (Offshore Technology 2019) will result in market growth to 34.9 MMT/yr. To meet that $25.5 \mathrm{MMT} / \mathrm{yr}$ growth in methanol production using carbon dioxide and hydrogen as feedstocks, $44 \mathrm{MMT} / \mathrm{yr}$ of carbon dioxide and $6 \mathrm{MMT} / \mathrm{yr}$ of hydrogen would be required at a 3:1 hydrogen to carbon dioxide molar ratio. Using a 79\% conversion efficiency of carbon dioxide, ${ }^{15}$ we estimate a hydrogen threshold price of $\$ 1.73 / \mathrm{kg}$, because that price is necessary to produce methanol with an equivalent production cost to fossil-sourced methanol, which is $\$ 0.5 / \mathrm{kg}$ (Elgowainy et al. 2020). We assume that the $44 \mathrm{MMT} / \mathrm{yr}$ of carbon dioxide required to produce methanol is sourced from ethanol plants.

We assume that the remaining serviceable consumption potential for the synthetic $\mathrm{HC}$ market could be used for the MTG market. Because our assumption is that $44 \mathrm{MMT} / \mathrm{yr}$ of the 100 MMT/yr of available concentrated carbon dioxide would be used for methanol for the chemical market (Elgowainy et al. 2020), we assume the remaining $56 \mathrm{MMT} / \mathrm{yr}$ would be used for MTG

\footnotetext{
${ }^{14}$ Hydrogen demand is estimated based on a 3:1 hydrogen to carbon dioxide molar ratio for methanol and MTG production based on simple stoichiometry converting 1 mole of carbon dioxide and 3 moles of hydrogen to 1 mole of methanol and 1 mole of water.

${ }^{15}$ The estimate of $79 \%$ carbon dioxide conversion efficiency to methanol is based on information publicly available at the time of publication. Higher conversion efficiencies are possible with a higher recycling rate of carbon dioxide. There are likely tradeoffs between carbon dioxide conversion efficiency, process energy efficiency, and economics. Manufacturing-scale plants have reported higher carbon dioxide utilization rates (>90\%), which can increase the potential for carbon dioxide to fuel production. We assume all carbon dioxide is ultimately converted but that only $79 \%$ is converted in each pass.
} 
markets. Converting that quantity of carbon dioxide would require 8.0 MMT/yr of hydrogen. However, because that carbon dioxide would originate from less-concentrated sources (refining and ammonia production) and the value of the gasoline product is assumed to be low, an extremely low hydrogen price would be necessary for it to be used for this application. To represent that requirement, we set the hydrogen threshold price to $\$ 0.00 / \mathrm{kg}$. Table 6 summarizes the demand and threshold prices for the hydrogen used for synthetic methanol and gasoline.

Table 6. Hydrogen Demand and Threshold Prices for Synthetic HC (Elgowainy et al. 2020)

\begin{tabular}{|c|c|c|c|}
\hline & $\begin{array}{l}\text { Hydrogen Price } \\
(\$ / \mathbf{k g})\end{array}$ & $\begin{array}{l}\text { Annual Hydrogen } \\
\text { Demand (MMT) }\end{array}$ & $\begin{array}{l}\text { Cumulative Hydrogen } \\
\text { Demand (MMT) }\end{array}$ \\
\hline Synthetic HC (Methanol) & 1.73 & 6.0 & 6.0 \\
\hline Synthetic HC (MTG) & 0.00 & 8.0 & 14.0 \\
\hline
\end{tabular}

The hydrogen threshold prices are the prices required for synthetic methanol to compete with methanol from natural gas, and for MTG to compete with petroleum gasoline.

The regional distribution of hydrogen for synthetic $\mathrm{HC}$ production is assumed to be located at the concentrated carbon dioxide sources from ethanol and SMR presented in Elgowainy et al. (2020). ${ }^{16}$ For methanol for the chemical market, we assume facilities are located at the ethanol plants.. For MTG, we assume facilities are located at the refining and current ammonia plants.

\subsection{Supplementing Natural Gas}

Experts believe that low concentrations of hydrogen can be injected into existing natural gas infrastructure without significant risk to end-use applications (Altfeld and Pinchbeck 2013). Such supplementation of natural gas with hydrogen is currently being demonstrated in Europe (ITM Power, n.d.). That option is considered in this analysis. Other options are not considered in this analysis. Those include using the natural gas system to transport hydrogen and separating the two components at or near the point of use (M. W. Melaina, Antonia, and Penev 2013) and producing methane from hydrogen and carbon dioxide and injecting the methane into the natural gas system.

The market size and threshold prices for natural gas supplementation are based on Elgowainy et al. (2020). At 20\% hydrogen (by volume) in natural gas, Elgowainy et al. (2020) estimate that 16 MMT of hydrogen can be injected into the U.S. natural gas pipeline system annually. We estimate that the price at which hydrogen will be competitive in the natural gas system is the price of natural gas on an HHV basis (assuming no incentives). We assume industrial-average natural gas prices for the year 2050 of $\$ 5.88$ per million British thermal units (mmBtu) in the AEO 2018 Reference scenario and \$10.23/mmBtu in the AEO 2018 LOGR scenario, corresponding to hydrogen prices of $\$ 0.80 / \mathrm{kg}$ and $\$ 1.40 / \mathrm{kg}$. These results are summarized in Table 7 and Table 8 . Consistent with the methods throughout this report, we do not consider larger economic effects such as the impact on natural gas prices of reducing natural gas demand at wellheads.

\footnotetext{
${ }^{16}$ Locations in Elgowainy et al. (2020) are based on U.S. Environmental Protection Agency facility-level greenhouse gas emission data (EPA 2017).
} 
Table 7. Hydrogen Demand and Threshold Price for Injection into the Natural Gas Pipeline System under the AEO Reference Scenario (Elgowainy et al. 2020)

\begin{tabular}{cc}
\hline Hydrogen Price $\mathbf{( \$ / k g )}$ & Annual Hydrogen Demand (MMT) \\
\hline 0.80 & 16
\end{tabular}

This hydrogen threshold price is based on the price that is equivalent to the natural gas price $(\$ 5.88 / \mathrm{mmBtu})$ on an HHV basis.

Table 8. Hydrogen Demand and Threshold Price for Injection into the Natural Gas Pipeline System under the AEO LOGR Scenario (Elgowainy et al. 2020)

\begin{tabular}{cc}
\hline Hydrogen Price (\$/kg) & Annual Hydrogen Demand (MMT) \\
\hline 1.40 & 16 \\
\hline
\end{tabular}

This hydrogen threshold price is based on the price that is equivalent to the natural gas price $(\$ 10.23 / \mathrm{mmBtu})$ on an HHV basis.

A spatial distribution of natural gas is derived from EIA using the 2015 AEO report of national use by census division (EIA 2015a). ${ }^{17}$ The data are disaggregated from census divisions to counties using an even distribution. Finally, the data are linearly scaled from 7 MMT, the hydrogen quantity corresponding the 2015 AEO natural gas use, the estimate from Elgowainy et al. (2020), 16 MMT. For mapping purposes, along with other demand data, the natural gas regional locations are normalized to county area.

\subsection{Seasonal Energy Storage for the Electric Grid}

Current grid operations primarily use central generation to supply distributed loads. That central generation includes baseload generators that operate nearly continuously, such as nuclear and coal generation, as well as intermediate and peaking generators designed to adjust output to follow the net load (Chang et al. 2013). Net load varies as the total load varies owing to temporal fluctuations in demand and as VRE generation (e.g., PV and wind) shifts owing to the availability of solar and wind resources.

We estimate the serviceable consumption potential for hydrogen storage at $15 \mathrm{MMT} / \mathrm{yr}$, which is the hydrogen required to replace natural gas generation in the ReEDS High Curtailment grid scenario described in more detail in Section 4.2. ReEDS is a capacity-expansion model (Eurek et al. 2016). Using it, we develop the ReEDS High Curtailment grid scenario to estimate the amount of generation exceeding load available at very high penetrations of renewable and nuclear electricity generation under the AEO LOGR scenario assumptions. The ReEDS grid scenarios include dispatchable generation - natural gas combustion turbine (NGCT), natural gas combined cycle (NGCC), and coal generation - in the generation fleet, because the cost to supply the load using VRE generation and energy storage is higher than the costs of the dispatchable generation options. We assume that NGCT and NGCC could potentially be replaced by seasonal storage; therefore, we estimate the seasonal storage serviceable consumption potential to be the quantity necessary to replace those generators. We assume that

\footnotetext{
${ }^{17}$ EIA provides the data with the unit of quads, but we convert to MMT of hydrogen using an HHV of 120.21
} $\mathrm{MJ} / \mathrm{kg}$. 
coal generation cannot be replaced by seasonal storage because most coal generators run during nearly all hours of the year, and thus regions with them require additional overall generation, not just seasonal storage. We use the ReEDS High Curtailment grid scenario instead of the ReEDS Low Renewable Energy (RE) Cost grid scenario for the serviceable consumption potential estimate (even though the ReEDS Low RE Cost scenario has more dispatchable electricity generation). ${ }^{18}$ Our methods and assumptions are detailed in Appendix C.

We estimate the hydrogen price requirements for seasonal storage by calculating the hydrogen prices necessary to match the levelized costs of energy (LCOEs) of natural gas generators for polymer electrolyte membrane (PEM) fuel cells $\left(\mathrm{H}_{2}-\mathrm{FC}\right)$ and hydrogen combustion turbines $\left(\mathrm{H}_{2}-\right.$ $\mathrm{CT}$ ). In the LCOE calculations, we use the capacity factors calculated within the ReEDS model runs. In each case, the most competitive technology $\left(\mathrm{H}_{2}-\mathrm{FC}\right.$ or $\left.\mathrm{H}_{2}-\mathrm{CT}\right)$ is the one that can use the higher-priced hydrogen to match the fossil-generated LCOE, and that higher-priced hydrogen sets the threshold price. The demands and threshold prices differ depending on the assumed natural gas price, because that price affects the mix of fossil generators and the prices necessary to compete with them (Table 9 and Table 10; see also Section 4.2 and Appendix C). The hydrogen price requirements might need to be reduced if other seasonal storage options cost less than dispatchable generation using natural gas (i.e., if hydrogen storage needs to compete with other seasonal storage options to replace natural gas generation). Additional analysis would be required to estimate the impacts of that competition.

Table 9. Hydrogen Demand and Required Threshold Prices for Seasonal Electricity Storage under the ReEDS High Curtailment Grid Scenario (Using the AEO LOGR Costs)

\begin{tabular}{lcccc}
\hline & $\begin{array}{l}\text { Annual Electricity } \\
\text { Generation to } \\
\text { Serve Load (TWh) }\end{array}$ & $\begin{array}{l}\text { Hydrogen } \\
\text { Price (\$/kg) }\end{array}$ & $\begin{array}{l}\text { Annual Hydrogen } \\
\text { Demand (MMT) }\end{array}$ & $\begin{array}{l}\text { Cumulative } \\
\text { Annual Hydrogen } \\
\text { Demand (MMT) }\end{array}$ \\
\hline NGCC generation & 252 & 1.10 & 14 & 14 \\
NGCT generation & 14 & 0.26 & 0.8 & 15
\end{tabular}

Quantities do not sum to the cumulative total due to rounding. The hydrogen threshold prices are based on the prices required to compete with conventional electricity generation.

Table 10. Hydrogen Demand and Required Threshold Prices for Seasonal Electricity Storage under the ReEDS Low RE Cost Grid Scenario (Using the AEO Reference Costs)

\begin{tabular}{lcccc}
\hline & $\begin{array}{l}\text { Annual Electricity } \\
\text { Generation to Serve } \\
\text { Load (TWh) }\end{array}$ & $\begin{array}{l}\text { Hydrogen } \\
\text { Price (\$/kg) }\end{array}$ & $\begin{array}{l}\text { Annual } \\
\text { Hydrogen } \\
\text { Demand (MMT) }\end{array}$ & $\begin{array}{l}\text { Cumulative Annual } \\
\text { Hydrogen Demand } \\
\text { (MMT) }\end{array}$ \\
\hline NGCC generation & 897 & 0.57 & 48 & 48 \\
NGCT generation & 82 & 0.55 & 4.4 & 52 \\
\hline
\end{tabular}

Quantities do not sum to the cumulative total due to rounding. The hydrogen threshold prices are based on the prices required to compete with conventional electricity generation.

\footnotetext{
18 The ReEDS High Curtailment grid scenario uses the AEO LOGR scenario's resource and technology costs. Its natural gas prices are higher than those in the ReEDS Low RE Cost grid scenario that uses the AEO Reference costs. Seasonal storage is more likely to be competitive with dispatchable generation under higher natural gas prices; therefore, we use those results as a more realistic estimate of the serviceable consumption potential of hydrogen for seasonal storage.
} 
The seasonal energy storage is assumed to be located at the sources of displaced conventional generation. Natural gas generation locations are determined from the respective ReEDS grid scenarios (see Appendix C), which are modeled to a geographic resolution of 134 U.S. balancing areas.

\subsection{Light-Duty Vehicles}

Hydrogen-powered FCEVs are an alternative to conventional gasoline-powered LDVs. Several FCEV models are currently available for lease or purchase, and over 45 U.S. hydrogen fueling stations have been built to supply hydrogen for LDVs (Satyapal 2020; California Fuel Cell Partnership 2020). The State of California has announced plans to fund 200 stations by 2025 (Office of Governor Edmund G. Brown Jr. 2018; Baronas et al. 2019), and industrial gas companies are developing additional fueling infrastructure in the Northeast (Air Liquide 2017). However, hydrogen consumption is minimal compared with the consumption of traditional fuels in this market (AFDC 2014). Adoption of FCEVs and resulting hydrogen demand will depend on a variety of factors, including the evolution of technology costs and characteristics, regulations and incentives, and consumer preference for alternative fuel vehicles.

We estimate the serviceable consumption potential for LDVs as the demand if FCEVs constituted $41 \%$ of the LDV fleet in 2050 (66 million of 163 million cars and 63 million of 153 million light-duty trucks). We base the fleet penetration on analysis from Roadmap to a U.S. Hydrogen Economy (2020), which estimates an FCEV sales share of $41 \%$ for passenger vehicles in 2050 using favorable assumptions for FCEVs. The fleet penetration is applied to the 2050 vehicle stock from Elgowainy et al. (2020) to estimate FCEV stock and a corresponding annual hydrogen demand of 21.4 MMT/yr (10.0 MMT/yr for cars and 11.4 MMT/yr for light-duty trucks). ${ }^{19}$

The LDV hydrogen demand curve is estimated using the MA3T vehicle-choice model to capture the effects of fuel price, vehicle price, and vehicle performance on consumer choice and resulting market penetration (Oak Ridge National Laboratory 2019). The method is discussed in detail in Elgowainy et al. (2020). Because the MA3T estimate of potential vehicle stock in 2050 is not for a mature market (i.e., the penetration of FCEVs as a fraction of the total fleet is growing rapidly) and the equilibrium method we are using is based on mature market estimates, we select the vehicle penetration when the market share for FCEVs is equilibrated in the vehicle-choice model (corresponding to the year 2075). ${ }^{20}$ We then multiply that market share by the total vehicle stock in 2050 to estimate the number of vehicles and resulting hydrogen demand. Hence, we are calculating the equilibrium FCEV penetration if that equilibrium would be achieved by 2050 . Elgowainy et al. (2020) set the 2050 hydrogen price in the vehicle-choice model to $\$ 2.20 / \mathrm{kg}$ at the terminal, which is equivalent to $\$ 5.03 / \mathrm{kg}$ at the pump. The $\$ 5.03 / \mathrm{kg}$ price is based on the DOE Hydrogen and Fuel Cell Technologies Office target of \$4/kg in 2007 dollars (Ramsden and Joseck 2018), which is inflated to 2016 dollars and includes an additional $\$ 0.53 / \mathrm{kg}$ in taxes.

\footnotetext{
${ }^{19}$ Demand estimates are based on fuel economies of 99.8 miles per gallon gasoline equivalent (mpgge) for cars and 64.3 mpgge for light-duty trucks.

${ }^{20}$ In 2050 , the new vehicle market penetration of FCEVs is $21 \%$, corresponding to a total fleet penetration of $11 \%$ (33 million vehicles). In comparison, the 2075 market penetration of FCEVs is $22 \%$, which equates to the total fleet penetration of $22 \%$ ( 75 million vehicles).
} 
These estimates assume cost reductions from current delivery and dispensing costs, which were estimated at \$12-13/kg in 2017 (Rustagi, Elgowainy, and Vickers 2018). The hydrogen selling price at the pump includes the costs of intra-city delivery and distribution. The equilibrium FCEV stock of 28 million cars and 40 million light-duty trucks demands $11.7 \mathrm{MMT} / \mathrm{yr}$ of hydrogen (4.3 MMT/yr for cars and 7.4 MMT/yr for light-duty trucks). In these estimates, lightduty FCEVs make up $22 \%$ of the projected fleet. Table 11 shows stock penetration by powertrain. Hydrogen demand and threshold price results are shown in Table 12.

Table 11. Projected LDV Stock Penetration by Powertrain from MA3T (Elgowainy et al. 2020)

\begin{tabular}{lccc}
\hline & Fuel Cell Electric & $\begin{array}{c}\text { Internal Combustion } \\
\text { Engine }^{\mathbf{a}}\end{array}$ & Electric Vehicles $^{\mathbf{b}}$ \\
\hline Light-duty cars & $18 \%$ & $15 \%$ & $67 \%$ \\
Light-duty trucks & $26 \%$ & $11 \%$ & $63 \%$ \\
\hline
\end{tabular}

a Includes gasoline, diesel, compressed natural gas, and ethanol flex fuel internal combustion engine vehicles ${ }^{b}$ Includes hybrid electric, plug-in hybrid electric, and battery electric vehicles

Table 12. Hydrogen Demand and Threshold Prices for Light-Duty FCEVs (Elgowainy et al. 2020)

\begin{tabular}{lcccc}
\hline & $\begin{array}{c}\text { Hydrogen Price } \\
\text { at Terminal } \mathbf{( \$ / k g )}\end{array}$ & $\begin{array}{c}\text { Hydrogen Price } \\
\text { at Pump (\$/kg) }\end{array}$ & $\begin{array}{c}\text { Annual Hydrogen } \\
\text { Demand (MMT) }\end{array}$ & $\begin{array}{c}\text { Cumulative } \\
\text { Hydrogen } \\
\text { Demand (MMT) }\end{array}$ \\
\hline Light-duty cars & 2.20 & 5.03 & 4.3 & 4.3 \\
Light-duty trucks & 2.20 & 5.03 & 7.4 & 11.7 \\
\hline
\end{tabular}

This hydrogen threshold price is based on vehicle-choice modeling with a hydrogen price of $\$ 2.20 / \mathrm{kg}$ at a city-edge terminal plus intra-city delivery and distribution costs. It is equivalent to approximately $\$ 5.03 / \mathrm{kg}$ dispensed. The terminal price is used to determine the economic potential. The Reference scenario (see Section 6.1) assumes no FCEV hydrogen demand due to the current high costs of delivery and dispensing.

To estimate the regional hydrogen demand for LDVs, we rely on national vehicle miles traveled (VMT) estimates for the serviceable consumption potential, and on the H2USA National Hydrogen Scenarios study for the economic potential (Melaina et al. 2017). For the serviceable consumption potential, demand corresponding to the full adoption of FCEVs is allocated to counties based on VMT using an internal NREL database of county-level VMT, developed as part of the Cities Leading through Energy Analysis and Planning project (DOE n.d.). For the economic potential, demand quantities are allocated to locations based on the regional distribution of the 2050 results in the H2USA National Expansion scenario. ${ }^{21}$ These results show that populations along the coasts, in Texas, and in the Great Lakes area account for most LDV hydrogen demand in an aggressive FCEV adoption scenario.

\subsection{Medium and Heavy-Duty Vehicles}

Hydrogen could also displace conventional fuels in the MDV and HDV markets. Current fuel consumption in these subsectors is dominated by diesel, but FCEVs may become more

${ }^{21}$ The National Expansion scenario was chosen for this analysis because it projects the highest level of hydrogen demand (8.8 MMT/yr). For each scenario, the distribution is selected from the modeled year in the H2USA National Expansion scenario that most closely matches the FCEV market in the economic potential scenario. 
prominent in the future, especially to meet ZEV targets, such as those set by the California Air Resources Board (CARB 2016b). FCEVs may be able to provide greater range for long-haul applications compared with battery-electric vehicles. The number of FCEV model offerings and vehicle use are growing across applications, with companies such as Toyota, General Motors, Nikola, and UPS announcing FCEV plans (O’Dell 2017a; 2017b; 2018a; 2018b; ZumMallen 2017).

We estimate the serviceable consumption potential of the MDV and HDV hydrogen market as equivalent to the hydrogen required if $35 \%$ of the fleet operated on hydrogen, based on the 2050 sales share estimate from Roadmap to a U.S. Hydrogen Economy (2020), which uses favorable assumptions for FCEVs. We apply the market penetration to the vehicle stock estimated in Elgowainy et al. (2020). Thus, we assume 4.2 million FCEVs of a 12 million MDV stock and 2.0 million FCEVs of a 5.7 million HDV stock in 2050. The resulting annual hydrogen demand is 8.2 MMT/yr (2.2 MMT/yr for MDVs and 6.0 MMT/yr for HDVs). ${ }^{22}$

The annual hydrogen demands in the demand-curve estimates for MDVs and HDVs are based on projected FCEV market shares modeled for LDVs in Elgowainy et al. (2020), as described above. We used LDV results because we did not have access to a tool to estimate MDV or HDV penetrations directly. We assume FCEV penetrations in the MDV and HDV markets will meet or exceed penetration in the LDV market because performance advantages of FCEVs over powertrains such as battery electric vehicles (e.g., range and refueling time) are more valuable for duty cycles required by MDVs and HDVs. To be conservative, we assume a mature market fleet penetration of $22 \%$ for both MDVs and HDVs, which is equal to our assumption of the total penetration of FCEV cars and light-duty trucks in a mature market. We also assume the same threshold price of $\$ 2.20 / \mathrm{kg}$ used for LDVs. The fleet penetration is applied to the 2050 stock as modeled in Elgowainy et al. (2020) and results in an FCEV stock of 4.2 MDVs and 2.0 million HDVs (out of total fleets of 12 million MDVs and 5.7 million HDVs). The FCEV stock corresponds to an annual hydrogen demand of 5.2 MMT/yr (1.4 MMT for MDVs and 3.8 MMT for HDVs). Table 13 summarizes these values.

Table 13. Hydrogen Demand and Threshold Prices for Medium- and Heavy-Duty FCEVs (Elgowainy et al. 2020)

\begin{tabular}{lcccc}
\hline & $\begin{array}{l}\text { Hydrogen Price at } \\
\text { Terminal } \mathbf{( \$ \mathbf { k g } )}\end{array}$ & $\begin{array}{l}\text { Hydrogen Price at } \\
\text { Pump } \mathbf{( \$ / \mathbf { k g } )}\end{array}$ & $\begin{array}{l}\text { Annual Hydrogen } \\
\text { Demand (MMT) }\end{array}$ & $\begin{array}{c}\text { Cumulative Hydrogen } \\
\text { Demand (MMT) }\end{array}$ \\
\hline MDVs & 2.20 & 5.03 & 1.4 & 1.4 \\
HDVs & 2.20 & 5.03 & 3.8 & 5.2 \\
\hline
\end{tabular}

We assume a threshold price equivalent to the price used for LDVs. The terminal price is used to determine the economic potential. The Reference scenario (see Section 6.1) assumes no FCEV hydrogen demand due to the current high costs of delivery and dispensing.

\footnotetext{
${ }^{22}$ Demand estimates are based on fuel economies of 32.6 mpgge for medium-duty trucks and 14.5 mpgge for heavyduty trucks (33 and $14.7 \mathrm{mi} / \mathrm{kg}$ hydrogen).
} 
Regional demand is estimated according to the same distribution used for LDVs. We scale the distribution of 2050 hydrogen demand in the H2USA National Expansion scenario (Melaina et al. 2017) to the demand quantities estimated in our scenarios for MDVs and HDVs. 


\section{Hydrogen Production}

Hydrogen can be produced from different technology pathways and diverse resources. Currently, most hydrogen in the United States is produced via natural gas SMR, totaling about $10 \mathrm{MMT} / \mathrm{yr}$. SMR is the most economic technology available in most cases, primarily owing to an abundance of low-cost natural gas. However, alternative hydrogen production technologies with differing costs and levels of maturity are available or under development. For example, interest in electrolysis - the splitting of water into hydrogen and oxygen using electricity-has grown in recent years. Electrolysis offers distinct advantages over SMR, and, although current electrolytic production costs are high, further R\&D - in addition to increased availability of low-cost renewable electricity - is expected to reduce costs. Electrolyzers vary by material and operating temperature; in addition to the electrolyte or membrane material, LTE $\left(<100^{\circ} \mathrm{C}\right)$ uses only electric power for hydrogen production, and $\operatorname{HTE}\left(>600^{\circ} \mathrm{C}\right)$ uses electricity and heat. Gasification of biomass or coal provides other hydrogen production pathways. Hydrogen can also be produced via other methods - such as photoelectrical, biochemical, and high-temperature thermochemical methods - but these technologies are at a preliminary level of development.

In this section, we detail the five hydrogen production technologies considered in this analysis: natural gas SMR, LTE using VRE, HTE using nuclear-generated heat, gasification of biomass, and gasification of coal. We do not consider hybrid methods such as HTE with other sources of heat owing to the variety of possible options. We focus on large-scale production technologies (often called central production technologies), because this analysis focuses on large markets. Delivery costs are added as discussed in Section 4.1, and distribution costs are subtracted from spatially dispersed demands (such as LDVs, discussed in Section 3.7). A discussion of emerging technologies is included in Section 4.6.

We calculate a technical potential for each technology based on total reserves for fossil and nuclear resources and annual resource availability for VRE and biomass. In addition, we calculate supply curves for SMR, biomass gasification, LTE, and HTE. We do not develop supply curves for hydrogen produced via coal gasification, because the high costs are not competitive with the other technologies included (see Section 4.5). The technology-specific supply curves are used to calculate the aggregated economic potential of hydrogen described in Section 6 .

\subsection{Steam Methane Reforming of Natural Gas}

The SMR process involves a catalytic conversion of natural gas and steam to carbon dioxide and hydrogen. Oil refining and ammonia production are the major consumers of SMR hydrogen; they currently use around 10 MMT of hydrogen produced on purpose in addition to about 4 MMT of byproduct hydrogen per year (Connelly, Elgowainy, and Ruth 2019). 
The technical potential of hydrogen produced from natural gas SMR is 17,800 MMT (Connelly et al. 2020). ${ }^{23}$ This estimate is based on 2,800 trillion cubic feet (Tcf) of technically recoverable natural gas resources, including proved and unproved reserves. The locations of natural gas reserves are included in Appendix E.

The cost to produce hydrogen via SMR is highly dependent on the price of natural gas. Using DOE's Hydrogen Analysis (H2A) model, we calculate regional hydrogen production costs based on industrial natural gas price projections in the AEO 2017 Reference and LOGR scenarios. For each census division and natural gas price projection, we calculate production costs for existing SMR facilities (assumed to have sunk capital costs) and new SMR facilities (which require new capital investment). The calculated hydrogen production costs are provided in Table 14 . We assume all default values in the $\mathrm{H} 2 \mathrm{~A}$ future central hydrogen production from natural gas case study without carbon dioxide capture and sequestration (CCS) ${ }^{24}$ (DOE 2018a), except for natural gas and electricity prices taken from AEO 2017 (EIA 2017a). That case study is for a 380 metric ton (MT) per day plant and estimates that $0.156 \mathrm{mmBtu}$ of natural gas are required to produce $1 \mathrm{~kg}$ of hydrogen (DOE 2018a). We did not use the case study with CCS because its levelized cost of hydrogen is higher than without CCS, and, because we did not include a cost of carbon in this analysis, not including CCS is more economic than including it.

We estimate the economic potential of hydrogen produced from natural gas SMR using the 2015 regional production quantities from IHS $(2015)^{25}$ and the production costs described above. For this analysis, we limit SMR future supply for non-ammonia production to three times current production levels in each region. ${ }^{26} \mathrm{We}$ also include SMR hydrogen supply for ammonia production, which is estimated to be 2.5 MMT for current facilities and 3.6 MMT for future facilities (see Section 3.3). Table 14 includes the hydrogen production costs and estimates of available hydrogen from SMR, including for ammonia production, for each region, based on AEO 2017 industrial natural gas price projections (Table 15). ${ }^{27}$ We estimate $10.3 \mathrm{MMT} / \mathrm{yr}$ of hydrogen are available from current SMR facilities, and an additional 17.3 MMT/yr are available from future SMR facilities, totaling to a potential 27.6 MMT/yr.

\footnotetext{
${ }^{23}$ The technical potentials for fossil resources are based on total reserves (compared to the VRE and biomass technical potentials, which are based on annual availability).

${ }^{24} \mathrm{H} 2 \mathrm{~A}$ models use discounted cash flow analysis based on economic assumptions to calculate the levelized cost of hydrogen production after taxes using an internal rate of return on capital investment. DOE provides a number of case studies. The "Future Central Hydrogen Production from Natural Gas without $\mathrm{CO}_{2}$ Sequestration version 3.2018" case study is used for SMR in this analysis.

25 The 2018 IHS Markit Chemical Economic Handbook reports 8.8 MMT of U.S. hydrogen capacity (Suresh et al. 2018), compared to 7.8 MMT reported in the 2015 version.

${ }^{26}$ This assumption is comparable with regional projected natural gas production growth in the AEO 2018 High Oil and Gas Resource case (EIA 2018a): production in the East is projected to increase 327\% from 2017 to 2050 , production in the Gulf Coast is projected to increase $209 \%$, and national production is projected to increase $206 \%$. We chose to limit the increase to three times the current production to roughly address the natural gas price increases that would likely occur due to the increases in demand for hydrogen production. Sensitivity scenarios with varying SMR growth limits are included in Section 6.8.2.

${ }^{27}$ Within the H2A model, prices estimates past 2050 are extrapolated based on the Global Change Assessment Model (Pacific Northwest National Laboratory n.d.).
} 
Table 14. Hydrogen Production Costs for Natural Gas SMR by Census Division

\begin{tabular}{lccc|ccc}
\hline & \multicolumn{5}{c}{ Hydrogen Production Cost $\mathbf{\$} / \mathbf{k g})$} \\
\cline { 2 - 6 } $\begin{array}{l}\text { Census } \\
\text { Division }\end{array}$ & $\begin{array}{l}\text { AEO } \\
\text { Reference }\end{array}$ & AEO LOGR & $\begin{array}{l}\text { Available } \\
\text { Hydrogen } \\
\text { (MMT/yr) }\end{array}$ & $\begin{array}{l}\text { AEO } \\
\text { Reference }\end{array}$ & AEO LOGR & $\begin{array}{c}\text { Available } \\
\text { Hydrogen } \\
\text { (MMT/yr) }\end{array}$ \\
\hline $\begin{array}{l}\text { West South } \\
\text { Central }\end{array}$ & $\$ 1.18$ & $\$ 2.05$ & 5.2 & $\$ 1.31$ & $\$ 2.19$ & 8.6 \\
$\begin{array}{l}\text { Mountain } \\
\text { East North }\end{array}$ & $\$ 1.44$ & $\$ 2.28$ & 0.3 & $\$ 1.57$ & $\$ 2.41$ & 0.4 \\
Central & $\$ 1.44$ & $\$ 2.38$ & 1.0 & $\$ 1.57$ & $\$ 2.51$ & 2.0 \\
$\begin{array}{l}\text { South Atlantic } \\
\text { West North }\end{array}$ & $\$ 1.45$ & $\$ 2.50$ & 0.3 & $\$ 1.58$ & $\$ 2.63$ & 0.3 \\
$\begin{array}{l}\text { Central } \\
\text { East South }\end{array}$ & $\$ 1.46$ & $\$ 2.33$ & 0.9 & $\$ 1.59$ & $\$ 2.46$ & 1.0 \\
Central & $\$ 1.48$ & $\$ 2.38$ & 0.5 & $\$ 1.62$ & $\$ 2.51$ & 0.7 \\
Middle Atlantic & $\$ 1.51$ & $\$ 2.31$ & 0.1 & $\$ 1.64$ & $\$ 2.44$ & 0.2 \\
$\begin{array}{l}\text { Pacific } \\
\text { New England }\end{array}$ & $\$ 1.59$ & $\$ 2.45$ & 2.1 & $\$ 1.73$ & $\$ 2.59$ & 4.1 \\
\hline Total & $\$ 1.63$ & $\$ 2.56$ & - & $\$ 1.76$ & $\$ 2.69$ & - \\
\hline
\end{tabular}

Census divisions are sorted by existing facility production costs for the AEO Reference scenario.

Hydrogen quantities may not sum to total due to rounding.

Table 15. Industrial Natural Gas Prices in 2050 from AEO 2017 (EIA 2017a)

\begin{tabular}{lcc}
\hline & \multicolumn{2}{c}{ Natural Gas Price $(\$ / m m B t u)$} \\
\cline { 2 - 3 } Census Division & AEO Reference & AEO LOGR \\
\hline West South Central & $\$ 5.51$ & $\$ 10.14$ \\
Mountain & $\$ 6.91$ & $\$ 11.34$ \\
Middle Atlantic & $\$ 7.28$ & $\$ 11.48$ \\
West North Central & $\$ 7.00$ & $\$ 11.59$ \\
East North Central & $\$ 6.90$ & $\$ 11.87$ \\
East South Central & $\$ 7.13$ & $\$ 11.88$ \\
South Atlantic & $\$ 6.94$ & $\$ 12.50$ \\
Pacific & $\$ 7.73$ & $\$ 12.26$ \\
New England & $\$ 7.92$ & $\$ 12.81$ \\
National Average & $\$ 6.55$ & $\$ 11.26$ \\
\hline
\end{tabular}


The resulting supply curves for hydrogen produced from natural gas SMR are shown in Figure 12. We develop two curves to reflect scenarios with low and high natural gas prices, which correspond to the natural gas price projections in the AEO Reference and LOGR scenarios. The 16 steps in the curves reflect the different production costs and quantities for existing and new facilities in the eight census divisions with current SMR production (New England has no current production from SMR, and we assume no future production in the region). The West South Central region, which includes Texas, has the lowest-cost natural gas and thus the lowest hydrogen production costs as well as the largest hydrogen production quantity. The natural gas price is so low in the West South Central region that hydrogen can be produced in new facilities, including the required return on capital investment, at prices lower than possible in existing facilities in some regions; thus, the two steps for the West South Central region are near the left of Figure 12. The total hydrogen supply via SMR hydrogen production is $27.6 \mathrm{MMT} / \mathrm{yr}$ at a cost of $\$ 1.73 / \mathrm{kg}$ assuming AEO Reference natural gas prices, and $\$ 2.59 / \mathrm{kg}$ assuming AEO LOGR natural gas prices.

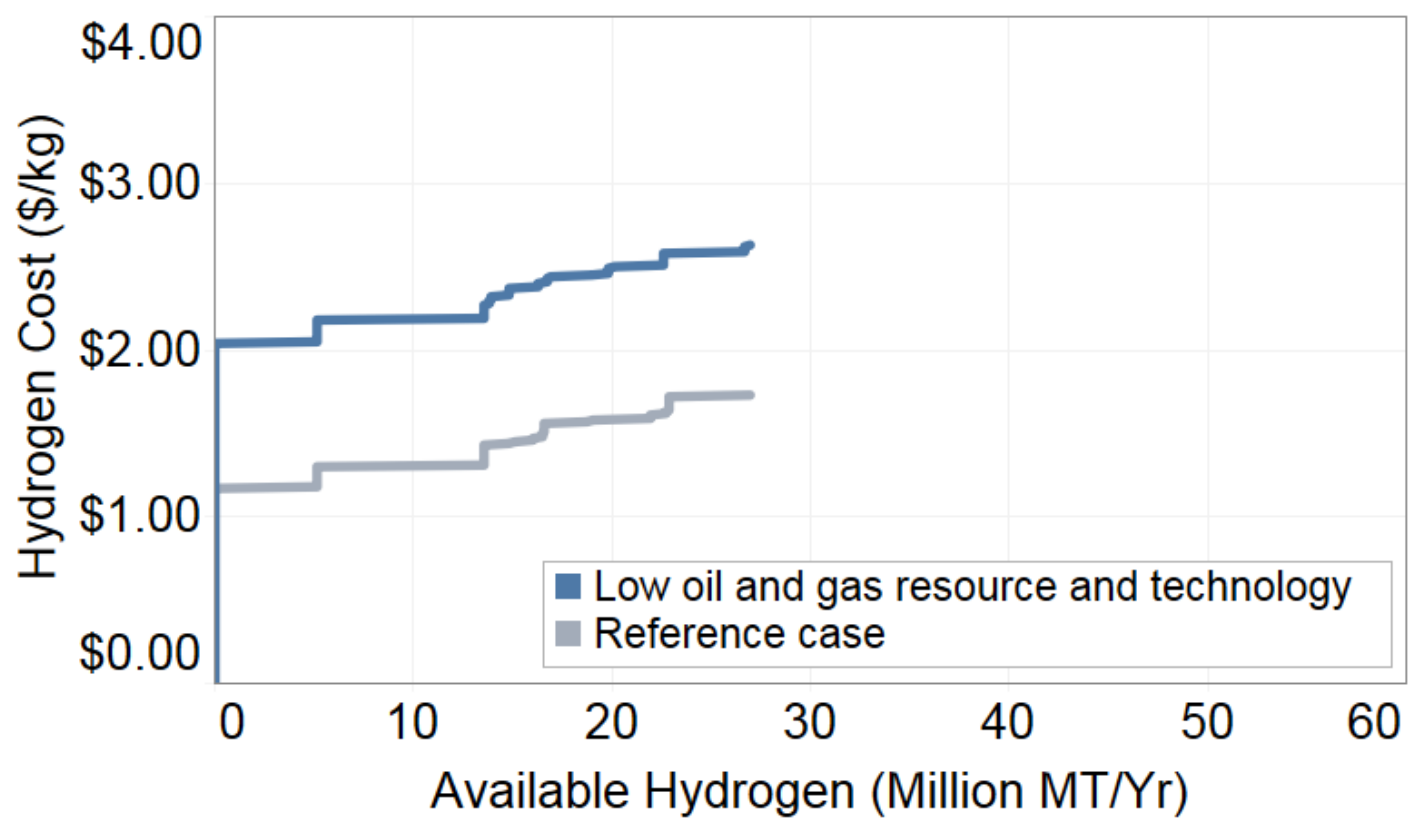

Figure 12. Hydrogen supply curve from natural gas SMR

In addition to the hydrogen production costs, we calculate a delivery adder to account for the costs associated with transmitting hydrogen from a central production facility to consumption areas. Delivery costs vary with location, quantity delivered, and delivery method (e.g., pipeline, gaseous truck, liquid truck), but estimating all potential delivery pathways and costs is outside the scope of this analysis. Instead, we use the Hydrogen Delivery Scenario Analysis Model (HDSAM) (ANL 2018) to calculate pipeline delivery costs for two scenarios: short-distance transmission and long-distance transmission, shown in Table 16 (see "Adder Total"). HDSAM simulates a hydrogen delivery system and estimates the associated costs using engineering principles and discounted cash flow analysis. The costs calculated for this analysis reflect a highvolume hydrogen scenario: we assume a delivery volume of 200,000 MT/yr in HDSAM. The delivery adder costs are added to the supply curves for each production technology. We assume most SMR plants are near demand sources. Therefore, we use the short-distance transmission 
cost of $\$ 0.12 / \mathrm{kg}$ in Table 16 for SMR production. Conversely, we use the long-distance transmission cost of $\$ 0.39 / \mathrm{kg}$ for production from LTE (Section 4.2), HTE (Section 4.3), and biomass (Section 4.4). The aggregated supply curves presented in Section 6.3 include the delivery adder costs.

Table 16. Delivery Adders for Hydrogen Supply Curves

\begin{tabular}{|c|c|c|c|c|c|c|c|c|}
\hline $\begin{array}{l}\text { Adder } \\
\text { Type }\end{array}$ & $\begin{array}{l}\text { Distance } \\
\text { (km) }\end{array}$ & $\begin{array}{l}\text { Transmission } \\
(\$ / \mathbf{k g})\end{array}$ & $\begin{array}{l}\text { Compression } \\
(\$ / \mathrm{kg})\end{array}$ & $\begin{array}{l}\text { Geologic } \\
\text { Storage } \\
(\$ / k g)\end{array}$ & $\begin{array}{l}\text { Adder } \\
\text { Total } \\
\text { (\$/kg) }\end{array}$ & $\begin{array}{l}\text { Inlet } \\
\text { Pressure } \\
\text { (atm) }\end{array}$ & $\begin{array}{l}\text { Outlet } \\
\text { Pressure } \\
\text { (atm) }\end{array}$ & $\begin{array}{l}\text { Pipeline } \\
\text { Diameter } \\
\text { (in) }\end{array}$ \\
\hline $\begin{array}{l}\text { Short } \\
\text { distance }\end{array}$ & 16 & $\$ 0.01$ & $\$ 0.06$ & $\$ 0.05$ & $\$ 0.12$ & 68 & 48 & 9.25 \\
\hline $\begin{array}{l}\text { Long } \\
\text { distance }\end{array}$ & 250 & $\$ 0.28$ & $\$ 0.06$ & $\$ 0.05$ & $\$ 0.39$ & 68 & 48 & 15.75 \\
\hline
\end{tabular}

Locations for existing SMR production are determined from the IHS Chemical Economics Handbook (IHS Markit 2015). We assume the same locations for future SMR supply. Locations for current and future SMR for ammonia production are assumed to be the same as those described in Section 3.3.

\subsection{Low-Temperature Electrolysis}

Low-temperature electrolysis is the splitting of water into hydrogen and oxygen using just electricity as a feedstock. This technology accounts for a small amount of current hydrogen production but has inherent advantages over SMR. For example, if the electrical energy used for electrolysis is sourced from renewable resources, such as PV or wind, hydrogen can be produced without fossil fuels. Furthermore, electrolyzers can act as a responsive load on power grids, owing to their ability to turn on and off within minutes and cycle output within sub-seconds (Eichman, Harrison, and Peters 2014). This capability will become increasingly valuable as the grid incorporates higher levels of VRE.

Although electrolysis has advantages, at current technology and electricity costs, the production cost of electrolytic hydrogen is significantly higher than the cost of hydrogen from SMR. This cost disadvantage limits the current use of electrolysis to select industries that require high-purity hydrogen. However, electrolysis production costs are expected to decrease. Current electrolyzer costs are around $\$ 900 / \mathrm{kW}$, with estimates of costs at full manufacturing economies of scale of $\$ 400 / \mathrm{kW} .{ }^{28} \mathrm{R} \& \mathrm{D}$ efforts supported by DOE aim to reduce electrolyzer equipment costs from $\$ 400 / \mathrm{kW}$ to $\$ 100 / \mathrm{kW}$ (at full manufacturing economies of scale) (Pivovar, Rustagi, and Satyapal 2018) providing industry can achieve that scale. In this analysis, we assume R\&D enables future reductions in electrolyzer capital cost and improvements in efficiencies from current technology. Opportunities for access to low-cost electricity from VRE resources may further reduce the cost of hydrogen from LTE.

\footnotetext{
28 These estimates are taken from H2A current and future case study inputs, which are based on manufacturer feedback (B. James et al. 2013).
} 
The technical potential for hydrogen produced from LTE based on wind, solar, hydropower, and geothermal resources is estimated in Connelly et al. (2020). To calculate the technical potential of these resources, we use a rate of $50.2 \mathrm{kWh}$ of electricity per $1 \mathrm{~kg}$ of hydrogen. This estimate is consistent with the H2A case study "Future Central Hydrogen Production from PEM Electrolysis version 3.2018" (DOE 2018a). ${ }^{29}$ The technical potential for electricity is 38,000 TWh/yr from total onshore and offshore wind resources, ${ }^{30} 260,000 \mathrm{TWh} / \mathrm{yr}$ from total solar resources (including PV and CSP), ${ }^{31} 2,500 \mathrm{TWh} / \mathrm{yr}$ from hydropower (including conventional hydropower and marine and hydrokinetic $[\mathrm{MHK}]),{ }^{32}$ and 25,000 TWh/yr from geothermal resources, corresponding to hydrogen potentials of $800 \mathrm{MMT} / \mathrm{yr}, 5,200 \mathrm{MMT} / \mathrm{yr}, 50 \mathrm{MMT} / \mathrm{yr}$, and 490 $\mathrm{MMT} / \mathrm{yr}$, respectively. Maps showing the geographic distribution of wind and solar resources are included in Appendix E.

For the economic potential, we use two estimates of electricity use: for current technology status, we assume $54.3 \mathrm{kWh}$ of electricity are required to produce $1 \mathrm{~kg}$ of hydrogen, ${ }^{33}$ based on the $\mathrm{H} 2 \mathrm{~A}$ case study "Current Central Hydrogen Production from PEM Electrolysis version 3.2018." For future technologies, we assume $50.2 \mathrm{kWh}$ of electricity are required, ${ }^{34}$ based on the H2A case study "Future Central Hydrogen Production from PEM Electrolysis version 3.2018" (DOE 2018a).

Electricity cost and availability are the major cost drivers for LTE, with availability impacting the LTE capacity factor. In the future central H2A case study, electricity cost accounts for $89 \%$ of the hydrogen production cost at a capacity factor of 97\% (DOE 2018a). Figure 13 shows the relationship between electricity price, capacity factor, and resulting levelized hydrogen cost (calculated from H2A) for several LTE capital costs. The figure shows that electricity price variations have a greater impact on levelized hydrogen costs than capacity factors do. Access to low-cost electricity would significantly reduce production costs for electrolytic hydrogen.

A potential source of low-cost electric energy is from dispatch-constrained generators, particularly VRE (wind and PV), but potentially nuclear power plants as well. As VRE penetration increases past an initial threshold, its value decreases because its inherent concurrent generation reduces the time-specific, marginal prices on the grid (Wiser et al. 2017). Even at lower penetrations, energy may be generated that would be curtailed without another demand for that electricity, such as hydrogen production, because there is no fuel or variable operating costs for VRE technologies. In addition to VRE, nuclear plants - which typically operate under limited ramping in the United States - could also provide low-cost electricity during periods of oversupply on the grid. We refer to the energy generated from these sources as LDE. In some situations, it may not make economic sense to build generation to provide electricity to the grid alone due to the price suppression, but because the LDE threshold price sets a price floor,

\footnotetext{
${ }^{29}$ Connelly et al. (2020) assume use of $51.3 \mathrm{kWh} / \mathrm{kg}$ hydrogen, reflecting updates to the H2A case study. The update has minimal effect $(2 \%)$ on hydrogen yield and levelized cost of hydrogen results.

30 7,000 TWh/yr are from offshore wind, and 31,000 TWh/yr are from land-based wind.

${ }^{31}$ 1,000 TWh/yr are from rooftop PV, 184,000 TWh/yr are from utility-scale PV, and 76,000 TWh/yr are from CSP.

$32300 \mathrm{TWh} / \mathrm{yr}$ are from conventional hydropower, $50 \mathrm{TWh} / \mathrm{yr}$ are from non-powered dams, $350 \mathrm{TWh} / \mathrm{yr}$ are from new stream-reach development, and 1,800 TWh/yr are from MHK.

33 The total use corresponds to $49.2 \mathrm{kWh}$ from electrolyzer stack use and $5.0 \mathrm{kWh}$ from balance of plant use.

34 The total use corresponds to $46.7 \mathrm{kWh}$ from electrolyzer stack use and $3.5 \mathrm{kWh}$ from balance of plant use.
} 
economics may become viable. In other cases, new generation just to produce LDE may make economic sense; however, depending on the electricity threshold price required for the supplemental demand and the levelized cost of energy production, it could make more sense to build new plants primarily to provide LDE, but with the ability to sell electricity to the grid when prices are high. For the purposes of environmental impact assessment, we assume all the LDE is from wind and PV generation. We assume almost all LDE will have a cost (i.e., not be $\$ 0 / \mathrm{MWh}$ ) but be available at prices lower than current wholesale electricity prices, which can improve the production costs for LTE.

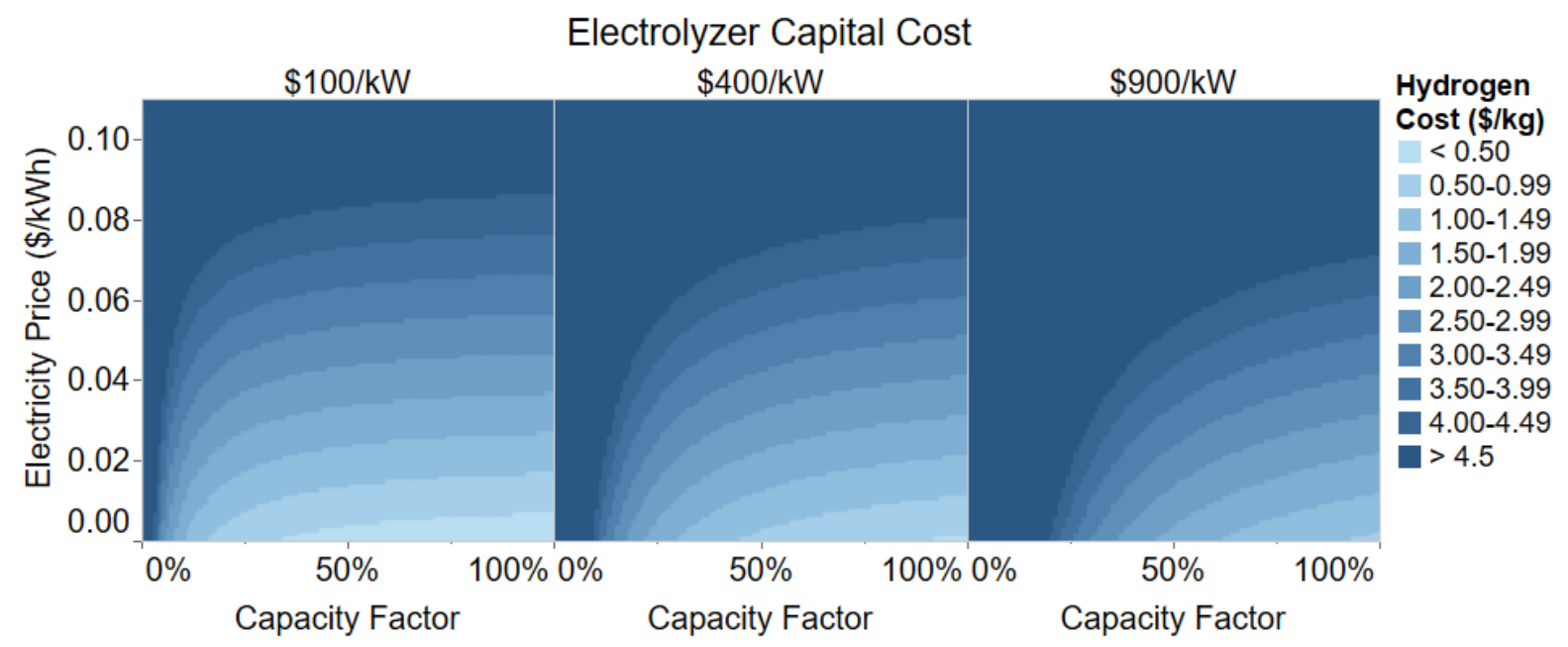

Figure 13. LTE hydrogen production cost for varying electricity price, capacity factor, and installed capital cost

Our estimate of the economic potential of LTE assumes only use of LDE as a feedstock, even though LTE can also use grid electricity or dedicated VRE generators to produce on-purpose hydrogen. Grid electricity can allow an LTE system to run at higher capacity factors, but the electricity price will be higher. Industrial electricity prices in 2050 from AEO 2018 (EIA 2018a) range from $\$ 0.070$ to $\$ 0.092 / \mathrm{kWh}$ across scenarios. ${ }^{35}$ Assuming a $97 \%$ capacity factor and a $\$ 200 / \mathrm{kW}$ capital cost, the resulting levelized cost of hydrogen for these electricity prices is $\$ 3.83-\$ 4.92 / \mathrm{kg}(\$ 4.02-\$ 5.12 / \mathrm{kg}$ with a capital cost of $\$ 400 / \mathrm{kW}$, and $\$ 3.73-\$ 4.83 / \mathrm{kg}$ with a capital cost of $\$ 100 / \mathrm{kW})$. Even with the increased capacity factors, the higher cost of grid electricity prohibits LTE hydrogen from being cost-competitive, so it is not considered here.

LTE can also be paired with dedicated wind and PV generators, which may provide electricity at a lower cost than grid electricity, but at lower capacity factors owing to the variable nature of the resource. Using the $2050 \mathrm{LCOE}$ and capacity factor estimates from the 2018 Annual Technology Baseline (NREL 2018a), the levelized cost of hydrogen ranges from $\$ 1.41-\$ 2.46 / \mathrm{kg}$ in the Low cost case and $\$ 1.79-\$ 3.17 / \mathrm{kg}$ in the Mid cost case for utility-scale PV, and from $\$ 1.16-\$ 3.95 / \mathrm{kg}$ in the Low cost case and $\$ 1.74-\$ 6.93 / \mathrm{kg}$ in the Mid cost case for onshore wind, assuming a

\footnotetext{
35 The range of prices corresponds to the High Oil and Gas Resource and Technology scenario $(\$ 0.070 / \mathrm{kWh})$ and the Low Oil and Gas Resource and Technology scenario $(\$ 0.092 / \mathrm{kWh})$.
} 
\$200/kW capital cost. ${ }^{36}$ Although dedicated VRE generators can potentially produce low-cost hydrogen, we assume that operators would benefit more financially from selling electricity to the grid when the income from that source would be higher instead of solely generating to produce hydrogen. Therefore, we do not consider dedicated systems in our economic potential analysis.

We estimate the potential LDE resource at high VRE penetrations using the ReEDS capacityexpansion model (Eurek et al. 2016) and the PLEXOS model (Energy Exemplar 2019). PLEXOS is a unit-commitment model, which makes commitment and dispatch decisions at an hourly resolution. ${ }^{37}$ The available resource - which depends on the willingness of markets to pay - is estimated at varying LDE prices $(\$ 0-\$ 30 / \mathrm{MWh}$, although very little is available at $\$ 0 / \mathrm{MWh})$. We base our estimates on the analysis by Ruth et al. (forthcoming), which details the modeling methods and the estimated impacts of LDE prices on the evolution of the power sector. The process used for that paper involves setting a price for LDE, using the ReEDS model to determine the capacity and generation mix that results in the minimum cost to meet load including a value for the LDE. The resulting capacity in 2050 is then modeled in PLEXOS to estimate the hourly dispatch decisions and resulting quantity of LDE available and its availability factor for each region. ${ }^{38}$ That process is repeated for multiple LDE prices to develop an LDE supply curve.

We develop two ReEDS grid scenarios and use them to estimate the LDE resource and create supply curves: Low RE $\operatorname{Cost}^{39}$ and High Curtailment, meant to reflect different conditions for VRE penetration (Ruth, Jadun, and Cole forthcoming). The scenarios are intended to capture a range, from moderate LDE availability in the ReEDS Low RE Cost grid scenario, to high LDE availability in the ReEDS High Curtailment grid scenario. Both scenarios assume the same optimistic technology costs for renewable energy, based on the 2017 Annual Technology Baseline Low cost case (NREL 2017a). ${ }^{40}$ However, the scenarios differ in natural gas price assumptions: the ReEDS Low RE Cost grid scenario assumes natural gas prices from the 2017 AEO Reference scenario, and the ReEDS High Curtailment grid scenario assumes prices from the 2017 AEO LOGR scenario, which projects higher prices than the Reference case (EIA 2017a). The ReEDS High Curtailment grid scenario also considers additional conditions that could lead to increased levels of curtailment, namely accelerated retirements of coal plants and extended nuclear lifetimes. Around $50 \mathrm{GW}$ of nuclear capacity are retired in the ReEDS Low RE Cost scenario, compared to less than $10 \mathrm{GW}$ in the ReEDS High Curtailment scenario. The assumed higher natural gas prices and extended baseload generator lifetimes lead to higher LDE

\footnotetext{
${ }^{36}$ In the 2018 Annual Technology Baseline, the LCOE for utility-scale PV systems ranges from $\$ 0.009$ $\$ 0.015 / \mathrm{kWh}(28 \%-16 \%$ capacity factor) in the Low case and $\$ 0.016-\$ 0.029 / \mathrm{kWh}(27 \%-15 \%$ capacity factor $)$ in the Mid case. For onshore wind, LCOE ranges from $\$ 0.014-\$ 0.056 / \mathrm{kWh}(58 \%-23 \%$ capacity factor) in the Low case and $\$ 0.025-\$ 0.111 / \mathrm{kWh}(55 \%-20 \%$ capacity factor) in the Mid case. The ranges in cost and performance estimates are due to technical and regional variability of the wind and solar resource.

${ }^{37}$ PLEXOS can model at the sub-hourly level, but hourly resolution is used for this analysis.

${ }^{38}$ In this analysis, we model LDE availability at the regional transmission organization level.

${ }^{39}$ This scenario corresponds to the Low RE Cost scenario in the NREL standard scenarios report (W. Cole et al. 2017).

40 The 2017 Annual Technology Baseline assumes the following capital costs in the Low cost case (in 2015 dollars): $\$ 962-\$ 1,051 / \mathrm{kW}$ for class $4-5$ onshore wind, $\$ 398 / \mathrm{kW}$ for utility PV, and $\$ 776 / \mathrm{kW}$ for 8-hour lithium-ion battery storage.
} 
in the ReEDS High Curtailment scenario at each price point compared to the ReEDS Low RE Cost scenario.

Electricity wholesale markets differ across the country (Federal Energy Regulatory Commission 2017). Access to LDE on the wholesale market would require significant changes to the current market structure in most cases. Without access to wholesale markets, LDE purchasers will need to pay higher retail prices. In structured markets, retail electricity prices are about \$20/MWh higher than the electricity selling price to account for non-energy services (e.g., capacity, ancillary services, market operation costs), based on data from PJM (Monitoring Analytics, LLC 2017). However, electrolyzers can also provide ancillary services to the grid (e.g., regulation or demand response) (Eichman, Harrison, and Peters 2014), thus providing value. For the analysis reported here, we roughly estimate that electrolyzers that provide ancillary services could be compensated such that the adder for non-energy services is reduced by $50 \%$, from $\$ 20 / \mathrm{MWh}$ to $\$ 10 / \mathrm{MWh}$, although the potential impact on prices depends on market prices for ancillary services and the size of those markets. Thus, we have three electricity price cases associated with purchasing LDE: 1) wholesale electricity selling prices ranging from $\$ 0-\$ 30 / \mathrm{MWh}, 2$ ) retail electricity prices at $\$ 20 / \mathrm{MWh}$ above wholesale, and 3) retail prices with a discount associated with the provision of ancillary services (i.e., compensation for the value electrolyzers can provide as dynamic grid resources), netting to $\$ 10 / \mathrm{MWh}$ above wholesale.

Figure 14 shows the national LDE supply curves, estimated for the year 2050 in the PLEXOS model. ${ }^{41}$ The results show that the amount of available LDE increases with threshold price. In the ReEDS Low RE Cost scenario (reference natural gas prices), we estimate that $110 \mathrm{TWh}$ of LDE are available with no threshold price $(\$ 0 / \mathrm{MWh}$ price), but that value increases to $430 \mathrm{TWh}$ at a wholesale price of $\$ 20 / \mathrm{MWh}$, and 3,500 TWh at a wholesale price of $\$ 30 / \mathrm{MWh}$. In the ReEDS High Curtailment grid scenario, we estimate even higher levels of available LDE, totaling $930 \mathrm{TWh}$ and 4,200 TWh at \$20/MWh and \$30/MWh wholesale prices, respectively. At a threshold price of $\$ 0 / \mathrm{MWh}$, the amount of LDE available represents only the electricity that would be curtailed under the ReEDS scenario assumptions, but as the threshold price increases, LDE includes both curtailed electricity and additional electricity that would not have been generated without the supplemental demand for hydrogen production.

${ }^{41}$ LDE is estimated in the ReEDS and PLEXOS models by region (based on 134 ReEDS regions in the United States), but here we present the national total. 


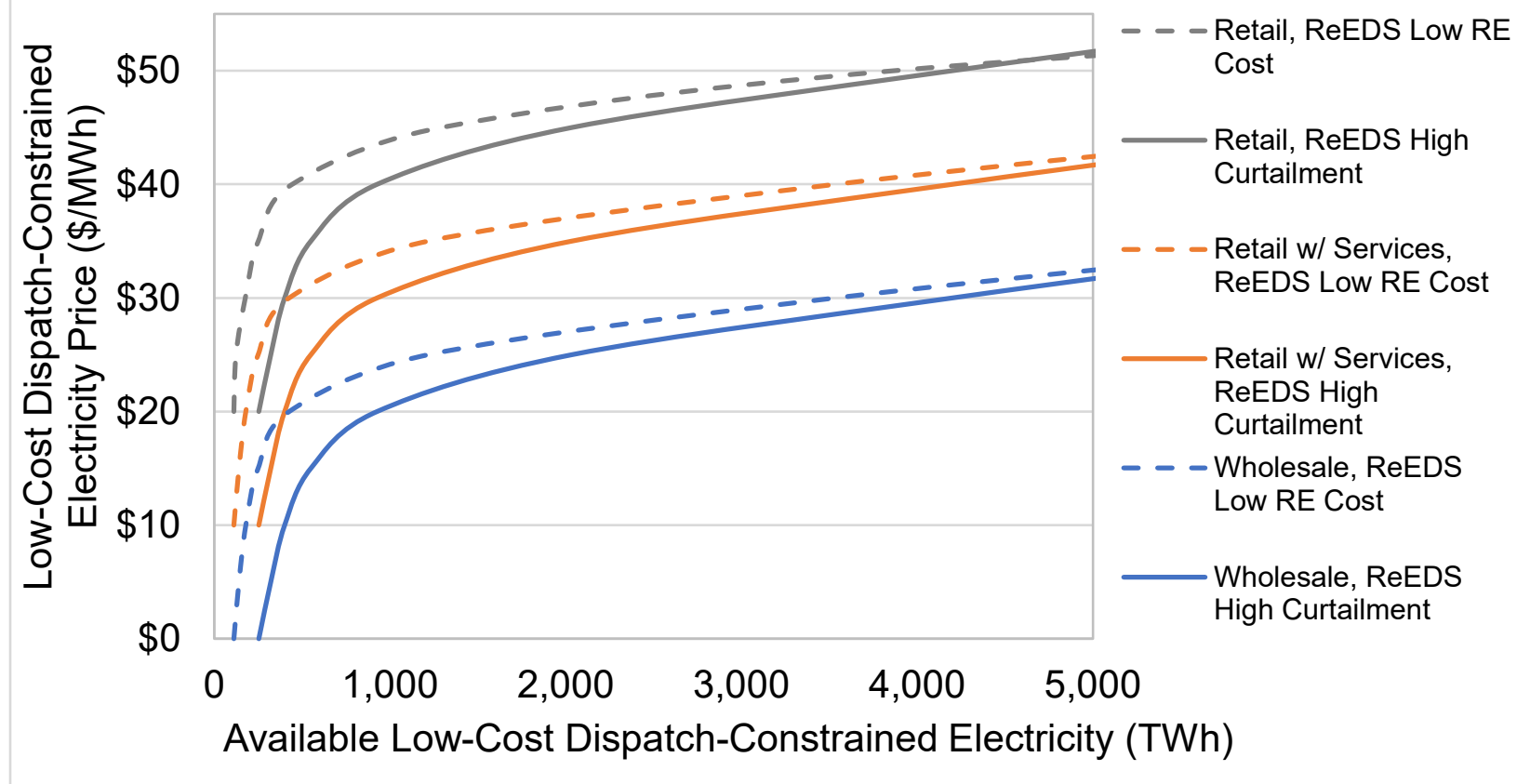

Figure 14. LDE supply curves

Regional and temporal variations in VRE affect where and when the LDE is available. The central and southwestern United States have the highest availability of LDE owing to the higher concentration of wind and solar resources in those regions (see Appendix E). Availability of LDE also varies by hour and by season, depending on wind and solar resources and electricity demand. This temporal variation will affect the utilization - and thus the economics - of an electrolyzer system designed to use LDE. For example, a system designed to capture all 930 TWh in the \$20/MWh ReEDS High Curtailment grid scenario would have a capacity factor of $22 \%$ based on PLEXOS results, which is much lower than the capacity factor for a system using grid electricity. ${ }^{42}$ Ruth et al. (forthcoming) provides additional detail and analysis on these temporal variations.

We calculate LTE hydrogen production costs using the current and future central PEM H2A case studies and the regional availability of LDE estimated from ReEDS. Default H2A values are assumed, except for electricity price, capital cost, and capacity factor. The H2A case study does not include a value for coproduct oxygen, so we do not. The inputs used for electricity price are the wholesale, retail, and retail with services LDE prices described above (ranging from $\$ 0$ to $\$ 50 / \mathrm{MWh})$. We assume electrolyzer capital costs ranging from $\$ 900 / \mathrm{kW}$, representing current costs, to $\$ 400 / \mathrm{kW}$, representing current technology costs at full economies of scale (B. James et al. 2013), and to $\$ 200 / \mathrm{kW}$, corresponding to additional R\&D improvements surpassing current technology (Pivovar, Rustagi, and Satyapal 2018). We also include estimates at $\$ 100 / \mathrm{kW}$, which we consider to be an optimistic, but achievable, cost. In this analysis, we assume improvements in cost and efficiency from the current technology in most scenarios.

\footnotetext{
${ }^{42}$ For example, the future PEM H2A case study assumes a capacity factor of $97 \%$.
} 
For each modeled region, we calculate production costs across a range of capacity factors representing the different system sizes required to capture either all available LDE (low capacity factor) or a limited amount of LDE (higher capacity factor). The quantity and capacity factor of available LDE are calculated from the hourly PLEXOS results. The variation in regional capacity factors results in different hydrogen production costs for the same LDE price. We assess the tradeoff between system size and capacity factor to select the appropriate size for each region. The optimal size is the one that results in the highest amount of available hydrogen for each hydrogen price. We assume that all LDE is available for LTE. Other controllable loads may compete for this resource, but analysis of their potential and economics is beyond the scope of this analysis.

Figure 15 shows the estimated national hydrogen supply curves by electrolyzer capital cost for a select set of scenarios and LDE price cases. The $\$ 900 / \mathrm{kW}$ scenario assumes current technology assumptions from $\mathrm{H} 2 \mathrm{~A}$, while the other scenarios assume future technology assumptions (namely, a lower electricity use as described above). We estimate that — with access to wholesale electricity market prices, $\$ 100 / \mathrm{kW}$ LTE capital cost, and the conditions assumed in the ReEDS High Curtailment grid scenario-20 MMT/yr of hydrogen can be economically produced at a cost of $\$ 1.40 / \mathrm{kg}$. In the ReEDS Low RE Cost grid scenario, which assumes reference natural gas prices, production costs of $\$ 1.50 / \mathrm{kg}$ are required to produce $20 \mathrm{MMT} / \mathrm{yr}$ of hydrogen with access to wholesale electricity prices. Production costs increase by around $\$ 1.00 / \mathrm{kg}$ with retail electricity prices, and they increase by around $\$ 0.50 / \mathrm{kg}$ assuming reduced retail prices from services to the grid (i.e., the net impact on expenses for electricity due to compensation for the value electrolyzers can provide as dynamic grid resources). In addition to LDE prices, LTE capital costs impact the resulting hydrogen production cost. In the ReEDS High Curtailment grid scenario with wholesale prices, the production cost for $20 \mathrm{MMT} / \mathrm{yr}$ of hydrogen increases from $\$ 1.40 / \mathrm{kg}$ at $\$ 100 / \mathrm{kW}$ to $\$ 1.80 / \mathrm{kg}$ at $\$ 400 / \mathrm{kW}$, and to $\$ 2.40 / \mathrm{kg}$ at $\$ 900 / \mathrm{kW}$ (which also assumes a higher electricity use). 


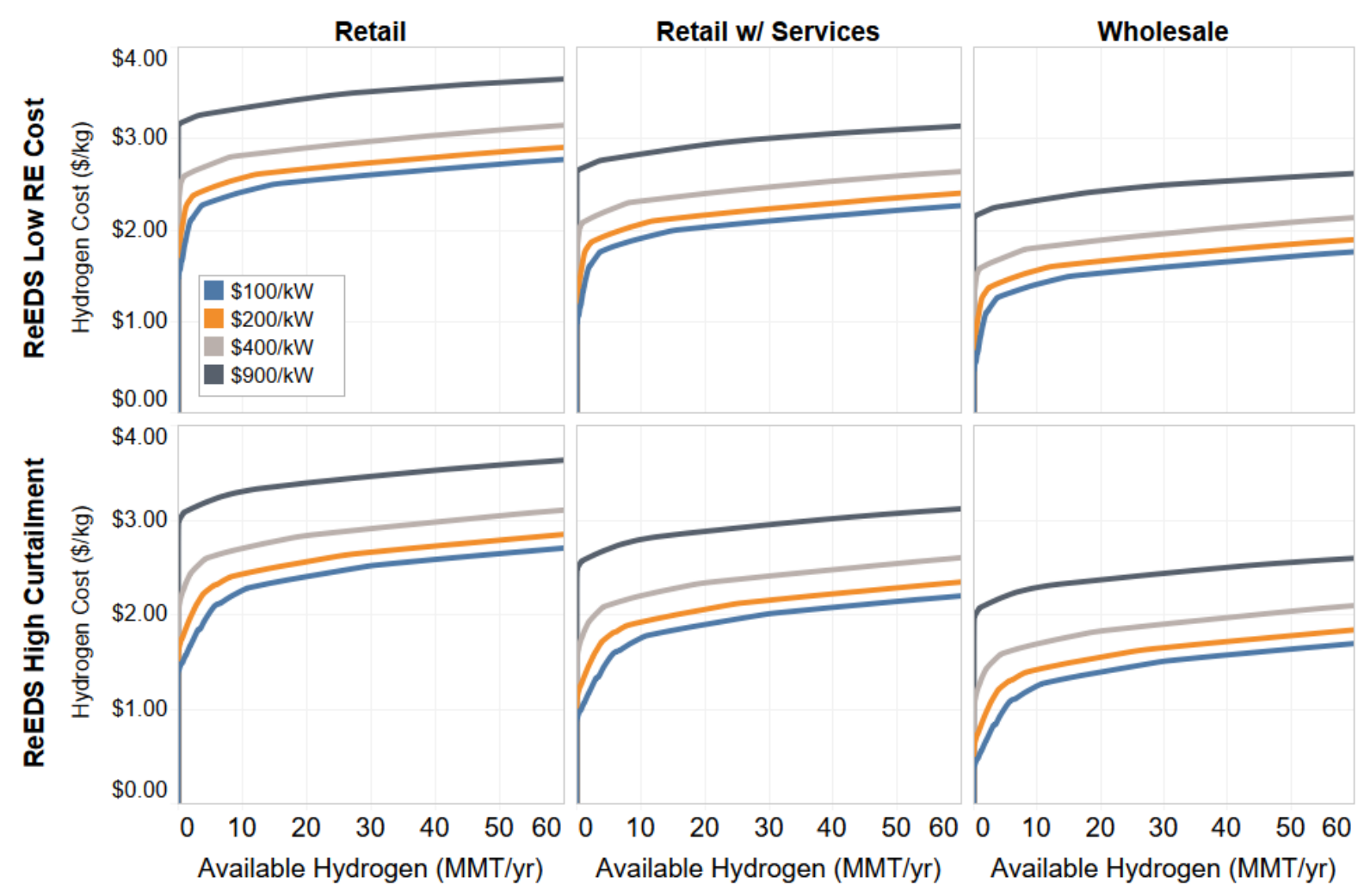

Figure 15. Hydrogen supply curve from LTE for the ReEDS Low RE Cost (top) and High Curtailment (bottom) grid scenarios

The $\$ 900 / \mathrm{kW}$ scenario assumes technology assumptions from the current H2A case study (DOE 2018a), while the other capital cost scenarios assume the future case study technology assumptions.

We add a delivery cost to the production costs shown in Figure 15 to account for the transmission of hydrogen to demand locations. The production from LTE is concentrated in the central and southwestern United States, while the demand centers for hydrogen tend to be more distributed along the coasts. Therefore, we assume transmission of hydrogen from LTE will be across greater distances compared with the transmission of hydrogen from SMR. We apply a long-distance delivery adder of $\$ 0.39 / \mathrm{kg}$ (Table 16) to the LTE production costs when developing the aggregated supply curves in Section 6.3.

The supply curves in Figure 15 aggregate each regional supply curve, but supply varies by region. We allocate hydrogen production from LTE using LDE based on the 134 regions in the ReEDS model. Production is primarily concentrated in the central United States, owing to the abundance of wind resource, and a smaller portion of production occurs in areas with quality solar resources, such as the Southwest. 


\subsection{High-Temperature Electrolysis Using Nuclear-Generated Heat}

High-temperature electrolysis has an operating range of over $600^{\circ} \mathrm{C}$ and uses electricity and heat to produce hydrogen. The electrical efficiency of electrolysis increases by up to $25 \%$ at higher operating temperatures. ${ }^{43}$ This increased efficiency can lower production costs compared with LTE, because the thermal energy required is generally less expensive than electrical energy. In this analysis, we consider HTE integrated with nuclear power plants as the source of heat and electricity. Specifically, we focus on solid oxide electrolysis (SOEC) technologies. SOEC technologies are not as mature as LTE PEM, but further SOEC R\&D could potentially lead to more cost-effective hydrogen production through HTE.

We do not estimate a technical potential for nuclear HTE because, to be consistent with other resources, we would need to use only the U.S. uranium resource, and the U.S. resource represents only a small fraction of the global resource. The Organisation for Economic Cooperation and Development's Nuclear Energy Agency and the International Atomic Energy Agency jointly estimate that the U.S. reasonably assured uranium resource at a forward-cost of production less than or equal to $\$ 260 / \mathrm{kg}$ is 470,000 metric tons (IAEA \& NEA 2014). ${ }^{44}$ However, there is a high level of uncertainty in that estimate and other reported data due to assumptions regarding ability to mine uranium on sensitive lands and allowances to extract uranium from seawater. Because we do not anticipate uranium resources will limit the nuclear HTE potential, we do not report them.

We estimate the impact on nuclear generation requirements and the levelized cost of nuclear HTE-generated hydrogen from nuclear using the H2A SOEC future case study's (DOE 2018a) HTE efficiency and a $45 \%$-efficient thermal power cycle (as could be achieved using high temperatures); the yield is $270,000 \mathrm{Btu}$ heat per $1 \mathrm{~kg}$ of hydrogen.

Integration of HTE with nuclear power plants can increase the economic competitiveness of existing plants. Since 2008, increased natural gas generation efficiency, falling natural gas prices, and increased penetration of renewable energy resources have resulted in decreasing wholesale electricity prices in competitive power markets, leading to reduced economic viability of nuclear power plants. Davis and Hausman (2016) show the recent trends in decreasing wholesale electricity prices compared with increasing nuclear operating costs. Nuclear operating costs have increased in part owing to rising labor costs and because of safety upgrades required after Japan's Fukushima Daiichi nuclear accident in 2011. These trends have put some nuclear plants in financial peril and have contributed to recent closures and announcements of near-term closures of U.S. nuclear power plants. HTE for hydrogen production can improve the economics of nuclear plants by allowing the plants to sell additional products produced from nuclear energy. In this analysis, we consider only dedicated hydrogen production plants, but hybrid systems

\footnotetext{
${ }^{43}$ In this analysis, we assume an HTE electricity use for future technologies of $35.3 \mathrm{kWh} / \mathrm{kg}$, and $38.3 \mathrm{kWh} / \mathrm{kg}$ when including thermal energy (Epiney et al. 2017; Rabiti et al. 2017). The total energy use for HTE is 24\% lower than our assumption for future LTE of $50.2 \mathrm{kWh} / \mathrm{kg}$, based on the H2A "Future Central Hydrogen Production from Polymer Electrolyte Membrane (PEM) Electrolysis version 3.2018" case study (DOE 2018a).

${ }^{44}$ We estimate a hydrogen production potential of 23,000 MMT from this resource based on a nuclear reactor mix for first-pass use of uranium of 50\% light-water reactors, $25 \%$ high-temperature gas reactors, and $25 \%$ molten-salt reactors, and using liquid-metal fast-breeder reactors to use the depleted uranium from the first-pass reactors, 470,000 metric tons of uranium can produce 7,200 quads of heat.
} 
could receive additional value for providing capacity and flexibility to the grid when not producing hydrogen.

We consider three categories of nuclear plants to develop supply curves for HTE: low-extensioncost plants, high-extension-cost plants, and new builds. The extension cost refers to the operating and maintenance costs of these plants. Nuclear power plants that are struggling financially in competitive power markets might be willing to explore hydrogen production. This contract rate would depend on local markets but would need to be at least the cost of power production at the plants, including operating and maintenance costs as well as costs associated with license extension. Low-extension-cost plants are primarily in markets with low average wholesale electricity prices. High-extension-cost plants operate in regulated and non-regulated markets with higher average prices in the wholesale power market; thus, they would require a higher price in a power-purchase agreement for hydrogen production. All other existing nuclear plants either reside in regulated markets and can only sell power owing to their market structure, or they reside in markets where they are more profitable selling electricity to the grid than they would be selling electricity at a contract rate. ${ }^{45} \mathrm{We}$ also consider new builds in this analysis, which would be constructed specifically to provide power and heat for hydrogen production. The costs of electricity from these three categories of plants are described below.

We classify existing nuclear plants as low extension cost, high extension cost, or not available for hydrogen production to develop the nuclear HTE supply curve. Plant operating statuses used for classification are based on EIA and recent media reports (Scott 2018; EIA 2019; Conca 2016; Entergy Newsroom 2019; Sholtis 2019). For the low-extension-cost category, we include plants that have announced future closures or have received recent state support, and plants located in deregulated states - according to the Nuclear Energy Institute (NEI 2015) - that do not already have a plant with an announced closure, as well as the Palo Verde Nuclear Power Plant in Arizona and the nuclear power plants in Minnesota (corresponding to $20 \mathrm{GW}$, about $20 \%$ of the current nuclear generation capacity). ${ }^{46}$ Those locations were chosen because they have both declining average electricity prices and potential hydrogen markets near them. For the highextension-cost category, we consider all other plants in deregulated states or in the Midcontinent Independent System Operator (MISO), New York Independent System Operator (NYISO), Electric Reliability Council of Texas (ERCOT), or PJM Interconnection territories (40 GW, about $40 \%$ of the current fleet). ${ }^{47} \mathrm{We}$ assume all remaining plants are not available for hydrogen production.

Different electricity prices are assumed to be available for HTE depending on the extension costs to convert existing nuclear plants or build new facilities. For plants with low extension costs (20

\footnotetext{
45 These plants are often part of vertically integrated utilities and are operated as baseload plants that produce electricity for approximately $\$ 25-\$ 35 / \mathrm{MWh}$. Thus, they are competitive in the power market.

46 The actual plant capacity of the selected plants totals $18.5 \mathrm{GW}$; for this analysis, the capacities of all lowextension-cost plants are scaled evenly to total $20 \mathrm{GW}$.

47 The actual plant capacity of the selected plants totals $36.0 \mathrm{GW}$; for this analysis, the capacities of all high extension cost plants are scaled evenly to total $40 \mathrm{GW}$.
} 
GW), we assume a contract with an electricity equivalent rate of $\$ 25 / \mathrm{MWh},{ }^{48}$ based on estimates of current nuclear operating expenses. The $75^{\text {th }}$ percentile of current nuclear operating expenses from Davis and Hausman (2016) is around \$25/MWh, and the World Nuclear Association (2017) reports average 2014 production costs of $\$ 24 / \mathrm{MWh}$. For plants with higher extension costs (40 GW of the fleet), we assume a $\$ 40 / \mathrm{MWh}$ electricity equivalent rate to account for additional costs resulting from post-Fukushima requirements (e.g., operator training and increased security measures) and other expenses that may be required to extend the operating licenses of nuclear plants. Lastly, we assume an electricity equivalent rate of $\$ 80 / \mathrm{MWh}$ electricity equivalent for new builds based on analysis from the International Energy Agency and the Organisation for Economic Co-operation and Development Nuclear Energy Agency (2015), which estimates the LCOE for U.S. nuclear plants at around $\$ 75 / \mathrm{MWh}$ assuming a 7\% discount rate, and around $\$ 95 /$ MWh assuming a $10 \%$ discount rate.

Hydrogen production costs for HTE are calculated using both the current and future H2A SOEC case studies (DOE 2018a). ${ }^{49}$ We use the electricity prices described above $(\$ 25, \$ 40$, and $\$ 80 / \mathrm{MWh}$ ) for electricity feedstock. Thermal energy prices are assumed to be $35 \%$ of electricity prices, which is based on the assumed thermal efficiency of nuclear plants $(32 \%)$ and factors in additional costs for piping and transmission of the heat. For current technology, we assume capital costs of $\$ 820 / \mathrm{kW}$, electricity use of $36.8 \mathrm{kWh} / \mathrm{kg}$, and thermal use of $16.5 \mathrm{kWh} / \mathrm{kg}$, which are consistent with the current $\mathrm{H} 2 \mathrm{~A}$ case study. Capital cost and use inputs for future technology are based on analysis assumptions from Idaho National Laboratory (Epiney et al. 2017; Rabiti et al. 2017): SOEC capital costs of $\$ 423 / \mathrm{kW}$, electricity use of $35.3 \mathrm{kWh}$ per $1 \mathrm{~kg}$ of hydrogen, and thermal use of $9.5 \mathrm{kWh}$ per $1 \mathrm{~kg}$ of hydrogen are used. ${ }^{50}$ Lastly, we assume a plant capacity of 624 tonne/day of hydrogen for future technology, and a capacity of $566 \mathrm{MT} /$ day for current technology (compared with the H2A default of 50 tonne/day). ${ }^{51}$ All other inputs to H2A are the default case study values including no value for coproduct oxygen. Alternative configurations including hybrids that use lower-priced electricity generation and nuclear-generated heat are not considered in this analysis but could be considered in subsequent work.

The resulting supply curves for HTE are shown in Figure 16. The three steps in each curve correspond to the three categories of nuclear plants: low extension cost, high extension cost, and new builds. We estimate that with current technology $3.8 \mathrm{MMT} / \mathrm{yr}$ of hydrogen can be economically produced at a hydrogen cost of $\$ 1.91 / \mathrm{kg}$, corresponding to $20 \mathrm{GW}$ of converted nuclear plant capacity, and an additional 7.7 MMT/yr can be produced at $\$ 2.58 / \mathrm{kg}$, corresponding to a converted nuclear plant capacity of $40 \mathrm{GW}$. In addition, we estimate that new nuclear plants can produce hydrogen at $\$ 4.34 / \mathrm{kg}$. For future technology, $4.2 \mathrm{MMT} / \mathrm{yr}$ of

\footnotetext{
48 The electricity equivalent rate is for corresponding rates for electricity and heat for the HTE. Thus $\$ 25$ per MWh electric $\left(\mathrm{MWh}_{\mathrm{e}}\right)$ is $\$ 8.75$ per $\mathrm{MWh}$ thermal energy $\left(\mathrm{MWh}_{\mathrm{th}}\right)$ owing to a $32 \%$ electricity generation efficiency and additional costs for piping and transmission of the heat. Likewise, the $\$ 40 / \mathrm{MWh}_{\mathrm{e}}$ rate is $\$ 14 / \mathrm{MWh}_{\mathrm{th}}$, and the $\$ 80 / \mathrm{MWh}_{\mathrm{e}}$ is $\$ 28 / \mathrm{MWh}_{\mathrm{th}}$.

49 The "Current Central Hydrogen Production from Solid Oxide Electrolysis version 3.2018" and "Future Central Hydrogen Production from Solid Oxide Electrolysis version 3.2018" H2A case studies are used.

${ }^{50}$ For reference, the H2A future case study default values are $\$ 430 / \mathrm{kW}$ for capital costs, $35.1 \mathrm{kWh} / \mathrm{kg}$ for electricity use, and $11.5 \mathrm{kWh} / \mathrm{kg}$ for heat use.

${ }^{51}$ The plant capacity of $624 \mathrm{MT} /$ day is based on a 1,000-MWe light water reactor plant, operating at a $90 \%$ capacity factor. The current technology capacity is estimated to correspond to the same size nuclear plant $(1,000 \mathrm{MWe})$, but with the higher electricity and heat use assumed for current technology.
} 
hydrogen can be produced at a cost of $\$ 1.29 / \mathrm{kg}$, an additional $8.4 \mathrm{MMT} / \mathrm{yr}$ can be produced at $\$ 1.89 / \mathrm{kg}$, and new builds can produce hydrogen at $\$ 3.49 / \mathrm{kg}$. The total hydrogen production is calculated based on both the use rates described above and the average plant capacity factors based on EIA (2017f); new builds are assumed to have a 90\% capacity factor.

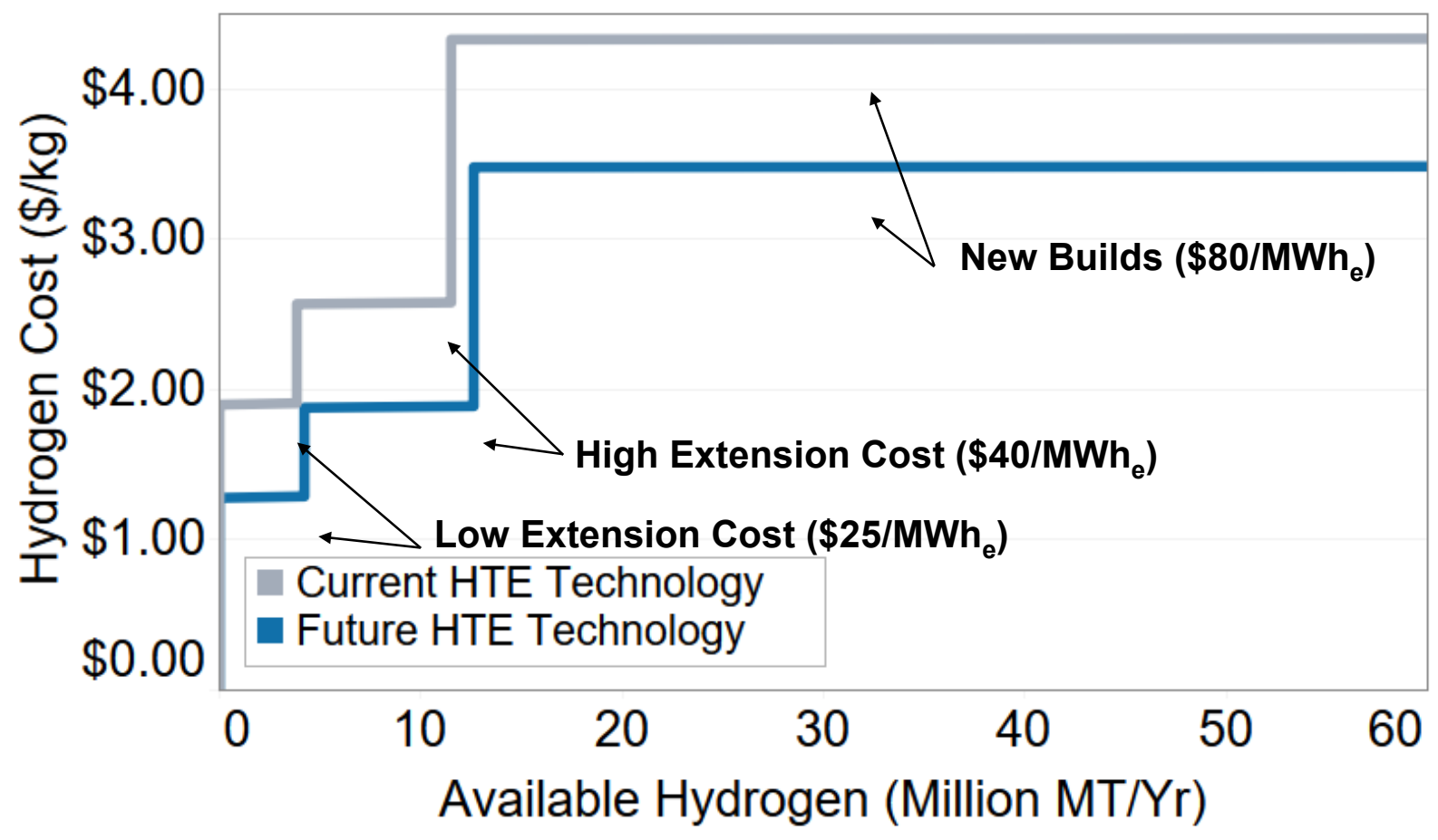

Figure 16. Hydrogen supply curve for HTE

As with LTE, we add a long-distance delivery cost of $\$ 0.39 / \mathrm{kg}$ (Table 16) to the production costs shown in Figure 16. Nuclear plants are likely to be further from demand centers than are SMR facilities, so longer transmission distances will be required. The delivery adder is included in the HTE production costs used to calculate the aggregated supply curves described in Section 6.3.

Heat and electricity for HTE can be generated by multiple sources. As a point of comparison, grid electricity could be coupled with heat generated by combusting natural gas. Using the $\mathrm{H} 2 \mathrm{~A}$ future SOEC case study with a 2050 startup year, this results in a levelized hydrogen production cost of $\$ 3.84 / \mathrm{kg}$ (assuming industrial electricity and natural gas prices from the AEO 2017 Reference case), with feedstock making up $83 \%$ of the cost. The levelized production cost decreases to $\$ 1.83 / \mathrm{kg}$ when assuming an electricity price of $\$ 25 / \mathrm{MWh}$. Because those prices are higher than prices from HTE-connected nuclear power plants with the same electricity prices, only nuclear-powered HTE is considered in this analysis.

We locate hydrogen production from nuclear HTE at the respective nuclear plants in each cost category described above. 


\subsection{Production from Biomass Resources}

Hydrogen production from biomass resources - either solid biomass or methane as biogas - is another option for producing hydrogen renewably. However, competition for biomass among alternative end uses, especially biofuel production, may limit use for hydrogen production.

Biomass gasification involves gasification of solid biomass into a synthesis gas followed by steam reforming of the synthesis gas to separate the hydrogen. The H2A case studies for biomass gasification include a detailed process description (DOE 2018a). The assumed yield for biomass conversion, based on the H2A "Future Central Hydrogen Production via Biomass Gasification version 3.2018" (DOE 2018a), is $13.03 \mathrm{~kg}$ of bone dry woody biomass (242 MJ) required to produce $1 \mathrm{~kg}$ of hydrogen via biomass gasification (48.3\% production energy efficiency on a lower heating value [LHV] basis). Hydrogen can also be produced from biogas (methane) via SMR, with an assumed use of $3.49 \mathrm{~kg}$ of methane per $1 \mathrm{~kg}$ of hydrogen (Connelly et al. 2020).

In our technical potential estimates, we report estimates of hydrogen produced from solid biomass gasification based on the analysis of Connelly et al. (2020). ${ }^{52}$ An estimated 800-1,200 million short tons/yr of biomass (dry basis) are technically recoverable in the United States. The biomass resource equates to a hydrogen production potential of 50-80 MMT/yr. For the technical potential estimates in this report, we use the higher value of each: 1,200 million short tons/yr biomass (dry) and $80 \mathrm{MMT} / \mathrm{yr}$ hydrogen. Appendix E includes the geographic distribution of the 1,200 million short tons/yr of available biomass resource.

The economic potential for hydrogen production from biomass is estimated for gasification of solid biomass. We do not estimate the economic potential of production from biogas, because the costs will be equivalent to SMR of natural gas, or higher, depending on whether biogas commands a premium as compared to natural gas. ${ }^{53}$ The estimates for biomass gasification are based on analysis from the 2016 BTS (DOE 2016), which estimates the quantity of energy crops and agricultural, forest, and waste residues available at different biomass prices, totaling over 800 million dry metric tons. ${ }^{54}$ Biomass prices in the BTS include grower payment, harvest, and collection. To estimate the total price of biomass at the gasification plant gate, we add a delivery price of $\$ 25.22 /$ metric ton ( $\$ 22.92 /$ short ton) (Hartley et al. 2018). The biomass gasification process described above uses woody biomass as a feedstock. For consistency, we convert the variety of biomass feedstocks included in the BTS to a woody biomass equivalent ${ }^{55}$ using HHVs (see Appendix I). ${ }^{56}$ The hydrogen costs are estimated using the H2A future central biomass gasification case, using a 2050 startup year, and electricity and natural gas prices from AEO 2017 (EIA 2017a). Figure 17 shows the resulting supply curve for hydrogen production from

\footnotetext{
${ }^{52}$ Connelly et al. (2020) also include estimates for technical potential of biogas (product gas from anaerobic digestion of organic wastes), but we do not consider this in our biomass technical potential.

${ }^{53}$ The natural gas market uses biogas when it is available. Because hydrogen production from natural gas is included in this analysis, and the price of biogas will be the same as or higher than the natural gas price, biogas could be a fraction of the natural gas reported in the results.

54 The BTS scenarios are based on the year 2040 .

${ }^{55}$ We use poplar as the representative woody biomass.

${ }^{56}$ HHVs are used from the Biomass Energy Data Book (DOE 2010) and the Ontario Ministry of Agriculture, Food, and Rural Affairs (2011).
} 
biomass gasification, assuming natural gas prices from the AEO Reference case. Using prices from the LOGR case increases the hydrogen cost by $\$ 0.02 / \mathrm{kg}$.

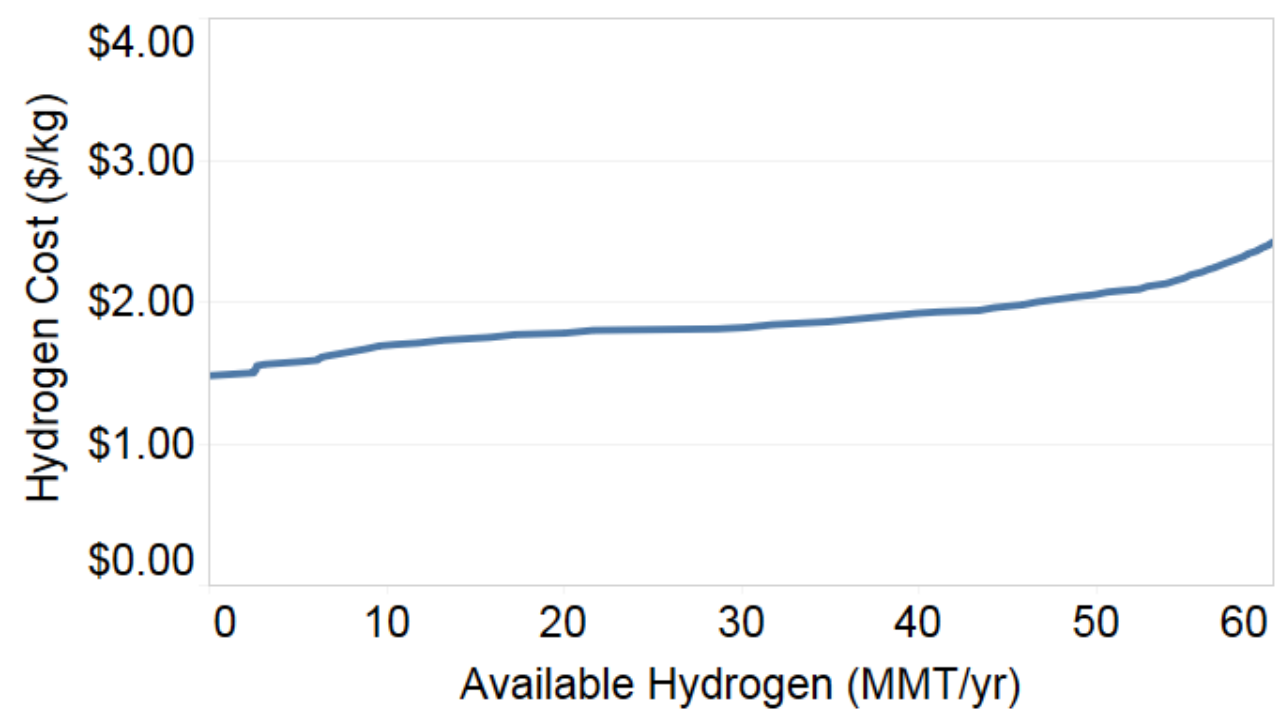

Figure 17. Hydrogen supply curve for biomass gasification

As with LTE and HTE, we add a long-distance delivery cost of $\$ 0.39 / \mathrm{kg}$ (Table 16) to the production costs shown in Figure 17. The delivery adder is included in the biomass gasification production costs used to calculate the aggregated supply curves described in Section 6.3.

Locations for hydrogen production via biomass gasification are determined from the state-level availability of biomass resources provided in the BTS results. Similar to biomass demand discussed in Section 3.4, we distribute regional biofuel production evenly to locations with oil refining, ammonia production, metals refining, or SMR, because those locations will likely have the industrial infrastructure available for biomass gasification.

The alternative end uses for biomass, especially construction materials and biofuel production, may create competition for biomass, thus limiting its potential availability for hydrogen production. Owing to these competing end uses, we only consider biomass availability for gasification as a sensitivity analysis (Section 6.8.5), and we do not include hydrogen production from biomass in the core economic potential scenarios.

\subsection{Production from Coal}

The process for coal gasification is similar to that for biomass gasification: a feedstock is converted to a synthesis gas, and hydrogen is separated out. See the DOE H2A coal gasification case studies for additional process information (DOE 2018a). Here we consider coal gasification technologies that include CCS. We used the DOE H2A current case study, which is based on case 2-2 from the National Energy Technology Laboratory (NETL) (2010), a 30-year plant life, 
and a 2050 startup year. ${ }^{57}$ The coal gasification with CCS process modeled by NETL assumes $8.57 \mathrm{~kg}$ of Illinois \#6 coal are required to produce $1 \mathrm{~kg}$ of hydrogen (Connelly et al. 2020). ${ }^{58}$ That estimate is currently being updated (personal communication with Walter Shelton, September 2019). As more information regarding coal gasification becomes publicly available, it will be used to inform updates to this analysis.

We estimate the levelized cost of hydrogen production from coal gasification to be $\$ 2.04$ $\$ 2.15 / \mathrm{kg}$. The range of costs is due to varying transport costs depending on which region the coal is sourced from. ${ }^{59}$ Adding a hydrogen delivery cost of $\$ 0.39 / \mathrm{kg}$ results in a total cost of $\$ 2.43-$ $\$ 2.54 / \mathrm{kg}$; at this cost, coal-generated hydrogen does not play a role in the economic potential analysis. Therefore, we do not include it in our economic potential scenarios.

The technical potential for hydrogen produced from coal is based on the 470 billion short tons of total recoverable U.S. coal reserves reported in Connelly et al. (2020). That quantity of coal could produce $50,000 \mathrm{MMT}$ of hydrogen at the utilization rate of $8.57 \mathrm{~kg}$ of coal per $1 \mathrm{~kg}$ of hydrogen. ${ }^{60}$

\subsection{Other Production Technologies}

Hydrogen can be produced from various other technologies in addition to those described above. PEC cells and solar thermochemical (STCH) cycles are two water-splitting technologies at lower technology-readiness levels than LTE and HTE. PEC cells convert solar energy into electricity, which can then be used to electrolyze water, producing hydrogen and oxygen. Direct PEC conversion theoretically allows for efficiency gains compared to PV generation with conventional electrolysis owing to the elimination of electrical current collection and transmission losses (B. D. James et al. 2009). STCH cycles use solar heat, or a combination of heat and electrolysis, to produce hydrogen via reduction of materials followed by oxidation (TIAX LLC 2011). Table 17 shows the hydrogen production costs from the DOE future H2A case studies for PEC and STCH, assuming a 2050 startup year. Because solar energy is the primary feedstock for these technologies, the production costs are driven by the technology capital costs.

\footnotetext{
57 This reference study is for a specific technology that requires the use of bituminous coal, which is fed in the reactor as a slurry. Analogous studies of coal to hydrogen production using sub-bituminous and lignite coals are unavailable at this time. However, the use of other coal types, for example lignite and sub-bituminous coal, is technically feasible. Examples of currently operating large-scale gasification plants include:

- $\quad$ https://www.netl.doe.gov/research/Coal/energy-systems/gasification/gasifipedia/great-plains

- $\quad$ https://www.netl.doe.gov/research/Coal/energy-systems/gasification/gasifipedia/sasol

58 The LHV of Illinois \#6 coal is $24,806 \mathrm{Btu} / \mathrm{kg}$. The H2A coal gasification case study uses electric steam utility coal, which has a lower LHV of 21,546; thus, a higher use of $9.70 \mathrm{~kg}$ is assumed in the case study.

${ }^{59}$ The per-kilogram hydrogen production costs using Illinois \#6 coal for various regions are: \$2.04 (Ohio), \$2.07 (Indiana, Illinois, Michigan, Wisconsin, Kentucky, Tennessee), and \$2.15 (Texas, Louisiana, Oklahoma, Arkansas).

${ }^{60}$ The technical potential for fossil resources are based on total reserves (compared to the VRE and biomass technical potentials, which are based on annual availability).
} 
Table 17. Central Hydrogen Production Costs for Emerging Technologies

\begin{tabular}{|c|c|c|}
\hline Technology & $\begin{array}{l}\text { Hydrogen } \\
\text { Production } \\
\text { Cost }(\$ / k g)\end{array}$ & Reference \\
\hline $\begin{array}{l}\mathrm{PEC} \text { (dual-bed } \mathrm{FeO}_{2} \text { colloidal } \\
\text { suspension at } 5 \% \text { conversion } \\
\text { efficiency) }\end{array}$ & 3.88 & $\begin{array}{l}\text { "Future Central Hydrogen Production from } \\
\text { Photoelectrochemical Type } 2 \text { version } 3.2018 \text { " } \\
\text { H2A case study (DOE 2018a) }\end{array}$ \\
\hline $\begin{array}{l}\text { PEC (tracking solar concentrators at } \\
20 \% \text { conversion efficiency) }\end{array}$ & 4.27 & $\begin{array}{l}\text { "Future Central Hydrogen Production from } \\
\text { Photoelectrochemical Type } 4 \text { version } 3.2018 \text { " } \\
\text { H2A case study (DOE 2018a) }\end{array}$ \\
\hline $\begin{array}{l}\text { STCH ferrite cycle ( } 90 \% \text { capacity } \\
\text { factor) }\end{array}$ & 2.49 & $\begin{array}{l}\text { "Future Central Hydrogen Production from } \\
\text { Solar Thermo-Chemical Ferrite Cycle version } \\
3.2018 \text { " H2A case study (DOE 2018a) }\end{array}$ \\
\hline $\begin{array}{l}\text { STCH ferrite cycle ( } 30 \% \text { capacity } \\
\text { factor) })^{\mathrm{a}}\end{array}$ & 7.45 & $\begin{array}{l}\text { "Future Central Hydrogen Production from } \\
\text { Solar Thermo-Chemical Ferrite Cycle version } \\
3.2018 \text { " H2A case study (DOE 2018a) with a } \\
30 \% \text { capacity factor }\end{array}$ \\
\hline
\end{tabular}

a The H2A default case assumes a $90 \%$ capacity factor, but assumes the system operates only "on-sun" with no thermal storage used. The $30 \%$ capacity factor case is included for reference.

Emerging technologies — such as PEC, STCH, microbial electrolysis, and biological fermentation - have the potential to achieve wide-scale viability and provide system benefits. However, they are not included in this analysis owing to their lower technology-readiness levels and higher hydrogen production costs compared to the other technologies analyzed. 


\section{Serviceable Consumption Potential and Technical Potential}

The sum of the serviceable consumption potentials for hydrogen demands reported in Section 3 is $106 \mathrm{MMT} / \mathrm{yr}: 29 \mathrm{MMT} / \mathrm{yr}$ for fuel cell vehicles, $15 \mathrm{MMT} / \mathrm{yr}$ for seasonal storage for electricity, and $62 \mathrm{MMT} / \mathrm{yr}$ for industrial use (including oil refining, metals refining, ammonia, biofuels, and synthetic $\mathrm{HC}$ ) and blending into the natural gas system. Table 18 summarizes the serviceable consumption potentials for hydrogen demands, compared to current consumption.

Table 18. Serviceable Consumption Potential for Hydrogen Demands

\begin{tabular}{lcc}
\hline Application & $\begin{array}{c}\text { Serviceable } \\
\text { Consumption Potential } \\
\text { (MMT/yr) }\end{array}$ & $\begin{array}{c}\text { 2015 Market for On- } \\
\text { Purpose } \mathbf{H}_{\mathbf{2}} \text { (MMT/yr) }\end{array}$ \\
\hline Oil refining & 7 & 6 \\
Metals refining & 12 & 0 \\
Ammonia & 4 & 3 \\
Biofuels & 9 & 0 \\
Synthetic HC & 14 & 1 \\
Natural gas supplementation & 16 & 0 \\
Seasonal energy storage for the electric grid & 15 & 0 \\
\hline Industry and Storage Subtotal & $\mathbf{7 7}$ & $\mathbf{1 0}$ \\
\hline Light-duty FCEVs & 21 & 0 \\
Medium- and heavy-duty FCEVs & 8 & 0 \\
\hline Transportation Fuel Subtotal & $\mathbf{2 9}$ & $\mathbf{0}$ \\
\hline Total & $\mathbf{1 0 6}$ & $\mathbf{1 0}$ \\
\hline
\end{tabular}

Demands between hydrogen uses that provide the same social service (e.g., oil refining and direct hydrogen use for transportation) are not assumed to impact the cumulative market sizes, because additional products are assumed to be exported.

The serviceable consumption potential for light-duty and medium- and heavy-duty FCEVs are based on $41 \%$ and $35 \%$ market penetrations, respectively.

Oil refining is rounded from 7.5 MMT/yr to $7 \mathrm{MMT} / \mathrm{yr}$ in this table so that the total and subtotals match the sum of the rounded values.

Figure 18 shows the aggregated locations of the serviceable consumption potential for industrial use, and Figure 19 shows the locations for industrial use and injection into the natural gas system. The addition of hydrogen for FCEVs is shown in Figure 20, and all hydrogen applications included in this report are shown in Figure 21. Appendix E includes maps for each individual demand application. Details regarding location assumptions for the serviceable consumption potential of each application are reported in Section 3 and summarized in Appendix D. Because specific locations are identified for industrial applications, they appear as large potential demands in their counties, and many counties do not have any demands. Counties with 
the largest serviceable consumption potentials are primarily locations with refineries and ammonia production facilities, because of their hydrogen demands, and those with ethanol plants, because of the potential to use the carbon dioxide they produce. Locations for hydrogen injection into natural gas are disaggregated from census division data as discussed in Section 3.6; thus, they are more evenly distributed, and fewer counties have demands below the color threshold in the figure. At $29 \mathrm{MMT} / \mathrm{yr}$, the serviceable consumption potential for FCEVs overwhelms the other potential demands, so almost all counties shift to a darker color compared to the previous figures. Including electrical energy storage increases demand in areas where conventional generators are needed to supplement VRE resources.

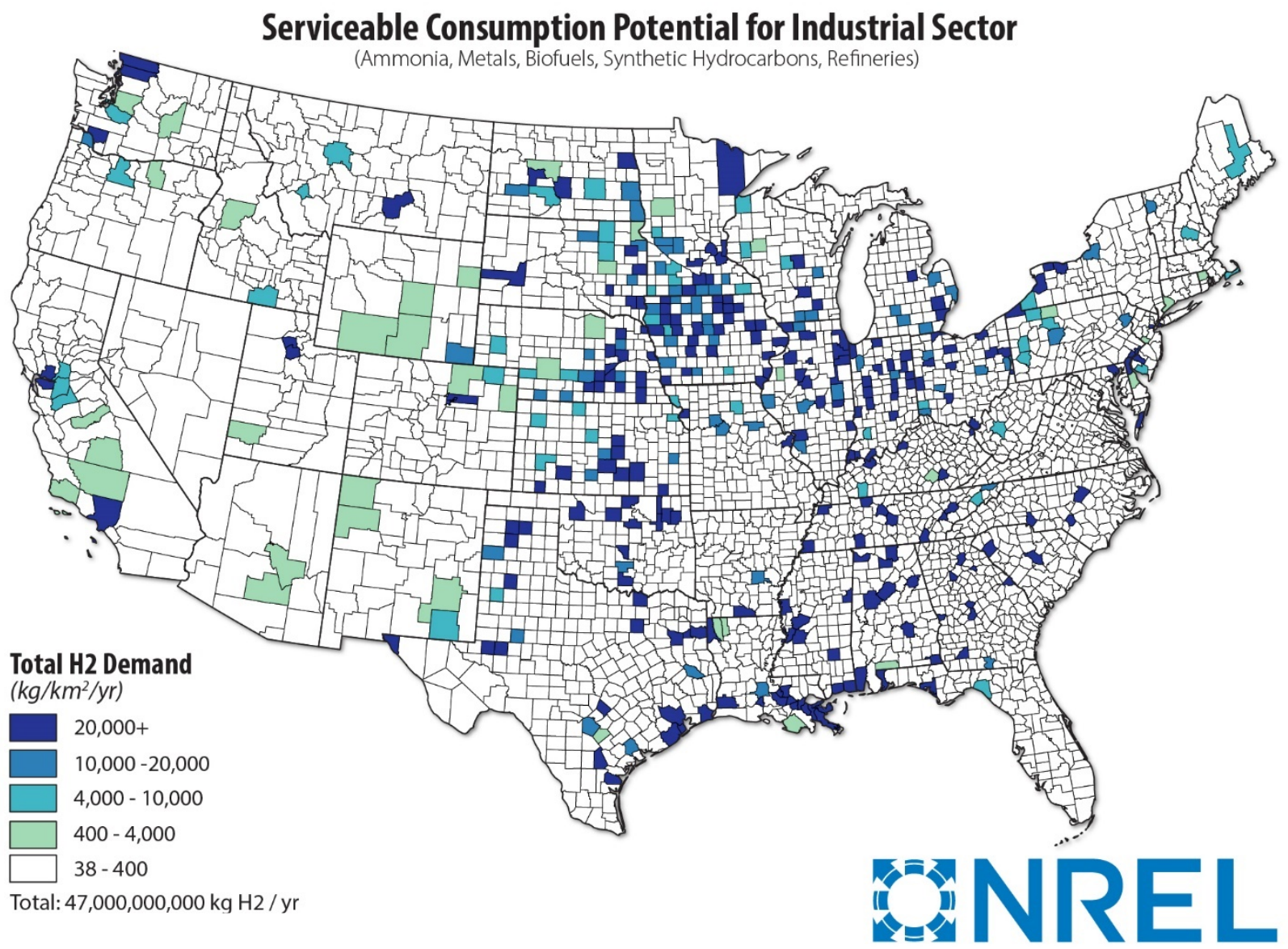

Figure 18. Locations of aggregated serviceable consumption potentials for industrial hydrogen applications

Industrial applications include oil refining, metals refining, ammonia, biofuels, and synthetic HC. 


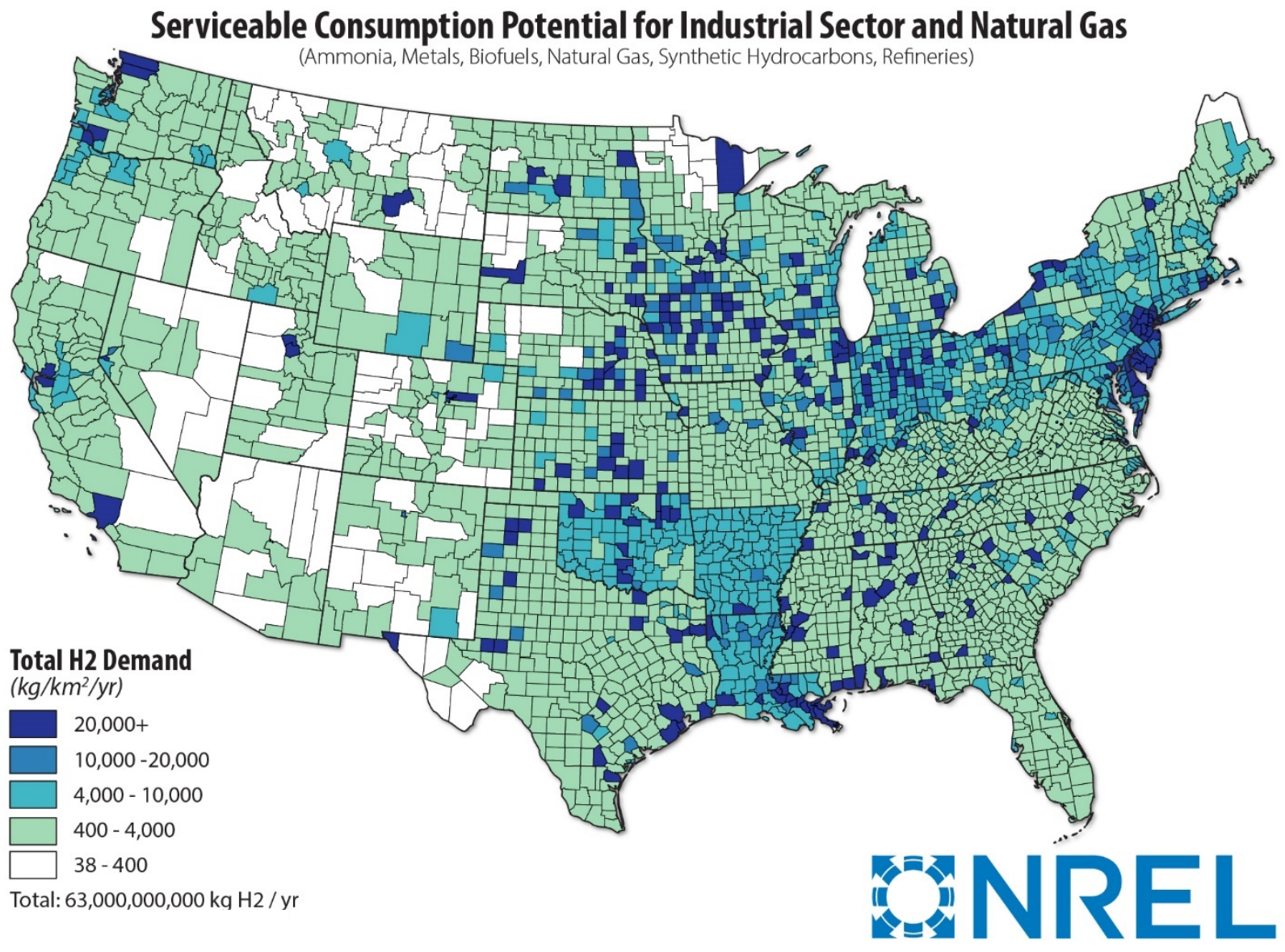

Figure 19. Locations of aggregated serviceable consumption potentials for industrial hydrogen applications and injection into the natural gas system

Industrial applications include oil refining, metals refining, ammonia, biofuels, and synthetic HC. 


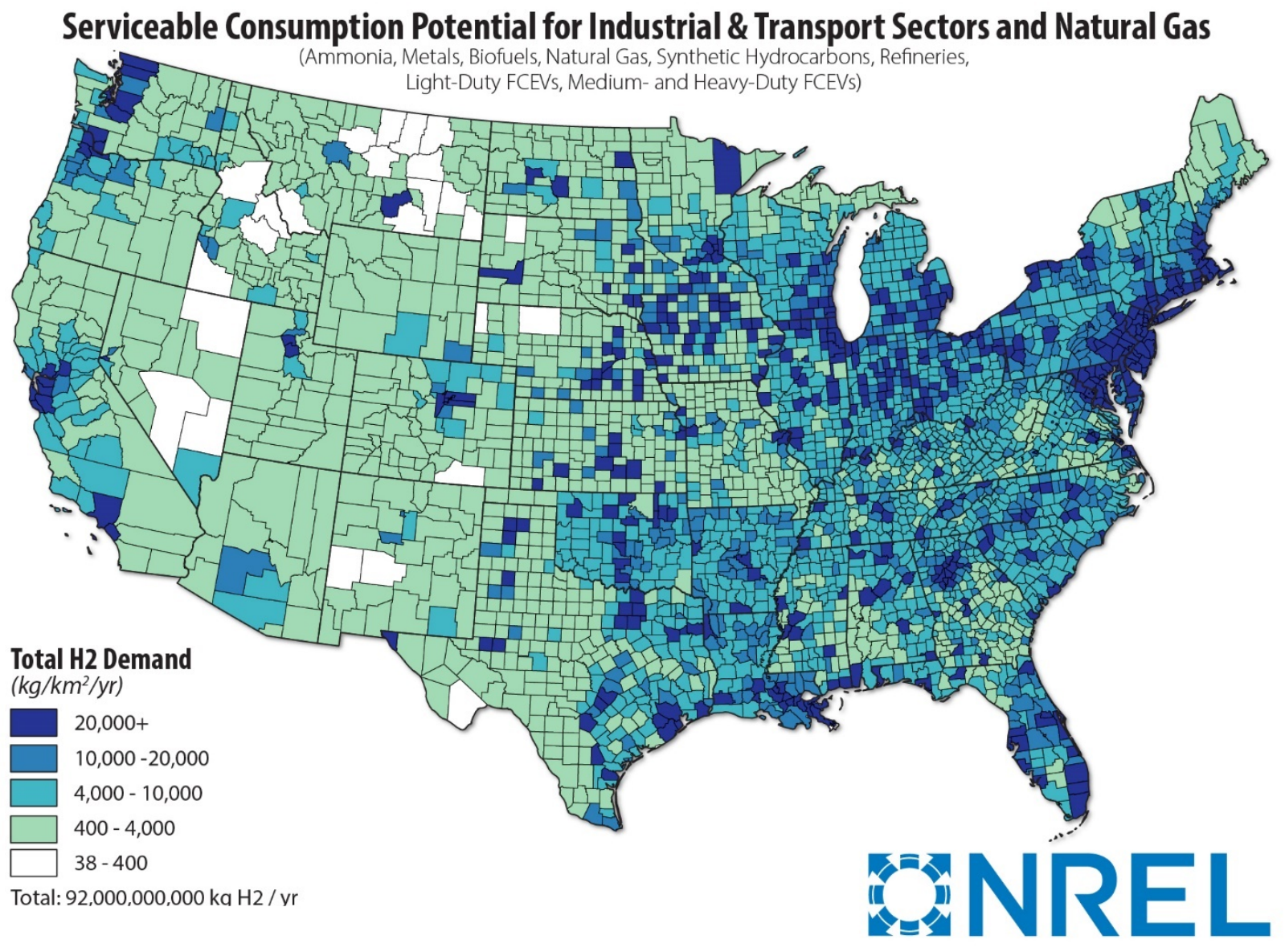

Figure 20. Locations of aggregated serviceable consumption potentials for industrial hydrogen applications, injection into the natural gas system, and transportation

Industrial applications include oil refining, metals refining, ammonia, biofuels, and synthetic HC. 


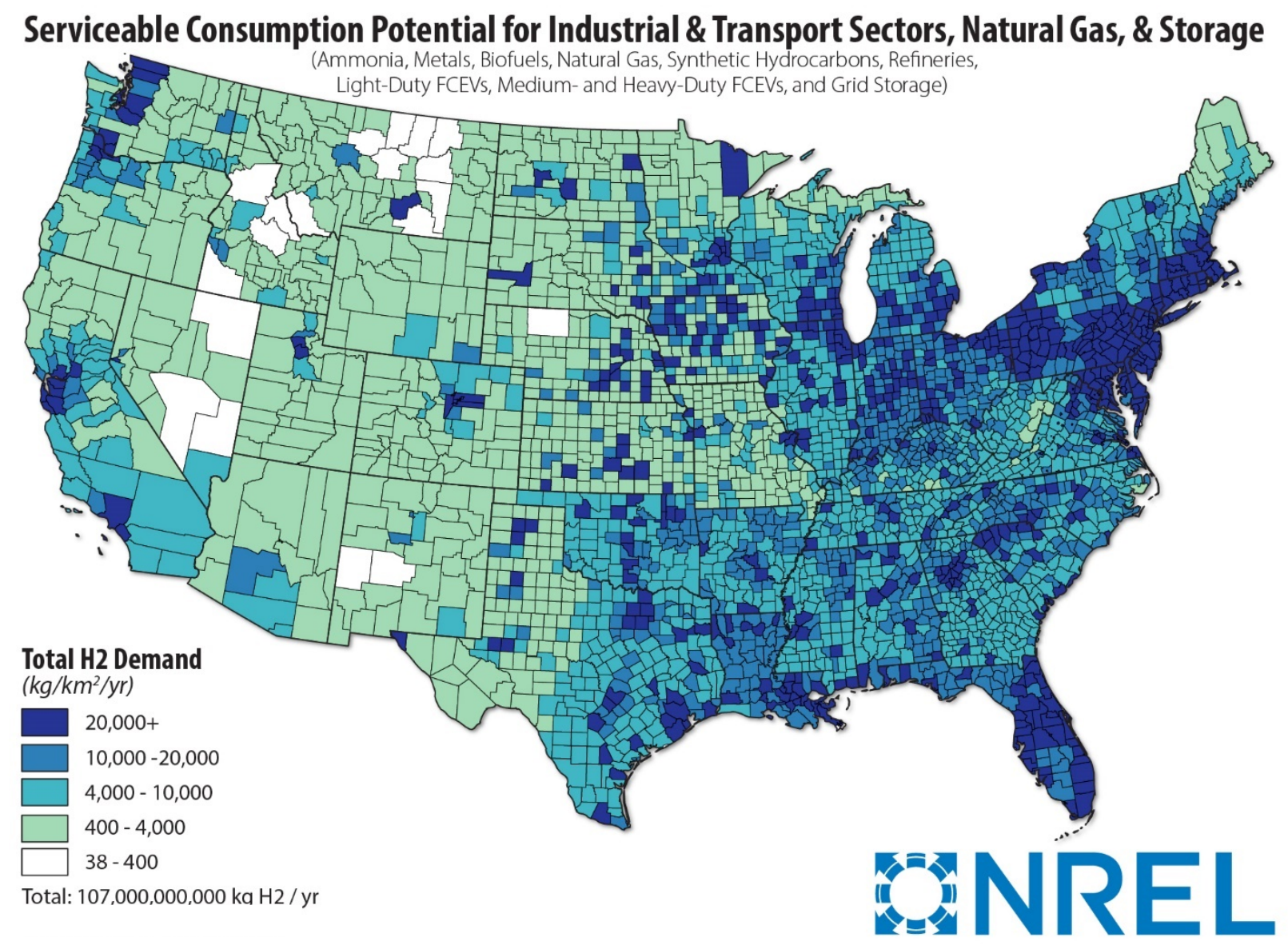

Figure 21. Locations of aggregated serviceable consumption potentials for all hydrogen applications

We compare the serviceable consumption potential sizes for hydrogen demands to the technical potential of renewable, fossil, and nuclear resources to determine whether supplies could meet the potential demand. Table 19 summarizes the impacts generating $106 \mathrm{MMT} / \mathrm{yr}$ of hydrogen would have on the technical potential of solar, wind, hydropower, geothermal, water power, and biomass resources if all the hydrogen were generated from a single resource, based on estimates from Connelly et al. (2020) (summarized in Sections 4.2 and 4.4). Connelly et al. (2020) estimate around $260,000 \mathrm{TWh} / \mathrm{yr}$ of solar potential. Assuming $50.2 \mathrm{kWh}^{61}$ of electricity to produce $1 \mathrm{~kg}$ of hydrogen, 260,000 TWh/yr of electricity could be used to produce 5,200 MMT/yr of hydrogen. Even if solar is used to meet the serviceable hydrogen consumption potential and the current electricity demand, only about $2.1 \%$ of the resource is required. If only wind energy is used to meet the demand, approximately $15 \%$ of the combined onshore and offshore technical potential of 38,000 TWh/yr is required (Connelly et al. 2020). Meeting the serviceable consumption potential with geothermal energy would require $22 \%$ of the resource $(25,000$ $\mathrm{TWh} / \mathrm{yr}$ ). Hence, the United States has sufficient solar, wind, and geothermal resources to meet the serviceable consumption potential for hydrogen.

\footnotetext{
${ }^{61}$ See footnote 29.
} 
The solid biomass and hydropower resources, on the other hand, are insufficient to meet the serviceable consumption potential for hydrogen. Approximately $20 \%$ of the biomass resource was consumed in 2017 for wood products, pulp, and other existing products. About $160 \%$ of the 1,200 million short tons/yr technical potential of the solid biomass resource-estimated in the BTS (DOE 2016) and summarized by Connelly et al. (2020)—would be required to add 106 $\mathrm{MMT} / \mathrm{yr}$ of hydrogen to the existing demands. For electrolysis, $820 \%$ of the conventional hydropower resource $(700 \mathrm{TWh} / \mathrm{yr})$ and $300 \%$ of the advanced hydropower resource $(1,800$ $\mathrm{TWh} / \mathrm{yr}$ ) would be required. Thus, $230 \%$ of the total hydropower resource (conventional and advanced $-2,500 \mathrm{TWh} / \mathrm{yr}$ ) would be required.

In summary, biomass and hydropower could each meet about half of the serviceable consumption potential market but not the full quantity, whereas the technical potentials for wind, solar, and geothermal are each sufficient to meet the total serviceable consumption potential.

Table 19. Impact of Generating the Serviceable Consumption Potential for Hydrogen on Technical Potential Renewable Resource Supplies

\begin{tabular}{lcccc}
\hline & $\begin{array}{l}\text { 2017 } \\
\text { Consumption } \\
\text { (quad/yr) }\end{array}$ & $\begin{array}{l}\text { Quantity } \\
\text { Required To } \\
\text { Produce 106 } \\
\text { MMT/yr } \\
\text { (quad/yr) }\end{array}$ & $\begin{array}{l}\text { Total } \\
\text { Technical } \\
\text { Potential } \\
\text { (quad/yr) }\end{array}$ & $\begin{array}{l}\text { Percentage of Technical } \\
\text { Potential Required to } \\
\text { Meet 2017 Consumption } \\
\text { and Produce 106 MMT/yr } \\
\text { of Hydrogen (quad/yr) }\end{array}$ \\
\hline $\begin{array}{l}\text { Solar electricity } \\
\text { Wind electricity }\end{array}$ & 0.31 & 18.2 & 890 & $2.1 \%$ \\
$\begin{array}{l}\text { Conventional } \\
\text { hydropower electricity }\end{array}$ & 0.87 & 18.2 & 130 & $15 \%$ \\
$\begin{array}{l}\text { Advanced hydropower } \\
\text { electricitya }\end{array}$ & 1.0 & 18.2 & 2.4 & $820 \%$ \\
$\begin{array}{l}\text { Geothermal electricity } \\
\text { Solid biomass }\end{array}$ & 0.0 & 18.2 & 6.2 & $300 \%$ \\
\hline
\end{tabular}

The solar and wind values are calculated on a generated-electricity basis. Connelly et al. (2020) report technical potential on a fossil fuel equivalent basis assuming a $36 \%$ conversion efficiency of fossil resources to electricity for current resources, and $37 \%$ efficiency for future resources; thus they report technical potentials of 2,400 quad/yr for solar, 350 quad/yr for wind, 6.4 quad/yr for hydropower, 230 quad/yr for geothermal, and 17 quad/yr for advanced hydropower. The biomass values are calculated on an HHV basis.

a Includes MHK technologies.

Figure 22 shows whether the locations of onshore wind and PV resources are near hydrogen demand locations. Most counties in the country (those in blue) have the onshore wind and PV resources necessary to exceed their serviceable hydrogen consumption potentials. Counties in red have serviceable hydrogen consumption potentials exceeding their onshore wind and PV resources. Many of those counties contain populous cities where the hydrogen demand for LDVs has potential to be high. Other locations colored red (e.g., those in Appalachia) have few onshore wind or PV resources, so they would likely depend on delivered hydrogen from other counties, or on fossil, nuclear, or other resources if their hydrogen demand grows close to their serviceable consumption potential sizes. Many of those areas are near nuclear electricity generators, so 
transitioning those generators to use a fraction of their energy to produce hydrogen could meet their demands. ${ }^{62}$

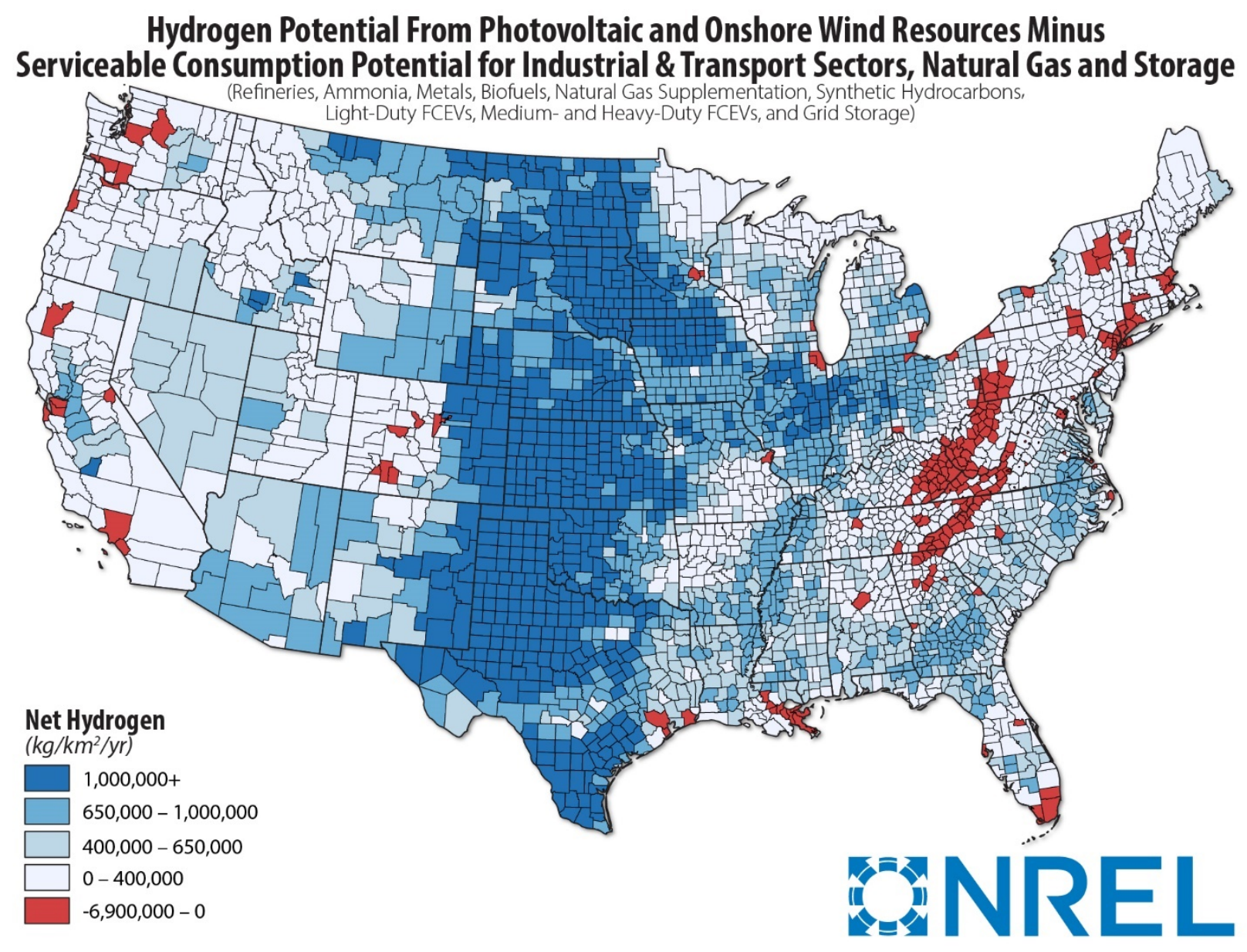

Figure 22. County-by-county differences between the technical potential for hydrogen production from onshore wind and PV resources and serviceable consumption potential for all hydrogen demands

Figure 23 summarizes the impacts generating $106 \mathrm{MMT} / \mathrm{yr}$ of hydrogen would have on natural gas, coal, and nuclear resources. Because hydrogen is unlikely to be produced from any single resource, the impacts shown in the figure can be considered upper bounds. Increasing hydrogen production from natural gas from its 2017 level of $10 \mathrm{MMT} / \mathrm{yr}$ to $106 \mathrm{MMT} / \mathrm{yr}$ would increase the demand for natural gas by $18 \mathrm{quad} / \mathrm{yr}$, to $46 \mathrm{quad} / \mathrm{yr}$. The United States has about 2,800 Tcf (2,600 quads) of natural gas in proven and unproven reserves (both conventional and unconventional resources); thus, at a consumption rate of $46 \mathrm{quad} / \mathrm{yr}$, the country has approximately 55 years of proven and unproven natural gas reserves available. Approximately $23 \mathrm{quad} / \mathrm{yr}$ of coal would be needed to produce $106 \mathrm{MMT} / \mathrm{yr}$ of hydrogen. More additional coal is required than natural gas, because the conversion of coal to hydrogen is less efficient than the conversion of natural gas to hydrogen (Connelly et al. 2020). The U.S. coal resource is much larger than the natural gas resource; at the 2017 U.S. coal consumption plus additional

\footnotetext{
${ }^{62}$ Figure E-16 in Appendix E shows nuclear locations in relation to supply and demand by county.
} 
consumption to produce $106 \mathrm{MMT} / \mathrm{yr}$ of hydrogen, 260 years of the demonstrated reserve base are available. Thus, there are sufficient domestic fossil resources to meet both current demands and the serviceable consumption potential for hydrogen for many years into the future. It is important to note that these estimates do not account for sequestration of carbon emissions. If sequestration is desired, impacts on efficiency and availability of geologic formations suitable for carbon sequestration could constrain natural gas and coal use and thus reduce the effective resources

Meeting the serviceable consumption potential from nuclear would increase uranium consumption by 29 quad/yr (increasing the total from 8 quad/yr to $37 \mathrm{quad} / \mathrm{yr}$ ). Given the uncertainty in potential uranium resources, as described in Section 4.3, we do not estimate the years to depletion, but we do not anticipate resources to limit the nuclear potential for hydrogen production.

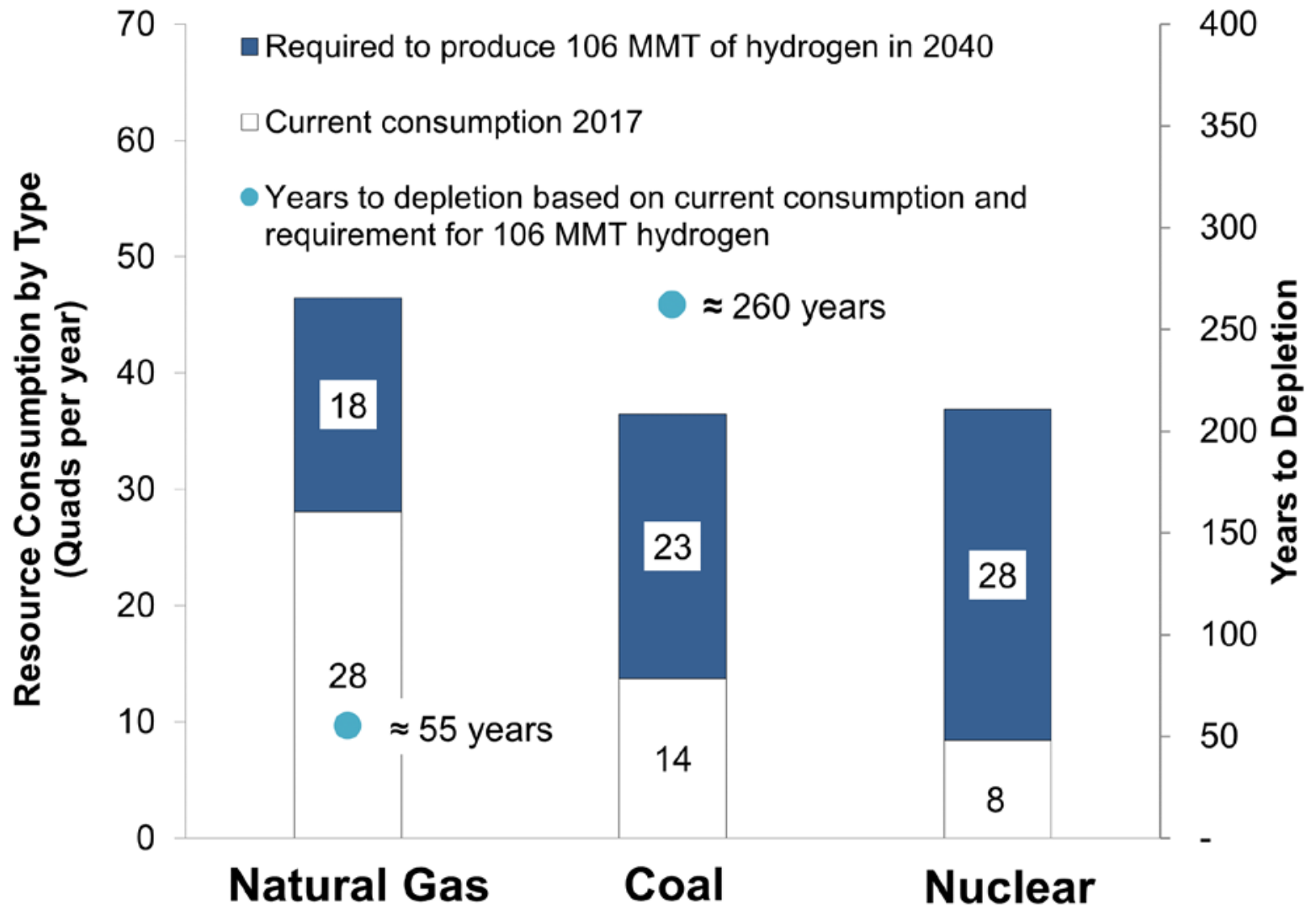

Figure 23. Impact of generating the serviceable hydrogen consumption potential on fossil and nuclear resource consumption (bars, left axis) and years to resource depletion for natural gas and coal (points, right axis)

Coal and natural gas are on an HHV basis, and nuclear is on a potential thermal energy basis. Coal use estimates are consistent with assumptions in NETL case study assuming bituminous coal (NETL 2010).

* Years to depletion are calculated assuming carbon dioxide emissions are not sequestered. If sequestration is desired, impacts on efficiency and availability of geologic formations suitable for carbon sequestration could constrain natural gas and coal use and thus reduce the effective resources. 


\section{Economic Potential}

\subsection{Definition of Five National Scenarios}

We estimate the economic potential of the H2@Scale concept to quantify the size of a potential domestic hydrogen market, how hydrogen could be produced to supply that market, and the applications that hydrogen from that market could support. We develop national supply and demand curves under five scenarios and use them to estimate the hydrogen market at economic equilibrium as described in Section 2.2.

Our five scenarios span a range of assumptions about future conditions, including technology advancements (e.g., electrolyzer cost reductions), infrastructure development (e.g., the availability of hydrogen delivery and fuel dispensing), the performance of related markets (e.g., natural gas prices), the potential for market accessibility (e.g., the opportunity to purchase LDE at the selling price into the wholesale power market), and other national decisions (e.g., whether a premium will be paid for domestically produced metals). Table 20 summarizes the five scenarios, which range from the Reference scenario (assuming current technology status and strong market competition) to the Lowest-Cost Electrolysis scenario (assuming optimistic technology development and market structures).

Three additional scenarios lie between those two endpoints. First, the R\&D Advances + Infrastructure scenario differs from the Reference scenario by including expected hydrogen technology development and demand growth; it also assumes a higher threshold price for hydrogen for metals refining (which might be driven by growth in the domestic metals refining industry). Second, the Low NG Resource/High NG Price scenario uses the AEO Low Oil and Gas Resource and Technology (LOGR) scenario's natural gas prices rather than the lower AEO Reference natural gas prices assumed for the Reference and R\&D Advances + Infrastructure scenarios. That change increases the price of hydrogen production from natural gas. To be consistent, the Low NG Resource/High NG Price scenario uses the ReEDS High Curtailment scenario's electricity mix - in which wind and solar are more competitive with natural gas generation - and increases the price point at which hydrogen would be injected into the natural gas system. Third, the Aggressive Electrolysis R\&D scenario differs from the Low NG Resource/High NG Price scenario through lower LTE capital costs and inclusion of monetary value for grid services provided by LTE (i.e., LDE is available at a price between retail and wholesale prices). 
Table 20. Five Scenarios Used for Economic Potential Estimates

\begin{tabular}{|c|c|c|c|c|c|}
\hline & Reference & $\begin{array}{l}\text { R\&D Advances } \\
+ \text { Infrastructure }\end{array}$ & $\begin{array}{l}\text { Low NG } \\
\text { Resource/ } \\
\text { High NG } \\
\text { Price }\end{array}$ & $\begin{array}{l}\text { Aggressive } \\
\text { Electrolysis } \\
\text { R\&D }\end{array}$ & $\begin{array}{l}\text { Lowest-Cost } \\
\text { Electrolysis }\end{array}$ \\
\hline Description & $\begin{array}{l}\text { Current } \\
\text { status of } \mathrm{H}_{2} \\
\text { technologies; } \\
\text { low NG } \\
\text { prices }\end{array}$ & $\begin{array}{l}\text { Expected cross- } \\
\text { sector } \mathrm{H}_{2} \\
\text { technology } \\
\text { improvement } \\
\text { and demand } \\
\text { growth; robust } \\
\mathrm{H}_{2} \text { demand for } \\
\text { metals; no } \\
\text { electrolysis for } \\
\text { grid support; low } \\
\text { NG prices }\end{array}$ & $\begin{array}{l}\text { Expected } \\
\text { cross-sector } \\
\mathrm{H}_{2} \text { demand } \\
\text { growth; robust } \\
\mathrm{H}_{2} \text { demand for } \\
\text { metals; no } \\
\text { electrolysis for } \\
\text { grid support; } \\
\text { high NG } \\
\text { prices }\end{array}$ & $\begin{array}{l}\text { Robust metals } \\
\mathrm{H}_{2} \text { demand } \\
\text { growth; limited } \\
\text { electrolysis for } \\
\text { grid support; } \\
\text { high NG prices }\end{array}$ & $\begin{array}{l}\text { Robust metals } \\
\mathrm{H}_{2} \text { demand } \\
\text { growth; } \\
\text { electrolysis } \\
\text { providing grid } \\
\text { support; high } \\
\text { NG prices }\end{array}$ \\
\hline $\begin{array}{l}\text { Natural gas } \\
\text { prices }\end{array}$ & \multicolumn{2}{|c|}{ AEO 2017 Reference scenario } & \multicolumn{3}{|c|}{ AEO 2017 LOGR scenario } \\
\hline Grid scenario & \multicolumn{2}{|c|}{ ReEDS Low RE Cost } & \multicolumn{3}{|c|}{ ReEDS High Curtailment } \\
\hline Availability of & \multicolumn{5}{|c|}{$\begin{array}{l}\text { Hydrogen generation from SMR for non-ammonia production is capped at three } \\
\text { times current levels ( } 23 \text { MMT hydrogen/yr) }\end{array}$} \\
\hline SMR facilities & \multicolumn{5}{|c|}{$\begin{array}{l}\text { Hydrogen generation from SMR estimated for future ammonia production is capped } \\
\text { at } 5 \text { MMT hydrogen/yr (based on Section 3.3) }\end{array}$} \\
\hline $\begin{array}{l}\text { Availability of } \\
\text { nuclear } \\
\text { reactors for } \\
\mathrm{H}_{2} \text { production }\end{array}$ & \multicolumn{5}{|c|}{$\begin{array}{l}20 \mathrm{GW}(20 \%) \text { of current fleet available at low cost }\left(\$ 25 / \mathrm{MWh}_{\mathrm{e}} \text { equivalent) }\right. \\
\text { Additional } 40 \mathrm{GW}(40 \%) \text { available at moderate cost }(\$ 40 / \mathrm{MWh} \text { equivalent) }\end{array}$} \\
\hline $\begin{array}{l}\text { HTE capital } \\
\text { costs }\end{array}$ & $\$ 820 / \mathrm{kW}$ & \multicolumn{4}{|l|}{$\$ 423 / \mathrm{kW}$} \\
\hline $\begin{array}{l}\text { LTE capital } \\
\text { costs }\end{array}$ & $\$ 900 / \mathrm{kW}$ & \multicolumn{2}{|l|}{$\$ 400 / \mathrm{kW}$} & $\$ 200 / \mathrm{kW}$ & $\$ 100 / \mathrm{kW}$ \\
\hline $\begin{array}{l}\text { LDE market } \\
\text { assumption }\end{array}$ & \multicolumn{3}{|c|}{ Available at retail price } & $\begin{array}{l}\text { Available at } \\
\text { price between } \\
\text { retail and } \\
\text { wholesale }\end{array}$ & $\begin{array}{l}\text { Available at } \\
\text { wholesale } \\
\text { price }\end{array}$ \\
\hline $\begin{array}{l}\text { Metals } \\
\text { demand }\end{array}$ & $\begin{array}{l}\text { Must } \\
\text { compete with } \\
\text { existing } \\
\text { technologies }\end{array}$ & \multicolumn{4}{|c|}{$\begin{array}{l}\text { Markets are willing to pay a premium for metals refined using } \\
\text { hydrogen }\end{array}$} \\
\hline $\begin{array}{l}\text { Distribution } \\
\text { for FCEVs }\end{array}$ & $\begin{array}{l}\text { Current } \\
\text { costs }\end{array}$ & \multicolumn{4}{|c|}{ Hydrogen and Fuel Cell Technologies Office cost targets met } \\
\hline $\begin{array}{l}\text { Other } \\
\text { demands }\end{array}$ & \multicolumn{5}{|c|}{$\begin{array}{l}\text { Expected demand growth based on competition with other technologies as described } \\
\text { in Section } 3 .\end{array}$} \\
\hline
\end{tabular}




\subsection{Aggregated Demand Curves}

The total potential domestic hydrogen market is based on estimated demand from the following applications: oil refining, metals refining, ammonia, biofuels, synthetic $\mathrm{HC}$ (methanol and MTG), natural gas supplementation, light-duty FCEVs, medium- and heavy-duty FCEVs, and seasonal energy storage for the electrical grid. We aggregate the potential demand quantities and draw on the estimated threshold prices from Section 3 to develop national hydrogen demand curves for our five scenarios.

Table 21 summarizes hydrogen demand and assumed price points for each scenario. The price points are primarily based on the analysis in Section 3, except for metals in some cases. In all scenarios except Reference, we assume a premium for metals refined using hydrogen, therefore increasing the price at which they become economically competitive to $\$ 2.50 / \mathrm{kg}$. Variations in prices for seasonal electricity storage are due to the differences in natural gas price assumptions. To reiterate the discussion in Section 3, the demand curve price points do not represent the actual prices paid for hydrogen in each market, but rather estimate the "threshold price" for hydrogen in these markets based on the hydrogen price to compete with other options or the lack of a lowcost alternative. In addition, for the FCEV applications, the values are the price estimates for what the market is willing to pay without including distribution costs (as discussed in Section 3.8 ); thus, retail prices are the sum of the prices reported and distribution costs.

Table 21. Summary of Hydrogen Demand Price Points and Cumulative Annual Quantities for H2@Scale Scenarios

\begin{tabular}{|c|c|c|c|c|c|}
\hline Demand & Reference & $\begin{array}{l}\text { R\&D } \\
\text { Advances + } \\
\text { Infrastructure }\end{array}$ & $\begin{array}{l}\text { Low NG } \\
\text { Resource/ } \\
\text { High NG } \\
\text { Price }\end{array}$ & $\begin{array}{l}\text { Aggressive } \\
\text { Electrolysis } \\
\text { R\&D }\end{array}$ & $\begin{array}{l}\text { Lowest- } \\
\text { Cost } \\
\text { Electrolysis }\end{array}$ \\
\hline Oil refining & \multicolumn{5}{|l|}{$7.5 \mathrm{MMT}$ at $\$ 3.00 / \mathrm{kg}$} \\
\hline Metals refining & $\begin{array}{l}4 \mathrm{MMT} \text { at } \$ 1.70 / \mathrm{kg} \\
12 \mathrm{MMT} \text { at } \$ 0.80 / \mathrm{kg}\end{array}$ & $\begin{array}{l}4 \mathrm{MMT} \text { at } \\
\$ 2.50 / \mathrm{kg} \\
12 \mathrm{MMT} \text { at } \\
\$ 0.80 / \mathrm{kg}\end{array}$ & \multicolumn{3}{|c|}{$\begin{array}{l}4 \mathrm{MMT} \text { at } \$ 2.50 / \mathrm{kg} \\
12 \mathrm{MMT} \text { at } \$ 1.40 / \mathrm{kg}\end{array}$} \\
\hline Ammonia & \multicolumn{5}{|l|}{$\begin{array}{l}2.5 \mathrm{MMT} \text { at } \$ 3.00 / \mathrm{kg} \\
3.6 \mathrm{MMT} \text { at } \$ 2.00 / \mathrm{kg}\end{array}$} \\
\hline Biofuels & \multicolumn{5}{|l|}{$8.7 \mathrm{MMT}$ at $\$ 3.00 / \mathrm{kg}$} \\
\hline $\begin{array}{l}\text { Synthetic HC } \\
\text { (methanol) }\end{array}$ & \multicolumn{5}{|l|}{$6.0 \mathrm{MMT}$ at $\$ 1.73 / \mathrm{kg}$} \\
\hline $\begin{array}{l}\text { Synthetic HC } \\
\text { (MTG) }\end{array}$ & \multicolumn{5}{|l|}{$8.0 \mathrm{MMT}$ at $\$ 0.00 / \mathrm{kg}$} \\
\hline Natural gas & \multicolumn{2}{|l|}{$16 \mathrm{MMT}$ at $\$ 0.80 / \mathrm{kg}$} & \multicolumn{3}{|c|}{$16 \mathrm{MMT}$ at $\$ 1.40 / \mathrm{kg}$} \\
\hline $\begin{array}{l}\text { Light-duty } \\
\text { FCEVs }\end{array}$ & $0 \mathrm{MMT}^{\mathrm{a}}$ & \multicolumn{4}{|c|}{$11.7 \mathrm{MMT}$ at $\$ 2.20 / \mathrm{kg}^{\mathrm{b}}$} \\
\hline $\begin{array}{l}\text { Medium- \& } \\
\text { heavy-duty } \\
\text { FCEVs }\end{array}$ & $0 \mathrm{MMT}^{\mathrm{a}}$ & \multicolumn{4}{|c|}{$5.2 \mathrm{MMT}$ at $\$ 2.20 / \mathrm{kg}^{\mathrm{b}}$} \\
\hline
\end{tabular}




\begin{tabular}{|l|l|l|l|l|l|}
\hline Demand & Reference & $\begin{array}{l}\text { R\&D } \\
\text { Advances + } \\
\text { Infrastructure }\end{array}$ & $\begin{array}{l}\text { Low NG } \\
\text { Resource/ } \\
\text { High NG } \\
\text { Price }\end{array}$ & $\begin{array}{l}\text { Aggressive } \\
\text { Electrolysis } \\
\text { R\&D }\end{array}$ & $\begin{array}{l}\text { Lowest- } \\
\text { Cost } \\
\text { Electrolysis }\end{array}$ \\
\hline $\begin{array}{l}\text { Seasonal } \\
\text { electricity } \\
\text { storage }\end{array}$ & $\begin{array}{l}48 \mathrm{MMT} \text { at } \$ 0.57 / \mathrm{kg} \\
52 \mathrm{MMT} \text { at } \$ 0.55 / \mathrm{kg}\end{array}$ & $\begin{array}{l}14 \mathrm{MMT} \text { at } \$ 1.10 / \mathrm{kg} \\
15 \mathrm{MMT} \text { at } \$ 0.26 / \mathrm{kg}\end{array}$ \\
\hline
\end{tabular}

Hydrogen quantities are the cumulative demand at each price point.

a The Reference scenario assumes no FCEV hydrogen demand due to the high current costs of delivery and dispensing (see Section 3.8).

b Price does not include intra-city delivery and distribution costs. The equivalent price at the pump is $\$ 5.03 / \mathrm{kg}$. Details are provided in Section 3.8.

The aggregated demand curves for each scenario are shown in Figure 24. All scenarios assume the same level of hydrogen demand (18.7 MMT/yr) for applications with a high willingness to pay of $\$ 3.00 / \mathrm{kg}$ (for oil refining, existing ammonia production, and biofuels). The Reference scenario assumes no hydrogen demand for FCEVs, and the hydrogen for metals production is driven only by economics. All other scenarios assume that markets would pay a premium for metals refined with hydrogen, so the demand curves show an additional 4 MMT/yr of demand at $\$ 2.50 / \mathrm{kg}$ for metals (compared to $\$ 1.70 / \mathrm{kg}$ in the Reference scenario). All the non-Reference scenarios also assume 16.9 MMT/yr of hydrogen demand for FCEV applications, at $\$ 2.20 / \mathrm{kg}$. Demand in the R\&D Advances + Infrastructure scenario is equal to demand in the Low NG Resource/High NG Price, Aggressive Electrolysis R\&D, and Lowest-Cost Electrolysis scenarios at prices above $\$ 1.40 / \mathrm{kg}$, but below that price the demand varies due to differences in assumed natural gas prices, which affect the threshold prices for hydrogen for injection into the natural gas system, additional metals production, and seasonal energy storage. Demands between hydrogen uses that provide the same social service (e.g., oil refining and direct hydrogen use for transportation) are not assumed to impact the cumulative market sizes, because additional products are assumed to be exported. For example, the independent demand for refining is 7.5 $\mathrm{MMT} / \mathrm{yr}$, and the independent demand for FCEVs is $16.9 \mathrm{MMT} / \mathrm{yr}$. In scenarios with the hydrogen price low enough to include both demands, we estimate the cumulative quantity of hydrogen to be 24.4 MMT/yr, because - consistent with the methods in Elgowainy et al. (2020) — excess refining products are exported. 


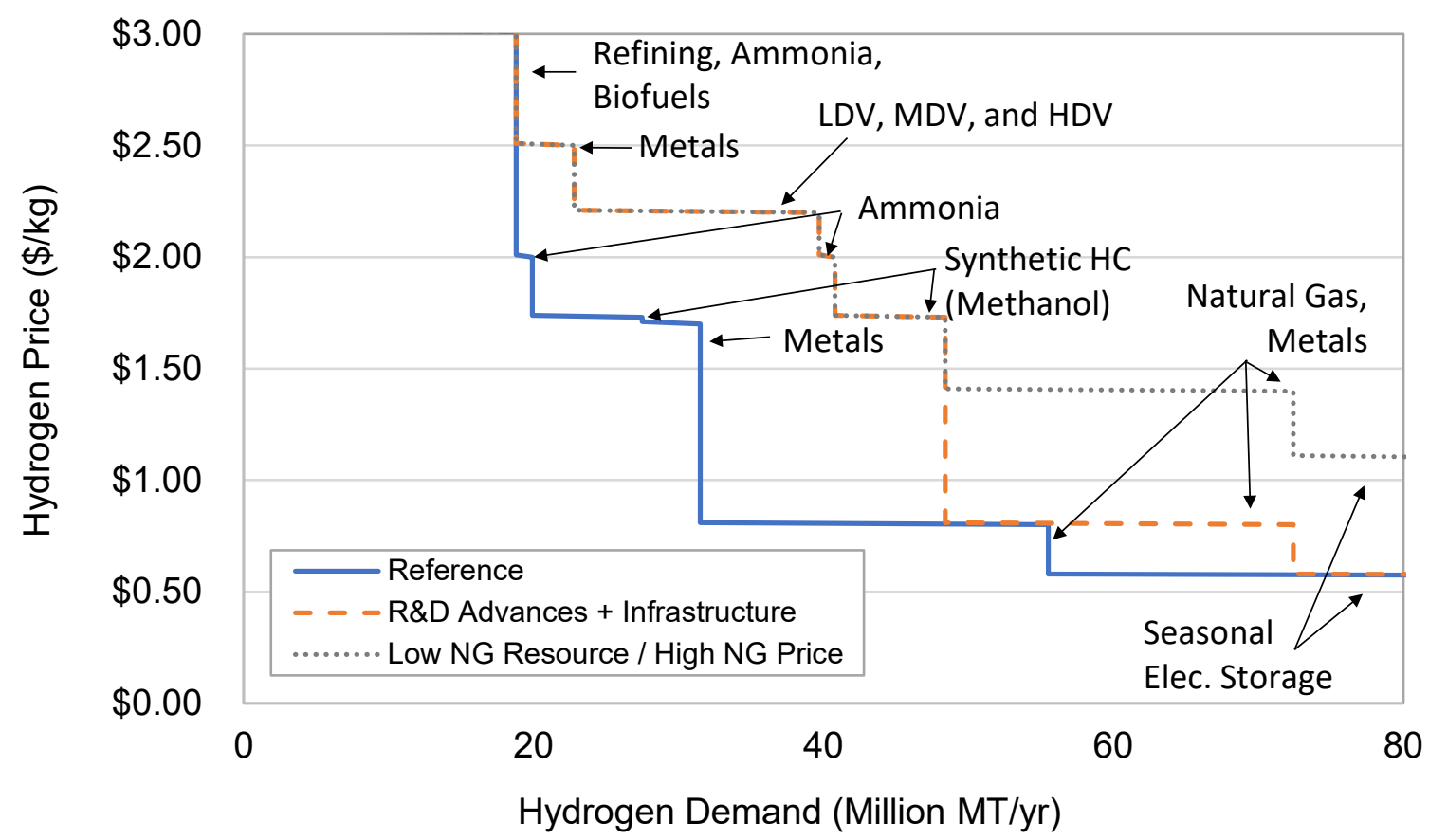

Figure 24. Aggregated demand curves for H2@Scale scenarios

The Aggressive Electrolysis R\&D and Lowest-Cost Electrolysis scenarios assume the same demand curve as the Low NG Resource/High NG Price scenario.

LDV, MDV, and HDV prices do not include intra-city delivery and distribution costs. The equivalent price at the pump is $\$ 5.03 / \mathrm{kg}$. Details are provided in Section 3.8 .

\subsection{Aggregated Supply Curves}

We develop aggregated national supply curves for the five scenarios based on the estimates for SMR-, HTE-, and LTE-produced hydrogen presented in Section 4. Supply curves for biomass gasification are included in the economic potential sensitivities (Section 6.8), and we do not include potential coal supply curves because of the higher costs of coal gasification compared to other production technologies as discussed in Section 4.5. Table 22 summarizes the hydrogen price points and quantities for each scenario. Each scenario's description and key assumptions are provided in Table 20 above. Price points include delivery from centralized production to industrial-scale demands where appropriate and to city-gate terminals when distribution is required as reported in Section 4.1. SMR price points differ across scenarios based on natural gas assumptions: the Reference and R\&D Advances + Infrastructure scenarios use AEO Reference natural gas price projections, while the other scenarios assume higher natural gas prices consistent with the AEO LOGR case. We also estimate varying prices and quantities for LTE, owing to assumed LTE capital costs and LDE market access (and natural gas prices for the bulk power system, as described in Section 4.2). The Lowest-Cost Electrolysis scenario has the most favorable assumptions on cost and LDE market access, resulting in the lowest price point. 
Table 22. Summary of Hydrogen Maximum Supply Price Points and Corresponding Annual Cumulative Quantities for H2@Scale Scenarios

\begin{tabular}{|c|c|c|c|c|c|}
\hline Supply & Reference & $\begin{array}{l}\text { R\&D } \\
\text { Advances + } \\
\text { Infrastructure }\end{array}$ & $\begin{array}{l}\text { Low NG } \\
\text { Resource/ } \\
\text { High NG } \\
\text { Price }\end{array}$ & $\begin{array}{l}\text { Aggressive } \\
\text { Electrolysis } \\
\text { R\&D }\end{array}$ & $\begin{array}{l}\text { Lowest-Cost } \\
\text { Electrolysis }\end{array}$ \\
\hline $\begin{array}{l}\text { SMR (including } \\
\text { for ammonia } \\
\text { production) }\end{array}$ & \multicolumn{2}{|c|}{$\begin{array}{l}\text { Current capacity of existing SMR } \\
\text { facilities: } 10.3 \mathrm{MMT} \text {, at } \$ 1.75 / \mathrm{kg} \text { (based } \\
\text { on census division) } \\
\text { Future capacity of SMR facilities: } 27.6 \\
\text { MMT, at } \$ 1.88 / \mathrm{kg} \text { (based on census } \\
\text { division) }\end{array}$} & \multicolumn{3}{|c|}{$\begin{array}{l}\text { Current capacity of existing SMR facilities: } \\
10.3 \mathrm{MMT} \text {, at } \$ 2.68 / \mathrm{kg} \text { (based on census } \\
\text { division) } \\
\text { Future capacity of SMR facilities: } 27.6 \mathrm{MMT} \text {, } \\
\text { at } \$ 2.81 / \mathrm{kg} \text { (based on census division) }\end{array}$} \\
\hline $\begin{array}{l}\text { HTE with } \\
\text { nuclear heat }\end{array}$ & $\begin{array}{l}3.8 \mathrm{MMT} \text { at } \$ 2.30 / \mathrm{kg} \\
11.5 \mathrm{MMT} \text { at } \$ 2.97 / \mathrm{kg} \\
\text { New builds at } \$ 4.73 / \mathrm{kg}\end{array}$ & \multicolumn{4}{|c|}{$\begin{array}{l}4.2 \mathrm{MMT} \text { at } \$ 1.68 / \mathrm{kg} \\
12.6 \mathrm{MMT} \text { at } \$ 2.28 / \mathrm{kg} \\
\text { New builds at } \$ 3.88 / \mathrm{kg}\end{array}$} \\
\hline LTE & $60 \mathrm{MMT}$ at $\$ 4.04 / \mathrm{kg}$ & $\begin{array}{l}60 \mathrm{MMT} \text { at } \\
\$ 3.54 / \mathrm{kg}\end{array}$ & $\begin{array}{l}60 \mathrm{MMT} \text { at } \\
\$ 3.51 / \mathrm{kg}\end{array}$ & $\begin{array}{l}60 \mathrm{MMT} \text { at } \\
\$ 2.74 / \mathrm{kg}\end{array}$ & $\begin{array}{l}60 \mathrm{MMT} \text { at } \\
\$ 2.09 / \mathrm{kg}\end{array}$ \\
\hline
\end{tabular}

Hydrogen quantities are the cumulative supply at each price point. Since the LTE values are on a curve, only the maximum point is reported in this table.

Hydrogen prices represent the price at a city-edge terminal and include a delivery adder in addition to production costs: $\$ 0.12 / \mathrm{kg}$ for SMR (short-distance transmission) and $\$ 0.39 / \mathrm{kg}$ for electrolysis and biomass (long-distance transmission).

The top panel of Figure 25 compares the supply curves for the Reference and R\&D Advances + Infrastructure scenarios. At hydrogen prices below around $\$ 1.70 / \mathrm{kg}$, the supply curves for these scenarios are equivalent, because SMR makes up all of hydrogen production at lower prices and both scenarios have the same SMR technology assumptions. Above $\$ 1.70 / \mathrm{kg}$, the supply curves diverge primarily due to lower HTE capital cost assumptions in the R\&D Advances + Infrastructure scenario (LTE supply does not show up in either supply curve at prices below around $\$ 3.00 / \mathrm{kg}$ ). At prices between $\$ 1.70 / \mathrm{kg}$ and $\$ 3.00 / \mathrm{kg}, 4-10 \mathrm{MMT} / \mathrm{yr}$ more hydrogen are available from HTE in the R\&D Advances + Infrastructure scenario compared with the Reference scenario. At prices over $\$ 3.00 / \mathrm{kg}$, LTE hydrogen production growths exponentially in the R\&D Advances + Infrastructure scenario (and at a price around $\$ 4.00 / \mathrm{kg}$ in the Reference scenario).

The Low NG Resource/High NG Price, Aggressive Electrolysis R\&D, and Lowest-Cost Electrolysis scenarios (bottom panel of Figure 25) include higher natural gas prices assumptions, and more optimistic technology assumptions in Aggressive Electrolysis R\&D and Lowest-Cost Electrolysis. Compared with the R\&D Advances + Infrastructure scenario, hydrogen prices in the Aggressive Electrolysis R\&D scenario are around $\$ 0.30-\$ 0.70 / \mathrm{kg}$ higher at quantities below around $30 \mathrm{MMT} / \mathrm{yr}$, and similar at quantities around 30-40 MMT/yr. Prices in the Aggressive Electrolysis R\&D scenario are also similar to those in the Low NG Resource/High NG Price 
scenario at quantities below around $25 \mathrm{MMT} / \mathrm{yr}$. As hydrogen quantities rise above $40 \mathrm{MMT} / \mathrm{yr}$, prices in the Aggressive Electrolysis R\&D scenario become increasingly lower compared with prices in the Reference, R\&D Advances + Infrastructure, and Low NG Resource/High NG Price scenarios - as the supply becomes dominated by LTE-produced hydrogen. At hydrogen

quantities above around $32 \mathrm{MMT} / \mathrm{yr}$, prices in the Lowest-Cost Electrolysis scenario are lowest owing to favorable LTE economics in that scenario. Below $32 \mathrm{MMT} / \mathrm{yr}$, LTE hydrogen in the Lowest-Cost Electrolysis scenario is price-competitive with SMR in the Reference and R\&D Advances + Infrastructure scenarios. 

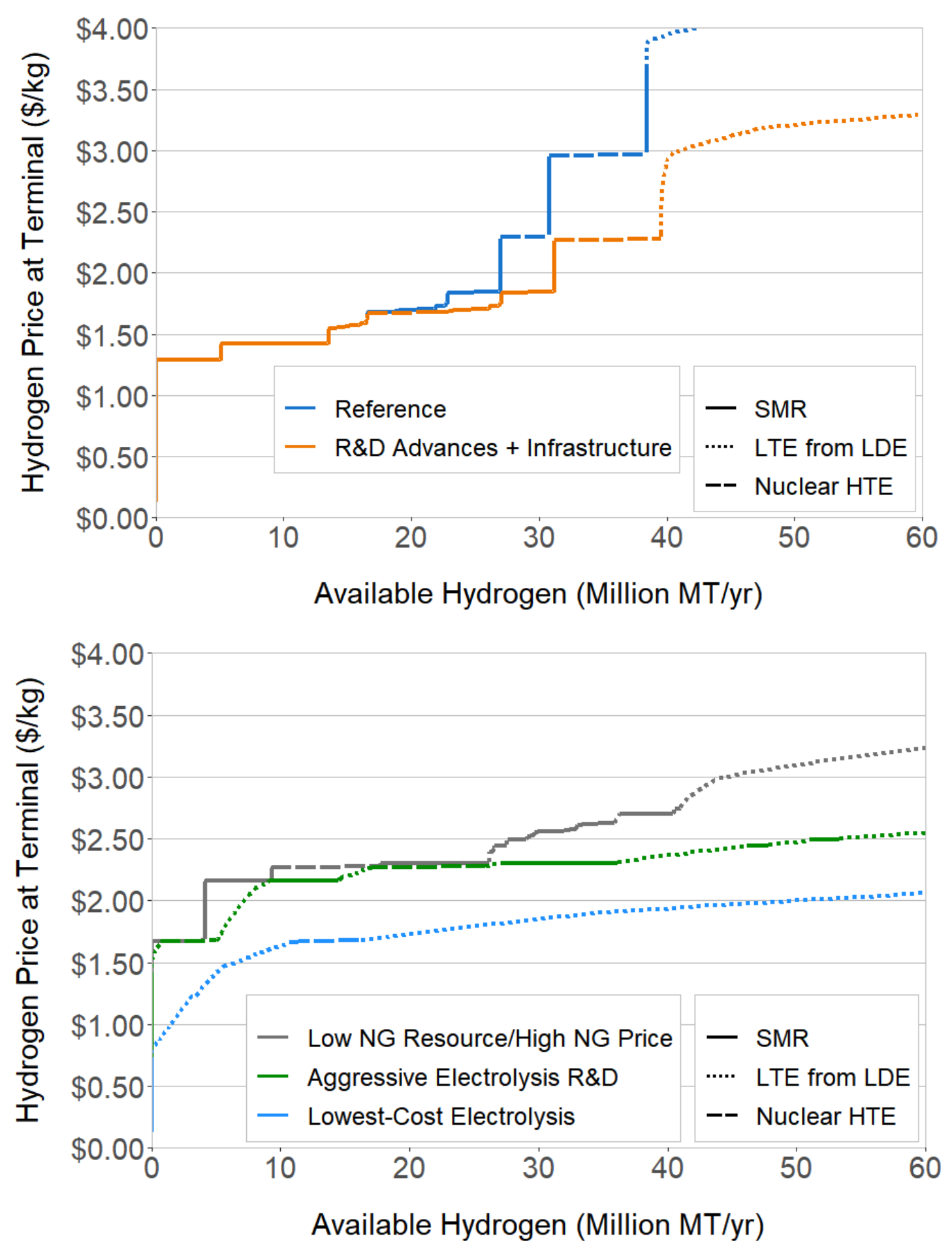

Figure 25. Aggregated supply curves for Reference and R\&D Advances + Infrastructure scenarios (top), and Low NG Resource/High NG Price, Aggressive Electrolysis R\&D, and Lowest-Cost Electrolysis scenarios (bottom)

Hydrogen price represents the price available at a city-edge terminal. 


\subsection{Economic Potential Results}

We plot the demand and supply curves from Sections 6.2 and 6.3 for each of the five scenarios to calculate each scenario's economic equilibrium, as discussed in Section 2.2. We use the supply and demand curve intersection points to estimate the domestic hydrogen market size and its wholesale price.

The intersection points identify the technologies used to produce the hydrogen in each scenario as well as the applications using hydrogen. We estimate the impact on primary energy use and emissions as the difference between our scenarios and the alternative providing the same products and energy as described in Section 2.3. Figure 26 shows each scenario's supply and demand curves and their intersections.

The wholesale hydrogen price estimate is not intended to be used as a target or expected market price. Instead, it indicates the price at which hydrogen could be produced to meet potential uses in a market at equilibrium. Markets are seldom at equilibrium, so a mature market's actual price could easily be higher or lower. Markets under transition (i.e., growing or shrinking) are unlikely to be at equilibrium prices, because the factors that cause change in market size impact prices.

Likewise, many parameters impact market equilibrium. For example, the lower-cost natural gas feedstock and increased demands in the R\&D Advances + Infrastructure scenario result in larger market sizes, because the cost to produce hydrogen is lower. Because so many parameters impact the market equilibrium and its quantity and price, and because the methodology is discrete, minor changes in assumptions could impact the actual market equilibrium estimated here.

Table 23 (page 67) reports the resulting supplies and demand applications for each scenario. The market size ranges from 22-41 MMT/yr of hydrogen across the five scenarios. There is no demand for synthetic MTG fuel production, injection into the natural gas system, or seasonal electricity storage in any of the scenarios, because the threshold prices for all of these applications are too low for hydrogen to outcompete other options for those applications.

In the Reference scenario, the hydrogen demands include today's demands plus some growth in biofuels and synthetic methanol production. Today's primary markets (oil refining and ammonia production) constitute $11 \mathrm{MMT} / \mathrm{yr}$. An additional $9 \mathrm{MMT} / \mathrm{yr}$ of hydrogen go to biofuels production, because the biofuels threshold price is high; we assume that mandates, rather than hydrogen price, will drive this demand (see Section 3.4). The remaining $2 \mathrm{MMT} / \mathrm{yr}$ of demand are for methanol. All of the hydrogen is produced via SMR of natural gas, even though the SMR capacity must be doubled to meet that demand as discussed in Section 4.1.

The R\&D Advances + Infrastructure scenario results in a larger market compared to the Reference scenario owing to increased demands from FCEVs and metals refining and to lowercost hydrogen production via HTE at nuclear power plants. FCEVs account for $8 \mathrm{MMT} / \mathrm{yr}$ of growth (5.8 MMT/yr for light-duty FCEVs and 2.6 MMT/yr for medium- and heavy-duty FCEVs), and metals account for $4 \mathrm{MMT} / \mathrm{yr}$ of growth, while demand for ammonia decreases by $1 \mathrm{MMT} / \mathrm{yr}$, and the $2 \mathrm{MMT} / \mathrm{yr}$ for methanol disappear.

The SMR production cost is higher in the Low NG Resource/High NG Price scenario because of higher natural gas prices, resulting in economic equilibrium at a smaller market size: $23 \mathrm{MMT} / \mathrm{yr}$ 
in the Low NG Resource/High NG Price scenario versus $31 \mathrm{MMT} / \mathrm{yr}$ in the R\&D Advances + Infrastructure scenario. The entire $8 \mathrm{MMT} / \mathrm{yr}$ reduction is due to the disappearance of FCEV demands. Non-SMR production technologies also become more cost-competitive, resulting in 13 MMT/yr of hydrogen production from nuclear HTE.

In the Aggressive Electrolysis R\&D scenario, we assume a lower purchase price for LTE and electricity prices between wholesale and retail, resulting in $8 \mathrm{MMT} / \mathrm{yr}$ of hydrogen produced via LTE at less than $\$ 2.30 / \mathrm{kg}$. The demands are the same in this scenario as in the Low NG Resource/High NG Price scenario.

The hydrogen market is largest in the Lowest-Cost Electrolysis scenario, at $41 \mathrm{MMT} / \mathrm{yr}$. In this scenario, further reductions in the LTE purchase price allow electrolytic hydrogen to be more competitive than natural gas SMR. The resulting aggregated hydrogen production price is low enough to meet the full demand for FCEVs at $\$ 2.20 / \mathrm{kg}$, and the full demand for current and future ammonia production. Because hydrogen produced via LTE is lower cost than the higherextension-cost HTE, it displaces some production from HTE (compared with the Aggressive Electrolysis R\&D scenario).

Natural gas price assumptions have the largest impact on the supply curves, with higher prices driving the curves up and reducing the equilibrium market size. Reducing the LTE capital costs from $\$ 400 / \mathrm{kW}$ to $\$ 200 / \mathrm{kW}$ partially overcomes higher natural gas prices. When the LTE capital costs drop to $\$ 100 / \mathrm{kW}$ and wholesale LDE prices are assumed, this effect more than offsets the higher natural gas prices. The lowest-cost fraction of HTE using nuclear energy is competitive with SMR and LTE at both natural gas prices. The higher-cost fractions of HTE using nuclear energy are competitive at lower natural gas prices, and are also competitive at higher natural gas prices, unless there are favorable conditions for LTE, in which cases LTE is lower cost than the higher-cost fractions of HTE. A sensitivity analysis on these scenario assumptions is included in Section 6.8. 

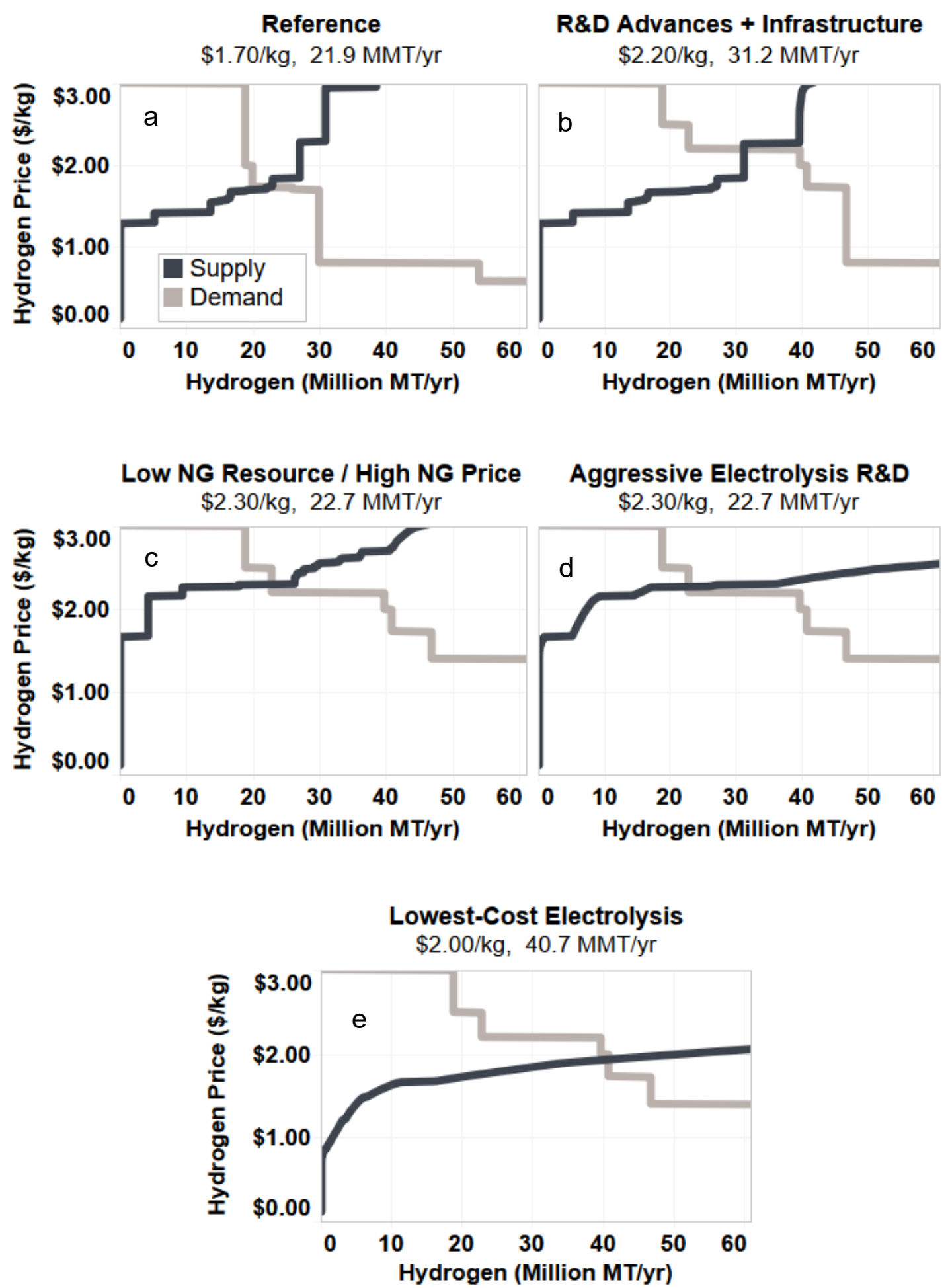

Figure 26. Supply and demand curves for the (a) Reference, (b) R\&D Advances + Infrastructure, (c) Low NG Resource/High NG Price, (d) Aggressive Electrolysis R\&D, and (e) Lowest-Cost Electrolysis scenarios

Hydrogen price represents the price available at a city-edge terminal. 
Table 23. Hydrogen Supply Sources and Demand Applications for Each Scenario (MMT/yr)

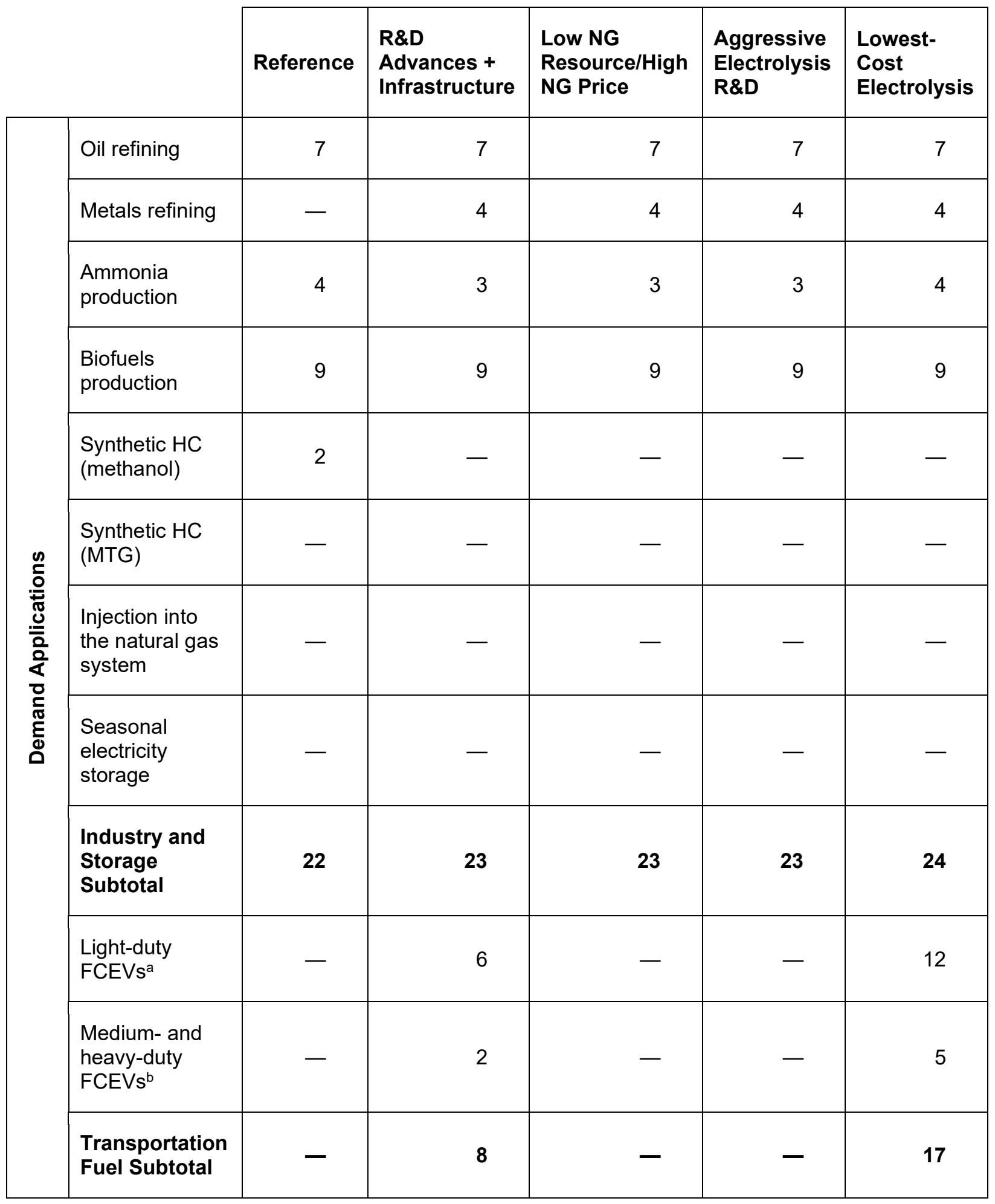




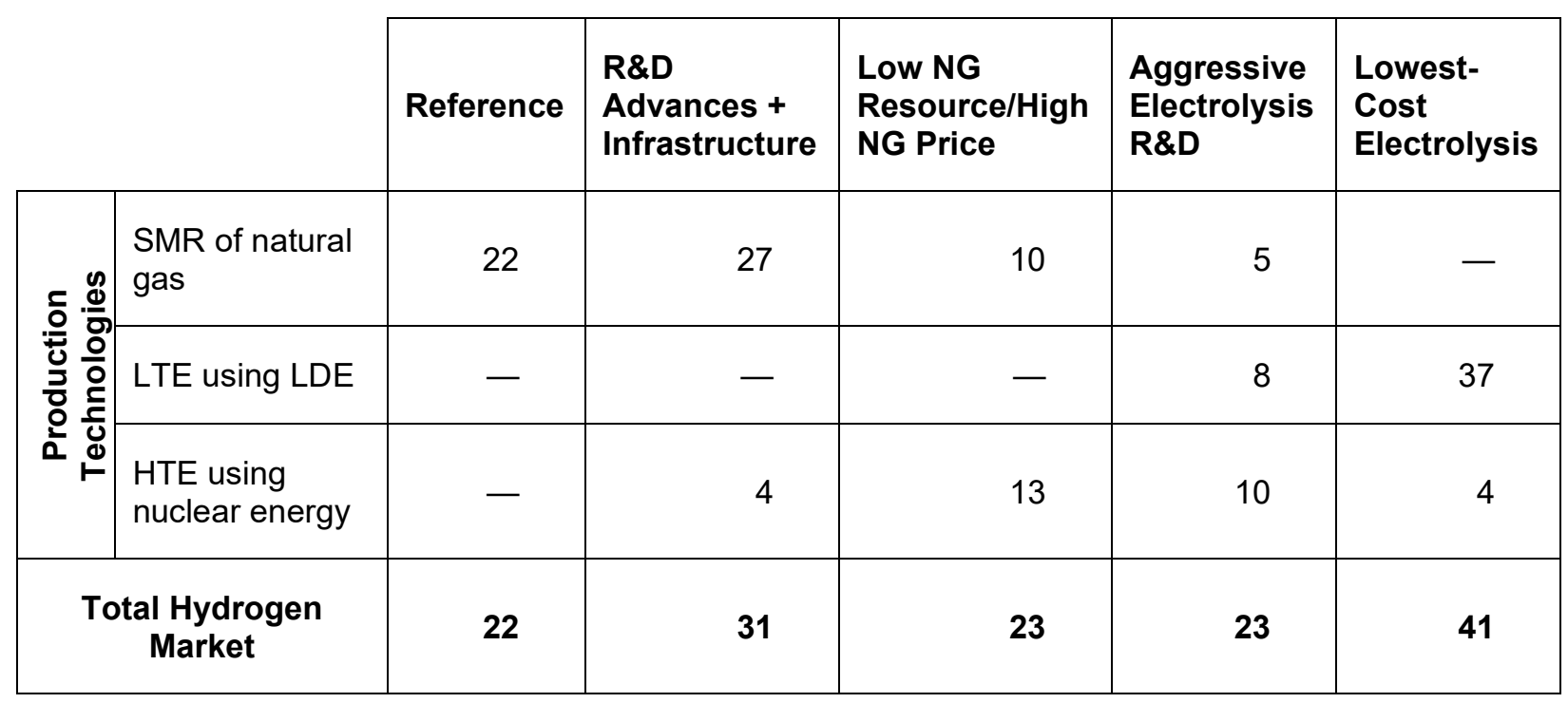

Oil refining is rounded from 7.5 MMT/yr to $7 \mathrm{MMT} / \mathrm{yr}$ and medium- and heavy-duty FCEV is rounded from 2.6 MMT/yr to $2 \mathrm{MMT} / \mathrm{yr}$ in this table so that the total and subtotals match the sum of the rounded values

a The penetrations of FCEVs in the light-duty car stock are $8 \%$ and $18 \%$, and the penetrations of FCEVs in the lightduty truck stock are $13 \%$ and $26 \%$ for the R\&D Advances + Infrastructure and Lowest-Cost Electrolysis scenarios, respectively.

b The penetrations of FCEVs in the MDV and HDV stock are 11\% and 22\% for the R\&D Advances + Infrastructure and Lowest-Cost Electrolysis scenarios, respectively.

The market size estimates for all of our economic scenarios are between the Roadmap to a U.S. Hydrogen Economy (2020) demand potential estimates for 2050, and our serviceable consumption potential is higher than the Roadmap's estimates (Table 24). Because the Roadmap aggregates some of the values differently than we did, we disaggregate them to be consistent with our categories. Both studies indicate that hydrogen is likely to continue to be used for oil refining, ammonia production, and methanol production for the chemicals market. Both show that production of methanol for MTG would require technology development or policies that are outside the scope of each analysis. Both analyses also identify metals refining as an economically viable market in the optimistic scenarios (Roadmap's Aggressive scenario and our Lowest-Cost Electrolysis scenario). The use of hydrogen for FCEVs is limited in both analyses' more conservative scenarios, but it appears in the more aggressive scenarios. However, the Roadmap's Aggressive scenario has a much higher penetration (27 MMT/yr) than our LowestCost Electrolysis scenario (17 MMT/yr) owing to our limitation on hydrogen availability at the equilibrium price. The Roadmap's Aggressive scenario's results include hydrogen as fuel for buildings and industry (shown as injection into the natural gas system in the table), but our results do not, because the Roadmap includes potential policy drivers that are outside our scope. The Roadmap also differs from our analysis by including seasonal electricity storage, again owing to differences in policy assumptions. 
Table 24. Comparison of Hydrogen Market Sizes (MMT/yr) between the Roadmap to a U.S. Hydrogen Economy (2020) and Our H2@Scale Analysis

\begin{tabular}{|c|c|c|c|c|c|c|}
\hline & \multirow{3}{*}{$\begin{array}{l}\text { Roadmap } \\
\text { Base } \\
\text { Scenario } \\
2050 \\
\text { Demand } \\
8\end{array}$} & \multirow{3}{*}{$\begin{array}{l}\text { Roadmap } \\
\text { Aggressive } \\
\text { Scenario } \\
2050 \text { Demand } \\
8\end{array}$} & & & \\
\hline & & & & \multirow{2}{*}{$\begin{array}{r}\text { H2@Scale } \\
\text { Reference } \\
7\end{array}$} & \multirow{2}{*}{$\begin{array}{l}\text { H2@Scale } \\
\text { Lowest-Cost } \\
\text { Electrolysis } \\
7\end{array}$} & \multirow{2}{*}{$\begin{array}{l}\text { H2@Scale } \\
\text { Serviceable } \\
\text { Consumption } \\
\text { Potential } \\
7\end{array}$} \\
\hline \multirow{10}{*}{ 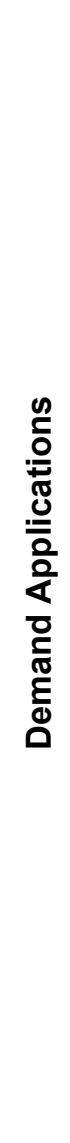 } & Oil refining & & & & & \\
\hline & Metals refining & - & 3 & - & 4 & 12 \\
\hline & $\begin{array}{l}\text { Ammonia } \\
\text { production }\end{array}$ & 5 & $5^{a}$ & 4 & 4 & 4 \\
\hline & $\begin{array}{l}\text { Biofuels } \\
\text { production }\end{array}$ & 1 & $1^{\mathrm{a}}$ & 9 & 9 & 9 \\
\hline & $\begin{array}{l}\text { Synthetic HC } \\
\text { (methanol) } \\
\text { production }\end{array}$ & 2 & 2 & 2 & - & 6 \\
\hline & $\begin{array}{l}\text { Synthetic HC } \\
\text { (MTG) } \\
\text { production }\end{array}$ & - & - & - & - & 8 \\
\hline & $\begin{array}{l}\text { Injection into the } \\
\text { natural gas } \\
\text { system }\end{array}$ & - & 13 & - & - & 16 \\
\hline & $\begin{array}{l}\text { Seasonal } \\
\text { electricity } \\
\text { storage }\end{array}$ & 1 & 4 & - & - & 15 \\
\hline & $\begin{array}{l}\text { Industry and } \\
\text { Storage } \\
\text { Subtotal }\end{array}$ & 17 & 36 & 22 & 24 & 77 \\
\hline & $\begin{array}{l}\text { Transportation } \\
\text { Fuel }\end{array}$ & 3 & 27 & - & 17 & 29 \\
\hline \multicolumn{2}{|c|}{ Total Hydrogen Market } & 20 & 63 & 22 & 41 & 106 \\
\hline
\end{tabular}

Oil refining in the H2@Scale columns is rounded from 7.5 MMT/yr to $7 \mathrm{MMT} / \mathrm{yr}$ in this table so that the total and subtotals match the sum of the rounded values.

a Does not include additional potential upside from other uses.

\subsection{Impacts on the Electric Grid}

Using LDE to produce hydrogen impacts the grid's optimal generation mix, because it provides an additional revenue stream to generators that produce electricity at times when supply exceeds demand. If the market will pay for the LDE instead of letting it be curtailed, the annual income for those generators increases, investment in them becomes more viable, and - in some situations - such investments result in generators being built that would not have been built without the LDE value. We use the ReEDS and PLEXOS models to estimate the impacts of LDE value on the generator mix and subsequent generation, as described in Section 4.2. 
Table 25 reports the LDE price for each scenario and the resulting impacts on the electric grid. The first row (electricity generation that exceeds load) reports the total electrical energy generated annually that exceeds the loads estimated for the industrial, buildings, and transportation sectors (reported as the sum of generation for load, hydrogen, and curtailment minus the generation for load alone). Generation exceeds load in all cases, because the least-cost solution in ReEDS is for non-dispatchable generators (wind and PV) to produce excess electricity during some hours. We define LDE as the electrical energy that exceeds projected buildings, industrial, and electric vehicle loads. With higher hydrogen market prices and improved LTE technologies, the quantity of LDE increases, because it is competitive with other hydrogen-generation options and other options to provide the same energy services. The secondto-last row in Table 25 reports the price that LTEs pay for the LDE in each scenario. Because not all of the LDE is available all hours of the year, we estimate an optimal capacity factor and utilization of LDE that results in the lowest-cost hydrogen.

No hydrogen is produced via LTE in the Reference, R\&D Advances + Infrastructure, or Low NG Resource/High NG Price scenarios. Because the electrolyzer equipment cost is lower in the Aggressive Electrolysis R\&D scenario, and the price of LDE is assumed to be lower due to electrolyzers providing ancillary services, LTE-produced hydrogen becomes cost-competitive and provides $8 \mathrm{MMT} / \mathrm{yr}$ to the market. To meet that demand, $400 \mathrm{TWh} / \mathrm{yr}$ of LDE are required and, owing to the optimal LDE utilization factor, $790 \mathrm{TWh} / \mathrm{yr}$ of excess electricity are generated (16\% greater than the load without the LDE). The LTEs pay a weighted average of $\$ 17 / \mathrm{MWh}$ for that LDE, varying regionally across the price range. At the lower LTE equipment costs in the Lowest-Cost Electrolysis scenario, LTE-produced hydrogen is more competitive, and thus the scenario includes $37 \mathrm{MMT} / \mathrm{yr}$ of LTE-produced hydrogen from 1,800 TWh/yr of electricity; electricity generation increases to $45 \%$ greater than the industrial, buildings, and transportation loads. 
Table 25. Impacts of H2@Scale Scenarios on the Electric Grid

\begin{tabular}{|c|c|c|c|c|c|}
\hline & Reference & $\begin{array}{c}\text { R\&D } \\
\text { Advances + } \\
\text { Infrastructure }\end{array}$ & $\begin{array}{l}\text { Low NG } \\
\text { Resource/ } \\
\text { High NG } \\
\text { Price }\end{array}$ & $\begin{array}{c}\text { Aggressive } \\
\text { Electrolysis } \\
\text { R\&D }\end{array}$ & $\begin{array}{l}\text { Lowest-Cost } \\
\text { Electrolysis }\end{array}$ \\
\hline $\begin{array}{l}\text { Electricity } \\
\text { generation that } \\
\text { exceeds load } \\
\text { (TWh/yr) }\end{array}$ & 80 & 80 & 200 & 790 & 2,300 \\
\hline $\begin{array}{l}\text { Percentage of } \\
\text { electricity } \\
\text { generation that } \\
\text { exceeds load } \\
\text { (annual basis) }\end{array}$ & $2 \%$ & $2 \%$ & $4 \%$ & $16 \%$ & $45 \%$ \\
\hline $\begin{array}{l}\text { LDE used to } \\
\text { produce hydrogen } \\
\text { (TWh/yr) }\end{array}$ & - & - & - & 400 & 1,800 \\
\hline $\begin{array}{l}\text { LDE wholesale } \\
\text { average price }^{a} \\
\text { [range across } \\
\text { regions] (\$/MWh) }\end{array}$ & $\mathrm{N} / \mathrm{A}$ & N/A & $\mathrm{N} / \mathrm{A}$ & $\begin{array}{c}\$ 17 \\
{[\$ 0-\$ 21]}\end{array}$ & $\begin{array}{c}\$ 25 \\
{[\$ 0-\$ 26]}\end{array}$ \\
\hline $\begin{array}{l}\text { Average capacity } \\
\text { factor of LDE used } \\
\text { to produce } \\
\text { hydrogen }{ }^{\text {[range }} \\
\text { across regions] }\end{array}$ & $\mathrm{N} / \mathrm{A}$ & $\mathrm{N} / \mathrm{A}$ & $\mathrm{N} / \mathrm{A}$ & $\begin{array}{c}50 \% \\
{[10 \%-80 \%]}\end{array}$ & $\begin{array}{c}54 \% \\
{[10 \%-75 \%]}\end{array}$ \\
\hline
\end{tabular}

a Weighted by hydrogen production

Figure 27 and Figure 28 show the impacts of LTE hydrogen production using electricity generation capacity and wind and PV generation, respectively. Because it uses LDE, LTE hydrogen production provides an additional income stream that drives additional investment in wind capacity and, to a lesser extent, PV capacity. That additional capacity can produce some electricity during peak hours, thus reducing the need for natural gas combustion turbines and reducing their capacity. However, most of the increased wind and PV capacity is used to generate hydrogen. For example, total PV and wind generation increases by over 2,000 TWh from the Low NG Resource/High NG Price scenario to the Lowest-Cost Electrolysis scenario (from 3,100 to 5,200 TWh), but the generation to serve load only increases by $180 \mathrm{TWh}$ (Figure 28 ). At above $\$ 25 / \mathrm{MWh}$, the price of LDE begins to approach the LCOE from wind and PV generators in some regions, which increases the proportion of generation to produce hydrogen, because it may be more profitable than producing electricity to serve load. Appendix G includes additional detail on electricity generation and capacity. 


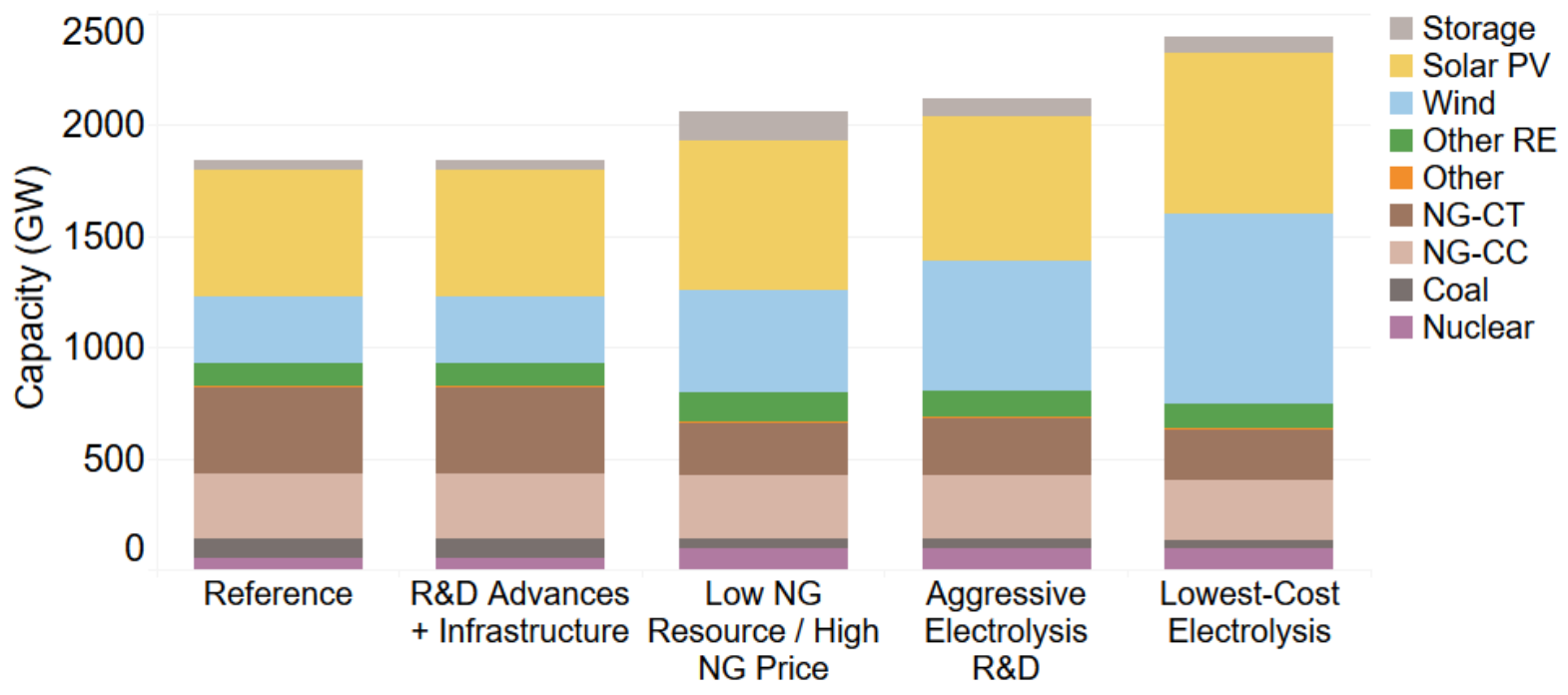

Figure 27. Electricity generation capacities for each scenario

Other RE includes hydropower, geothermal, biopower, CSP, and landfill gas. Other includes oil-gas-steam and imports. The Reference and R\&D Advances + Infrastructure scenarios assume the ReEDS Low RE Cost grid scenario. The other scenarios assume the ReEDS High Curtailment grid scenario.

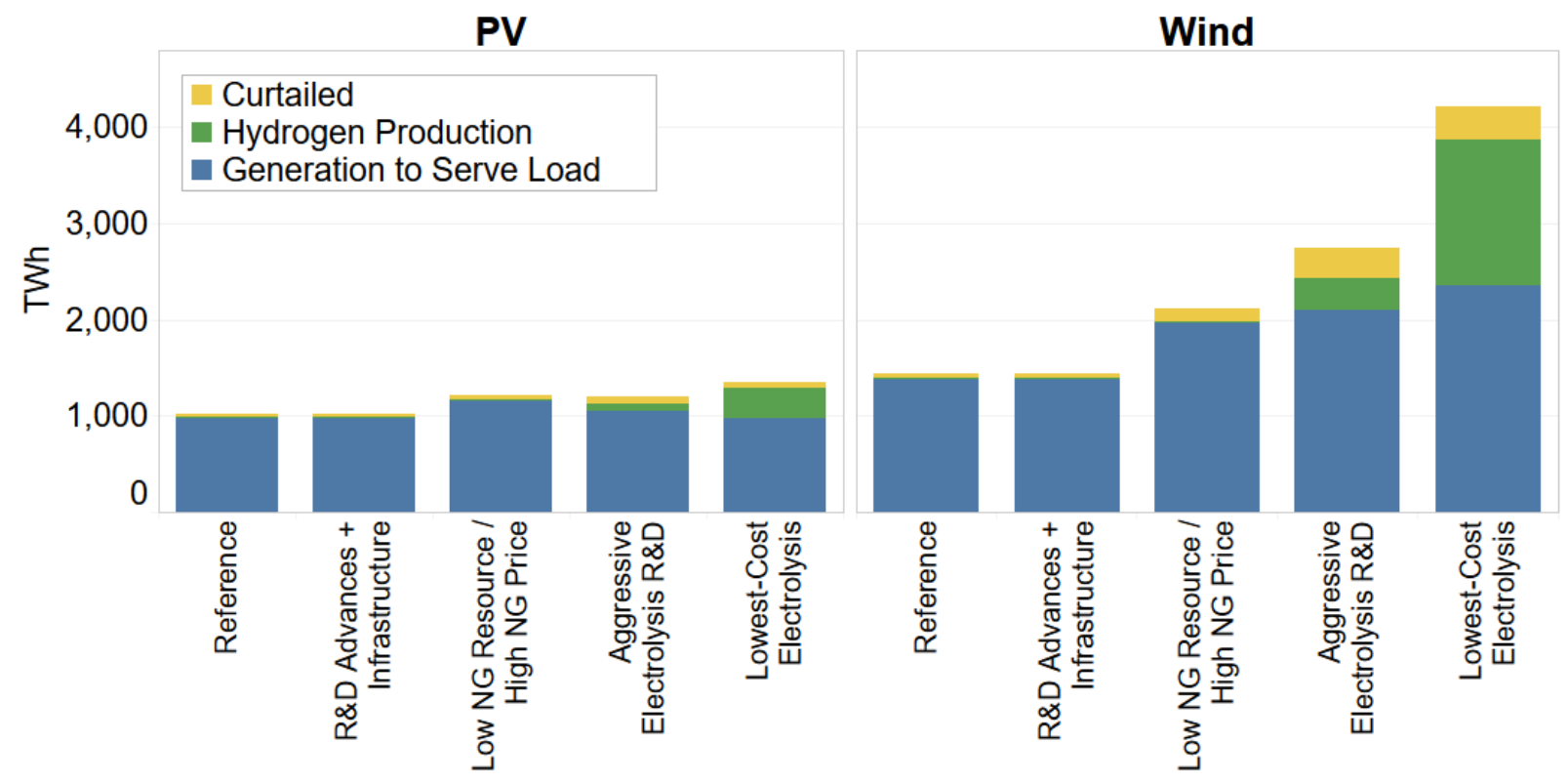

Figure 28. PV and wind generation for each scenario, broken out by load, hydrogen production, and curtailment

Table 26 shows the estimated reductions in emissions and fuel use from a 2050 reference scenario (primarily based on EIA's AEO) for the generation mixes projected in the two ReEDS grid scenarios used for this analysis (described in Section 4.2). The scenarios are shown for an LDE price of $\$ 0 / \mathrm{MWh}$ to provide baselines that exclude impacts from potential hydrogen markets. The emissions and fuel-use reductions for each of our five scenarios (Table 27 in the following section) are compared to the respective baselines shown here. 
Table 26. Emissions and Fuel-Use Reductions due to Estimated Changes in Power Sector without H2@Scale

\begin{tabular}{|l|c|c|c|}
\cline { 2 - 4 } \multicolumn{1}{c|}{} & $\begin{array}{c}\text { 2050 Reference } \\
\text { Scenario }\end{array}$ & $\begin{array}{c}\text { ReEDS Low RE Cost Grid } \\
\text { Scenario with \$0/MWh } \\
\text { LDE Price }\end{array}$ & $\begin{array}{c}\text { ReEDS High Curtailment } \\
\text { Grid Scenario with \$0/MWh } \\
\text { LDE Price }\end{array}$ \\
\cline { 2 - 4 } & $\begin{array}{c}\text { Energy Use and } \\
\text { Emissions }\end{array}$ & \multicolumn{2}{|c|}{$\begin{array}{c}\text { Reductions in Emissions or Energy Use from } \\
\text { 2050 Reference Scenario }\end{array}$} \\
\hline $\begin{array}{l}\text { Nitrogen oxides } \\
\text { (NOx) } \\
\text { (thousand MT) }\end{array}$ & 12,000 & 450 & 940 \\
\hline $\begin{array}{l}\text { Sulfur oxides (SOx) } \\
\text { (thousand MT) }\end{array}$ & 5,000 & 860 & 1,700 \\
\hline $\begin{array}{l}\text { Particles with } \\
\text { diameters 10 } \\
\text { micrometers and } \\
\text { smaller (PM10) } \\
\text { (thousand MT) }\end{array}$ & 3,000 & 60 & 130 \\
\hline $\begin{array}{l}\text { Crude oil } \\
\text { (million barrels) }\end{array}$ & 6,700 & - & 1,400 \\
\hline $\begin{array}{l}\text { Carbon dioxide } \\
\text { (CO) } \\
\text { (million MT) }\end{array}$ & 5,300 & 640 & \\
\hline
\end{tabular}

$\mathrm{CO}_{2}$ and crude oil projections are from AEO 2017 (EIA 2017a). NOx, SO , and PM 10 emissions are 2014 values based on the 2014 National Emissions Inventories Report (EPA 2016).

\subsection{Impacts on the U.S. Energy System}

The H2@Scale concept has the potential to benefit the full U.S. energy system by impacting both energy generation and use. Hence, we develop Sankey diagrams that describe the energy system (Walter 2009), and we compare those without H2@Scale to those for each of our five H2@Scale scenarios. This section discusses those Sankey diagrams and quantifies potential impacts on key energy system metrics including fossil energy use, petroleum use, and electricity generation quantity and mix. Appendix $\mathrm{H}$ includes additional Sankey diagrams for all scenarios and comparisons.

Figure 29 provides a baseline for comparison to the H2@Scale scenarios developed in this report. It is a Sankey diagram showing the U.S. estimated energy use in 2050 for the ReEDS Low RE Cost scenario (the AEO Reference Case with electricity generation modified to match the ReEDS Low RE Cost grid scenario's results discussed in Section 4.2). The energy input for electricity generation from solar, wind, and geothermal is reported as the avoided fossil energy generation to be consistent with the methodology used for other Sankey diagrams (EIA, n.d.). ${ }^{63}$ The annual U.S. fossil energy use is $78 \mathrm{quad} / \mathrm{yr}$. This scenario does not include any of the

\footnotetext{
${ }^{63}$ For example, the line showing solar generation of 9.5 quad/yr represents $3.5 \mathrm{quad} / \mathrm{yr}$ of solar generation but is reported at $9.5 \mathrm{quad} / \mathrm{yr}$ to be on the same basis as fossil energy inputs. The conversion assumes an efficiency of $37 \%$, which is the average efficiency of fossil generation in AEO. The difference (6.1 quad/yr) is included in rejected energy from electricity generation.
} 
hydrogen estimates discussed in this report, so only the current hydrogen use of $1.7 \mathrm{quad} / \mathrm{yr}$ of natural gas to produce $1.3 \mathrm{quad} / \mathrm{yr}$ hydrogen is shown. In this case, hydrogen generation requires $1.5 \%$ of the annual U.S. primary energy demand.

Figure 30 and Figure 31 show results for the Reference scenario and differences between it and the ReEDS Low RE Cost scenario, respectively. In the Reference scenario, petroleum use decreases $2.3 \mathrm{quad} / \mathrm{yr}$, while natural gas use increases $2.1 \mathrm{quad} / \mathrm{yr}$, resulting in a small reduction (0.2 quad/yr) in fossil energy use. In Figure 31, black lines indicate where values in the

Reference scenario exceed those in the ReEDS Low RE Cost scenario, and red lines indicate the opposite. It has no lines where the values in the Reference and ReEDS Low RE Cost scenarios are the same. Increased biofuel penetration reduces the petroleum demand, but it also increases both the quantity of hydrogen and biomass to the transportation sector, because the conversion of biomass to fuel is reported within the transportation sector. The hydrogen market of $22 \mathrm{MMT} / \mathrm{yr}$ is $(3.0 \mathrm{quad} / \mathrm{yr})$ is $2.6 \%$ of the primary energy use of $115 \mathrm{quad} / \mathrm{yr}$. All hydrogen in the Reference scenario is produced via SMR of natural gas, so natural gas demand grows.

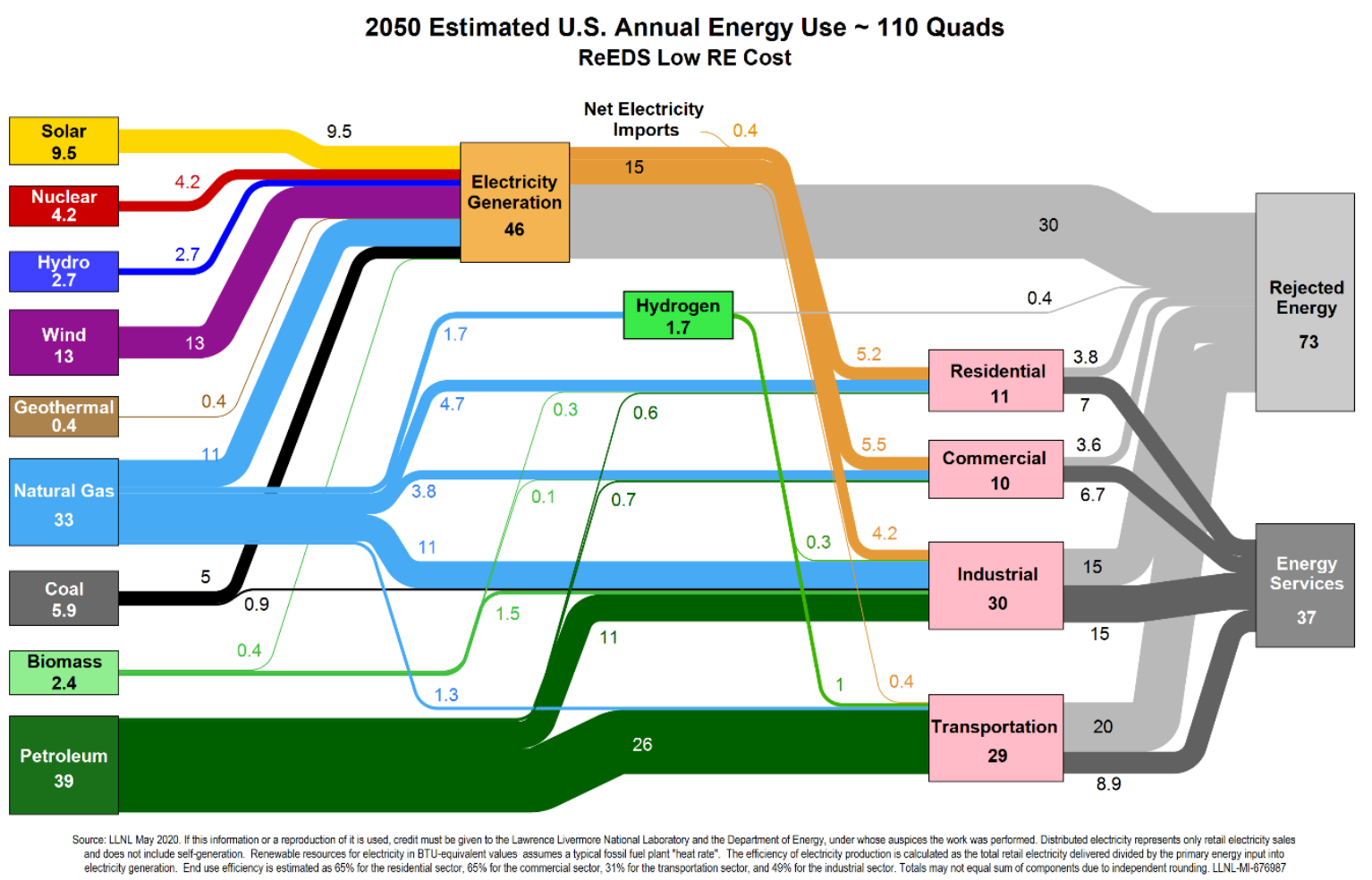

Figure 29. Energy-use Sankey diagram for the ReEDS Low RE Cost scenario 
2050 Estimated U.S. Annual Energy Use 115 Quads

Reference

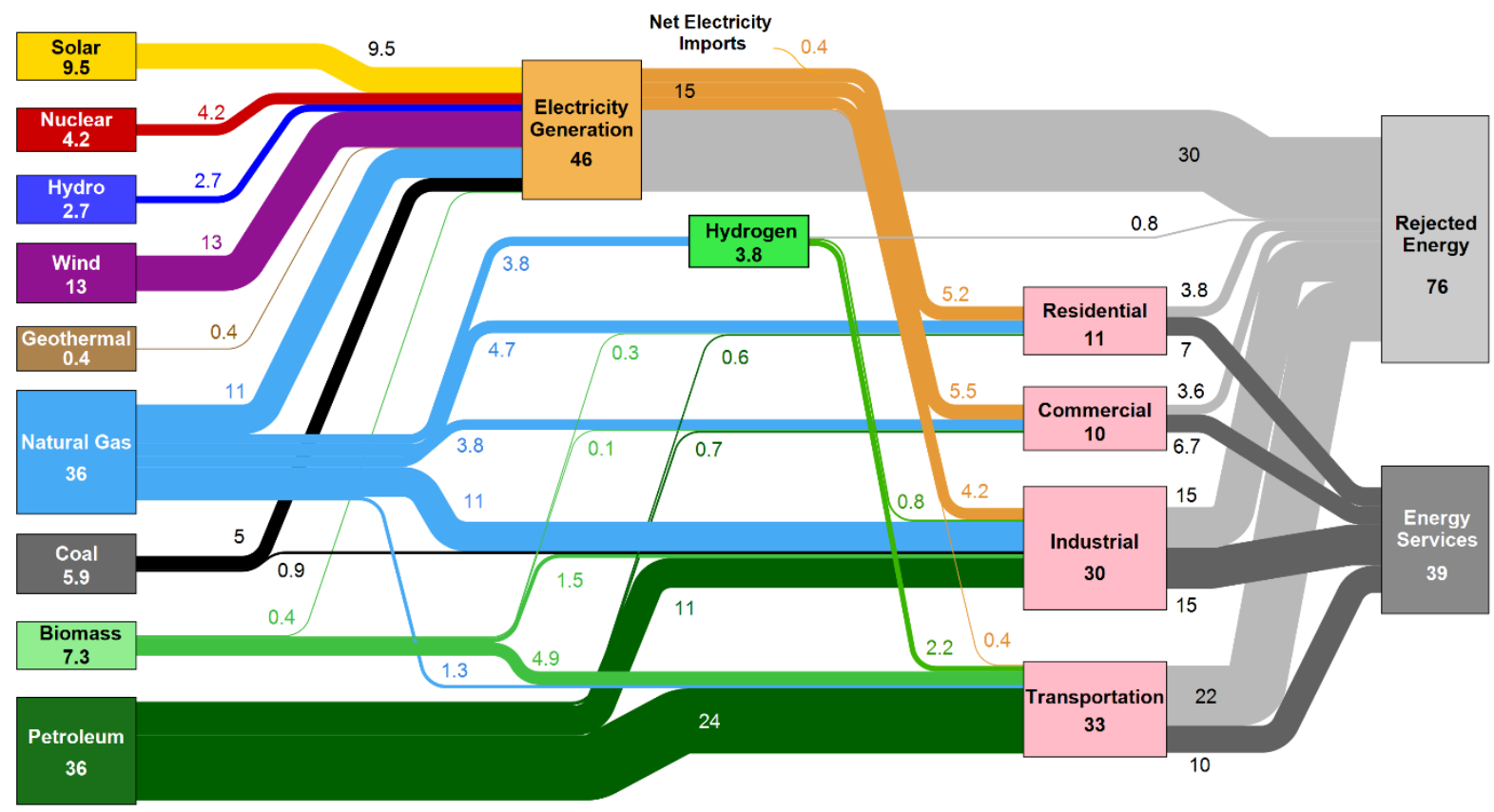

Source: LINL May 2020 . If this information or a reproduction of ti is used, credit must be given to the Lawrence Livermore National Laboratory and the Department of Energy, under whose auspices the work was performed. Distributed electricity represents only retail electricity sales

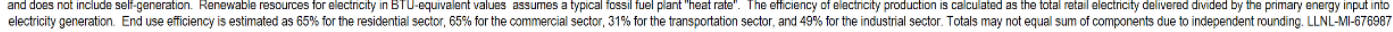

Figure 30. Energy-use Sankey diagram for the Reference scenario

2050 Energy Use Difference Between 'Reference' and 'ReEDS Low RE Cost'

(Quadrillion BTUs)

Note: Boxes represent Reference values

Black Flows indicate Reference uses more energy than ReEDS Low RE Cost

Red Flows indicate ReEDS Low Cost uses more energy than Reference
Ren

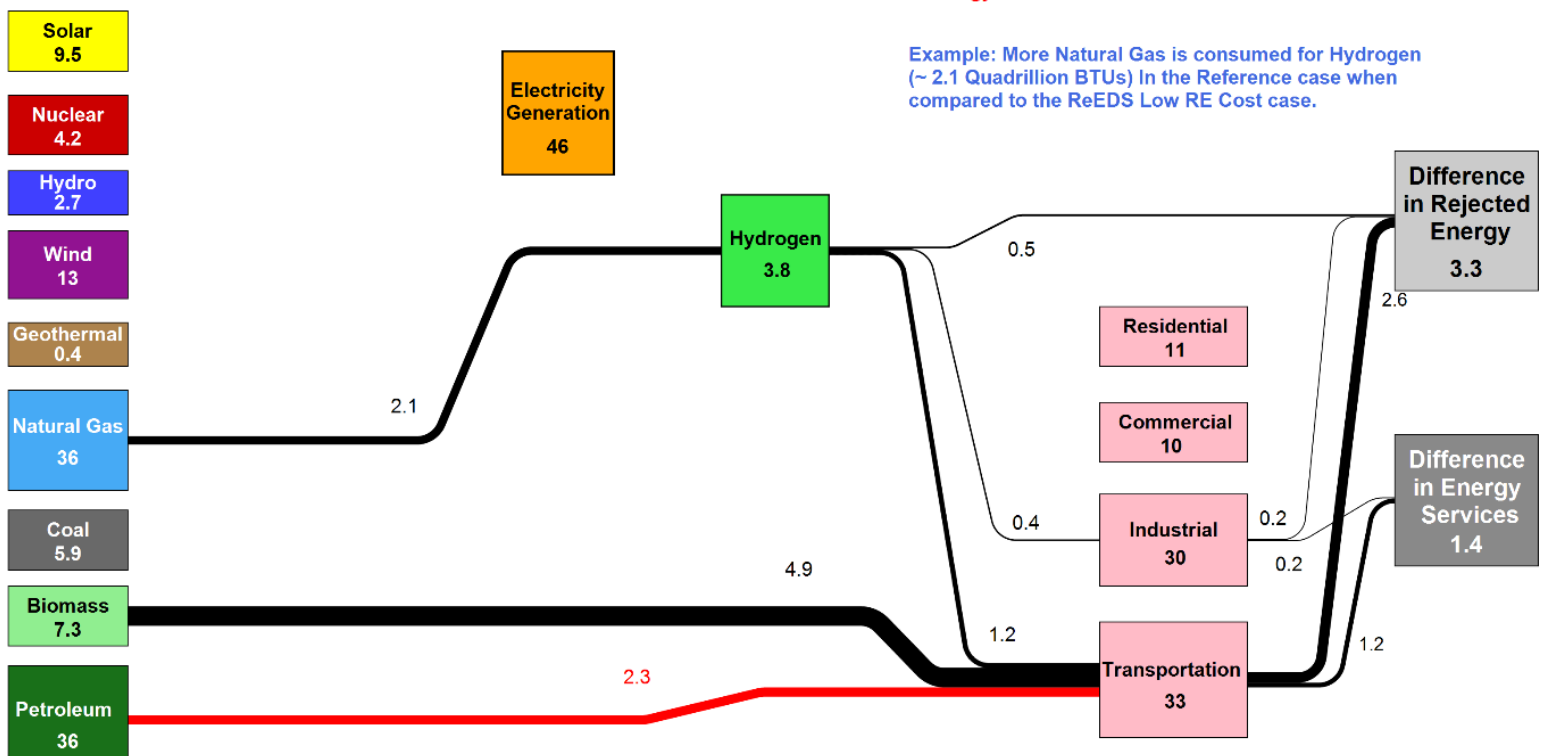

36

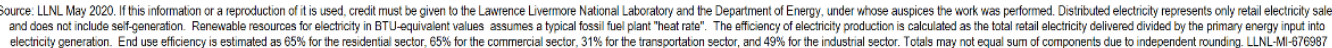

Figure 31. Difference in energy use between the ReEDS Low RE Cost and Reference scenarios, showing reduced petroleum demand due to increased biofuel use 
In the R\&D Advances + Infrastructure scenario, 2 quad/yr of additional petroleum reductions are observed due to increased penetration of FCEVs and increased biofuel use for aviation (Figure 32). Natural gas use also grows owing to higher SMR hydrogen production, and nuclear energy use increases by 1.7 quad/yr to meet the $4 \mathrm{MMT} / \mathrm{yr}$ of hydrogen production from nuclear HTE. The R\&D Advances + Infrastructure scenario results in a 2 quad/yr reduction in fossil energy use.

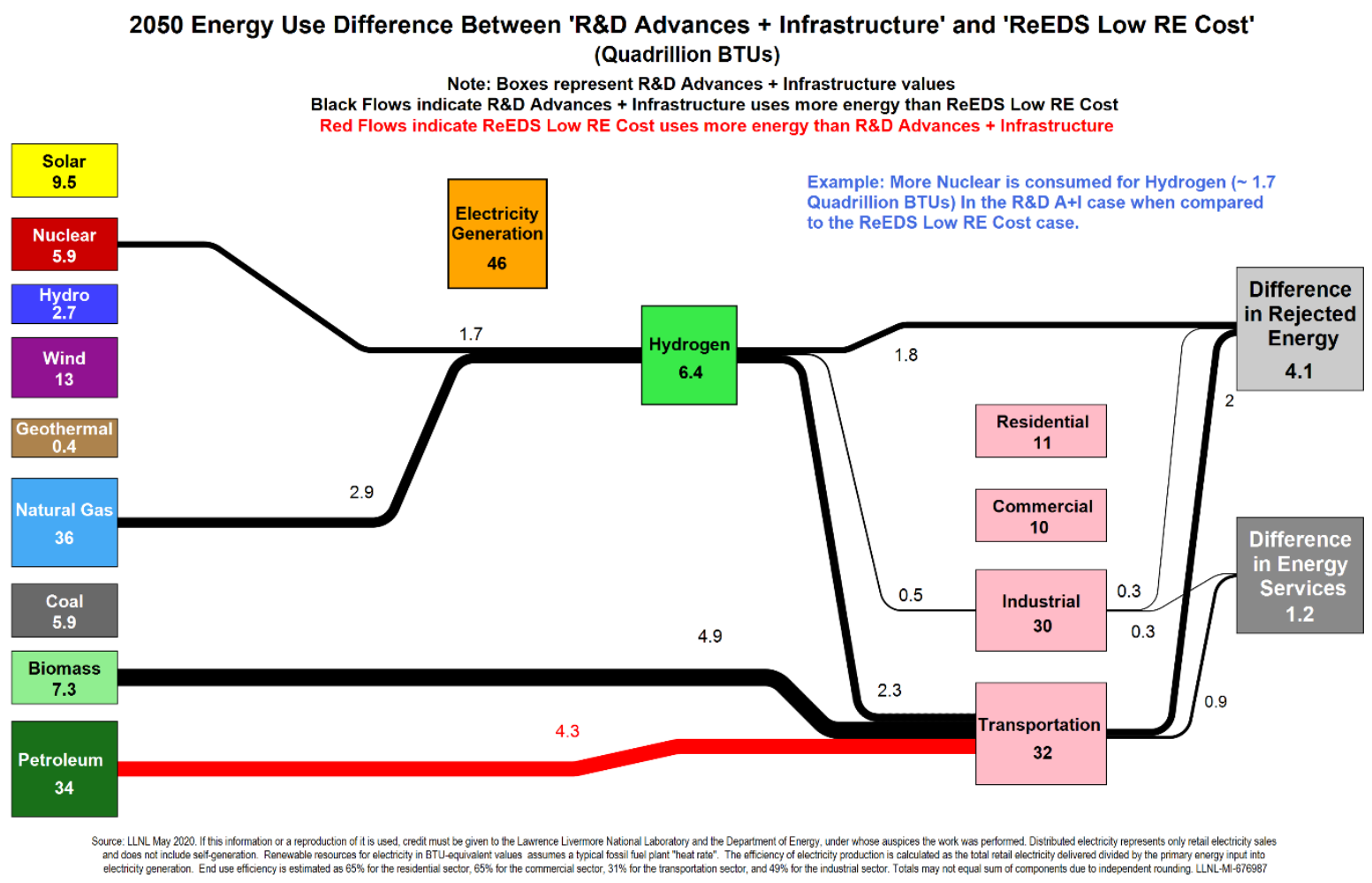

Figure 32. Difference in energy use between the ReEDS Low RE Cost and R\&D Advances + Infrastructure scenarios, showing reduced petroleum demand due to increased FCEV penetrations and increased biofuel use

Analogous to Figure 29, Figure 33 is a baseline for comparison to the other scenarios developed in this report. Specifically, Figure 33 reports the U.S. energy use for the ReEDS High Curtailment scenario, which is based on the AEO LOGR scenario and the corresponding ReEDS High Curtailment grid scenario. Thus, the hydrogen demand and production in Figure 29 and Figure 33 are the same, but the electricity generation mix differs - the total fossil energy use is 65 quad/yr in the ReEDS High Curtailment scenario. The Low NG Resource/High NG Price, Aggressive Electrolysis R\&D, and Lowest-Cost Electrolysis scenarios are all built upon the AEO LOGR scenario, so they are compared to this baseline below.

Figure 34 and Figure 35 are the difference diagrams showing the differences between the ReEDS High Curtailment scenario (Figure 33) and the Low NG Resource/High NG Price scenario and Aggressive Electrolysis R\&D scenario to the ReEDS High Curtailment scenario, respectively. The black lines indicate where the H2@Scale scenario energy flows are greater, and the red lines indicate where the ReEDS High Curtailment scenario flows are greater. In the Low NG Resource/High NG Price scenario, the total nuclear production increases due to avoided 
retirements and the additional nuclear energy is used to produce hydrogen. Because natural gas prices are higher than the Reference scenario, nuclear-generated hydrogen is more economic than hydrogen from natural gas. Biofuel demand increases both the quantity of hydrogen and biomass to the transportation sector, and it reduces the petroleum requirement by 2.3 quad/yr. The total fossil energy demand in the Low NG Resource/High NG Price scenario is 63 quad/yr.

In the aggressive electrolysis R\&D scenario, the total primary energy for electricity generation increases from 47 quad/yr in the ReEDS High Curtailment Scenario to 50 quad/yr owing to the increased use of electricity to produce hydrogen, which includes increased rejected energy from electricity. ${ }^{64}$ Wind generation is higher in the Aggressive Electrolysis R\&D scenario, and solar generation is lower owing to changes in the optimal electricity generation mix caused by increased LDE value - more wind generation is economically built because the corresponding LDE can be sold when generation exceeds load, and that additional wind generation outcompetes solar generation to meet the grid's demands. For the same reasons, less nuclear generation is retired in the economically optimum generator mix. Because hydrogen use for metals refining is expected to offset imports instead of other domestic processes, there is no offset of fossil energy for that purpose in the industrial sector (the hydrogen demand is shown in the scenario's Sankey diagram). The total fossil energy demand in the Aggressive Electrolysis R\&D scenario is 62 quad $/ \mathrm{yr}$, which is $3 \%$ lower than the fossil energy demand in the ReEDS High Curtailment scenario.

Figure 36 shows the Sankey diagram for the Lowest-Cost Electrolysis scenario, and Figure 37 shows the difference compared to the ReEDS High Curtailment scenario (Figure 33). The Lowest-Cost Electrolysis scenario produces the most dramatic energy-use differences among our five scenarios, because it has the largest hydrogen market and the one with the largest quantity of electrolytic hydrogen. The total annual U.S. fossil energy use drops from $78 \mathrm{quad} / \mathrm{yr}$ in the ReEDS Low RE Cost scenario and 65 quad/yr in the ReEDS High Curtailment scenario to 56 quad $/ \mathrm{yr}(28 \%$ and $14 \%$ reductions, respectively). Wind and solar generation increase by 15 and $2.3 \mathrm{quad} / \mathrm{yr}$, respectively, to provide energy for hydrogen production and the grid. The demand for natural gas is reduced by $2.6 \mathrm{quad} / \mathrm{yr}: 1.7 \mathrm{quad} / \mathrm{yr}$ because all the hydrogen production is electrolytic, and 0.9 quad/yr due to increased use of wind and solar to produce electricity. There is a slight increase in coal demand due to improved economics for a small amount of coal generation. At 8 quad/yr, the hydrogen market in the Lowest-Cost Electrolysis scenario is $6.4 \%$ of primary energy. Hydrogen production requires $17 \%$ of primary energy when calculated using an avoided fossil energy generation method. ${ }^{64}$

Appendix H includes the Sankey diagrams for the Low NG Resource/High NG Price scenario and the Aggressive Electrolysis R\&D scenario.

\footnotetext{
${ }^{64}$ Not all of that energy is actually rejected energy, because - for energy input for electricity generation from solar, wind, and geothermal - the Sankey diagrams reports the avoided fossil energy generation to be consistent with the methodology used for other Sankey diagrams.
} 


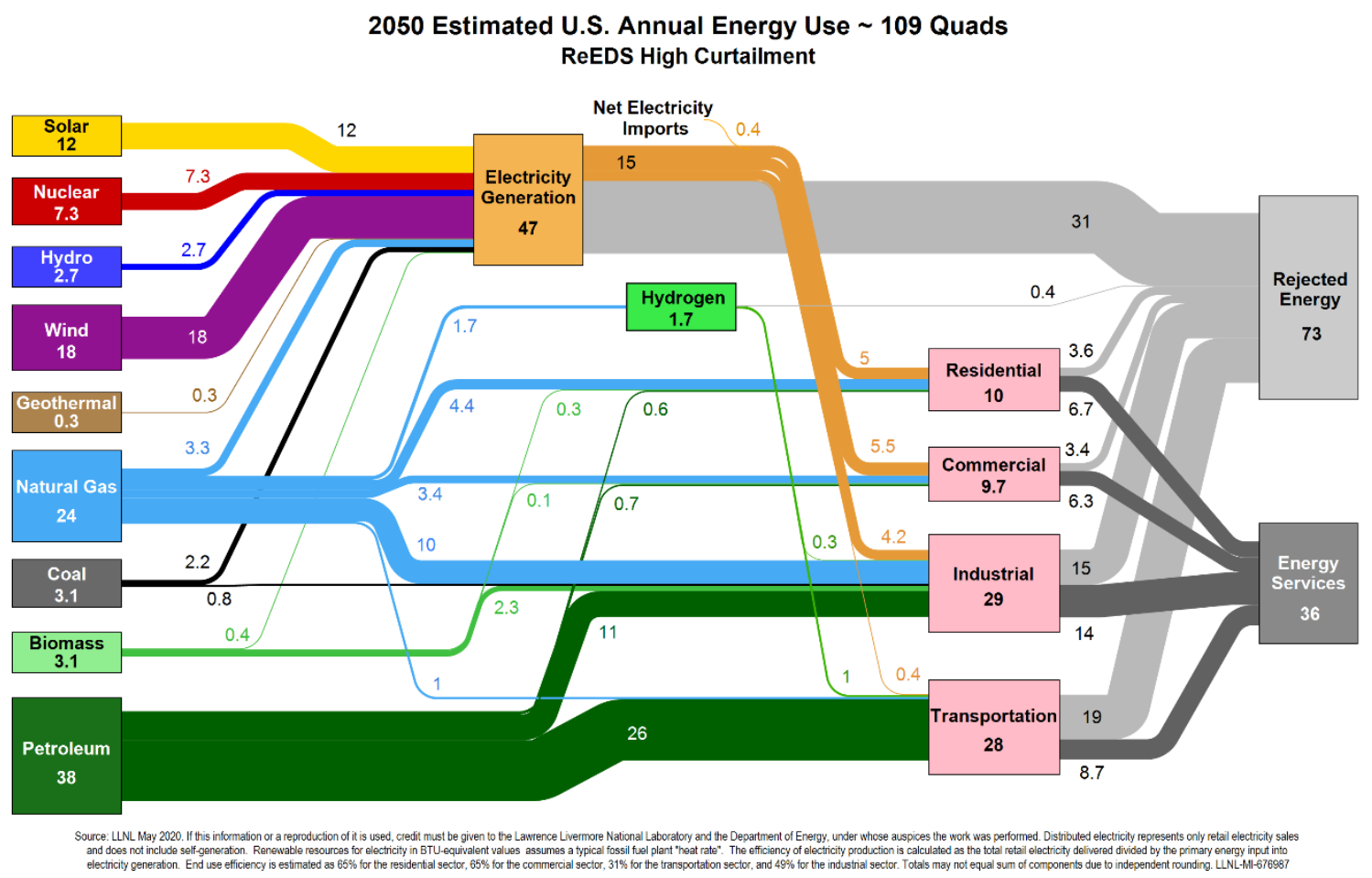

Figure 33. Energy-use Sankey diagram for the ReEDS High Curtailment scenario

2050 Energy Use Difference Between 'Low NG Resource/High NG Price' and 'ReEDS High Curtailment' (Quadrillion BTUs)

Note: Boxes represent Low NG Resource / High NG Price values

Black Flows indicate Low NG Resource / High NG Price uses more energy than ReEDS High Curtailment

Red Flows indicate ReEDS High Curtailment uses more energy than Low NG Resource / High NG Price

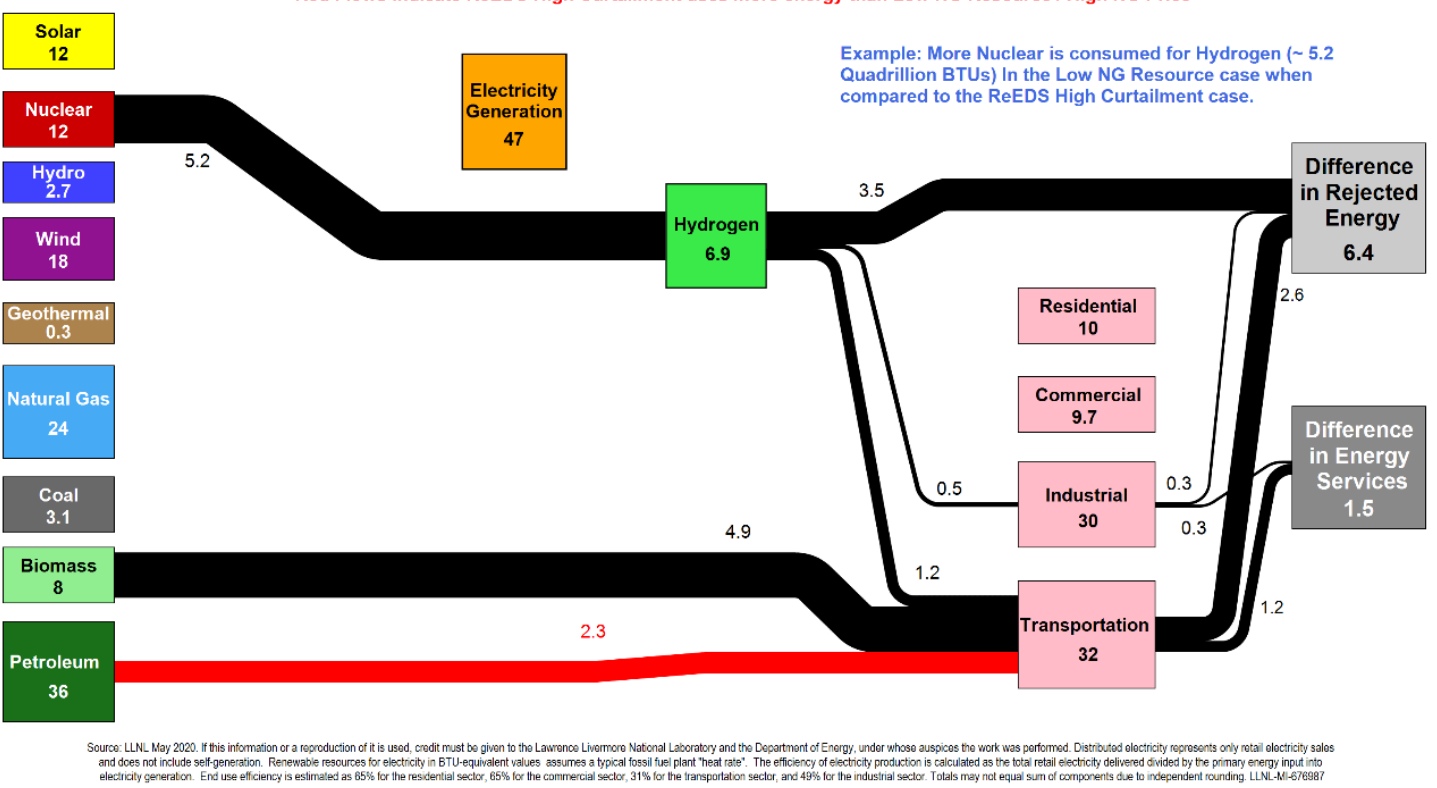

Figure 34. Difference in energy use between the ReEDS High Curtailment and Low NG Resource/High NG Price scenarios 
2050 Energy Use Difference Between 'Aggressive Electrolysis R\&D' and 'ReEDS High Curtailment' (Quadrillion BTUs)

Note: Boxes represent Aggressive Electrolysis R\&D values Black Flows indicate Aggressive Electrolysis R\&D uses more energy than ReEDS High Curtailment Red Flows indicate ReEDS High Curtailment uses more energy than Aggressive Electrolysis R\&D

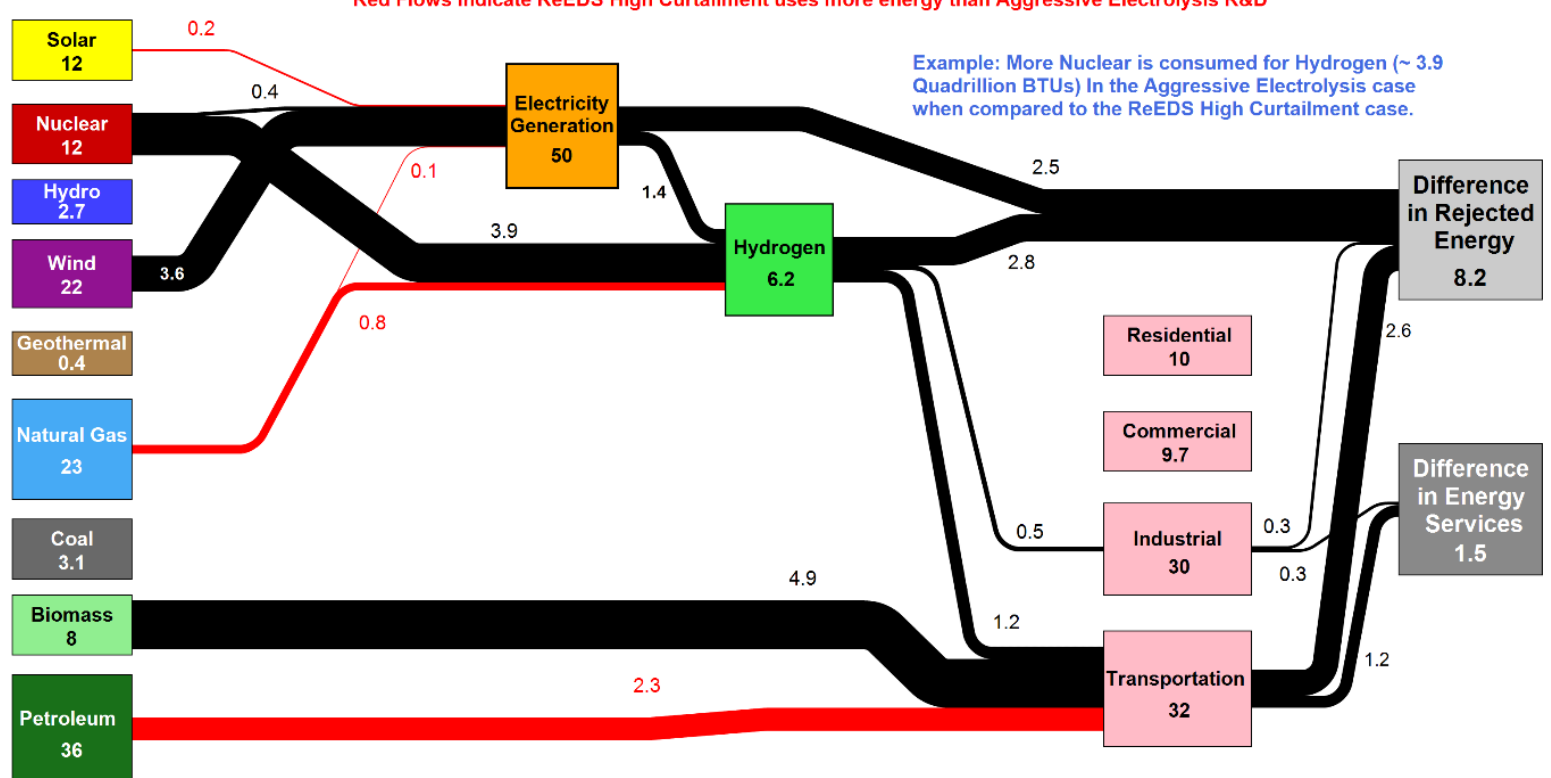

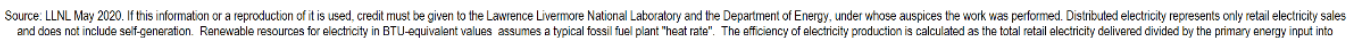

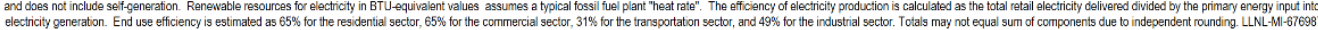

Figure 35. Difference in energy use between the ReEDS High Curtailment and Aggressive Electrolysis R\&D scenarios, showing increased wind and nuclear generation for grid energy and hydrogen production and decreased petroleum use due to biofuels

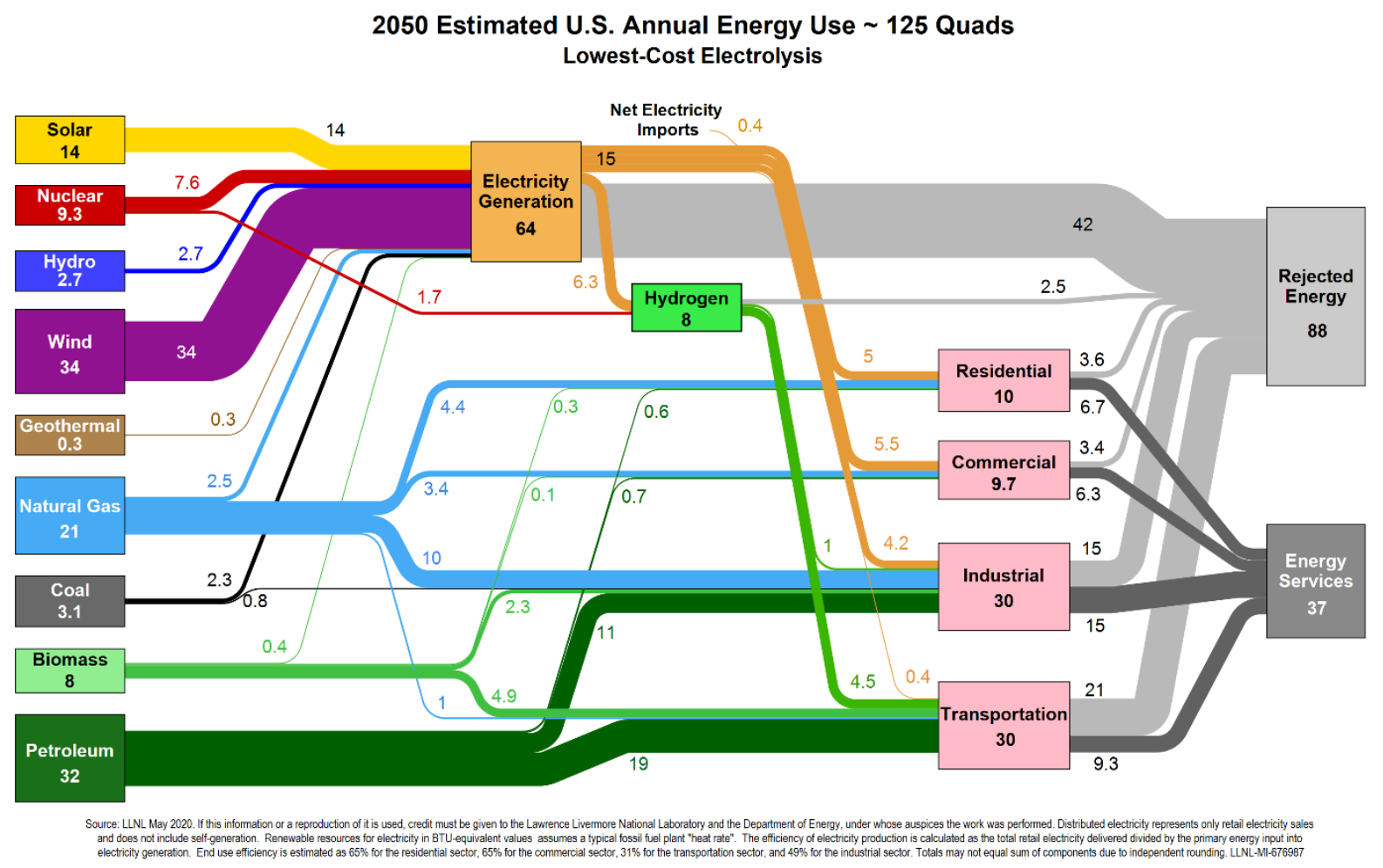

Figure 36. Energy-use Sankey diagram for the Lowest-Cost Electrolysis scenario 
2050 Energy Use Difference Between 'Lowest-cost Electrolysis' and 'ReEDS High Curtailment' (Quadrillion BTUs)

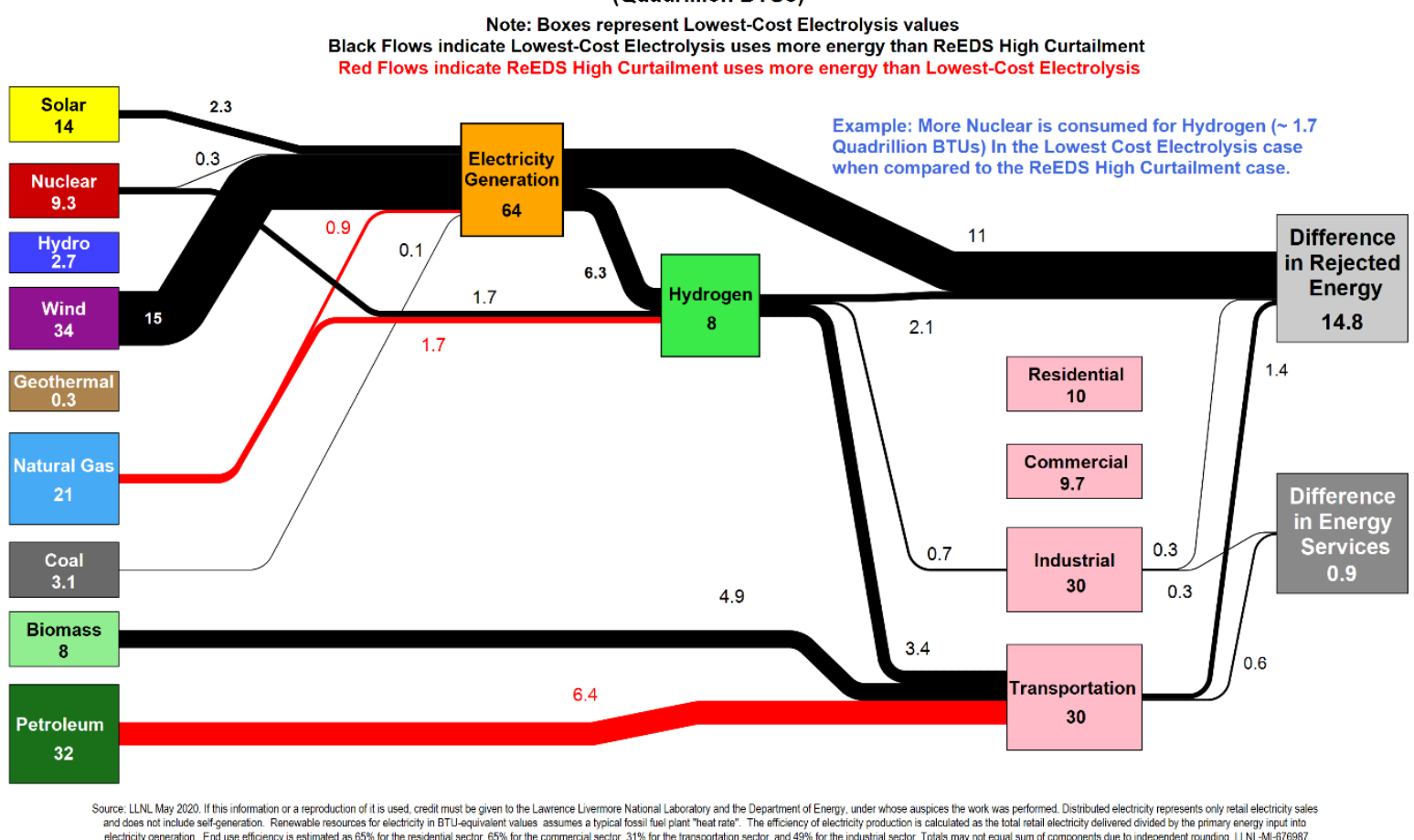

Figure 37. Difference in energy use between the ReEDS High Curtailment and Lowest-Cost Electrolysis scenarios, showing increased wind and solar to produce grid electricity and hydrogen, reduced natural gas for electricity and hydrogen, and petroleum displaced by hydrogen and biofuels for transportation

H2@Scale could reduce emissions because of its potential to reduce fossil energy use. We report the incremental emissions reductions to isolate the impacts of hydrogen from the declining carbon intensity of the power sector. Table 27 shows the emissions and petroleum-use reductions incremental to the reductions from power-sector changes presented in Figure 27 and Figure 28, and the electricity system emissions reported in Table 26: the Reference and R\&D Advances + Infrastructure scenarios are compared to the ReEDS Low RE Cost scenario, and all other scenarios are compared to the ReEDS High Curtailment scenario as described in Section 6.1. Both absolute and relative values are reported in Table 27.

The Lowest-Cost Electrolysis scenario reduces petroleum use and carbon dioxide emissions by $15 \%$ and $19 \%$, respectively, from the ReEDS High Curtailment scenario. Those reductions are primarily due to the substitution of FCEVs for gasoline- and diesel-burning internal combustion engine vehicles and higher penetration of biofuels, as discussed above. Across scenarios, reductions in $\mathrm{NO}_{\mathrm{x}}$ and $\mathrm{SO}_{\mathrm{x}}$ are relatively small owing to emission controls on internal combustion engine vehicles, and particulates generally increase slightly due to the higher $\mathrm{PM}_{10}$ emissions of biofuels compared to gasoline. Compared with the results of the Lowest-Cost Electrolysis scenario, the petroleum-use and emissions impacts of the other scenarios are smaller. 
Table 27. Emissions and Petroleum-Use Reductions for H2@Scale Scenarios

\begin{tabular}{|c|c|c|c|c|c|}
\hline & Reference & $\begin{array}{l}\text { R\&D Advances } \\
+ \text { Infrastructure }\end{array}$ & $\begin{array}{c}\text { Low NG } \\
\text { Resource/ } \\
\text { High NG Price }\end{array}$ & $\begin{array}{c}\text { Aggressive } \\
\text { Electrolysis } \\
\text { R\&D }\end{array}$ & $\begin{array}{l}\text { Lowest- } \\
\text { Cost } \\
\text { Electrolysis }\end{array}$ \\
\hline $\begin{array}{l}\mathrm{NO}_{x} \\
\text { (thousand MT) }\end{array}$ & $110(1 \%)$ & $210(2 \%)$ & $150(1 \%)$ & $170(2 \%)$ & $490(4 \%)$ \\
\hline $\begin{array}{l}\mathrm{SO}_{\mathrm{x}} \\
\text { (thousand MT) }\end{array}$ & $7(<1 \%)$ & $33(1 \%)$ & $17(1 \%)$ & $28(1 \%)$ & $100(3 \%)$ \\
\hline $\begin{array}{l}\mathrm{PM}_{10} \\
\text { (thousand MT) }\end{array}$ & $-35(-1 \%)$ & $-19(-1 \%)$ & $-36(-1 \%)$ & $-35(-1 \%)$ & $14(<1 \%)$ \\
\hline $\begin{array}{l}\text { Crude Oil } \\
\text { (million barrels) }\end{array}$ & $320(5 \%)$ & $680(10 \%)$ & $320(5 \%)$ & $320(5 \%)$ & $1,000(15 \%)$ \\
\hline $\begin{array}{l}\mathrm{CO}_{2} \text { equivalent } \\
\left(\mathrm{CO}_{2} \mathrm{e}\right) \\
\text { (million } \mathrm{MT})\end{array}$ & $120(3 \%)$ & $250(6 \%)$ & $240(6 \%)$ & $290(7 \%)$ & $750(19 \%)$ \\
\hline
\end{tabular}

Negative values indicate an increase in emissions.

The values in parentheses represent the percentage decrease from each scenario's baseline 2050 ReEDS grid scenario: the Reference and R\&D Advances + Infrastructure scenarios are compared to the ReEDS Low RE Cost grid scenario, and all other scenarios are compared to the ReEDS High Curtailment scenario.

\subsection{Spatial Aspects of Economic Potential Scenarios}

Figure 38 - Figure 42 show the hydrogen production and demand locations based on the regionalization methods described in Sections 3 and 4. The methods used to determine supply and demand locations are summarized in Appendix D.

The supply in the Reference scenario (Figure 38) is primarily in the Gulf Coast and major metropolitan areas where steam methane reformers currently exist. There are also smaller supply locations, especially in the Midwest at the locations of current ammonia production facilities. Hydrogen demands are focused on the current locations of refineries and ammonia production facilities and sources of biomass for biofuels.

In the R\&D Advances + Infrastructure scenario (Figure 39), in addition to the locations in the Reference scenario, SMR locations on the west coast also supply hydrogen, and nuclear plants in the Midwest, East coast, and Southwest supply HTE hydrogen. Demand grows compared to the Reference scenario in major metropolitan areas as a result of FCEV markets, and demand for metals refining is located in the Midwest and Southeast.

Supply locations for the Low NG Resource/High NG Price scenario (Figure 40) are more concentrated along the Gulf Coast, in the Midwest, and in the East. Higher natural gas prices cause SMR locations in the West to be less economic, and they make nuclear HTE more economic. The demand is limited to locations for oil refining, ammonia, metals refining, and biofuel production. 
The Aggressive Electrolysis R\&D scenario (Figure 41) has hydrogen production via LTE primarily in the midwestern and central states, because most of the LDE used for electrolysis is generated where the wind resource is best. The demand locations are unchanged from those in the Low NG Resource/High NG Price scenario (Figure 40).

The supply locations in the Lowest-Cost Electrolysis scenario (Figure 42) differ dramatically from those in the other scenarios, because $90 \%$ of the hydrogen is produced by LTE and is located where the LDE is available - the midwestern and central regions, where the wind resource is the greatest. In addition, SMR is not used to produce hydrogen in this scenario, so there is limited production on the Gulf Coast and in the West. The demand for use in FCEVs is larger and spread more broadly across the country.

In general, hydrogen demand is near population centers, because most current oil refineries and ammonia plants are near population centers, and demand growth is dominated by FCEVs operating primarily in these areas. However, demands for metals refining, biofuel production, and possibly methanol production could be in rural areas. Production locations are highly technology dependent. SMR is close to demand locations because the natural gas system is ubiquitous and SMR plants can be built to the size needed. HTE is likely to be far from most demand sites because heat cannot be transmitted easily over long distances. LTE is typically located far from demand centers to align with high wind and solar generation, but it could be farther from the electricity source if transmission is available. Biomass conversion is close to the resource because of the cost of transporting biomass. Hence, if non-SMR alternatives for hydrogen production are to be developed, improved technology and infrastructure for transporting hydrogen from production areas to demand centers likely will be needed. 


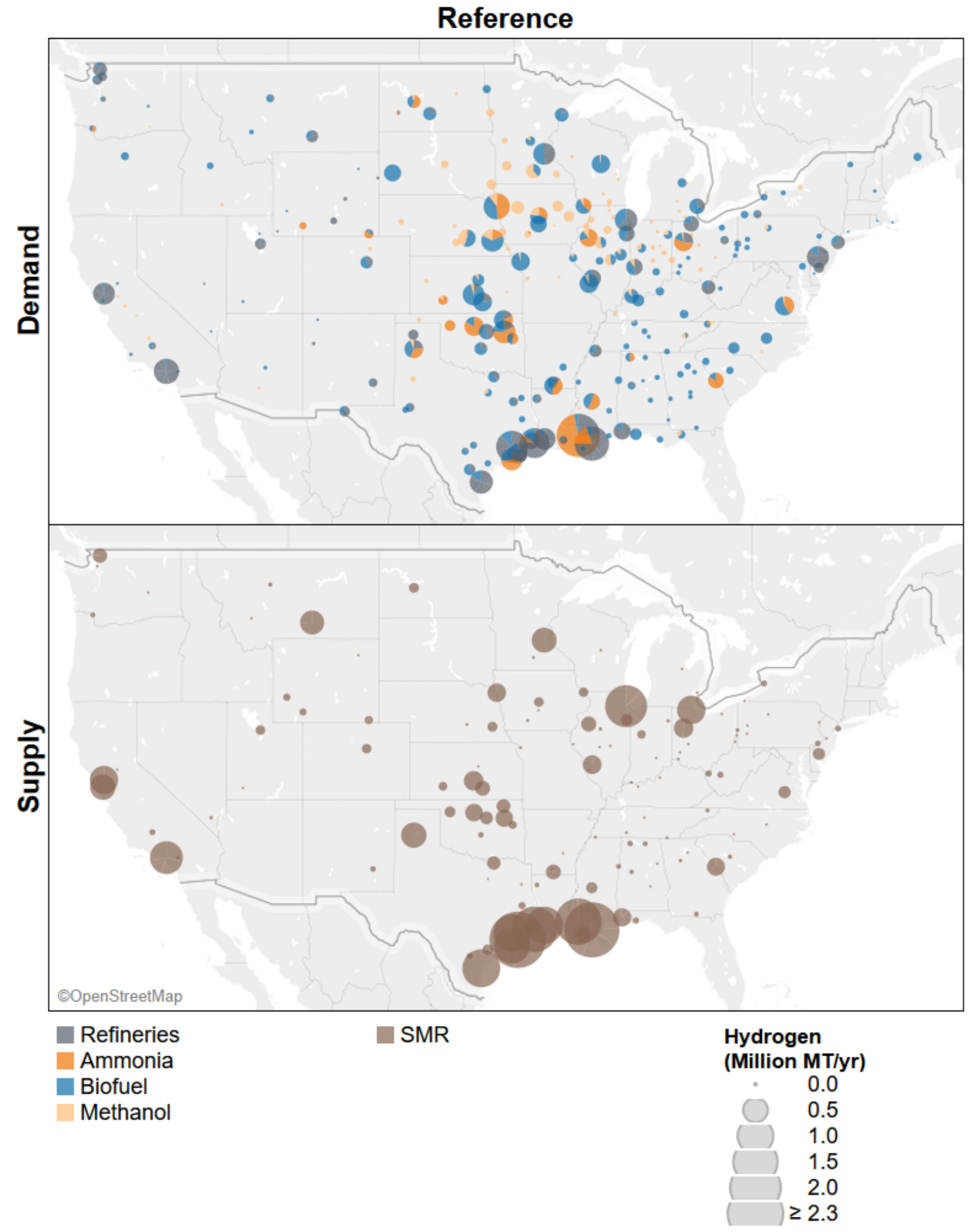

Figure 38. Supply and demand locations for the Reference scenario 


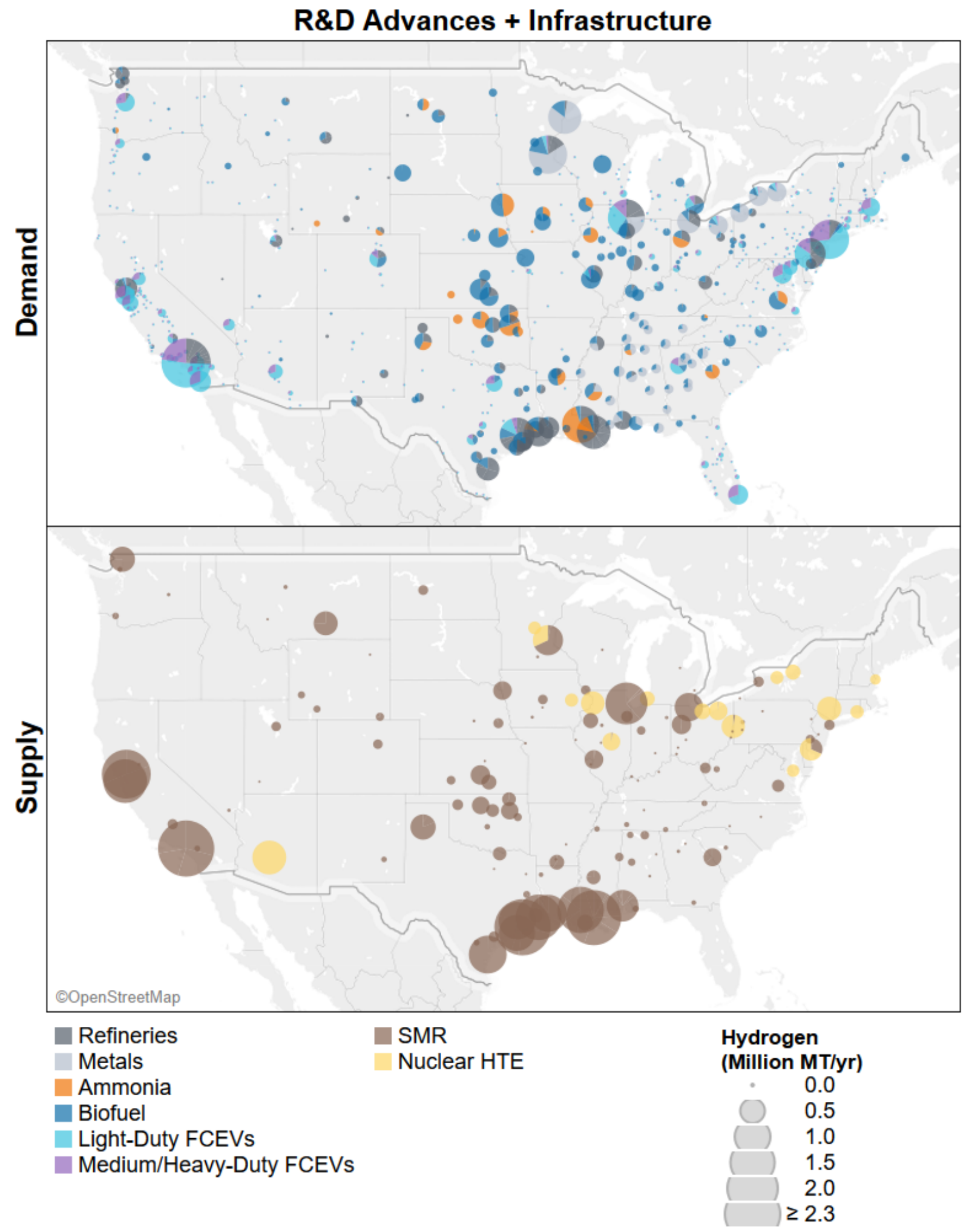

Figure 39. Supply and demand locations for the R\&D Advances + Infrastructure scenario 


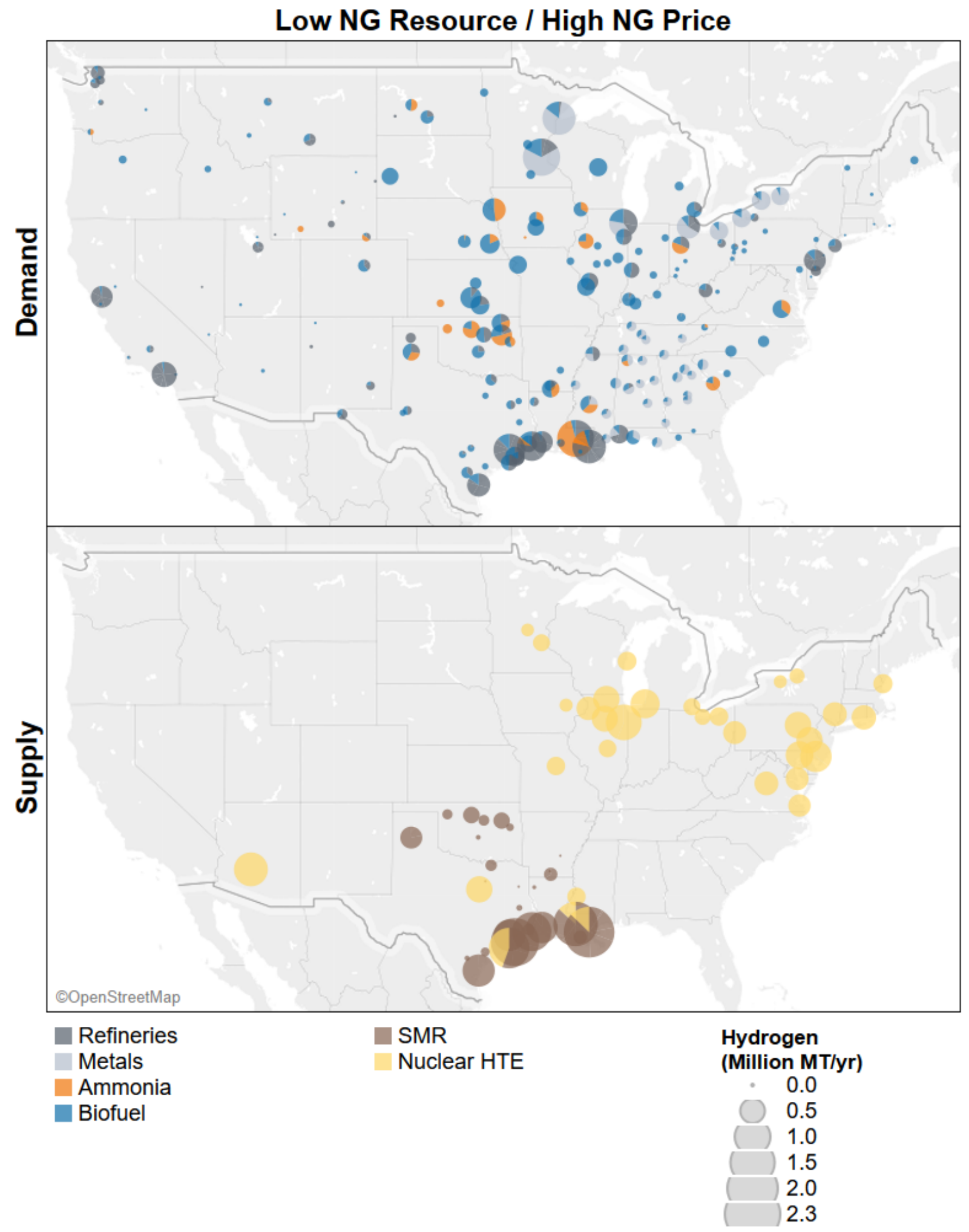

Figure 40. Supply and demand locations for the Low NG Resource/High NG Price scenario 


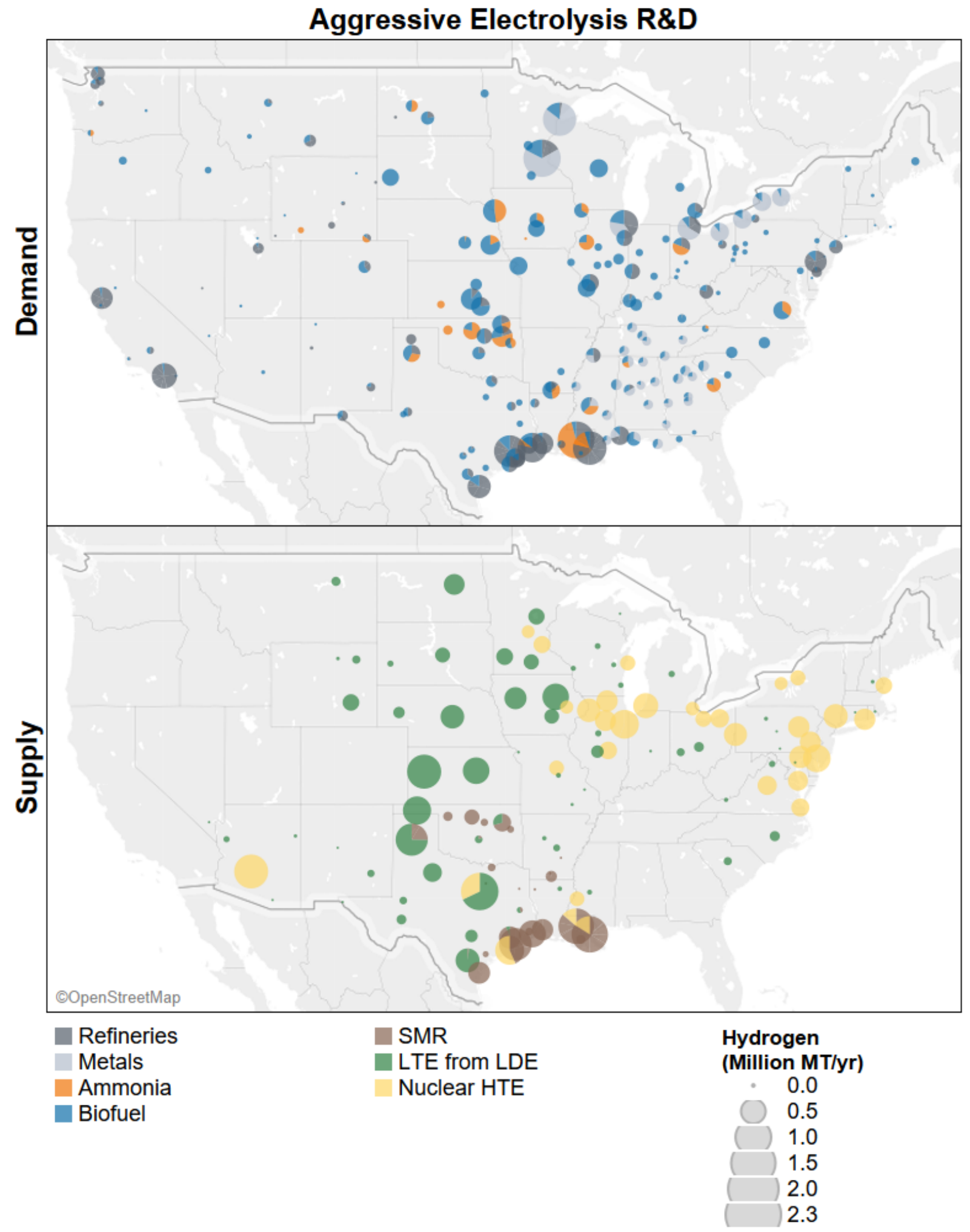

Figure 41. Supply and demand locations for the Aggressive Electrolysis R\&D scenario 


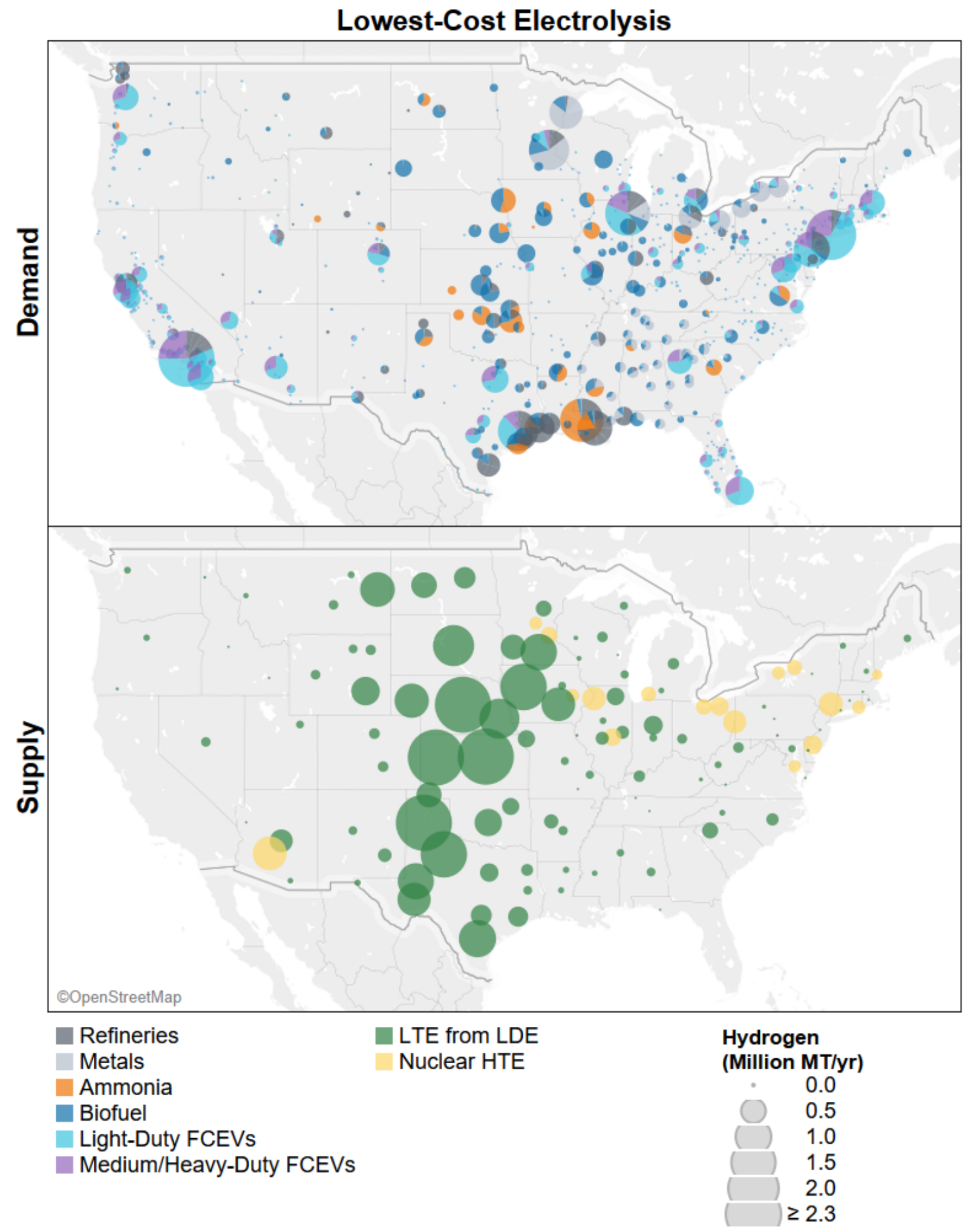

Figure 42. Supply and demand locations for the Lowest-Cost Electrolysis scenario 


\subsection{Economic Potential Sensitivities}

The economic potentials estimated for each scenario described in Section 6.4 depend on the assumed future conditions that determine the cost and availability of hydrogen supply and demand. In this section, we explore the sensitivity of the projected hydrogen market to changes in key assumptions: natural gas prices, SMR availability, HTE and LTE capital costs, market access for LDE, biomass resource availability, FCEV penetration, and external drivers of hydrogen demand for metals refining, synthetic fuels, injection into the natural gas system, and seasonal electricity storage. Specifically, we vary the assumptions for the five core scenarios presented in Table 20.

\subsubsection{Natural Gas Prices}

Natural gas prices affect hydrogen supply curves by directly influencing SMR-produced hydrogen costs and by shaping the projected evolution of the power sector: higher natural gas prices facilitate higher penetration of VRE generation, which increases the amount of LDE available for LTE-produced hydrogen. As a result, variations in natural gas prices can shift the balance of economic competitiveness between SMR and LTE. The Reference and R\&D Advances + Infrastructure scenarios assume lower (AEO Reference) natural gas prices, but all other scenarios assume higher (AEO LOGR) prices. Here we alter these assumptions to use lower prices for all scenarios.

Two of our core scenarios are identical except for their natural gas price assumptions: the R\&D Advances + Infrastructure scenario assumes lower (AEO Reference) prices, and the Low NG Resource/High NG Price scenario assumes higher (AEO LOGR) prices. With no other factors to improve the economics of LTE-based hydrogen production, increasing the natural gas price increases SMR hydrogen costs, thus reducing the size of the hydrogen market and increasing the share of HTE-produced hydrogen.

All of our other core scenarios assume the higher (AEO LOGR) natural gas prices. Figure 43 and Figure 44 show the impact of assuming lower (AEO Reference) natural gas prices in each of these scenarios instead. In the Aggressive Electrolysis R\&D scenario, lower natural gas prices increase the hydrogen market size by $14 \mathrm{MMT} / \mathrm{yr}$ (to satisfy FCEV demand) because of the higher availability of SMR hydrogen below the $\$ 2.20 / \mathrm{kg}$ price point.

In the Lowest-Cost Electrolysis scenario, lower natural gas prices increase the hydrogen market size by 1 MMT (to satisfy methanol demand) and reduce the equilibrium price from $\$ 2.00 / \mathrm{kg}$ to $\$ 1.70 / \mathrm{kg}$. At the same time, assuming lower natural gas prices in this scenario shifts the shares of hydrogen production attributed to SMR versus electrolysis: SMR accounts for no production under the core (higher natural gas price) scenario, but it accounts for $52 \%$ of production when natural gas prices are lower.

The changes in demand curves shown in Figure 43 are due to the changes in economic competitiveness of hydrogen for seasonal energy storage based on the lower-cost natural gas. However, these changes do not affect the use of hydrogen for seasonal energy storage. In these three scenarios, lower natural gas prices increase the hydrogen market sizes by providing additional low-cost hydrogen. At lower natural gas prices, SMR often outcompetes LTE, thus reducing its market shares. 


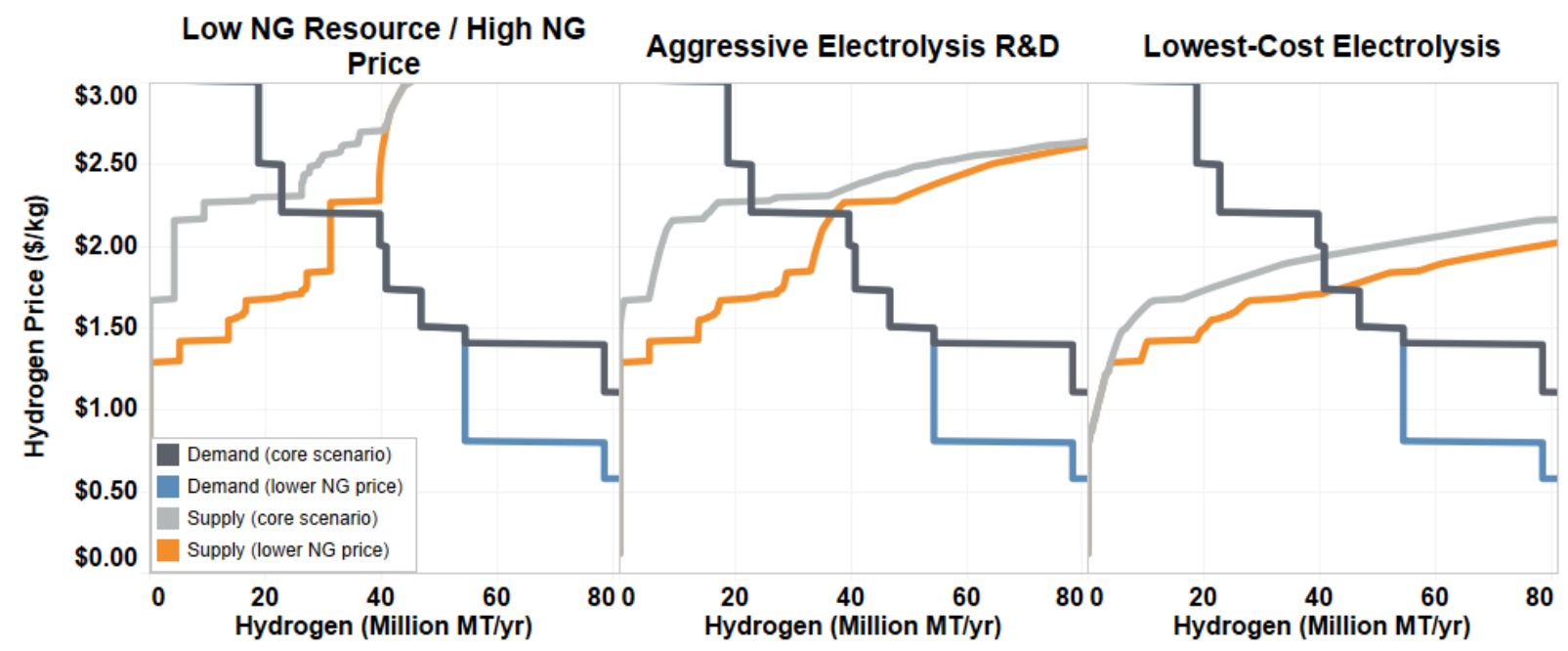

Figure 43. Supply and demand curves assuming higher (AEO LOGR) natural gas prices in core scenarios versus lower (AEO Reference) natural gas prices in sensitivity scenarios

The lower natural gas price sensitivity scenario for the Low NG Resource/High NG Price scenario is equivalent to the R\&D Advances + Infrastructure core scenario.

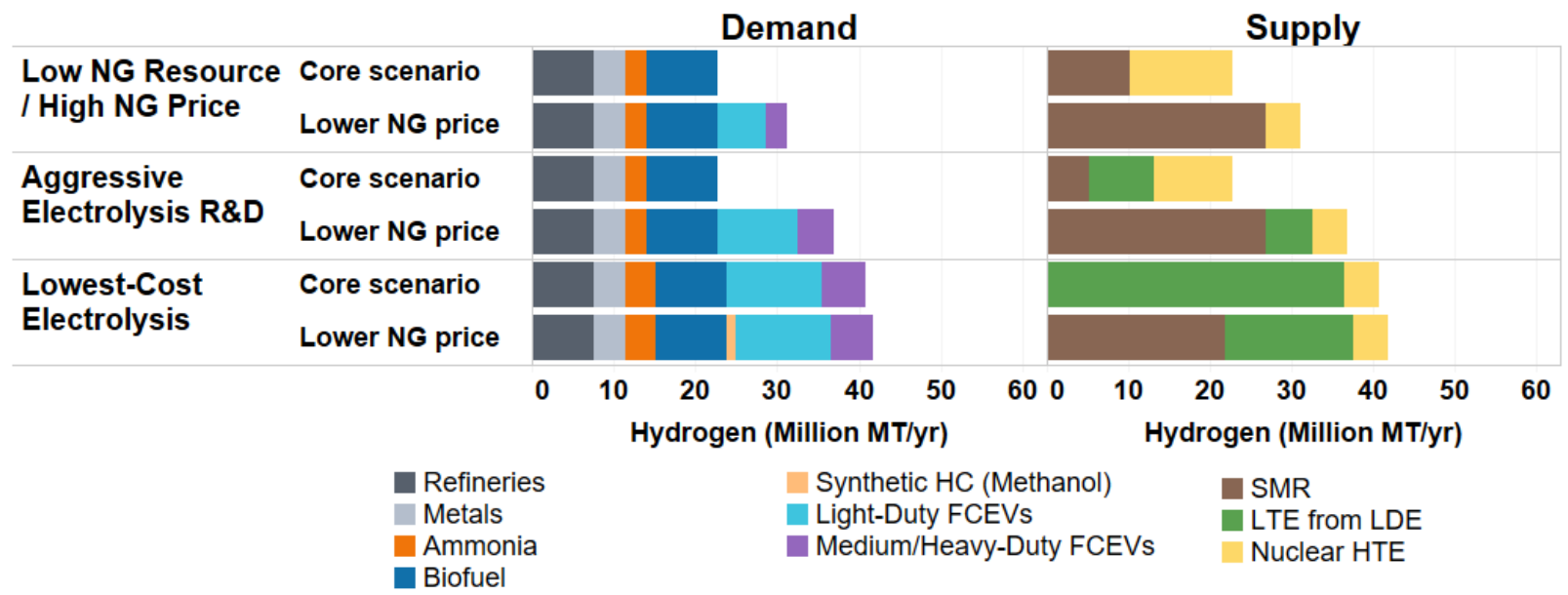

Figure 44. Supply and demand applications assuming higher (AEO LOGR) natural gas prices in core scenarios versus lower (AEO Reference) natural gas prices in sensitivity scenarios

The lower natural gas price sensitivity scenario for the Low NG Resource/High NG Price scenario is equivalent to the R\&D Advances + Infrastructure core scenario.

\subsubsection{Natural Gas SMR Availability}

In each of our core scenarios, we assume future SMR capacity can increase to three times current capacity, as estimated from IHS (2015) in Section 4.1. This growth is consistent with some regional AEO projections (see footnote 26). To explore the impact of this assumption, here we include four sensitivity scenarios: increasing the capacity growth assumption to five times current capacity, decreasing the capacity growth assumption to two times current capacity, no new SMR production available, and no SMR supply at all (representing a potential future with 
severe regulatory, resource, and/or technology limitations on SMR). Figure 45 and Figure 46 compare these sensitivity scenarios with the five core scenarios.

Increasing the SMR capacity to five times current levels increases the equilibrium markets sizes in the Reference and R\&D Advances + Infrastructure scenarios, but it has no impact on the other scenarios. In the Reference scenario, the increased low-cost SMR supply ( $8 \mathrm{MMT} / \mathrm{yr}$ ) goes to metals and methanol demand, while in R\&D Advances + Infrastructure the increased supply (10 $\mathrm{MMT} / \mathrm{yr}$ ) goes to ammonia and FCEV demand.

Limiting the SMR capacity to two times current levels and limiting to current capacity (no new SMR) also only impact the Reference and R\&D Advances + Infrastructure scenarios. In the Reference scenario, demand for ammonia and methanol decrease by $3 \mathrm{MMT} / \mathrm{yr}$, and nuclear HTE increases by $1 \mathrm{MMT} / \mathrm{yr}$. In R\&D Advances + Infrastructure, the limited supply and resulting higher price of hydrogen becomes uneconomic for FCEV applications and all FCEV demand disappears ( $8 \mathrm{MMT} / \mathrm{yr})$. Nuclear HTE supply increase by $1 \mathrm{MMT} / \mathrm{yr}$, offsetting some of the SMR reduction. The economic potentials of the other scenarios include SMR hydrogen production only from existing SMR facilities, so the limited SMR supply does not affect market size or production mix.

Eliminating SMR supply reduces market sizes in the Reference, R\&D Advances + Infrastructure, and Low NG Resource/High NG Price scenarios. In the Reference scenario, methanol demand (2 $\mathrm{MMT} / \mathrm{yr}$ ) and a portion of hydrogen demand for ammonia, biofuels, and oil refining ( $8 \mathrm{MMT} / \mathrm{yr}$ ) become uneconomic as the equilibrium hydrogen price increases to just over $\$ 3.00 / \mathrm{kg}$. We assume a higher willingness to pay of $\$ 3.00 / \mathrm{kg}$ for these applications, but this price could be higher (in which case the market size would stay the same, but the equilibrium price would increase). The adjusted supply for the Reference scenario is made up entirely of HTE. The R\&D Advances + Infrastructure scenario with no SMR results in the same market as the Reference scenario with no SMR. In the Low NG Resource/High NG Price scenario, the market size is reduced somewhat because the LTE supply is too expensive fully compensate for the elimination of SMR. In the Aggressive Electrolysis R\&D scenario, HTE and LTE supplies increase to account for the lack of hydrogen supply from SMR, with no impact on market size (hydrogen price increases slightly). The economic potential in the Lowest-Cost Electrolysis scenario does not include SMR, so limited SMR supply does not alter this scenario. Thus, limited availability of natural gas SMR has only small impacts on hydrogen markets assuming higher natural gas prices and attainment of the Aggressive Electrolysis R\&D scenario's targets (or more aggressive targets). 

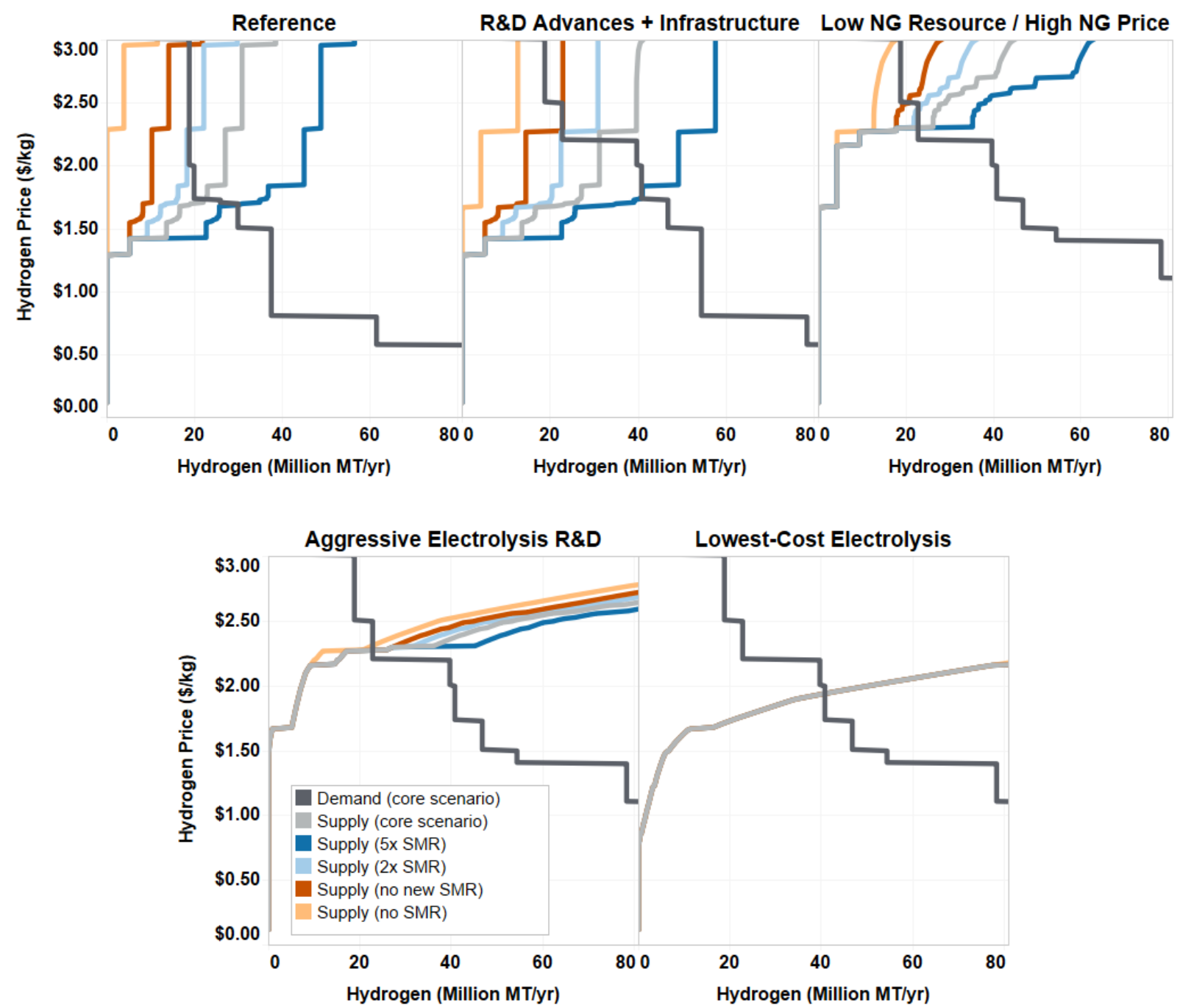

Figure 45. Supply and demand curves for core and SMR availability sensitivity scenarios 


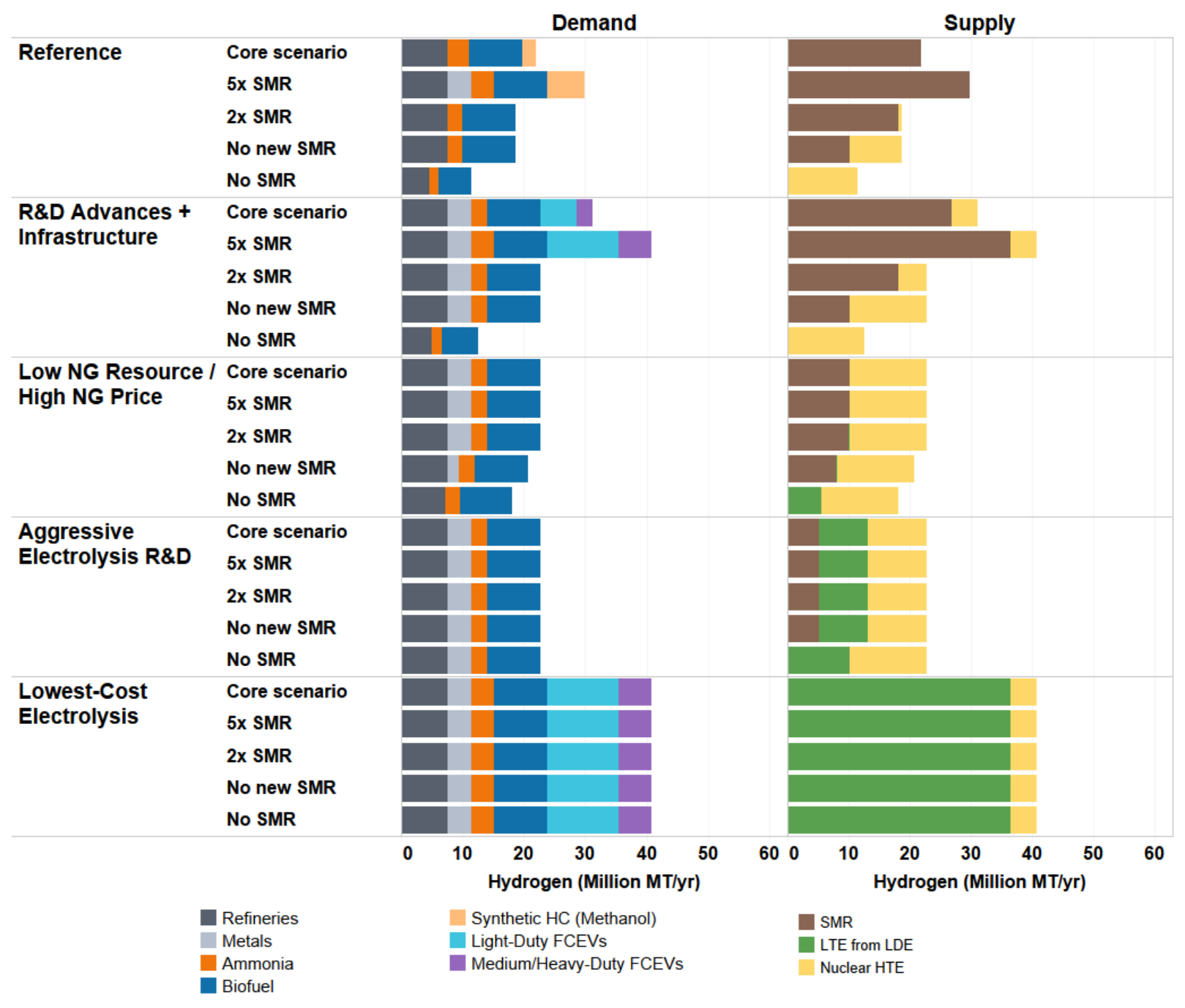

Figure 46. Supply and demand applications for core and SMR availability sensitivity scenarios

\subsubsection{LTE Cost and Electricity Market Access}

In this section, we show that the capital cost and end-use price of LDE for LTE hydrogen production can significantly affect the economics of LTE and the potential hydrogen market size. In our core scenarios, we vary assumed LTE capital costs from $\$ 900 / \mathrm{kW}$ (Reference), to $\$ 400 / \mathrm{kW}$ (R\&D Advances + Infrastructure, Low NG Resource/High NG Price), to $\$ 200 / \mathrm{kW}$ (Aggressive Electrolysis R\&D), and finally to $\$ 100 / \mathrm{kW}$ (Lowest-Cost Electrolysis). We also vary assumed LDE prices from retail prices (Reference, R\&D Advances + Infrastructure, Low NG Resource/High NG Price), to in between retail and wholesale selling prices (Aggressive Electrolysis R\&D), to wholesale selling prices (Lowest-Cost Electrolysis). 
Figure 47 shows the effect of LTE cost and LDE market access on hydrogen market size with higher natural gas price assumptions (consistent with the AEO LOGR case). Access to wholesale prices results in larger market sizes, regardless of capital cost assumptions. Assuming wholesale rather than retail LDE prices, the market size grows by 5,17 , and, $18 \mathrm{MMT} / \mathrm{yr}$ with $\$ 400$, $\$ 200$, and $\$ 100 / \mathrm{kW}$ LTE capital costs, respectively. Capital cost reductions have an increasing effect at lower LDE prices. Under retail prices, the lower $\$ 100 / \mathrm{kW}$ capital cost results in displacement of $4 \mathrm{MMT} / \mathrm{yr}$ from SMR, but it does not increase market size, compared to $\$ 400 / \mathrm{kW}$. However, with wholesale LDE prices, market size grows by $13 \mathrm{MMT} / \mathrm{yr}$ with a capital cost reduction from $\$ 400$ to $\$ 100 / \mathrm{kW}$. The equilibrium price also generally decreases with lower capital costs and LDE prices. Overall, the combination of lower capital cost and wholesale LDE prices is required for substantial expansion. However, LDE price has a somewhat greater impact on market size than electrolyzer capital cost does. Very low capital costs provide little market expansion without wholesale LDE prices. Similarly, market expansion is modest in the absence of capital cost reductions, even when wholesale LDE prices are available. 


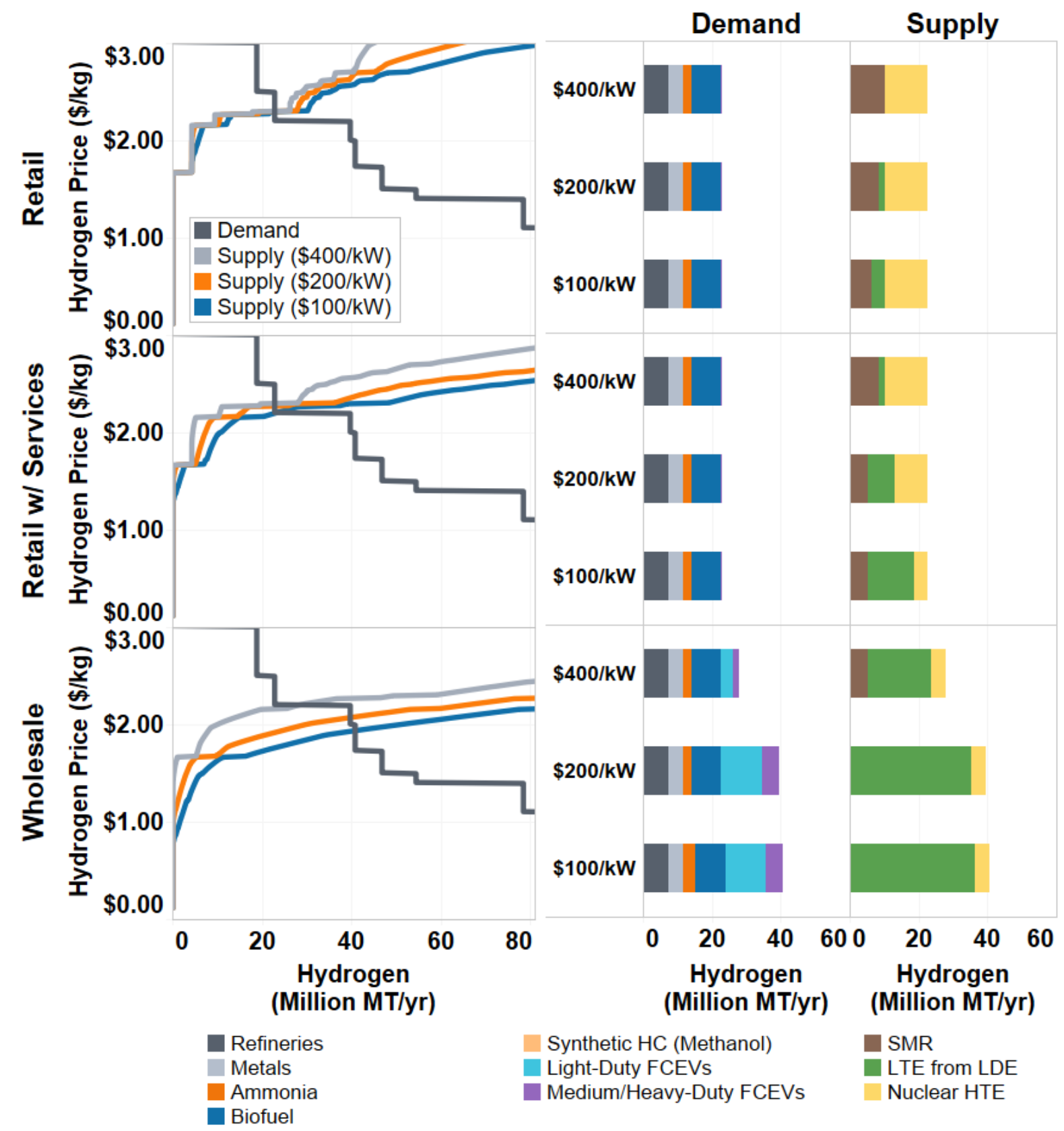

Figure 47. Supply and demand curves (left) and applications (right) for LDE market access and LTE capital cost sensitivity scenarios, with supply and demand curves based on higher natural gas price assumptions

The Low NG Resource/High NG Price scenario assumes retail LDE prices and \$400/kW LTE capital costs. The Aggressive Electrolysis R\&D scenario assumes LDE prices between wholesale and retail (retail with services) and $\$ 200 / \mathrm{kW}$ LTE capital costs. The Lowest-Cost Electrolysis scenario assumes wholesale LDE prices and \$100/kW LTE capital costs. 


\subsubsection{Nuclear HTE Cost}

Similar to LTE, technology capital cost can also impact the economic competitiveness of hydrogen produced via HTE. In our core scenarios, we assume a capital cost of $\$ 820 / \mathrm{kW}$ in the Reference scenario and $\$ 423 / \mathrm{kW}$ in all others. Here, we compare those scenarios to scenarios with a $\$ 100 / \mathrm{kW}$ capital cost (Figure 48 and Figure 49). The sensitivity scenarios consider HTE using nuclear-generated electricity and heat, as discussed in Section 4.3.

Lower HTE costs result in larger market sizes for the scenarios with lower natural gas prices: the Reference scenario increases by $4 \mathrm{MMT} / \mathrm{yr}$ (from methanol demand) and the R\&D Advances + Infrastructure scenario increases by $9 \mathrm{MMT} / \mathrm{yr}$ (from FCEV demand). In both cases, the increased market sizes are from HTE production. In the Low NG Resource/High NG Price scenario, lower HTE costs have no impact on results, because HTE from existing nuclear is already in the supply and the lower cost is not low enough to enable other demand markets. In the Aggressive Electrolysis R\&D scenario, production from HTE displaces some production from LTE (and increases demand by $1 \mathrm{MMT} / \mathrm{yr}$ for FCEVs), but in the Lowest-Cost Electrolysis scenario lower HTE costs have no impact on the market equilibrium results due to the abundance of even lower-cost LTE hydrogen. Thus, HTE technology with lower capital cost could potentially increase the hydrogen market size even when constrained to use only nucleargenerated energy as it is in this analysis, especially when competing with SMR, but may not compete with the lowest-cost LTE hydrogen with favorable conditions. 

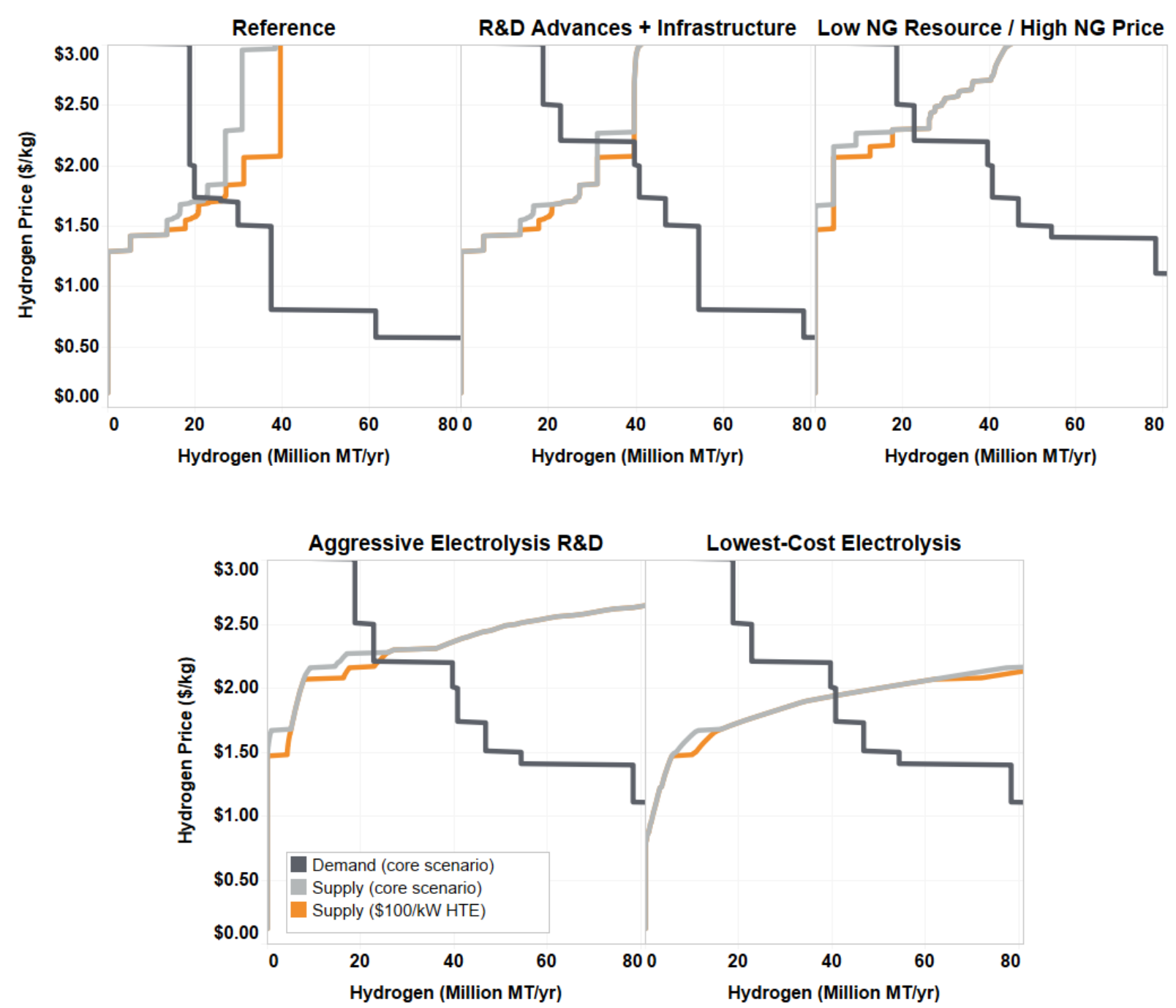

Figure 48. Supply and demand curves for core and HTE sensitivity scenarios

The Reference scenario assumes $\$ 820 / \mathrm{kW}$ HTE capital costs. All other scenarios assume $\$ 423 / \mathrm{kW}$ HTE capital costs. 


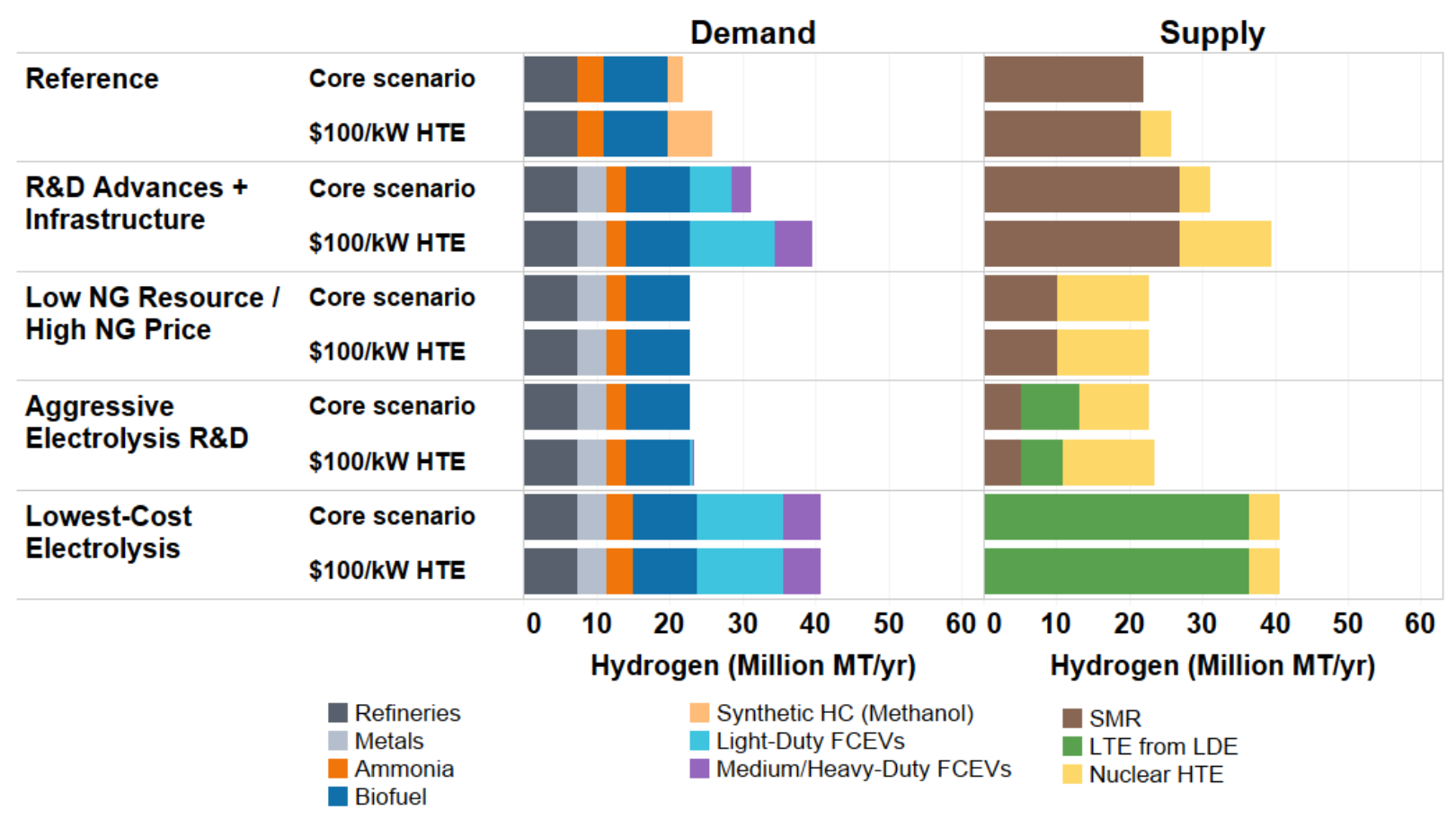

Figure 49. Supply and demand applications for core and HTE sensitivity scenarios

The Reference scenario assumes $\$ 820 / \mathrm{kW}$ HTE capital costs. All other scenarios assume $\$ 423 / \mathrm{kW}$ HTE capital costs.

\subsubsection{Biomass Resource Availability}

In our core scenarios, we assume biomass resource is not available for hydrogen production via biomass gasification. Here we assume biomass resource is available, using the supply curves described in Section 4.4 to assess the impact on market size and the potential market share for the biomass production technology (Figure 50 and Figure 51). In the Reference scenario, biomass resource availability does not compete with SMR at the given hydrogen price, and there are no impacts on results. Biomass availability in the R\&D Advances + Infrastructure scenario results in growth in FCEV markets (9 MMT/yr) supplied by biomass gasification hydrogen. Growth in FCEV demand also occurs in the Low NG Resource/High NG Price and Aggressive Electrolysis R\&D scenarios (11 MMT/yr and $14 \mathrm{MMT} / \mathrm{yr}$ growth, respectively), but biomass gasification is lower cost than new SMR capacity and the higher-extension-cost HTE, so it displaces production from these sources. In the Lowest-Cost Electrolysis scenario, biomass resource availability does not enlarge markets, but it does displace $3 \mathrm{MMT} / \mathrm{yr}$ of LTE hydrogen. Thus, if the U.S. biomass resource is available for hydrogen production, it could increase the hydrogen market size by up to $14 \mathrm{MMT} / \mathrm{yr}$, but the impact is smaller when the cost of electrolysis is low. 

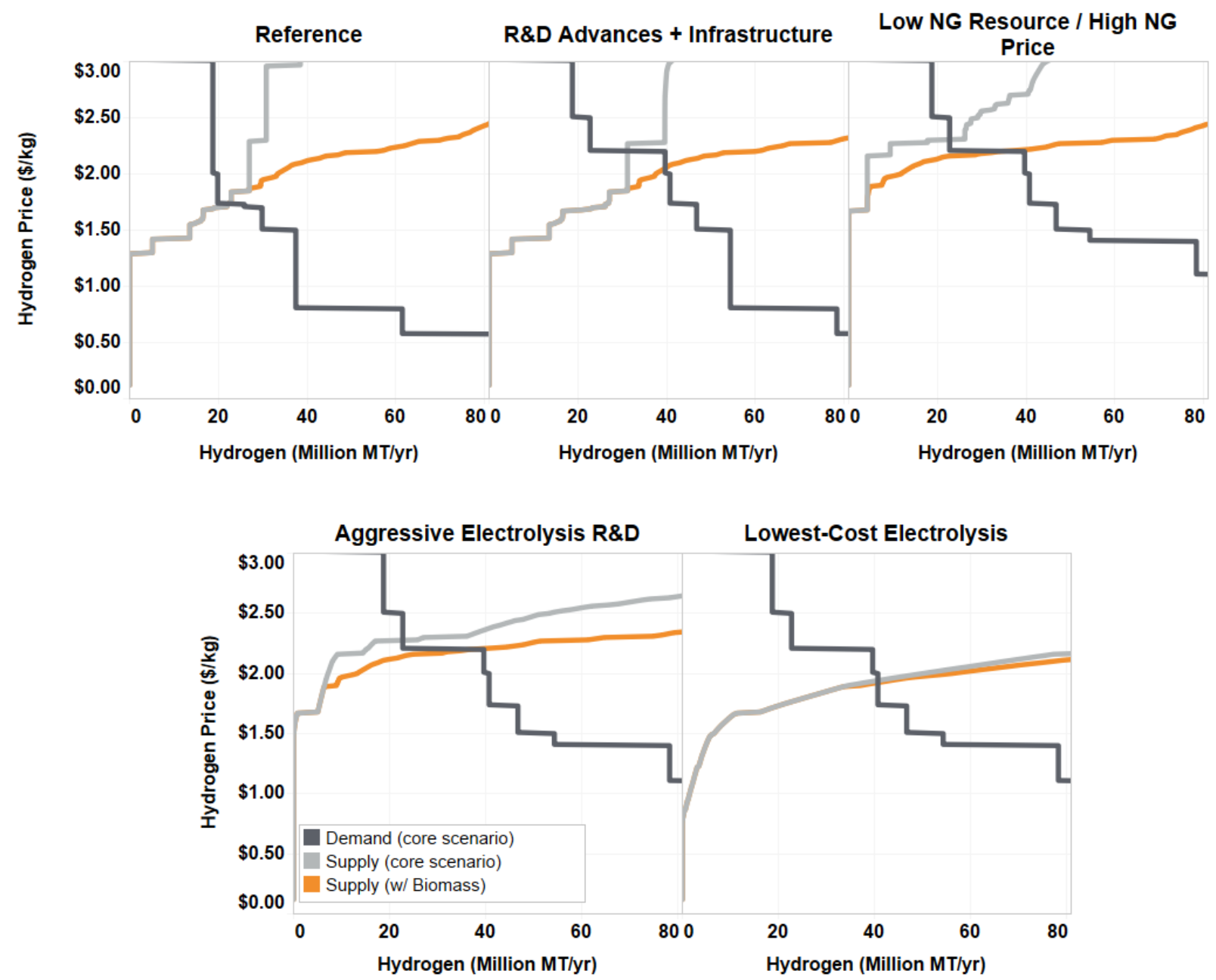

Figure 50. Supply and demand curves for core and biomass resource availability sensitivity scenarios 


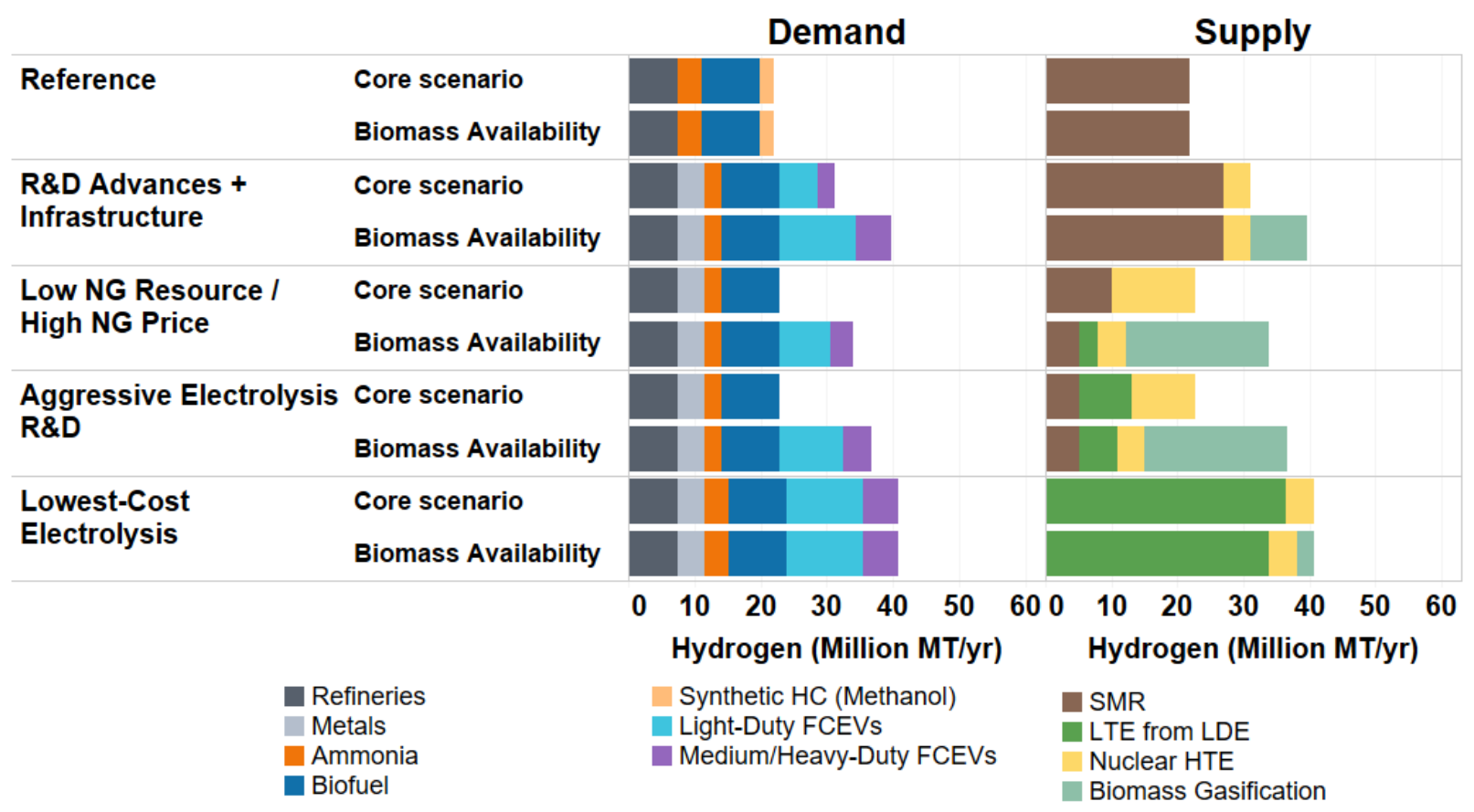

Figure 51. Supply and demand applications for core and biomass resource availability sensitivity scenarios

\subsubsection{Metals Refining}

We assume a high threshold price for hydrogen in metals refining owing to non-economic drivers in our core scenarios, except for the Reference scenario. We assume the threshold price increases from $\$ 1.70 / \mathrm{kg}$ to $\$ 2.50 / \mathrm{kg}$. When we remove that price increase, metals refining requires hydrogen prices lower than the market equilibrium for each of those cases; thus, either the market size is smaller (the Low NG Resource/High NG Price, Aggressive Electrolysis R\&D, and Lowest-Cost Electrolysis scenarios) or the hydrogen demand for metals refining is replaced by another demand (additional FCEV demand in the R\&D Advances + Infrastructure scenario) see Figure 52 and Figure 53. Clearly, non-economic drivers can have measurable impacts on market size and composition. 


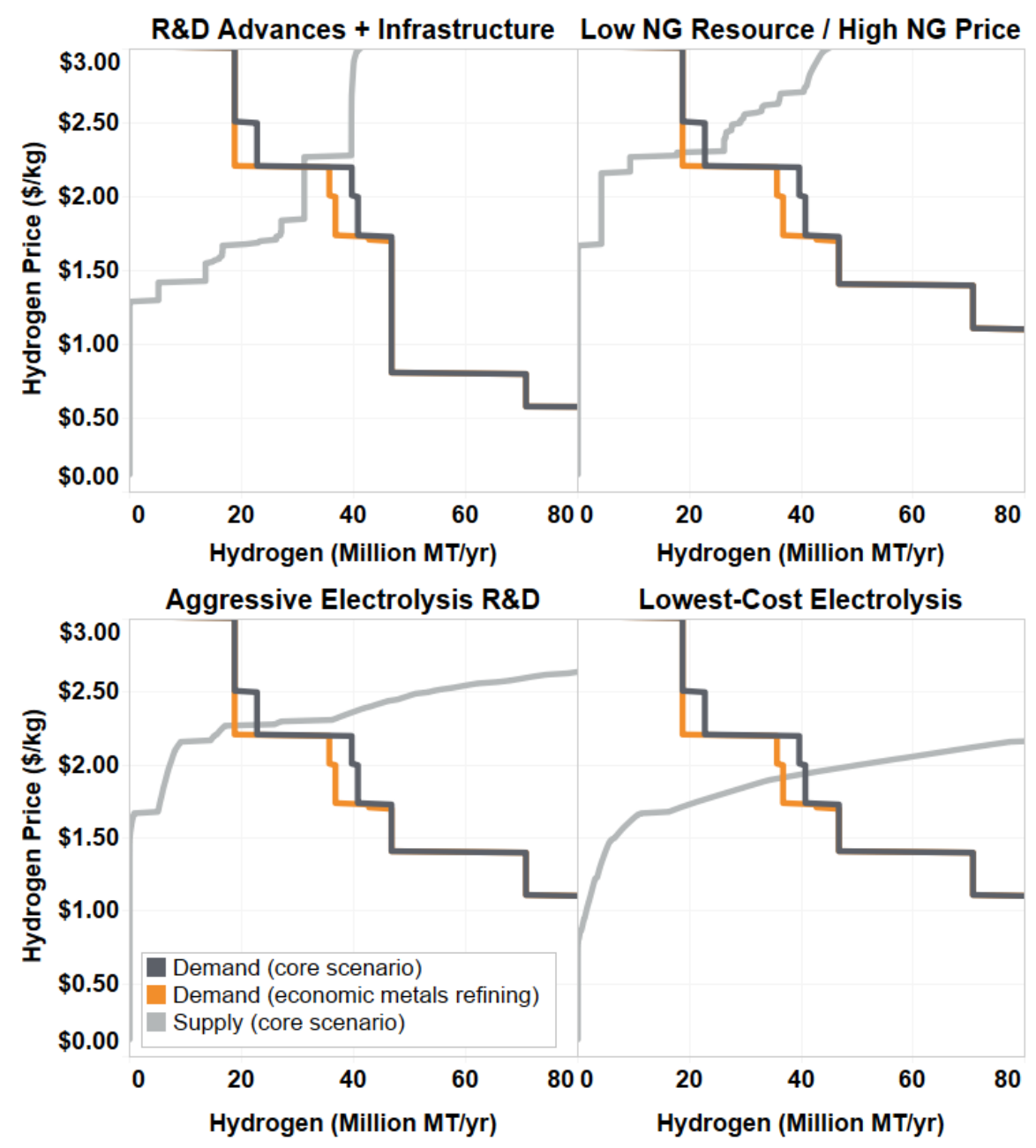

Figure 52. Supply and demand curves for core and metals refining sensitivity scenarios 


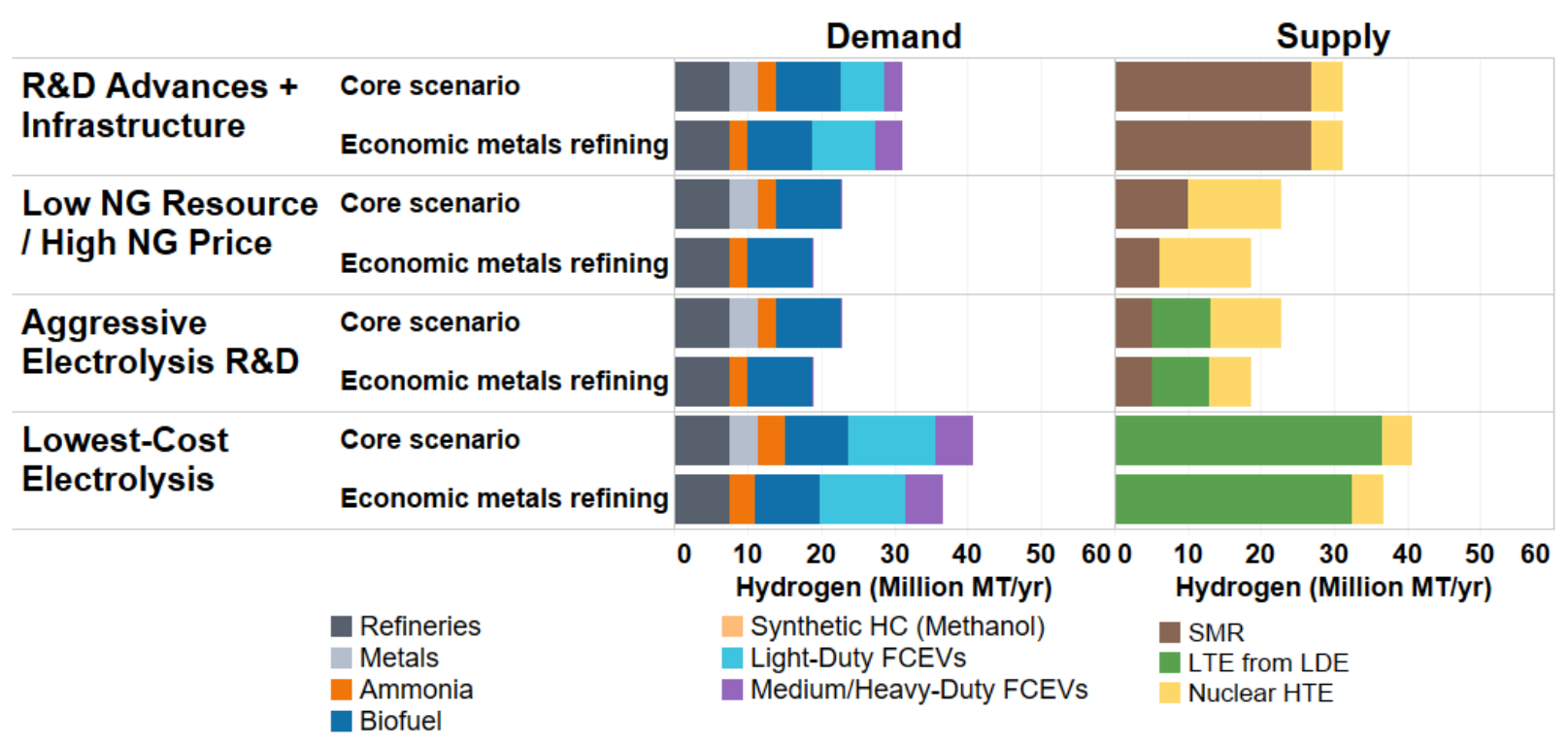

Figure 53. Supply and demand applications for core and metals refining sensitivity scenarios

\subsubsection{FCEV Penetration}

The potential penetration of FCEVs in the core economic potential scenarios is based on vehiclechoice modeling of LDVs using MA3T, as described in Section 3.8. The vehicle-choice model scenario represents one potential future by estimating the impact of economic drivers (e.g., fuel prices, vehicles prices, and vehicle performance) as well as other factors of consumer preference (e.g., range, refueling availability), but it does not include all potential drivers of penetration (e.g., policy, evolution of consumer preference) nor does it include uncertainty estimates of the resulting penetration. To examine the effect of different FCEV penetrations in scenarios with FCEV demand, ${ }^{65}$ we include sensitivity scenarios of FCEV penetration for LDVs, MDVs, and HDVs equal to the serviceable consumption potential of $29 \mathrm{MMT} / \mathrm{yr}$ at a threshold price of $\$ 2.20 / \mathrm{kg}$ at the terminal (see Sections 3.8 and 3.9) and sensitivity scenarios with no FCEV penetration, shown in Figure 54 and Figure 55.

In the R\&D Advances + Infrastructure scenario, increasing FCEV penetration has no impact on the economic potential results, because that scenario is constrained by supply availability. Additional supply is not available at the FCEV threshold price of $\$ 2.20 / \mathrm{kg}$ to meet demand growth. With no FCEV penetration, the market size decreases by $5 \mathrm{MMT} / \mathrm{yr}$ due to a decrease of $8 \mathrm{MMT} / \mathrm{yr}$ from FCEV but a growth in demand for ammonia and methanol (3 MMT/yr), which have lower threshold prices.

Alternative FCEV penetrations have a more significant impact in the Lowest-Cost Electrolysis scenario due to high availability of low-cost electrolytic hydrogen. Increasing FCEV penetration results in market growth of $11 \mathrm{MMT} / \mathrm{yr}$. FCEV demand increases by $12 \mathrm{MMT} / \mathrm{yr}$, offsetting 1 MMT/yr less ammonia, which has a lower threshold price. The demand increase is met entirely

\footnotetext{
${ }^{65}$ Changing the FCEV penetration assumptions has no impact on the Reference, Low NG Resource/High NG Price, and Aggressive Electrolysis R\&D scenarios.
} 
from LTE supply. Assuming no FCEV penetration decreases the market size by $17 \mathrm{MMT} / \mathrm{yr}$, all corresponding to FCEV demand.

Increasing FCEV demand assumptions can result in larger market sizes, but only if sufficient supply is available at the corresponding threshold price. Limited FCEV demand can decrease total market size, but it may allow for activation of other demand applications (e.g., synthetic methanol) if low-cost hydrogen is available.

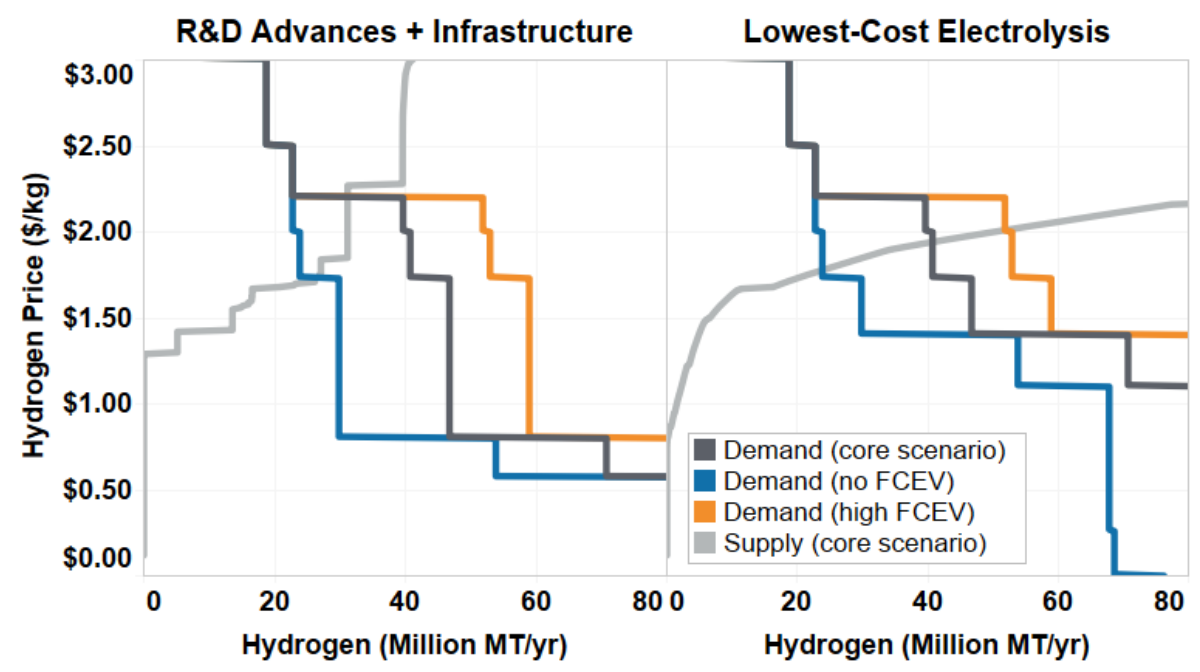

Figure 54. Supply and demand curves for core and FCEV penetration sensitivity scenarios

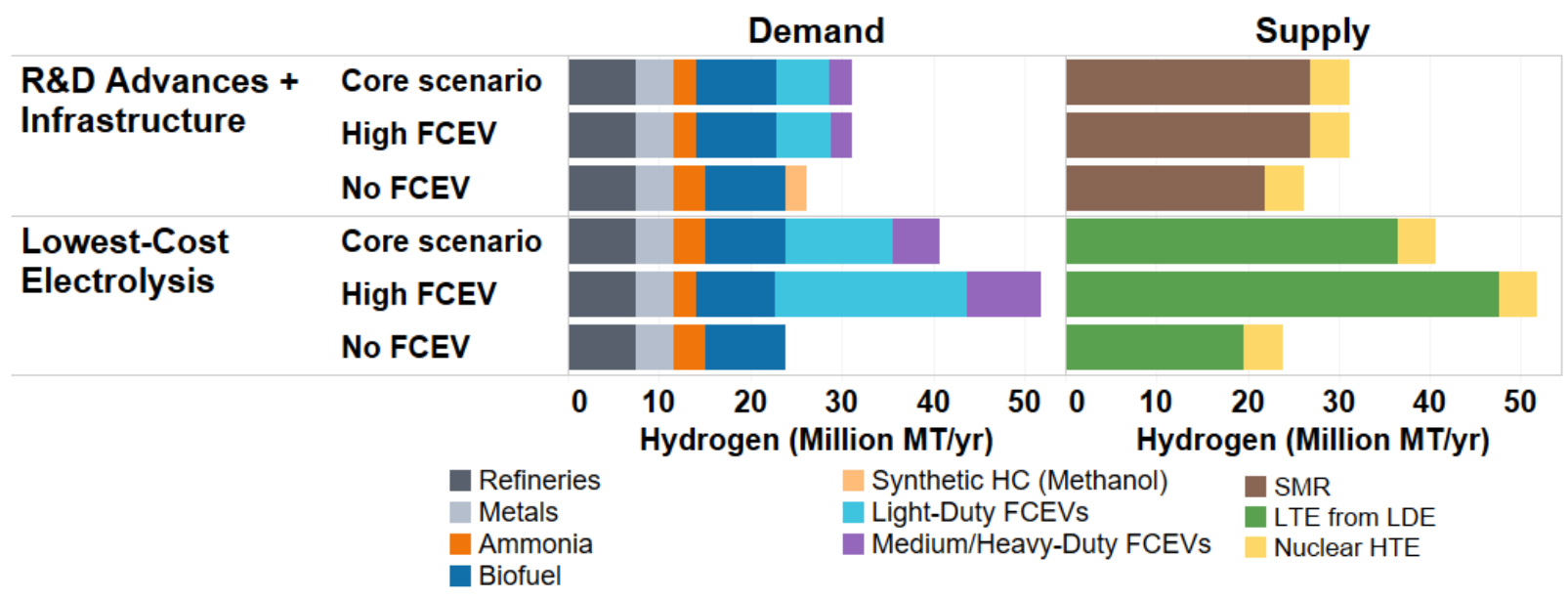

Figure 55. Supply and demand applications for core and FCEV penetration sensitivity scenarios 


\subsubsection{Biofuel Penetration}

In the core scenarios, we assume a biofuel penetration of $50 \%$ of the aviation jet fuel market. In this section, we present sensitivity analyses assuming no biofuel penetration of aviation fuel and $100 \%$ penetration (with the same threshold price of $\$ 3.00 / \mathrm{kg}$ ) — see Figure 56 and Figure 57.

Assuming no biofuel penetration of $9 \mathrm{MMT} / \mathrm{yr}$ results in decreased market sizes in every economic potential scenario except for the R\&D Advances + Infrastructure scenario (which is the only scenario constrained by supply availability near the market equilibrium point). In the R\&D Advances + Infrastructure scenario, the decrease in biofuel demand is offset entirely by an increase in FCEV demand (9 MMT/yr). In other scenarios, the decreased demand results in a market size decrease of 9 MMT/yr (Low NG Resource/High NG Price and Lowest-Cost Electrolysis) or is only partially offset (Reference scenario demand increases $1 \mathrm{MMT} / \mathrm{yr}$ for metals and $4 \mathrm{MMT} / \mathrm{yr}$ for synthetic methanol, and Aggressive Electrolysis R\&D scenario demand increases by $1 \mathrm{MMT} / \mathrm{yr}$ for FCEVs).

In all scenarios, higher biofuel demand results in larger market sizes. In the Reference, R\&D Advances + Infrastructure, and Low NG Resource/High NG Price scenarios, the increased biofuel demand displaces markets in the core scenarios, because there is insufficient production to meet demand at the given hydrogen price or the market equilibrium occurs at prices higher than the threshold prices for those applications. In the Aggressive Electrolysis R\&D and LowestCost Electrolysis scenarios, all biofuel hydrogen demand growth is met (9 MMT/yr).

Thus, increased biofuel penetration can increase hydrogen market sizes, particularly if low-cost hydrogen production is available. Reduced biofuel penetration can limit market sizes, especially if other demand applications are not available at similar threshold prices. 


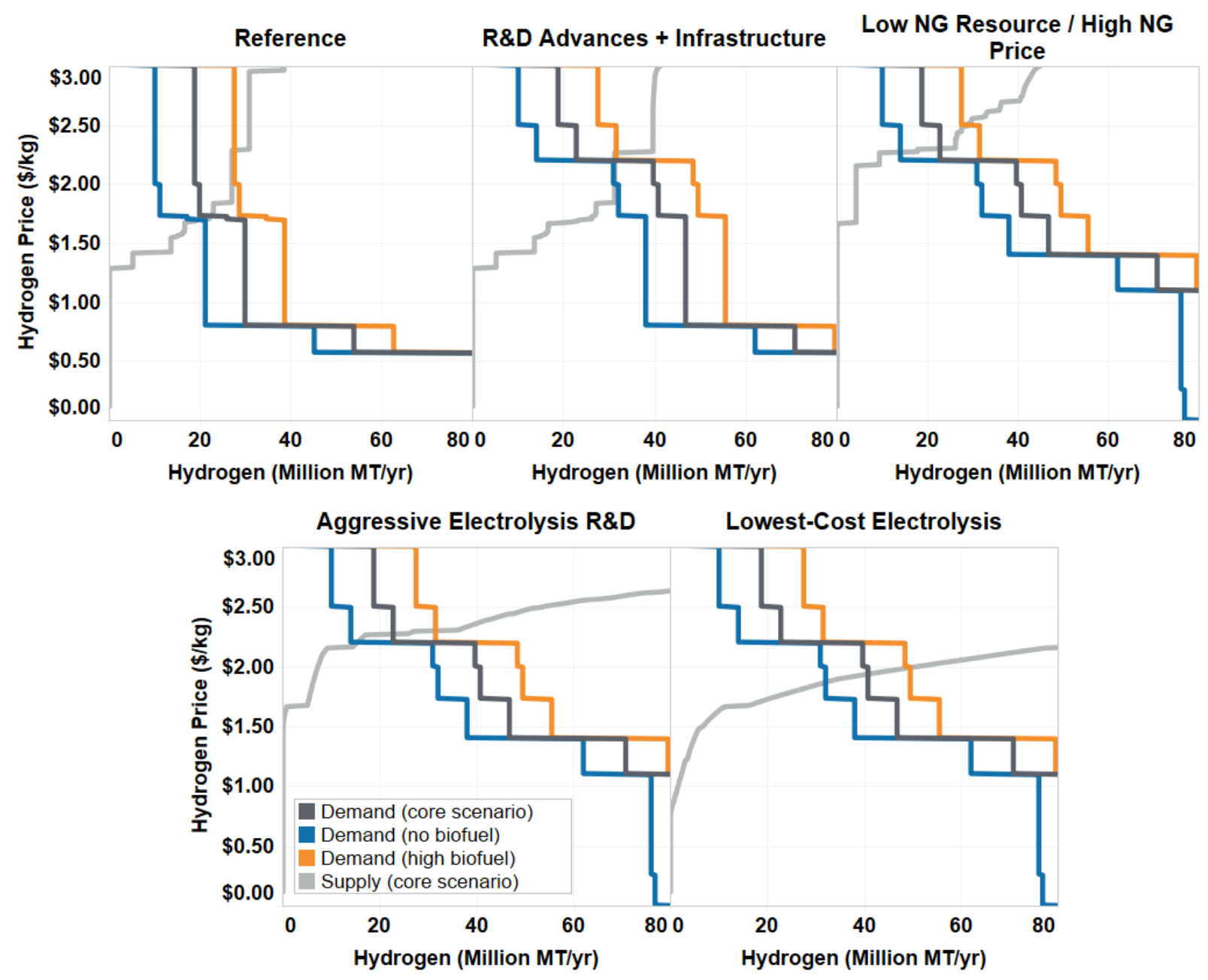

Figure 56. Supply and demand curves for core and biofuel penetration sensitivity scenarios 


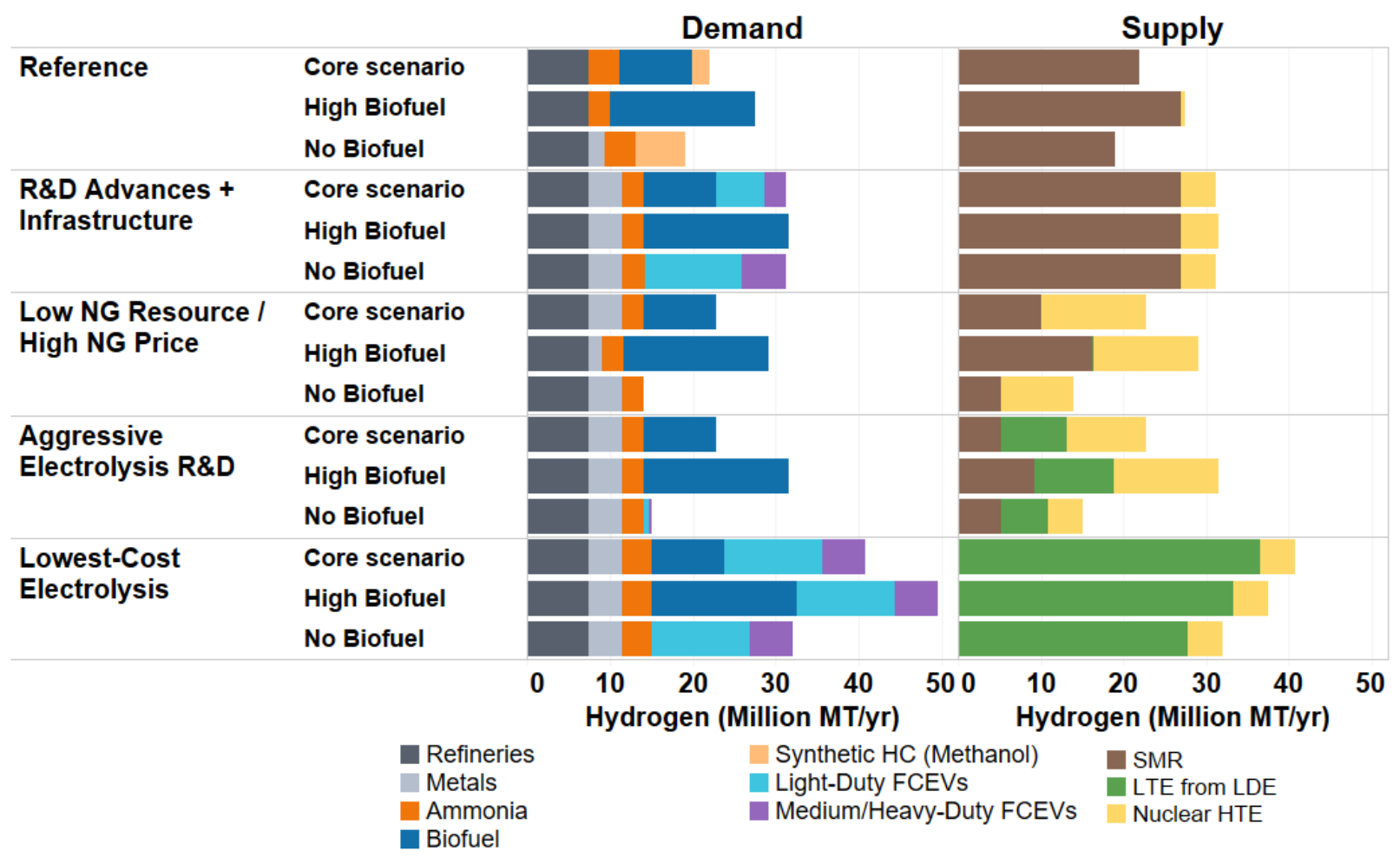

Figure 57. Supply and demand applications for core and biofuel penetration sensitivity scenarios

\subsubsection{Increased Demand Support}

In our core analysis, we assume that all new hydrogen demands - except for metals refining in some scenarios - compete economically. To explore future scenarios with non-economic drivers for other hydrogen demands, we perform sensitivity analyses on select scenarios, increasing the threshold price for hydrogen for MTG fuel, injection into the natural gas system, and seasonal electricity storage - see Figure 58 and Figure 59. The threshold price assumed in each sensitivity scenario by demand application is shown in Table 28. The largest economic potential market is $94 \mathrm{MMT} / \mathrm{yr}$, with the Lowest-Cost Electrolysis scenario's supply curve and demand support for all the applications considered here. This is over 100\% larger than the largest market among our core scenarios (Lowest-Cost Electrolysis, $41 \mathrm{MMT} / \mathrm{yr}$ ), showing the large impact that increased demand support can have. 
Table 28. Demand Price Points for Increased Demand Support Sensitivity Scenarios

\begin{tabular}{lccc}
\hline Scenario Sensitivity & $\begin{array}{c}\text { Hydrogen price for } \\
\text { Synthetic HC (MTG) } \\
\mathbf{( \$ / \mathbf { k g } )}\end{array}$ & $\begin{array}{c}\text { Hydrogen price for } \\
\text { natural gas } \\
\text { injection } \mathbf{( \$ / k g )}\end{array}$ & $\begin{array}{c}\text { Hydrogen price for } \\
\text { seasonal energy } \\
\text { storage (\$/kg) }\end{array}$ \\
\hline Synthetic HC (MTG) Support & 3.00 & 1.40 & $0.26-1.48$ \\
Natural Gas Support & 0.00 & 3.00 & $0.26-1.48$ \\
$\begin{array}{l}\text { Storage Support } \\
\begin{array}{l}\text { Synthetic HC (MTG), Natural } \\
\text { Gas, and Storage Support }\end{array}\end{array}$ & 0.00 & 1.40 & 3.00 \\
\hline
\end{tabular}
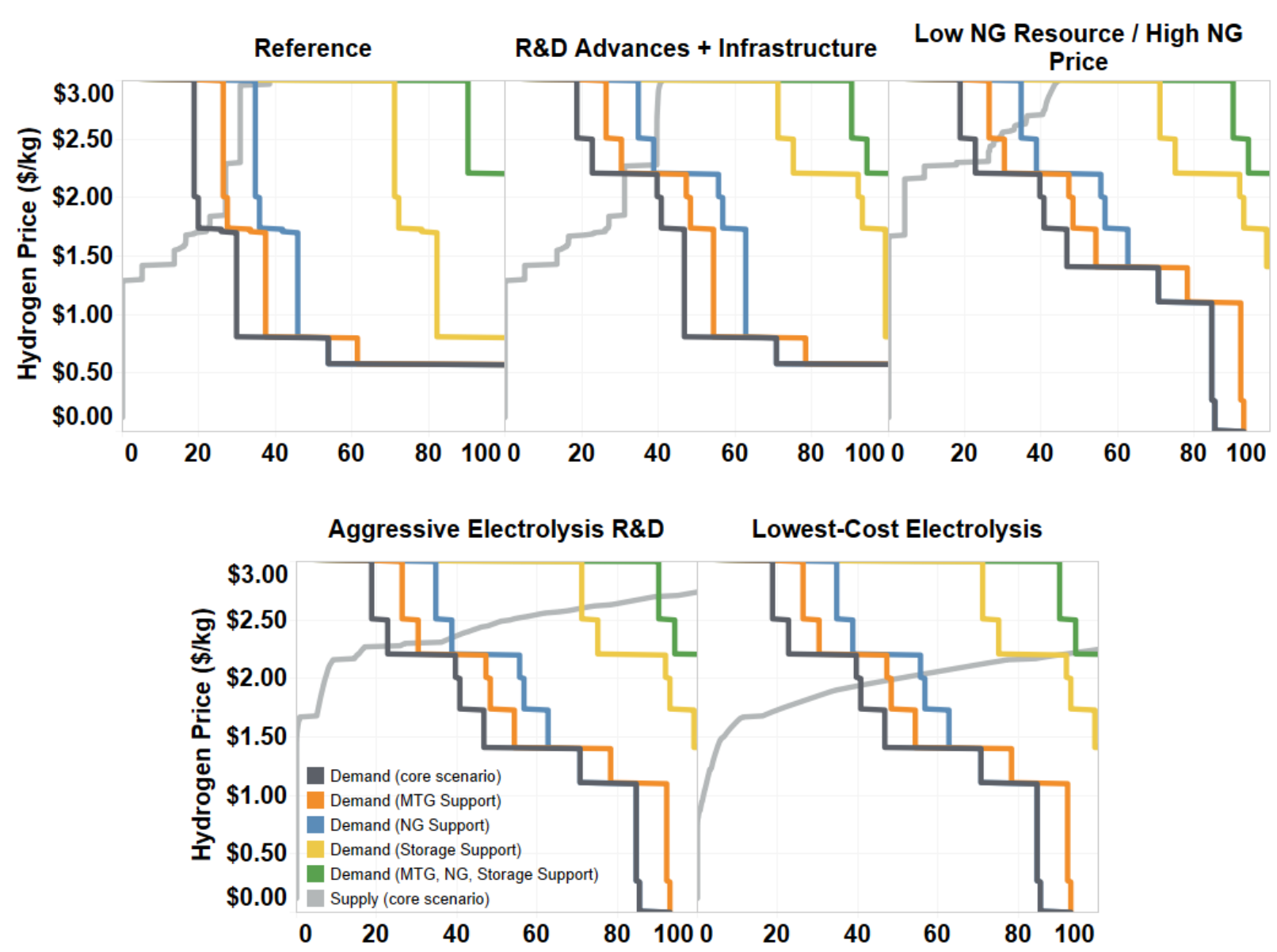

Figure 58. Supply and demand curves for core and demand support sensitivity scenarios 


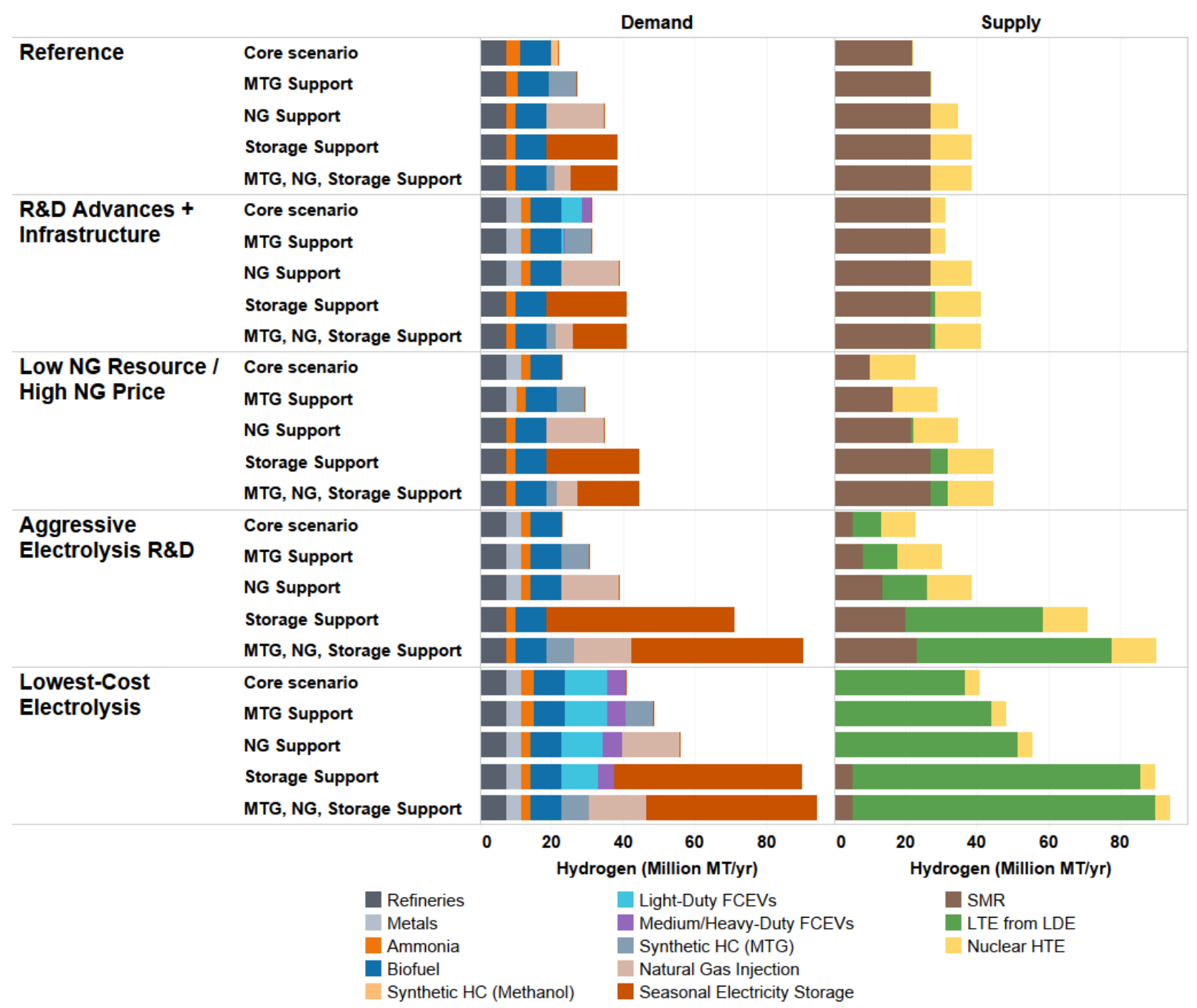

Figure 59. Supply and demand applications for core and demand support sensitivity scenarios

\subsubsection{Summary of Economic Potential Sensitivities}

Summaries of all supply- and demand-side sensitivities are shown in Figure 60 and Figure 61. Supply-side sensitivities include those scenarios with alternative assumptions for hydrogen supply from SMR, LTE, HTE, or biomass gasification. The demand-side sensitivities include those scenarios with alternative assumptions for hydrogen demand, including support for metals refining, biofuel and FCEV penetration, and additional demand support. Across the range of sensitivities, alternative assumptions for supply and demand result in scenarios with both smaller and larger hydrogen markets than estimated in the core scenarios. Market size reductions are a result of limited low-cost hydrogen production resources (e.g., higher natural gas prices, limited natural gas availability for SMR availability, and higher LTE costs) and decreases in demand penetrations (e.g., no hydrogen penetration in biofuels or FCEVs). Larger markets sizes are mostly a result of increased demand penetration or demand support (e.g., support for hydrogen for synthetic fuels, natural gas supplementation, and seasonal storage), but also from greater availability of low-cost hydrogen production (e.g., biomass availability for biomass gasification, and lower-cost LTE and HTE). Market size estimates range from 12-42 MMT/yr in the supply sensitivities and 14-94 MMT/yr in the demand sensitivities. 


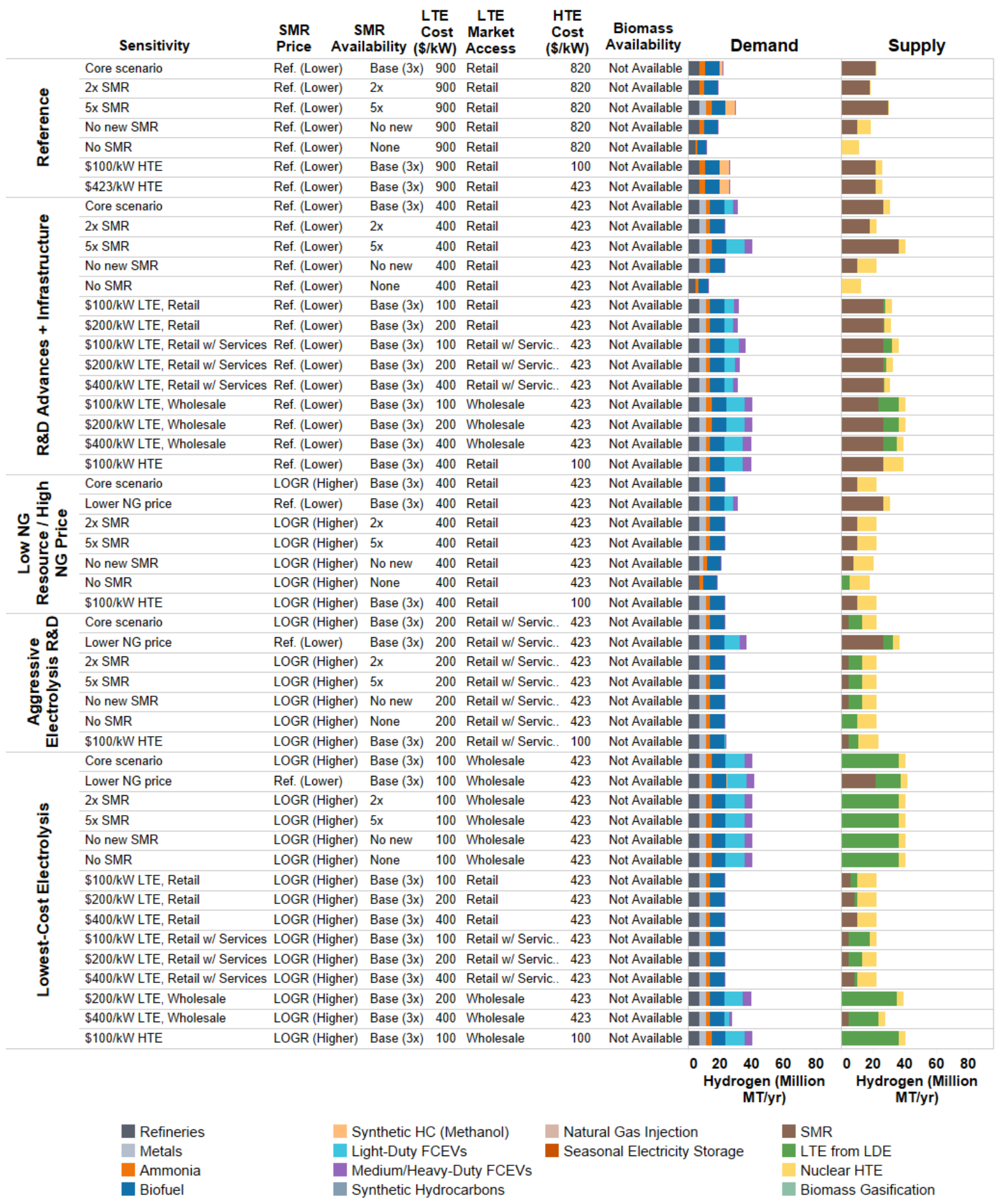

\section{Figure 60. Summary of scenario settings and supply and demand applications for core and} supply-related sensitivities

"Base" setting refers to the value in the core scenario. LOGR = AEO Low Oil and Gas Resource and Technology scenario, Ref. $=$ AEO 2017 Reference scenario 


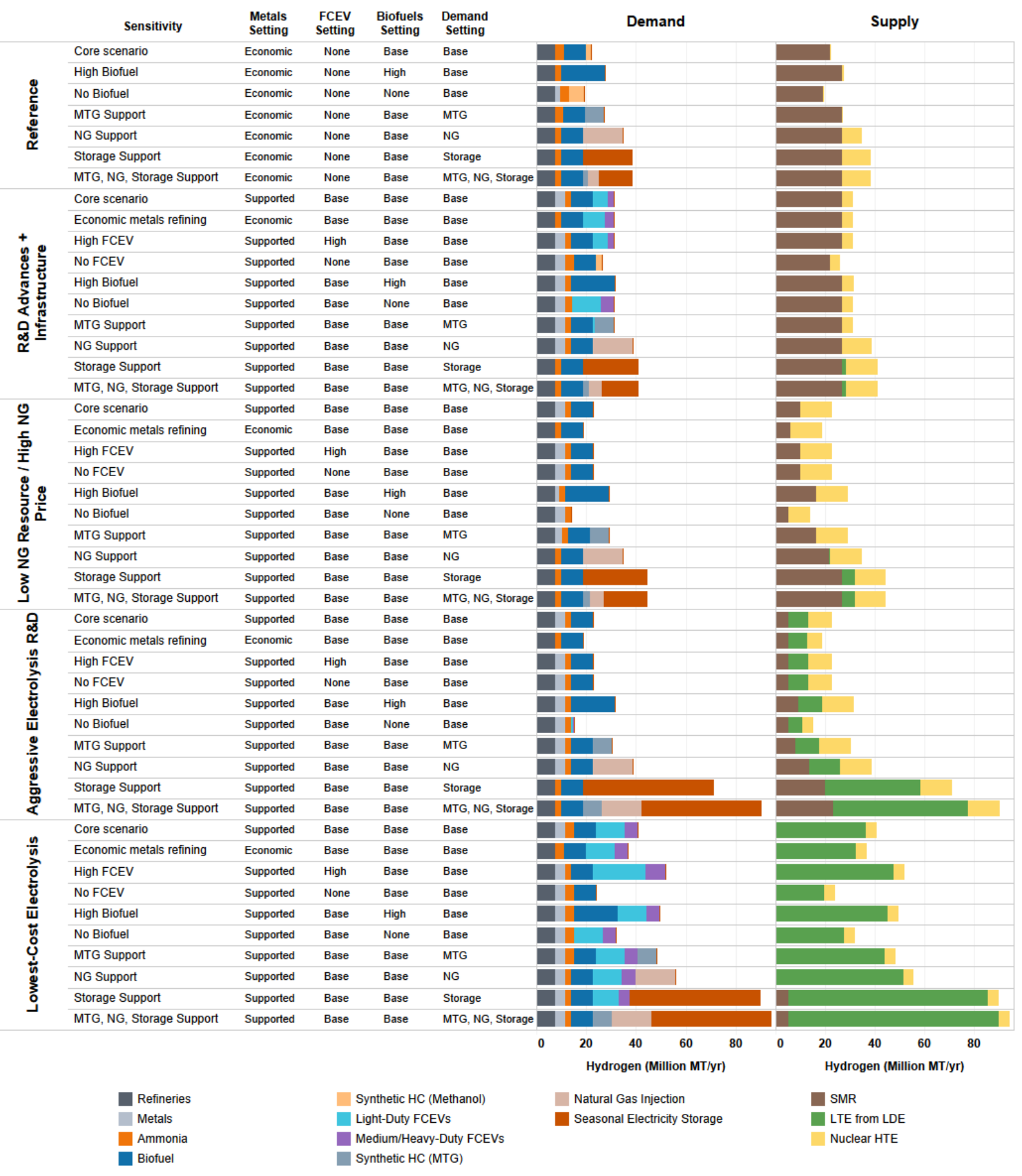

Figure 61. Summary of scenario settings and supply and demand applications for core and demand-related sensitivities

"Base" setting refers to the value in the core scenario. 


\section{Conclusions}

This initial analysis indicates that the H2@Scale concept could have a large impact on the U.S. energy system. We consider mature hydrogen markets in the middle of the $21^{\text {st }}$ century within the contiguous United States. We assume multiple potential R\&D improvements, several possible drivers affecting various markets, and potential changes in costs for purchasing electricity.

The serviceable consumption potential of the U.S. hydrogen market - the quantity of hydrogen that would be consumed to serve the portion of the market that could be captured without considering economics (i.e., if the price of hydrogen were $\$ 0 / \mathrm{kg}$ over an extended period) - is $106 \mathrm{MMT} / \mathrm{yr}$, approximately 11 times larger than the current market. Most of that potential demand would be for applications that are currently served by energy sources other than hydrogen. Today, most hydrogen demand is for oil refining and ammonia production, yet those current demands account for only $8 \%$ of the serviceable consumption potential. FCEVs constitutes about one quarter of the serviceable consumption potential: $21 \mathrm{MMT} / \mathrm{yr}$ for light-duty FCEVs and $8 \mathrm{MMT} / \mathrm{yr}$ for medium- and heavy-duty FCEVs. Almost half of the potential market is for industrial processes, including synthetic HC production (14 MMT/yr), metals refining (12), oil refining (7), ammonia production (4), and biofuel production (9). The final quarter is for hydrogen that supports other energy systems: seasonal electricity storage (15 MMT/yr) and injection into the natural gas system (16). Considering other hydrogen applications, hydrogen's serviceable consumption potential could be larger.

The technical potential of U.S. resources is sufficient to supply the serviceable hydrogen consumption potential. If all the serviceable consumption potential of $106 \mathrm{MMT} / \mathrm{yr}$ were supplied via the U.S. solar resource, only $2.1 \%$ of the solar resource's annual technical potential would be required. Similarly, only $15 \%$ of the combined onshore and offshore wind resource's annual technical potential or $22 \%$ of the geothermal annual technical potential would be required. Only the biomass and hydropower resources are limited: $160 \%$ of the biomass technical potential or $230 \%$ of the hydropower technical potential would be required to produce hydrogen and satisfy other demands if it were the only resource used. We do not anticipate uranium resources would limit the nuclear HTE potential, because there is a high level of uncertainty in that estimate and other reported data due to assumptions regarding ability to mine uranium on sensitive lands and allowances to extract uranium from seawater. Natural gas reserves in the United States could produce $106 \mathrm{MMT} / \mathrm{yr}$ for hydrogen while satisfying other demands for 55 years, assuming that carbon dioxide emissions are not sequestered. If the hydrogen were produced from coal instead, the U.S. coal resource could satisfy hydrogen demand and other demands for 260 years, assuming that carbon dioxide emissions are not sequestered. Even in the unlikely circumstance that hydrogen demand reaches its serviceable consumption potential, the United States has more than enough resources to meet all the demands and make hydrogen a key component of its energy system.

We estimate hydrogen's economic potential to be 22-41 MMT/yr in the contiguous United States depending on resource prices, market conditions, hydrogen technology R\&D and fueling infrastructure availability, and the prices various users will pay for hydrogen, which depend on the cost of other technologies that provide the same services without changes to the current federal and state policy. Hydrogen market size and demand and supply mixes for each of our five 
H2@Scale scenarios are shown in Figure 62. These estimates are based on our assumptions regarding technology improvements and related markets as well as on markets reaching equilibrium. They also include simple hydrogen transport and storage cost assumptions. Additional analysis would be necessary to understand regional issues, estimate transport and storage costs rigorously, and identify key factors in economic transitions. Those analyses could quantify differences between likely market equilibria and our estimates as well as whether equilibrium might be reached and when that might occur.

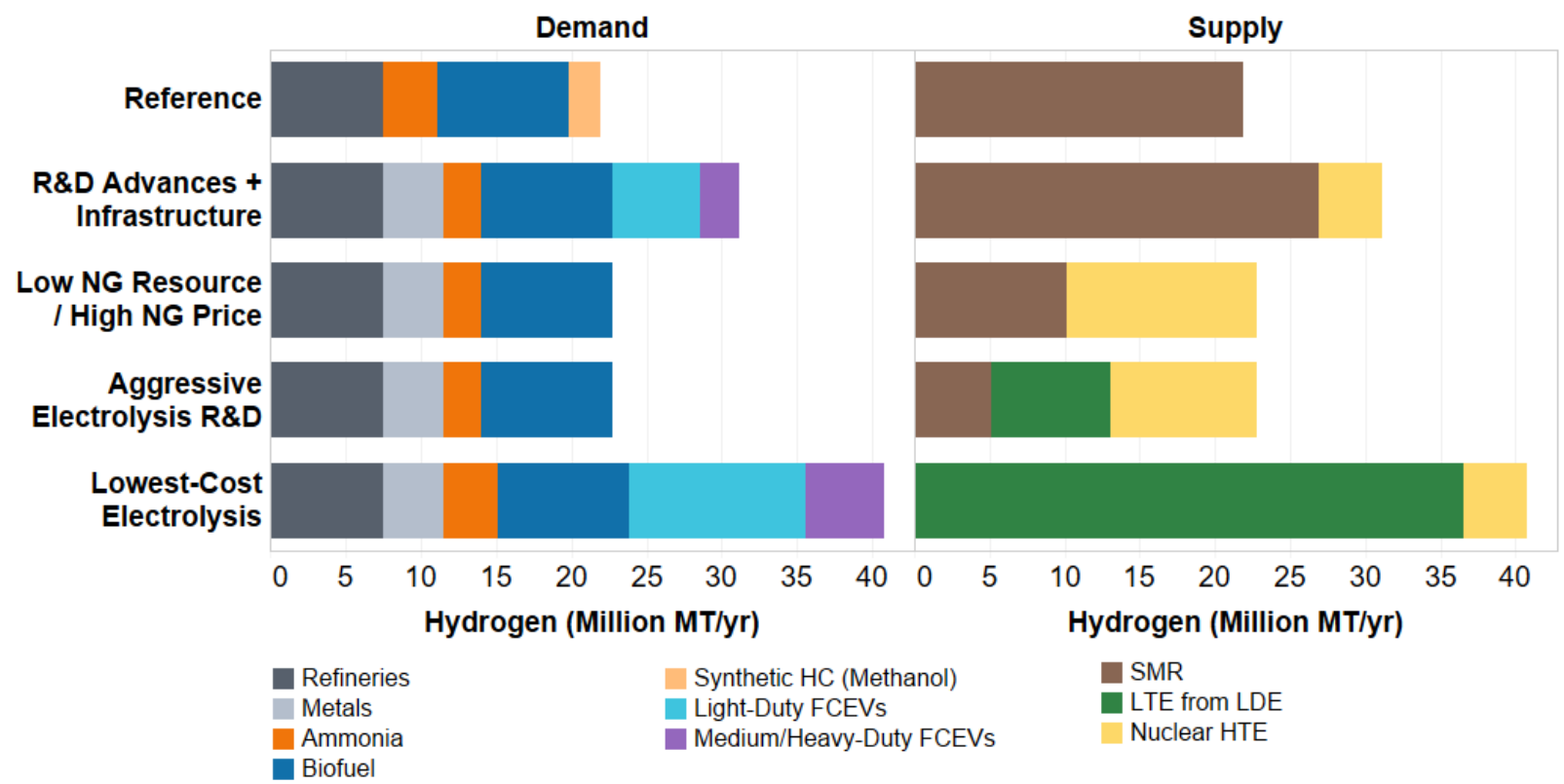

Figure 62. Hydrogen supply sources and demand applications for each H2@Scale scenario

The Reference scenario has a hydrogen market size of $22 \mathrm{MMT} / \mathrm{yr}$. It is based on the current status of hydrogen technologies and expected hydrogen demand growth across all sectors. It assumes U.S. Energy Information Administration Annual Energy Outlook Reference scenario natural gas prices and electrolysis costs based on current technology with robust supply chains, but it does not include fueling infrastructure development for FCEVs or compensation for grid support (i.e., LDE is available at retail price). All hydrogen production is from natural gas via SMR, because the cost of nuclear- and LTE-generated hydrogen is too high to compete with SMR. The current hydrogen markets (oil refining, ammonia, and methanol) and biofuel production are the primary demands in this scenario owing to the lack of alternatives for hydrogen for those processes.

The R\&D Advances + Infrastructure scenario has a larger market size of $31 \mathrm{MMT} / \mathrm{yr}$, because it includes increased hydrogen demands for metals refining and FCEVs (light-duty and medium/heavy-duty). The FCEV demand is driven by achieving the threshold hydrogen price of $\$ 5.00$ at the fueling station $(\$ 2.20 / \mathrm{kg}$ at the terminal) and in the price of FCEVs. This and following scenarios include assumptions that delivery and dispensing technologies meet targets and the infrastructure develops. However, the demand from FCEVs squeezes out some demand growth for ammonia and methanol by driving the hydrogen price up. As in the Reference scenario, the vast majority of hydrogen production is from natural gas via SMR, with a fraction 
produced via nuclear HTE. Just under half of the hydrogen is used for oil refining, metals refining, and ammonia production; the other half is used for biofuels production and FCEVs.

At $23 \mathrm{MMT} / \mathrm{yr}$, the Low NG Resource/High NG Price scenario has a smaller market than the R\&D Advancements + Infrastructure scenario, because higher natural gas prices drive higher hydrogen prices. Demands for oil refining, metals refining, ammonia, and biofuels are the same as in the R\&D Advances + Infrastructure Scenario, but insufficient low-cost hydrogen is available for any FCEV use. Higher natural gas prices also result in a larger market share for nuclear HTE-generated hydrogen (approximately 55\%).

The Aggressive Electrolysis R\&D scenario includes lower-cost LTE than the first three scenarios and retains the demand assumptions in the R\&D Advances + Infrastructure and Low NG Resource/High NG Price scenario. The resulting market size of $23 \mathrm{MMT} / \mathrm{yr}$ is the same as in the Low NG Resource/High NG Price scenario, but the market shares for generation change. Owing to the more aggressive LTE technology and electricity price assumptions, LTE-generated hydrogen is more competitive and takes about one third of the market, while SMR falls to about $22 \%$ and nuclear HTE to about $43 \%$.

The Lowest-Cost Electrolysis scenario has the largest market (41 MMT/yr) owing to its combination of high demand and low hydrogen prices enabled by low-cost LTE technologies and access to wholesale LDE prices. Approximately 90\% (37 MMT/yr) of the hydrogen is produced using LTE, with the remaining $4 \mathrm{MMT} / \mathrm{yr}$ from nuclear HTE. The larger ammonia market requiring $4 \mathrm{MMT} / \mathrm{yr}$ appears in this scenario as it does in the Reference scenario. In addition, this scenario has the highest FCEV demand (17 MMT/yr) because it has the lowest hydrogen price.

By comparing these results to the impacts of scenarios that do not have integrated hydrogen energy systems, we draw several key conclusions about potential of the H2@Scale concept:

The domestic hydrogen market could increase 2 - to 4-fold if $R \& D$ targets are met and market and transition barriers are overcome. At those market sizes, hydrogen production is $4-17 \%$ of primary energy use. If the requisite conditions are achieved, hydrogen could provide energy and feedstock options that cost less than competing alternatives. In the Reference scenario, the hydrogen market size is $22 \mathrm{MMT} / \mathrm{yr}$ which is double the current market and equivalent to $3.0 \mathrm{quad} / \mathrm{yr}$ (2.6\% of primary energy). At $41 \mathrm{MMT} / \mathrm{yr}$ ( $8 \mathrm{quad} / \mathrm{yr})$, the hydrogen market in the Lowest-Cost Electrolysis scenario is $6.4 \%$ of primary energy. Hydrogen production requires $17 \%$ of primary energy when calculated using an avoided fossil energy generation method. ${ }^{66}$

Conditions shown to maximize that increase include reducing the purchase price of LTEs to at most $\$ 200 / \mathrm{kW}$ (as in the Aggressive Electrolysis R\&D scenario) but more beneficially to $\$ 100 / \mathrm{kW}$ (as in the Lowest-Cost Electrolysis scenario) and having access to at least some compensation for providing grid services (as in the Aggressive Electrolysis R\&D scenario) but

\footnotetext{
${ }^{66}$ The fossil energy generation method puts renewable and fossil resources on the same basis. Electricity from renewable resources is reported as primary energy that would be required if it were generated using fossil resources at an efficiency of $37 \%$ - the average efficiency of fossil generation in AEO.
} 
more beneficially access to wholesale LDE prices (as in the Lowest-Cost Electrolysis scenario). The combination of lower capital cost and access to lower-cost electricity allows the LTE to use low-priced electricity when available. While using only low-priced electricity results in lower capacity factors than using electricity at all times, it also results in lower cost hydrogen supply. Although the combination of lower capital cost and wholesale LDE prices is required for substantial expansion, electricity price has a somewhat stronger impact on market size than the electrolyzer capital cost does. Very low capital costs provide little market expansion without wholesale LDE prices. Similarly, market expansion is modest in the absence of capital cost reductions, even when wholesale LDE prices are available.

An increased hydrogen market size can be realized even if low-cost LTE is not available as long as other hydrogen production options are available, including the following:

- SMR with low-cost natural gas - The low cost of natural gas in the R\&D Advances + Infrastructure scenario results in a large hydrogen market owing to cost-competitive FCEVs and fueling infrastructure, which is not observed in the scenarios with higher natural gas costs and without the lowest-cost LTE options (the Low NG Resource/High NG Price and Aggressive Electrolysis R\&D scenarios). We assume the quantity of natural gas reforming growth is capped at three times current values to approximate the potential natural gas price increases that would occur due to increased demand for hydrogen production. If LTE or LDE costs are high and the quantity of natural gas reforming were not capped, a larger hydrogen market would be possible.

- Low-cost HTE, even when constrained to use nuclear energy only-Our constraining of HTE technologies to be attached to nuclear plants limits their production to $13 \mathrm{MMT} / \mathrm{yr}$ or less in the scenarios we consider, depending on the cost of hydrogen from other sources. If HTE technology could employ additional cost-competitive energy sources (e.g., LDE or grid electricity coupled with natural gas-generated heat), the hydrogen market size might increase.

- Biomass - If the biomass resource is available for hydrogen production (because other potential applications do not outcompete for it), it supplies $22 \mathrm{MMT} / \mathrm{yr}$ of the hydrogen in a $34 \mathrm{MMT} / \mathrm{yr}$ market owing to its price competitiveness with natural gas, LTE, and HTE technologies.

Transportation is the largest new hydrogen market opportunity. Light-, medium-, and heavy-duty FCEV fuel constitutes 29 MMT/yr (27\%) of the serviceable consumption potential. That hydrogen demand could reduce petroleum use by up to $15 \%$. Among our economic potential scenarios, the Lowest-Cost Electrolysis scenario yields the largest reduction in petroleum use (15\%), because it has the highest FCEV penetration: $12 \mathrm{MMT} / \mathrm{yr}$ of hydrogen fuels $18 \%$ of cars and $26 \%$ of light-duty trucks, and $5 \mathrm{MMT} / \mathrm{yr}$ fuels $22 \%$ of the medium- and heavy-duty vehicle fleet.

Other new hydrogen markets are also possible. Biofuel production is consistently a growth market for hydrogen based on our assumptions that biofuels will have a significant share in the aviation fuels market and that hydrotreating and hydrogenation will be important in producing those fuels. Additional analysis on biofuel markets and process designs would improve the quantification of that opportunity. Metals refining is a growth opportunity across most of our scenarios; however, we assume market support to increase U.S. steel production using hydrogen. Additional R\&D is needed for steel production using hydrogen to meet our hydrogen demand 
target for this application. Synthetic methanol production for a methanol-to-gasoline (MTG) fuel does not appear in our core scenarios, but sensitivities indicate that technology R\&D and market opportunities such as a desire for non-fossil liquid fuels would result in growth of that market. Likewise, injection into natural gas pipelines and seasonal electricity storage do not appear in our core scenarios, because, within this national-scale analysis, hydrogen is not cost-competitive for these applications under our assumptions. However, this analysis does not capture the full variability of electricity net loads or potential policy/cost drivers of $100 \%$ or near- $100 \%$ renewable energy targets, emission reductions, and other factors that could impact those results.

LTE could boost renewable electricity generation deployment and utilization. When LTE contributes to hydrogen production in our scenarios, the capacity of renewable energy generation technologies increases because of additional demand for LDE. In addition, utilization of renewable electricity generators increases, because generation that exceeds the non-LTE load would be curtailed without the LTE. These two effects amplify the benefits of the integrated system. The renewable generators supply the grid when grid electricity is required, and they supply LTE hydrogen production with LDE when grid electricity is not required. In the LowestCost Electrolysis scenario, renewable electricity generation increases by more than $60 \%$ over the ReEDS High Curtailment scenario, and natural gas use for electricity decreases by $27 \%$.

The impacts of an integrated hydrogen system could be larger. We calculate a serviceable consumption potential hydrogen market size of $106 \mathrm{MMT} / \mathrm{yr}$ in the contiguous 48 states, more than 2.5 times as large as our largest estimate of economic potential (under the Lowest-Cost Electrolysis scenario), and we identify ample U.S. resources for satisfying this higher demand. However, non-economic drivers or economic conditions outside the scope of this analysis would be necessary to realize this demand. For example, higher-than-estimated prices for liquid fuels could increase the demand for hydrogen to fuel FCEVs more than our economic potential estimates indicate. Sensitivity analysis shows that —if drivers outside the scope of this analysis increase the demands for nonpetroleum fuel, hydrogen injection into the natural gas system, and seasonal electricity storage - the market size in the Lowest-Cost Electrolysis scenario could increase by over $100 \%$ (from 41 to $94 \mathrm{MMT} / \mathrm{yr}$ ).

In conclusion, this initial analysis shows that hydrogen has potential to provide technical and economic synergies when integrated across multiple sectors of the U.S. energy system. To realize the potential of the H2@Scale concept, continued R\&D and deployment are required, particularly with regard to electrolyzer technology. Also, continuing evolution of electricity markets that would allow electrolyzers to monetize the energy and grid services that they can provide would enable considerable opportunities. 


\section{Analysis Limitations and Additional Analysis Needs}

In this analysis, we try to consider the full spectrum of hydrogen demands and most production options, but we may not include all possibilities; thus, further investigation into possible demands and impacts of different supply options should be considered. On the demand side, further research into the potential of hydrogen as a chemical feedstock for industrial products is warranted especially for synthetic HCs and other key products that can be produced from hydrogen and carbon dioxide. Both concentrated and dilute carbon dioxide streams should be considered. Likewise, hydrogen could be used as an energy source for marine and rail applications; those applications should be considered. It is also a potential energy source for material handling equipment and tactical vehicles, but those markets are much smaller than other transportation markets.

Additional analysis of the threshold prices for hydrogen applications would be valuable, especially those with a single threshold price for a large quantity. The primary market requiring additional analysis is LDVs. Additional vehicle-choice modeling that includes variations on the hydrogen price (e.g., at $\$ 2.00 / \mathrm{kg}, \$ 2.10 / \mathrm{kg}, \$ 2.30 / \mathrm{kg}$, and $\$ 2.40 / \mathrm{kg}$ in addition to the $\$ 2.20 / \mathrm{kg}$ reported in this analysis) would provide more discrete market sizes and increase confidence in the results. Likewise, the market sizes for medium- and heavy-duty FCEVs would benefit from vehicle-choice modeling including a range of hydrogen prices instead of the price-insensitive ZEV analysis used in our study.

In addition, we do not perform a cross-cutting analysis of the LDV market. Because hydrogen is used for FCEVs, to produce gasoline and diesel, and for some biofuels, the fleet mix impacts the hydrogen demands and is impacted by hydrogen prices. The potential for PEVs to use LDE could also impact hydrogen prices and markets. A more in-depth study of those impacts and tradeoffs would improve the characterization of the potential for hydrogen in that market.

On the supply side, additional options are available for hydrogen production. One option is HTE that is not coupled with nuclear reactors but rather uses electricity from the grid (possibly LDE) and heat generated by combustion biogas, natural gas, or another feedstock. The supply curve for that option should be considered. Likewise, developing supply curves for hydrogen production via PEC pathways, solar-thermal routes, and photobiological options - and then integrating these curves into the overall supply curves - may identify opportunities to increase supplies at lower costs. Furthermore, detailed cost estimates for future LTE and HTE technologies will increase the confidence in supply curves. Those cost estimates should include considerations for byproduct value that decreases hydrogen's levelized cost. Natural gas prices in this analysis are from the AEO (EIA 2017a). Further analysis on impacts of exports and policies on natural gas prices is warranted.

Our analysis is based on national supply and demand curves with simple assumptions regarding delivery costs across regions and storage costs for hydrogen production and demand options that vary over time (e.g., production from LDE and demand for FCEVs). Analysis of the transportation and storage requirements and costs for each scenario is warranted. In addition, regionalizing the economics of hydrogen markets and estimating imports and exports across regions would improve the fidelity of the analytical results. Analysis of potential policy 
implications on both national and regional supply and demand curves also should be considered in future analyses.

The static nature of our supply and demand curves - by which they do not affect related markets - should be validated and adjusted if necessary. One of the first parameters that should be reviewed is the natural gas price. Using large quantities of natural gas to produce hydrogen likely would increase the natural gas price, thus increasing the cost of SMR hydrogen and resulting in smaller markets and/or larger shares of hydrogen produced from other sources. Likewise, large reductions in natural gas use for hydrogen production likely would reduce natural gas prices. Other economic effects would also impact our results, including lower petroleum prices due to displacement of petroleum in the transportation sector. We also do not consider potential impacts of hydrogen imports or exports, which could affect market sizes.

Another key consideration that we do not include is competition for resources such as land and water and how those might impact hydrogen prices. Likewise, we do not consider competition for LDE that might limit its availability to produce hydrogen.

Finally, we identify the economic potentials for several scenarios but do not consider how to reach those potentials. Analyzing the transition from today's market and infrastructure to future scenarios would clarify the feasibility of the economic potentials and related timing of investments. That analysis could identify requirements to make each scenario plausible as well as timing of R\&D and initial commercialization. It could also identify regulatory and market modifications that might be necessary. Such an analysis likely would identify near-term opportunities for hydrogen to serve as a valuable energy carrier. Considering transition needs and opportunities could require analysis of specific regions to support regional decisions. 


\section{References}

AFDC. 2014. "Transportation Energy Use by Mode and Fuel Type." Alternative Fuels Data Center. 2014. https://www.afdc.energy.gov/data/10661.

_. 2016. "Light-Duty AFV, HEV, and Diesel Model Offerings, by Fuel Type." Alternative Fuels Data Center. 2016. https://www.afdc.energy.gov/data/10303.

_. 2018. "Low Carbon Fuel Standard.” Alternative Fuels Data Center. 2018. https://www.afdc.energy.gov/laws/6308.

Air Liquide. 2017. "Air Liquide Ready to Build Hydrogen Station Network in New York." Air Liquide USA. February 9, 2017. https://industry.airliquide.us/air-liquide-ready-build-hydrogenstation-network-new-york.

Altfeld, K., and D. Pinchbeck. 2013. "Admissible Hydrogen Concentrations in Natural Gas Systems." Gas for Energy March.

http://www.gerg.eu/public/uploads/files/publications/GERGpapers/SD_gfe_03_13_Report_Altfe ld-Pinchbeck.pdf.

ANL. 2017. GREET ${ }^{\circledR}$ Model: The Greenhouse Gases, Regulated Emissions, and Energy Use in Transportation Model. Argonne, IL: Argonne National Laboratory. https://greet.es.anl.gov/.

—. 2018. "Hydrogen Delivery Scenario Analysis Model (HDSAM)." Argonne National Laboratory. 2018. https://hdsam.es.anl.gov/index.php?content=hdsam.

Auto Alliance. n.d. "State Electric Vehicle Mandate." Auto Alliance. Accessed June 22, 2018. https://autoalliance.org/energy-environment/state-electric-vehicle-mandate/.

Baronas, Jean, Gerhard Achtelik, Jane Berner, Phil Cazel, Miki Crowell, Leslie Goodbody, Andrew Martinez, Mark Johnson, Sebastian Serrato, and Lawrence Vettraino. 2019. "Joint Agency Staff Report on Assembly Bill 8: 2019 Annual Assessment of Time and Cost Needed to Attain 100 Hydrogen Refueling Stations in California." CEC-600-2019-039. California Energy Commission and California Air Resources Board.

BNEF. 2020. "Hydrogen Economy Outlook: Key Messages." https://data.bloomberglp.com/professional/sites/24/BNEF-Hydrogen-Economy-Outlook-KeyMessages-30-Mar-2020.pdf.

Braunsdorf, Philipp. 2018. "Country Overview Germany." Presented at the International Hydrogen Infrastructure Workshop, Boston, MA, September 11.

https://www.energy.gov/sites/prod/files/2018/10/f56/fcto-infrastructure-workshop-2018-1braunsdorf.pdf.

Brown, Austin, Philipp Beiter, Donna Heimiller, Carolyn Davidson, Paul Denholm, Jennifer Melius, Anthony Lopez, Dylan Hettinger, David Mulcahy, and Gian Porro. 2016. "Estimating Renewable Energy Economic Potential in the United States: Methodology and Initial Results." NREL/TP-6A20-64503. Golden, CO: National Renewable Energy Laboratory. https://www.nrel.gov/docs/fy15osti/64503.pdf. 
Brown, Daryl. 2016. “U.S. Hydrogen Production - 2015.” CryoGas International, July.

Brown, Trevor. 2018. "Ammonia Capacity in North America." Ammonia Industry. November 1, 2018. https://ammoniaindustry.com/download-ammonia-capacity-in-north-america/.

Brownlie, A.D., and M.F. Lloyd Prichard. 1963. "Professor Fleeming Jenkin, 1833-1885 Pioneer in Engineering and Political Economy." Oxford Economic Papers 15 (3): 204-16.

California Fuel Cell Partnership. 2020. "Stations Map.” 2020. https://cafcp.org/stationmap.

California ISO. 2018. "2017 Annual Report on Market Issues and Performance." http://www.caiso.com/Documents/2017AnnualReportonMarketIssuesandPerformance.pdf.

CARB. 2016a. "LCFS Basics." California Air Resources Board. 2016. https://www.arb.ca.gov/fuels/lcfs/background/basics.htm.

- 2016b. "Mobile Source Strategy." Sacramento: California Environmental Protection Agency. https://www.arb.ca.gov/planning/sip/2016sip/2016mobsrc.pdf.

. 2018. "CARB Amends Low Carbon Fuel Standard for Wider Impact.” September 27, 2018. https://ww2.arb.ca.gov/news/carb-amends-low-carbon-fuel-standard-wider-impact.

Cebulla, F., T. Naegler, and M. Pohl. 2017. "Electrical Energy Storage in Highly Renewable European Energy Systems: Capacity Requirements, Spatial Distribution, and Storage Dispatch." Journal of Energy Storage 14: 211-223.

CEC. 2019. "Total System Electric Generation.” California Energy Commission. 2019. https://www.energy.ca.gov/data-reports/energy-almanac/california-electricity-data/2018-totalsystem-electric-generation.

Chang, M.K., J.D. Eichman, F. Mueller, and S. Samuelsen. 2013. "Buffering Intermittent Renewable Power with Hydroelectric Generation: A Case Study in California." Applied Energy 112: $1-11$.

Chevrier, V. 2018. "Hydrogen Uses in Ironmaking.” Presented at the H2@Scale Workshop, Chicago, August 1.

Cole, W. J., C. Marcy, V. K. Krishnan, and R. Margolis. 2016. "Utility-Scale Lithium-Ion Storage Cost Projections for Use in Capacity Expansion Models." In 2016 North American Power Symposium (NAPS), 1-6. https://doi.org/10.1109/NAPS.2016.7747866.

Cole, Wesley, Trieu Mai, James Richards, Paritosh Das, and Paul Donohoo-Vallett. 2017. "2017 Standard Scenarios Report: A U.S. Electricity Sector Outlook.” Renewable Energy, 62.

Conca, James. 2016. "Illinois Sees The Light -- Retains Nuclear Power." Forbes. December 4, 2016. https://www.forbes.com/sites/jamesconca/2016/12/04/illinois-sees-the-light-retainsnuclear-power/. 
Connelly, E., A. Elgowainy, and M. Ruth. 2019. "Current Hydrogen Market Size: Domestic and Global.” DOE Hydrogen and Fuel Cells Program Record 19002. U.S. Department of Energy. https://www.hydrogen.energy.gov/pdfs/19002-hydrogen-market-domestic-global.pdf.

Connelly, E., M. Penev, A. Milbrandt, N. Gilroy, and M. Melaina. 2020. "Resource Assessment for Hydrogen Production." National Renewable Energy Laboratory.

CPUC. n.d. "Renewables Portfolio Standard (RPS) Program.” Accessed June 22, 2020. https://www.cpuc.ca.gov/rps/.

Davis, Lucas, and Catherine Hausman. 2016. "Market Impacts of a Nuclear Power Plant Closure." American Economic Journal: Applied Economics 8 (2): 92-122. https://doi.org/10.1257/app.20140473.

Denholm, Paul, Jennie Jorgenson, Marissa Hummon, Thomas Jenkin, David Palchak, Brendan Kirby, Ookie Ma, and Mark O’Malley. 2013. "The Value of Energy Storage for Grid Applications.” Technical Report NREL/TP-6A20-58465. Golden, CO: National Renewable Energy Laboratory. https://www.nrel.gov/docs/fy13osti/58465.pdf.

Denholm, Paul, Joshua Novacheck, Jennie Jorgenson, and Matthew O'Connell. 2016. "Impact of Flexibility Options on Grid Economic Carrying Capacity of Solar and Wind: Three Case Studies." NREL/TP-6A20-66854. Golden, CO: National Renewable Energy Laboratory. https://www.nrel.gov/docs/fy17osti/66854.pdf.

Denholm, Paul, Matthew O'Connell, Gregory Brinkman, and Jennie Jorgenson. 2015. "Overgeneration from Solar Energy in California: A Field Guide to the Duck Chart." NREL/TP6A20-65023. Golden, CO: National Renewable Energy Laboratory. https://www.nrel.gov/docs/fy16osti/65023.pdf.

DOE. 2010. "Biomass Energy Data Book: Edition 3.” Oak Ridge National Laboratory. https://info.ornl.gov/sites/publications/files/Pub28524.pdf.

—. 2016. "2016 Billion-Ton Report: Advancing Domestic Resources for a Thriving Bioeconomy, Volume I: Economic Availability of Feedstocks." ORNL/TM-2016/160. Oak Ridge, TN: Oak Ridge National Laboratory. https://www.energy.gov/sites/prod/files/2016/12/f34/2016_billion_ton_report_12.2.16_0.pdf.

—. 2018a. "H2A: Hydrogen Analysis Production Case Studies.” 2018. https://www.nrel.gov/hydrogen/h2a-production-case-studies.html.

. 2018b. "Fuel Cell Truck Powertrain R\&D Activities and Target Review Workshop: H2@Scale End Use Applications.” Chicago, IL, July 30.

https:/www.energy.gov/eere/fuelcells/fuel-cell-truck-powertrain-rd-activities-and-target-reviewworkshop-h2-scale-end-use.

n.d. "Cities Leading through Energy Analysis and Planning." Energy.Gov. Accessed April 8, 2019. https://www.energy.gov/eere/cities-leading-through-energy-analysis-andplanning. 
DSIRE. 2019. "Renewable \& Clean Energy Standards." Database of State Incentives for Renewables \& Efficiency. https://s3.amazonaws.com/ncsolarcen-prod/wpcontent/uploads/2019/07/RPS-CES-June2019.pdf.

Dufo-López, R., J.L. Bernal-Agustín, and J.A. Domínguez-Navarro. 2009. “Generation Management Using Batteries in Wind Farms: Economical and Technical Analysis for Spain." Energy Policy 37: 126-39.

Dutta, Abhijit, Kristiina Iisa, Michael Talmadge, Calvin Mukarakate, Michael Griffin, Eric Tan, Nolan Wilson, et al. 2020. "Ex Situ Catalytic Fast Pyrolysis of Lignocellulosic Biomass to Hydrocarbon Fuels: 2019 State of Technology and Future Research.” Renewable Energy, 44.

EIA. 2015a. “Annual Energy Outlook 2015.” 2015. https://www.eia.gov/outlooks/archive/aeo15/.

- 2015b. "Top 100 U.S. Oil and Gas Fields."

https://www.eia.gov/naturalgas/crudeoilreserves/top100/pdf/top100.pdf.

2015c. "Power-to-Gas Brings a New Focus to the Issue of Energy Storage from Renewable Sources.” U.S. Energy Information Administration. July 24, 2015. https:/www.eia.gov/todayinenergy/detail.php?id=22212.

. 2016. "Changes in Steel Production Reduce Energy Intensity - Today in Energy - U.S. Energy Information Administration (EIA).” July 29, 2016. https://www.eia.gov/todayinenergy/detail.php?id=27292.

—. 2017a. “Annual Energy Outlook 2017.” Washington, DC: U.S. Energy Information Administration. https://www.eia.gov/outlooks/aeo/data/browser/.

- 2017b. "Coal Explained: Use of Coal.” U.S. Energy Information Administration. 2017. https://www.eia.gov/energyexplained/index.php?page=coal_use.

—. 2017c. "Natural Gas Explained: Use of Natural Gas." U.S. Energy Information Administration. 2017.https://www.eia.gov/energyexplained/index.php?page=natural_gas_use.

_. 2017d. "Oil: Crude and Petroleum Products Explained: Use of Oil.” U.S. Energy Information Administration. 2017.

https://www.eia.gov/energyexplained/index.php?page=oil_use.

_. 2017e. "Petroleum \& Other Liquids: Refinery Capacity Report." https:/www.eia.gov/petroleum/refinerycapacity/archive/2017/refcap2017.php.

_.2017f. "U.S. Nuclear Generation and Generating Capacity." https://www.eia.gov/nuclear/generation/index.html.

- 2017g. "Use of Energy in the United States Explained: Energy Use for Transportation." U.S. Energy Information Administration. 2017. https://www.eia.gov/Energyexplained/?page=us_energy_transportation. 
_. 2018a. “Annual Energy Outlook 2018.” Washington, DC: U.S. Energy Information Administration. https://www.eia.gov/outlooks/aeo/.

- 2018b. "How Much Oil Consumed by the United States Comes from Foreign Countries?" U.S. Energy Information Administration. 2018.

https://www.eia.gov/tools/faqs/faq.php?id=32\&t=6.

—. 2019. "Despite Closures, U.S. Nuclear Electricity Generation in 2018 Surpassed Its Previous Peak." March 21, 2019. https://www.eia.gov/todayinenergy/detail.php?id=38792.

_. 2020a. "Monthly Energy Review, Table 1.3: Primary Energy Consumption by Source." 2020. https://www.eia.gov/totalenergy/data/monthly/.

—. 2020b. "Monthly Energy Review, Table 2.1: Energy Consumption by Sector.” 2020. https://www.eia.gov/totalenergy/data/monthly/.

_. 2020c. "Monthly Energy Review, Table 7.2a: Electricity Generation, Total (All Sectors)." 2020. https://www.eia.gov/totalenergy/data/monthly/.

- 2020d. "Use of Energy in the United States Explained: Energy Use for Transportation." 2020. https://www.eia.gov/Energyexplained/use-of-energy/transportation.php.

- n.d. "Primary Energy." U.S. Energy Information Administration. https://www.eia.gov/tools/glossary/index.php?id=Primary\%20energy.

Eichman, J., K. Harrison, and M. Peters. 2014. "Novel Electrolyzer Applications: Providing More Than Just Hydrogen.” NREL/TP-5400-61758. Golden, CO: National Renewable Energy Laboratory. https://www.nrel.gov/docs/fy14osti/61758.pdf.

Elgowainy, Amgad, Jeongwoo Han, Hao Cai, Michael Wang, Grant S. Forman, and Vincent B. DiVita. 2014. "Energy Efficiency and Greenhouse Gas Emission Intensity of Petroleum Products at U.S. Refineries." Environmental Science \& Technology 48 (13): 7612-24. https://doi.org/10.1021/es5010347.

Elgowainy, Amgad, Marianne Mintz, Uisung Lee, Thomas Stephens, Pingping Sun, Yan Zhou, Guiyan Zang, et al. 2020. "Assessment of the Potential Demand for Hydrogen in Vehicle and Industrial Applications.” ANL-20/35. Argonne, IL: Argonne National Laboratory.

Energy Exemplar. 2019. “PLEXOS® Simulation Software.” Energy Exemplar (blog). 2019. https://energyexemplar.com/products/plexos-simulation-software/.

Entergy Newsroom. 2019. "Pilgrim Nuclear Power Station Shut Down Permanently." May 31, 2019. https:/www.entergynewsroom.com/news/pilgrim-nuclear-power-station-shut-downpermanently/.

EPA. 2016. “2014 National Emissions Inventory.” Policies and Guidance.

https://www.epa.gov/air-emissions-inventories/2014-national-emissions-inventory-nei-data. 
- 2017. "Inventory of U.S. Greenhouse Gas Emissions and Sinks: 1990-2015." EPA 430P-17-001. Washington, DC: EPA. https://www.epa.gov/ghgemissions/inventory-us-greenhousegas-emissions-and-sinks-1990-2015.

Epiney, Aaron, Cristian Rabiti, Andrea Alfonsi, Paul Talbot, and Francesco Ganda. 2017.

"Report on the Economic Optimization of a Demonstration Case for a Static N-R HES

Configuration Using RAVEN.” INL/EXT-17-41915. Idaho National Laboratory.

Eudy, Leslie, and Matthew Post. 2018. "Fuel Cell Buses in U.S. Transit Fleets: Current Status 2018." Renewable Energy, 50.

Eurek, Kelly, Wesley Cole, David Bielen, Nate Blair, Stuart Cohen, Bethany Frew, Jonathan Ho, et al. 2016. "Regional Energy Deployment System (ReEDS) Model Documentation: Version 2016.” NREL/TP--6A20-67067, 1332909. https://doi.org/10.2172/1332909.

European Power to Gas. 2018. "Power to Gas Projects in Europe." European Power to Gas. 2018. http://www.europeanpowertogas.com/demonstrations.

FCTO. 2017. “Fuel Cells.” In Multi-Year Research, Development, and Demonstration Plan, 3.4. U.S. Department of Energy Fuel Cell Technologies Office.

https://www.energy.gov/sites/prod/files/2017/05/f34/fcto_myrdd_fuel_cells.pdf.

Federal Energy Regulatory Commission. 2017. "Electric Power Markets: National Overview." Federal Energy Regulatory Commission. 2017. https:/www.ferc.gov/market-oversight/mktelectric/overview.asp.

Frihammer, Vegard. 2018. "Scandinavian Update." Presented at the International Hydrogen Infrastructure Workshop, Boston, MA, September 11.

https:/www.energy.gov/sites/prod/files/2018/10/f56/fcto-infrastructure-workshop-2018-5frihammer.pdf.

Fueleconomy.gov. 2020. "Compare Fuel Cell Vehicles.” U.S. Department of Energy and U.S. Environmental Protection Agency. 2020. https://www.fueleconomy.gov/feg/fcv_sbs.shtml.

Governor's Interagency Working Group on Zero-Emission Vehicles. 2018. "2018 ZEV Action Plan: Priorities Update.” Sacramento, CA: State of California. https://static.business.ca.gov/wpcontent/uploads/2019/12/2018-ZEV-Action-Plan-Priorities-Update.pdf.

Green, Ed. 2018. "The Use of Hydrogen in the Iron and Steel Industry.” Presented at the H2@ Scale R\&D Consortium Kick-Off Meeting, Chicago, IL, August 1.

https://www.energy.gov/sites/prod/files/2018/08/f54/fcto-h2-scale-kickoff-2018-19-green.pdf.

H2USA. 2018a. "Fuel Cell Electric Vehicles." H2USA. 2018. http://www.h2usa.org/fuel-cellelectric-vehicles.

—. 2018b. "Why Hydrogen: Benefits of Hydrogen." H2USA. 2018.

http://www.h2usa.org/why-hydrogen. 
Hartley, Damon S., David N. Thompson, Hongqiang Hu, and Hao Cai. 2018. "Woody Feedstock 2018 State of Technology Report.” INL/EXT-18-51655-Rev000. Idaho National Lab. (INL), Idaho Falls, ID (United States). https://doi.org/10.2172/1606238.

Hydrogen and Fuel Cell Technical Advisory Committee. 2017. "2017 Annual Report of the Hydrogen and Fuel Cell Technical Advisory Committee."

https://www.hydrogen.energy.gov/pdfs/2017_htac_annual_report.pdf.

Hydrogen Council. 2017. "Hydrogen Scaling Up: A Sustainable Pathway for the Global Energy Transition." http://hydrogencouncil.com/wp-content/uploads/2017/11/Hydrogen-Scalingup_Hydrogen-Council_2017.compressed.pdf.

- 2020. "Path to Hydrogen Competitiveness: A Cost Perspective."

https://hydrogencouncil.com/wp-content/uploads/2020/01/Path-to-Hydrogen-

Competitiveness_Full-Study-1.pdf.

IAEA \& NEA. 2014. “Uranium 2014: Resources, Production and Demand.” NEA No. 7209. Issy-les-Moulineaux, France: International Atomic Energy Agency \& OECD Nuclear Energy Agency. https://www.oecd-nea.org/ndd/pubs/2014/7209-uranium-2014.pdf.

IEA. 2015. “Technology Roadmap Hydrogen and Fuel Cells.” Paris: International Energy Agency.

—. 2019. "The Future of Hydrogen: Seizing Today's Opportunities.” Paris: International Energy Agency. https://www.iea.org/reports/the-future-of-hydrogen.

IEA \& NEA, Organization for Economic Co-Opertation and Development, and Nuclear Energy Agency. 2015. "Projected Costs of Generating Electricity 2015 Edition." Paris: International Energy Agency and OECD Nuclear Energy Agency.

IHS Markit. 2015. “Chemical Economics Handbook: Hydrogen.” London: IHS Markit. https://ihsmarkit.com/products/hydrogen-chemical-economics-handbook.html.

IRENA. 2019. "Hydrogen: A Renewable Energy Perspective." Report Prepared for the 2nd Hydrogen Energy Ministerial Meeting in Tokyo, Japan. Abu Dhabi: IRENA.

https://www.irena.org/-

/media/Files/IRENA/Agency/Publication/2019/Sep/IRENA_Hydrogen_2019.pdf.

ITM Power. n.d. “Thüga Power-to-Gas Plant.” ITM Power. http://www.itmpower.com/project/thuga-power-to-gas.

James, Brian, Whitney Colella, Jennie Moton, G. Saur, and T. Ramsden. 2013. "PEM Electrolysis H2A Production Case Study Documentation.” NREL/TP--5400-61387, 1214980. https://doi.org/10.2172/1214980.

James, Brian D., George N. Baum, Julie Perez, and Kevin N. Baum. 2009. "Technoeconomic Analysis of Photoelectrochemical (PEC) Hydrogen Production.” 1218403.

https://doi.org/10.2172/1218403. 
Korpas, M., and C.J. Greiner. 2008. "Opportunities for Hydrogen Production in Connection with Wind Power in Weak Grids.” Renewable Energy 33: 1199-1208.

McMillan, Colin, Richard Boardman, Michael McKellar, Piyush Sabharwall, Mark Ruth, and Shannon Bragg-Sitton. 2016. "Generation and Use of Thermal Energy in the U.S. Industrial Sector and Opportunities to Reduce Its Carbon Emissions." NREL/TP-6A50-66763, INL/EXT16-39680. Golden, CO: Joint Institute for Strategic Energy Analysis.

https://www.nrel.gov/docs/fy17osti/66763.pdf.

Meeks, Noah, Uuganbayar Otgonbaatar, Frank Novachek, Richard Boardman, Mark Ruth, and Amgad Elgowainy. 2019. "Region Specific Merchant Hydrogen Market Assessment and Techno-Economic Assessment of Electrolytic Hydrogen Generation." Presented at the U.S. Department of Energy 2019 Annual Merit Review, Arlington, VA, April.

https://www.hydrogen.energy.gov/pdfs/review19/h2035_boardman_2019_p.pdf.

Melaina, M., B. Bush, M. Muratori, J. Zuboy, and S. Ellis. 2017. "National Hydrogen Scenarios: How Many Stations, Where, and When?" NREL/TP-5400-71083, 1461868. Prepared by the National Renewable Energy Laboratory for the H2USA Locations Roadmap Working Group. https://doi.org/10.2172/1461868.

Melaina, M.W., O. Antonia, and M. Penev. 2013. "Blending Hydrogen into Natural Gas Pipeline Networks: A Review of Key Issues.” Technical Report NREL/TP-5600-51995. Golden, CO: National Renewable Energy Laboratory. https:/www.nrel.gov/docs/fy13osti/51995.pdf.

Mohanpurkar, Manish, Yusheng Luo, Danny Terlip, Fernando Dias, Kevin Harrison, Joshua Eichman, Rob Hovsapian, and Jennifer Kurtz. 2017. "Electrolyzers Enhancing Flexibility in Electric Grids.” Energies 10: 1836. https://doi.org/doi:10.3390/en1011183.

Monitoring Analytics, LLC. 2017. "State of the Market Report for PJM, 2016: Volume 2, Detailed Analysis." Eagleville, PA: Monitoring Analytics, LLC.

http://monitoringanalytics.com/reports/PJM_State_of_the_Market/2016/2016-som-pjmvolume2.pdf.

NEI. 2015. "Nuclear Plants in Regulated and Deregulated States.” 2015. https://www.nei.org/resources/statistics/nuclear-plants-in-regulated-and-deregulated-states.

NETL. 2010. "Assessment of Hydrogen Production with CO2 Capture, Volume 1: Baseline State-of-the-Art Plants." DOE/NETL-2010/1434. National Energy Technology Laboratory.

NREL. 2017a. "NREL 2017 Annual Technology Baseline (ATB).” 2017.

https://atb.nrel.gov/electricity/2017/index.html.

—. 2017b. "Renewable Energy Potential (ReV) Model.” 2017.

https://www.nrel.gov/gis/renewable-energy-potential.html.

2018a. "NREL 2018 Annual Technology Baseline (ATB).” 2018.

https://atb.nrel.gov/electricity/2018/index.html. 
2018.

Oak Ridge National Laboratory. 2019. "MA3T.” 2019. https://teem.ornl.gov/ma3t.shtml.

O’Dell, John. 2017a. "Kenworth To Build Class 8 Hydrogen Fuel Cell and CNG-Electric Hybrid Drayage Trucks." Trucks.Com. May 2, 2017. https://www.trucks.com/2017/05/02/kenworthclass-8-hydrogen-fuel-cell-truck/.

_. 2017b. "UPS Launching World's First Fuel Cell Electric Class 6 Delivery Truck." Trucks.Com. May 2, 2017. https://www.trucks.com/2017/05/02/ups-fuel-cell-electric-deliverytruck/.

_. 2018a. "Anheuser-Busch Makes Record Order of 800 Nikola Fuel Cell Trucks." Trucks.Com. May 3, 2018. https://www.trucks.com/2018/05/03/anheuser-busch-nikola-truckorder/.

_. 2018b. "Toyota Unveils More Advanced Heavy-Duty Fuel Cell Truck Prototype." Trucks.Com. July 30, 2018. https://www.trucks.com/2018/07/30/toyota-advanced-fuel-celltruck/.

Office of Governor Edmund G. Brown Jr. 2018. "Governor Brown Takes Action to Increase Zero-Emission Vehicles, Fund New Climate Investments.” January 26, 2018. https://www.ca.gov/archive/gov39/2018/01/26/governor-brown-takes-action-to-increase-zeroemission-vehicles-fund-new-climate-investments/index.html.

Offshore Technology. 2019. "Middle East and North America Lead in Global Methanol Capacity Additions." Offshore Technology | Oil and Gas News and Market Analysis. July 30, 2019. https://www.offshore-technology.com/comment/global-methanol-capacity/.

Ontario Ministry of Agriculture, Food and Rural Affairs. 2011. "Biomass Burn Characteristics." http://www.omafra.gov.on.ca/english/engineer/facts/11-033.htm\#3.

Pacific Northwest National Laboratory. n.d. "The Global Change Assessment Model." Accessed March 1, 2019. http://jgcri.github.io/gcam-doc/overview.html.

Pivovar, Bryan, Neha Rustagi, and Sunita Satyapal. 2018. "Hydrogen at Scale (H2@Scale): Key to a Clean, Economic, and Sustainable Energy System." The Electrochemical Society Interface, 6.

Rabiti, C., A. Epiney, P. Talbot, J. S. Kim, S. Bragg-Sitton, A. Alfonsi, A. Yigitoglu, et al. 2017. "Status Report on Modelling and Simulation Capabilities for Nuclear-Renewable Hybrid Energy Systems." INL/EXT-17-43441. Idaho National Lab. (INL), Idaho Falls, ID (United States); Oak Ridge National Lab. (ORNL), Oak Ridge, TN (United States); Argonne National Lab. (ANL), Argonne, IL (United States). https://doi.org/10.2172/1408526.

Ramsden, Todd, and Fred Joseck. 2018. "Hydrogen R\&D Cost Target Calculation—2018 Update." U.S. Department of Energy Fuel Cell Technologies Office. https://www.hydrogen.energy.gov/pdfs/18004_h2_cost_target_calculation_2018.pdf. 
"Roadmap to a US Hydrogen Economy." 2020. http://www.fchea.org/us-hydrogen-study.

Rustagi, Neha, Amgad Elgowainy, and James Vickers. 2018. "Current Status of Hydrogen Delivery and Dispensing Costs and Pathways to Future Cost Reductions." DOE Hydrogen and Fuel Cells Program Record 18003. U.S. Department of Energy.

https://www.hydrogen.energy.gov/pdfs/18003_current_status_hydrogen_delivery_dispensing_co sts.pdf.

Ruth, Mark F., Paige Jadun, and Wesley Cole. forthcoming. "Potential Availability and Price of Low-Cost Dispatch-Constrained Electricity." Golden, CO: National Renewable Energy Laboratory.

Ruth, Mark F., Owen R. Zinaman, Mark Antkowiak, Richard D. Boardman, Robert S. Cherry, and Morgan D. Bazilian. 2014. "Nuclear-Renewable Hybrid Energy Systems: Opportunities, Interconnections, and Needs." Energy Conversion and Management 78 (February): 684-94. https://doi.org/10.1016/j.enconman.2013.11.030.

Satyapal, Sunita. 2020. "Hydrogen and Fuel Cell Technologies Office Update." Presented at the Hydrogen and Fuel Cell Technical Advisory Committee (HTAC) Meeting, Washington D.C., March 9. https://www.hydrogen.energy.gov/pdfs/01-satyapal-fcto-updates.pdf.

Scholz, Yvonne, Hans Christian Gils, and Robert C. Pietzcker. 2017. "Application of a HighDetail Energy System Model to Derive Power Sector Characteristics at High Wind and Solar Shares." Energy Economics 64 (May): 568-82. https://doi.org/10.1016/j.eneco.2016.06.021.

Schwartz, Robert A. 2010. Micro Markets: A Market Structure Approach to Microeconomic Analysis. Chichester: Wiley.

Scott, Michael. 2018. "Nuclear Power Outlook.” Energy Information Administration. https://www.eia.gov/outlooks/aeo/section_issues.php\#npo.

Shell. 2018. "Sky: Meeting the Goals of the Paris Agreement." Shell Scenarios. www.shell.com/skyscenario.

Sholtis, Brett. 2019. "Three Mile Island Nuclear Power Plant Shuts Down.” NPR. September 20, 2019. https://www.npr.org/2019/09/20/762762962/three-mile-island-nuclear-power-plant-shutsdown.

SoCalGas. 2018. "Power-to-Gas Technology." Southern California Gas Company. 2018. https://www.socalgas.com/smart-energy/renewable-gas/power-to-gas.

State of California. 2016. Short-Lived Climate Pollutants: Methane Emissions: Dairy and Livestock: Organic Waste: Landfills. https://leginfo.legislature.ca.gov/faces/billTextClient.xhtml?bill_id=201520160SB1383.

Suresh, Bala, Henry He, Ralf Gubler, and Yuko Yamaguchi. 2018. "Chemical Economics Handbook: Hydrogen.” London: IHS Markit. https://ihsmarkit.com/products/hydrogen-chemicaleconomics-handbook.html. 
Swierczynski, Maciej, Daniel-Ioan Stroe, Ana-Irina Stan, Remus Teodorescu, Rasmus Lærke, and Philip Carne Kjær. 2014. "Field Tests Experience from 1.6MW/400kWh Li-Ion Battery Energy Storage System Providing Primary Frequency Regulation Service.” In IEEE PES ISGT Europe 2013. Lyngby, Denmark: IEEE. https://doi.org/10.1109/ISGTEurope.2013.6695277.

TIAX LLC. 2011. "Support for Cost Analyses on Solar-Driven High Temperature Thermochemical Water-Splitting Cycles.” Lexington, MA: TIAX.

U.S. Congress. 2005. Energy Policy Act. https://www.govinfo.gov/content/pkg/PLAW109pub158/pdf/PLAW-109pub158.pdf.

U.S. Geological Survey. 2020. "USGS Domestic Continuous (Unconventional) Oil \& Gas Assessments, 2000-2018.” Assessment Summary Maps/Tables. 2020.

https://certmapper.cr.usgs.gov/data/apps/noga-summary/.

Walter, Katie. 2009. "Energy Goes with the Flow." Lawrence Livermore National Laboratory Science \& Technology Review September: 17-19.

Wei, Max, Timothy Lipman, Ahmad Mayyas, Joshua Chien, Shuk Chan, David Gosselin, Hanna Breunig, et al. 2014. "A Total Cost of Ownership Model for Low Temperature PEM Fuel Cells in Combined Heat and Power and Backup Power Applications.” LBNL-6772E, 1163271. Berkeley, CA: Lawrence Berkeley National Laboratory. https://doi.org/10.2172/1163271.

Wiser, Ryan H., Andrew Mills, Joachim Seel, Todd Levin, and Audun Botterud. 2017. "Impacts of Variable Renewable Energy on Bulk Power System Assets, Pricing, and Costs." 1411668. Berkeley, CA: Lawrence Berkeley National Laboratory. https://doi.org/10.2172/1411668.

World Nuclear Association. 2017. "Nuclear Power Economics and Project Structuring - 2017 Edition.” 2017/001. http://www.world-nuclear.org/getmedia/84082691-786c-414f-8178a26be866d8da/REPORT_Economics_Report_2017.pdf.aspx.

ZumMallen, Ryan. 2017. "General Motors Teases Heavy-Duty Hydrogen Fuel Cell Truck, Electric Lineup.” Trucks.Com. October 3, 2017. https://www.trucks.com/2017/10/03/generalmotors-hydrogen-fuel-cell-electric-truck/. 


\section{Appendix A. Summary of Economic Potential Assumptions}

This appendix summarizes the assumptions used to develop the supply and demand curves used to estimate the economic potential scenarios. Additional detail is found in the respective sections.

\section{A.1 Hydrogen Demand Assumptions}

This section details the assumptions used for hydrogen demand applications. For all applications except seasonal energy storage, assumptions are based on Elgowainy et al. (2020).

Table A-1. Oil Refining Assumptions

\begin{tabular}{|c|c|c|c|c|c|}
\hline & Reference & $\begin{array}{l}\text { Current } \\
\text { R\&D } \\
\text { Trajectory }\end{array}$ & $\begin{array}{l}\text { Low NG } \\
\text { Resource/ } \\
\text { High NG Price }\end{array}$ & $\begin{array}{l}\text { Aggressive } \\
\text { Electrolysis } \\
\text { R\&D }\end{array}$ & $\begin{array}{l}\text { Lowest-Cost } \\
\text { Electrolysis }\end{array}$ \\
\hline $\begin{array}{l}\text { Hydrogen } \\
\text { Threshold } \\
\text { Price }\end{array}$ & \multicolumn{5}{|l|}{$\$ 3.00 / \mathrm{kg}$} \\
\hline $\begin{array}{l}\text { Maximum } \\
\text { Hydrogen } \\
\text { Demand }\end{array}$ & 7.5 MMT/yr & & & & \\
\hline
\end{tabular}

Current annual hydrogen demand is 5.9 MMT (Elgowainy et al. 2020). This projected growth is primarily due to an increase in the estimated diesel-to-gasoline ratio as well as processing of lower-quality crude (lower API gravity and higher sulfur), which require higher hydrogen use.

Table A-2. Metals Refining Assumptions

\begin{tabular}{|c|c|c|c|c|c|}
\hline & Reference & $\begin{array}{l}\text { Current R\&D } \\
\text { Trajectory }\end{array}$ & $\begin{array}{l}\text { Low NG } \\
\text { Resource/ } \\
\text { High NG } \\
\text { Price }\end{array}$ & $\begin{array}{l}\text { Aggressive } \\
\text { Electrolysis } \\
\text { R\&D }\end{array}$ & $\begin{array}{l}\text { Lowest- } \\
\text { Cost } \\
\text { Electrolysis }\end{array}$ \\
\hline $\begin{array}{l}\text { Hydrogen } \\
\text { Threshold } \\
\text { Price }\end{array}$ & $\$ 0.80-\$ 1.70 / \mathrm{kg}$ & $\begin{array}{l}\$ 0.80-\$ 2.50 / \mathrm{kg} \\
\text { Assumed } \\
\text { premium for } \\
\text { metals refinded } \\
\text { with hydrogen }\end{array}$ & \multicolumn{3}{|c|}{$\begin{array}{l}\$ 1.40-\$ 2.50 / \mathrm{kg} \\
\text { Assumed premium for metals refinded with } \\
\text { hydrogen }\end{array}$} \\
\hline $\begin{array}{l}\text { Maximum } \\
\text { Hydrogen } \\
\text { Demand }\end{array}$ & $\begin{array}{l}4 \mathrm{MMT} / \mathrm{yr} \text { at } \\
\$ 1.70 / \mathrm{kg} \text { based } \\
\text { on } 30 \% \text { hydrogen } \\
\text { in DRI } \\
12 \mathrm{MMT} / \mathrm{yr} \text { at } \\
\$ 0.80 / \mathrm{kg} \text { based } \\
\text { on } 100 \% \\
\text { hydrogen in DRI, } \\
\text { competitive with } \\
\text { NG }\end{array}$ & $\begin{array}{l}4 \mathrm{MMT} / \mathrm{yr} \text { at } \\
\$ 2.50 / \mathrm{kg} \text { based } \\
\text { on } 30 \% \text { hydrogen } \\
\text { in DRI } \\
12 \mathrm{MMT} / \mathrm{yr} \text { at } \\
\$ 0.80 / \mathrm{kg} \text { based } \\
\text { on } 100 \% \\
\text { hydrogen in DRI, } \\
\text { competitive with } \\
\mathrm{NG}\end{array}$ & \multicolumn{3}{|c|}{$\begin{array}{l}4 \mathrm{MMT} / \mathrm{yr} \text { at } \$ 2.5 / \mathrm{kg} \text { based on } 30 \% \\
\text { hydrogen in DRI } \\
12 \mathrm{MMT} / \mathrm{yr} \text { at } \$ 1.40 / \mathrm{kg} \text { based on } 100 \% \\
\text { hydrogen in DRI, competitive with NG }\end{array}$} \\
\hline
\end{tabular}




\begin{tabular}{|c|c|c|c|c|c|}
\hline & Reference & $\begin{array}{l}\text { Current R\&D } \\
\text { Trajectory }\end{array}$ & $\begin{array}{l}\text { Low NG } \\
\text { Resource/ } \\
\text { High NG } \\
\text { Price }\end{array}$ & $\begin{array}{l}\text { Aggressive } \\
\text { Electrolysis } \\
\text { R\&D }\end{array}$ & $\begin{array}{l}\text { Lowest- } \\
\text { Cost } \\
\text { Electrolysis }\end{array}$ \\
\hline $\begin{array}{l}\text { Domestic } \\
\text { Steel } \\
\text { Production }\end{array}$ & \multicolumn{5}{|c|}{$\begin{array}{l}120 \mathrm{MMT} / \mathrm{yr} \\
\text { Projected growth from EIA (EIA 2016) }\end{array}$} \\
\hline $\begin{array}{l}\text { Hydrogen } \\
\text { Usage }\end{array}$ & \multicolumn{5}{|c|}{$0.1 \mathrm{MT}$ hydrogen/MT iron ore reduced } \\
\hline
\end{tabular}

In 2017, 106 MMT of steel were consumed domestically and 81 MMT were produced (Elgowainy et al. 2020).

Table A-3. Ammonia Assumptions

\begin{tabular}{|c|c|c|c|c|c|}
\hline & Reference & $\begin{array}{l}\text { Current } \\
\text { R\&D } \\
\text { Trajectory }\end{array}$ & $\begin{array}{l}\text { Low NG } \\
\text { Resource/ } \\
\text { High NG Price }\end{array}$ & $\begin{array}{l}\text { Aggressive } \\
\text { Electrolysis } \\
\text { R\&D }\end{array}$ & $\begin{array}{l}\text { Lowest-Cost } \\
\text { Electrolysis }\end{array}$ \\
\hline $\begin{array}{l}\text { Hydrogen } \\
\text { Threshold } \\
\text { Price }\end{array}$ & \multicolumn{5}{|c|}{$\begin{array}{l}\$ 2.00-\$ 3.00 / \mathrm{kg} \\
\$ 2.00 / \mathrm{kg} \text { is competitive with SMR }\end{array}$} \\
\hline $\begin{array}{l}\text { Maximum } \\
\text { Hydrogen } \\
\text { Demand }\end{array}$ & \multicolumn{5}{|c|}{$\begin{array}{l}2.5 \mathrm{MMT} / \mathrm{yr} \text { at } \$ 3.00 / \mathrm{kg} \\
3.6 \mathrm{MMT} / \mathrm{yr} \text { at } \$ 2.00 / \mathrm{kg} \\
\text { Assumed annual growth of } 1 \% \text { from } 2018 \text { to } 2050\end{array}$} \\
\hline
\end{tabular}

In 2018, 2.5 MMT of hydrogen was used for ammonia production (Elgowainy et al. 2020).

Hydrogen demand is estimated using the stoichiometric ratio 3 moles of hydrogen for 2 moles of ammonia production and an assumed plant capacity factor of $80 \%$.

Table A-4. Biofuels Assumptions

\begin{tabular}{|c|c|c|c|c|c|}
\hline & Reference & $\begin{array}{l}\text { Current } \\
\text { R\&D } \\
\text { Trajectory }\end{array}$ & $\begin{array}{l}\text { Low NG } \\
\text { Resourcel } \\
\text { High NG Price }\end{array}$ & $\begin{array}{l}\text { Aggressive } \\
\text { Electrolysis } \\
\text { R\&D }\end{array}$ & $\begin{array}{l}\text { Lowest-Cost } \\
\text { Electrolysis }\end{array}$ \\
\hline $\begin{array}{l}\text { Hydrogen } \\
\text { Threshold } \\
\text { Price }\end{array}$ & \multicolumn{5}{|l|}{$\$ 3.00 / \mathrm{kg}$} \\
\hline $\begin{array}{l}\text { Maximum } \\
\text { Hydrogen } \\
\text { Demand }\end{array}$ & \multicolumn{5}{|c|}{$\begin{array}{l}4 \mathrm{MMT} / \mathrm{yr} \\
\text { Based on meeting half of total projected jet fuel demand in 2050, which is } 38.6 \text { billion } \\
\text { gal/yr per the } 2017 \text { AEO Low Oil and Gas Resource and Technology (LOGR) scenario }\end{array}$} \\
\hline $\begin{array}{l}\text { Hydrogen } \\
\text { Usage }\end{array}$ & \multicolumn{5}{|c|}{$\begin{array}{l}76 \mathrm{~g} \mathrm{H}_{2} / \text { gal biofuel (fats, oils, and greases) } \\
490 \mathrm{~g} \mathrm{H}_{2} / \text { gal biofuel (Catalytic fast pyrolysis) }\end{array}$} \\
\hline
\end{tabular}


Table A-5. Synthetic Fuels and Chemicals Assumptions

\begin{tabular}{|c|c|c|c|c|c|}
\hline & Reference & $\begin{array}{l}\text { Current } \\
\text { R\&D } \\
\text { Trajectory }\end{array}$ & $\begin{array}{l}\text { Low NG } \\
\text { Resource/High } \\
\text { NG Price }\end{array}$ & $\begin{array}{l}\text { Aggressive } \\
\text { Electrolysis } \\
\text { R\&D }\end{array}$ & $\begin{array}{l}\text { Lowest-Cost } \\
\text { Electrolysis }\end{array}$ \\
\hline $\begin{array}{l}\text { Hydrogen } \\
\text { Threshold Price }\end{array}$ & \multicolumn{5}{|c|}{$\$ 1.73 / \mathrm{kg}$ for Methanol, $\$ 0.00 / \mathrm{kg}$ for MTG } \\
\hline $\begin{array}{l}\text { Maximum } \\
\text { Hydrogen } \\
\text { Demand }\end{array}$ & \multicolumn{5}{|c|}{ 6.0 MMT/yr for Methanol, 8.0 MMT/yr for MTG (14.0 MMT/yr total) } \\
\hline $\begin{array}{l}\text { Hydrogen } \\
\text { Usage }\end{array}$ & \multicolumn{5}{|c|}{3 moles $\mathrm{H}_{2}$ per mole of $\mathrm{CO}_{2}$} \\
\hline $\mathrm{CO}_{2}$ Availability & \multicolumn{5}{|c|}{$\begin{array}{l}100 \mathrm{MMT} / \mathrm{yr} \\
44 \mathrm{MMT} \text { from ethanol, and } 56 \mathrm{MMT} \text { from SMR (including ammonia) }\end{array}$} \\
\hline $\begin{array}{l}\text { Maximum } \\
\text { Methanol } \\
\text { Production }\end{array}$ & \multicolumn{5}{|c|}{$\begin{array}{l}25.5 \mathrm{MMT} / \mathrm{yr} \\
\text { Expected growth through 2030, limited to high purity } \mathrm{CO}_{2} \text { availability }\end{array}$} \\
\hline $\begin{array}{l}\text { Maximum MTG } \\
\text { Production }\end{array}$ & \multicolumn{5}{|c|}{$\begin{array}{l}32.3 \mathrm{MMT} / \mathrm{yr} \\
\text { Based on availability of } 56 \mathrm{MMT} \text { of } \mathrm{CO}_{2}\end{array}$} \\
\hline
\end{tabular}

The 2020 estimated annual capacity of domestic methanol production is 9.4 MMT (Elgowainy et al. 2020).

Table A-6. Seasonal Energy Storage Assumptions

\begin{tabular}{|c|c|c|c|c|c|}
\hline & Reference & $\begin{array}{l}\text { Current } \\
\text { R\&D } \\
\text { Trajectory }\end{array}$ & $\begin{array}{l}\text { Low NG } \\
\text { Resourcel } \\
\text { High NG } \\
\text { Price }\end{array}$ & $\begin{array}{l}\text { Aggressive } \\
\text { Electrolysis } \\
\text { R\&D }\end{array}$ & $\begin{array}{l}\text { Lowest-Cost } \\
\text { Electrolysis }\end{array}$ \\
\hline $\begin{array}{l}\text { Hydrogen } \\
\text { Threshold } \\
\text { Price }\end{array}$ & \multicolumn{2}{|c|}{$\begin{array}{l}\$ 1.10 / \mathrm{kg} \text { to replace natural } \\
\text { gas combined cycle } \\
\text { generation } \\
\$ 0.26 / \mathrm{kg} \text { to replace natural } \\
\text { gas combustion turbine } \\
\text { generation }\end{array}$} & \multicolumn{3}{|c|}{$\begin{array}{l}\$ 0.57 / \mathrm{kg} \text { to replace natural gas combined cycle } \\
\text { generation } \\
\$ 0.57 / \mathrm{kg} \text { to replace natural gas combustion turbine } \\
\text { generation }\end{array}$} \\
\hline $\begin{array}{l}\text { Maximum } \\
\text { Hydrogen } \\
\text { Demand }\end{array}$ & \multicolumn{2}{|c|}{$\begin{array}{l}48 \mathrm{MMT} / \mathrm{yr} \text { to replace } \\
\text { natural gas combined cycle } \\
\text { generation } \\
4.4 \mathrm{MMT} / \mathrm{yr} \text { to replace } \\
\text { natural gas combustion } \\
\text { turbine generation } \\
52 \mathrm{MMT} / \mathrm{yr} \text { total }\end{array}$} & \multicolumn{3}{|c|}{$\begin{array}{l}\$ 0.57 / 14 \mathrm{MMT} / \mathrm{yr} \text { to replace natural gas combined } \\
\text { cycle generation } \\
0.8 \mathrm{MMT} / \mathrm{yr} \text { to replace natural gas combustion } \\
\text { turbine generation } \\
15 \mathrm{MMT} / \mathrm{yr} \text { total }\end{array}$} \\
\hline $\begin{array}{l}\text { Grid } \\
\text { Assumptions }\end{array}$ & \multicolumn{2}{|c|}{$\begin{array}{l}\text { Consistent with low- } \\
\text { temperature electrolysis } \\
\text { assumptions (Section 4.2) }\end{array}$} & \multicolumn{3}{|c|}{$\begin{array}{l}\text { Consistent with low-temperature electrolysis } \\
\text { assumptions (Section 4.2) }\end{array}$} \\
\hline $\begin{array}{l}\text { PEM Fuel Cell } \\
\text { Cost }\end{array}$ & \multicolumn{5}{|l|}{$\$ 1000 / \mathrm{kW}$} \\
\hline $\begin{array}{l}\text { PEM Fuel Cell } \\
\text { Heat Rate }\end{array}$ & \multicolumn{5}{|c|}{ 6.12 mmBtu/MWh electricity } \\
\hline
\end{tabular}




\begin{tabular}{|c|c|c|c|c|c|}
\hline & Reference & $\begin{array}{l}\text { Current } \\
\text { R\&D } \\
\text { Trajectory }\end{array}$ & $\begin{array}{l}\text { Low NG } \\
\text { Resource/ } \\
\text { High NG } \\
\text { Price }\end{array}$ & $\begin{array}{l}\text { Aggressive } \\
\text { Electrolysis } \\
\text { R\&D }\end{array}$ & $\begin{array}{l}\text { Lowest-Cost } \\
\text { Electrolysis }\end{array}$ \\
\hline $\begin{array}{l}\text { Hydrogen } \\
\text { Combustion } \\
\text { Turbine Cost }\end{array}$ & \multicolumn{5}{|l|}{$\$ 833 / \mathrm{kW}$} \\
\hline $\begin{array}{l}\text { Hydrogen } \\
\text { Combustion } \\
\text { Turbine Heat } \\
\text { Rate }\end{array}$ & \multicolumn{5}{|c|}{$8.2 \mathrm{mmBtu} / \mathrm{MWh}$ electricity } \\
\hline
\end{tabular}

Assumptions detailed in Appendix C.

Table A-7. Light-Duty Vehicle Assumptions

\begin{tabular}{|c|c|c|c|c|c|}
\hline & Reference & $\begin{array}{l}\text { Current R\&D } \\
\text { Trajectory }\end{array}$ & $\begin{array}{l}\text { Low NG } \\
\text { Resource/ } \\
\text { High NG } \\
\text { Price }\end{array}$ & $\begin{array}{l}\text { Aggressive } \\
\text { Electrolysis } \\
\text { R\&D }\end{array}$ & $\begin{array}{l}\text { Lowest-Cost } \\
\text { Electrolysis }\end{array}$ \\
\hline $\begin{array}{l}\text { Hydrogen } \\
\text { Threshold Price } \\
\text { (Dispensed) }\end{array}$ & $\begin{array}{l}\text { No } \\
\text { penetration } \\
\text { assumed }\end{array}$ & \multicolumn{4}{|c|}{$\begin{array}{l}\text { Drops from } \$ 8.70 / \mathrm{kg} \text { in } 2020 \text { to } \$ 5.03 / \mathrm{kg} \text { dispensed in } 2050 \\
\text { (includes } \$ 0.53 / \mathrm{kg} \text { taxes) }\end{array}$} \\
\hline $\begin{array}{l}\text { Hydrogen } \\
\text { Threshold Price } \\
\text { (Terminal) }\end{array}$ & $\begin{array}{l}\text { No } \\
\text { penetration } \\
\text { assumed }\end{array}$ & \multicolumn{4}{|l|}{$\$ 2.20 / \mathrm{kg}$} \\
\hline $\begin{array}{l}\text { Hydrogen } \\
\text { Delivery and } \\
\text { Dispensing }\end{array}$ & $\begin{array}{l}\text { No } \\
\text { penetration } \\
\text { assumed }\end{array}$ & \multicolumn{4}{|c|}{$\begin{array}{l}\text { Included in dispensed hydrogen price, drops from } \$ 5.97 / \mathrm{kg} \text { in } \\
2015 \text { to } \$ 2.30 / \mathrm{kg} \text { in } 2050\end{array}$} \\
\hline $\begin{array}{l}\text { Maximum } \\
\text { Hydrogen } \\
\text { Demand }\end{array}$ & $\begin{array}{l}\text { No } \\
\text { penetration } \\
\text { assumed }\end{array}$ & \multicolumn{4}{|c|}{$12 \mathrm{MMT} / \mathrm{yr}$ (18\% penetration for cars, $26 \%$ for light-duty trucks) } \\
\hline Fuel Cell Cost & $\begin{array}{l}\text { No } \\
\text { penetration } \\
\text { assumed }\end{array}$ & \multicolumn{4}{|c|}{ Drops from $\$ 60 / \mathrm{kW}$ in 2020 to $\$ 33 / \mathrm{kW}$ in 2050} \\
\hline $\begin{array}{l}\text { Hydrogen } \\
\text { Storage Cost }\end{array}$ & $\begin{array}{l}\text { No } \\
\text { penetration } \\
\text { assumed }\end{array}$ & \multicolumn{4}{|c|}{ Drops from $\$ 670 / \mathrm{kg}$ in 2020 to $\$ 310 / \mathrm{kg}$ in 2050} \\
\hline Battery Cost & - & \multicolumn{4}{|c|}{ Drops from $\$ 250 / \mathrm{kWh}$ in 2020 to $\$ 125 / \mathrm{kWh}$ in 2050} \\
\hline Gasoline Price & - & \multicolumn{4}{|c|}{ Increases from $\$ 2.73 /$ gal in 2020 to $\$ 3.34 /$ gal in 2050} \\
\hline Electricity Price & - & \multicolumn{4}{|c|}{ Increases from 11.8 cents $/ \mathrm{kWh}$ in 2020 to 12.6 cents $/ \mathrm{kWh}$ in 2050} \\
\hline
\end{tabular}

Current dispensed hydrogen prices are around $\$ 13.40 / \mathrm{kg} ; \$ 12.30 / \mathrm{kg}$ is attributed to delivery and dispensing (Rustagi, Elgowainy, and Vickers 2018).

Assumptions on technology and fuel costs used in vehicle choice modeling using MA3T in Elgowainy et al. (2020). 
Table A-8. Medium- and Heavy-Duty Vehicle Assumptions

\begin{tabular}{|c|c|c|c|c|c|}
\hline & Reference & $\begin{array}{l}\text { Current R\&D } \\
\text { Trajectory }\end{array}$ & $\begin{array}{l}\text { Low NG } \\
\text { Resource/ } \\
\text { High NG } \\
\text { Price }\end{array}$ & $\begin{array}{l}\text { Aggressive } \\
\text { Electrolysis } \\
\text { R\&D }\end{array}$ & $\begin{array}{l}\text { Lowest-Cost } \\
\text { Electrolysis }\end{array}$ \\
\hline $\begin{array}{l}\text { Hydrogen } \\
\text { Threshold Price } \\
\text { (Dispensed) }\end{array}$ & $\begin{array}{l}\$ 0.00 / \mathrm{kg} \text { or } \\
\text { below }\end{array}$ & \multicolumn{4}{|c|}{$\$ 5.03 / \mathrm{kg}$ dispensed in 2050 (includes $\$ 0.53 / \mathrm{kg}$ taxes) } \\
\hline $\begin{array}{l}\text { Hydrogen } \\
\text { Threshold Price } \\
\text { (Terminal) }\end{array}$ & $\begin{array}{l}\$ 0.00 / \mathrm{kg} \text { or } \\
\text { below }\end{array}$ & \multicolumn{4}{|l|}{$\$ 2.20 / \mathrm{kg}$} \\
\hline $\begin{array}{l}\text { Hydrogen } \\
\text { Delivery and } \\
\text { Dispensing }\end{array}$ & $\begin{array}{l}\text { No } \\
\text { penetration } \\
\text { assumed }\end{array}$ & \multicolumn{4}{|c|}{$\$ 2.30 / \mathrm{kg}$ in 2050} \\
\hline $\begin{array}{l}\text { Maximum } \\
\text { Hydrogen } \\
\text { Demand }\end{array}$ & $\begin{array}{l}\text { No } \\
\text { penetration } \\
\text { assumed }\end{array}$ & \multicolumn{4}{|c|}{$\begin{array}{l}5.2 \mathrm{MMT} / \mathrm{yr}(22 \% \text { penetration) } \\
\text { Based on total light-duty vehicle penetration }\end{array}$} \\
\hline
\end{tabular}

Current dispensed hydrogen prices are around $\$ 13.40 / \mathrm{kg} ; \$ 12.30 / \mathrm{kg}$ is attributed to delivery and dispensing (Rustagi, Elgowainy, and Vickers 2018).

\section{A.2 Hydrogen Supply Assumptions}

This section details the assumptions used to develop hydrogen supply curves.

Table A-9. Steam Methane Reforming of Natural Gas Assumptions

\begin{tabular}{|c|c|c|c|c|c|}
\hline & Reference & $\begin{array}{l}\text { Current R\&D } \\
\text { Trajectory }\end{array}$ & $\begin{array}{l}\text { Low NG } \\
\text { Resource/ } \\
\text { High NG } \\
\text { Price }\end{array}$ & $\begin{array}{l}\text { Aggressive } \\
\text { Electrolysis } \\
\text { R\&D }\end{array}$ & $\begin{array}{l}\text { Lowest-Cost } \\
\text { Electrolysis }\end{array}$ \\
\hline $\begin{array}{l}\text { Natural } \\
\text { Gas Price }\end{array}$ & \multicolumn{2}{|c|}{$\begin{array}{l}\$ 6.60 / \mathrm{mmBtu} \\
2050 \text { Industrial price from AEO } \\
2017 \text { Reference case }\end{array}$} & \multicolumn{3}{|c|}{$\begin{array}{l}\$ 11.30 / \mathrm{mmBtu} \\
2050 \text { Industrial price from AEO } 2017 \text { LOGR case }\end{array}$} \\
\hline $\begin{array}{l}\text { Total SMR } \\
\text { Capacity }\end{array}$ & \multicolumn{5}{|c|}{$\begin{array}{l}27 \mathrm{MMT}_{2} / \mathrm{yr} \\
\text { Hydrogen generation from SMRs for non-ammonia production is capped at three times } \\
\text { current levels ( } 23 \mathrm{MMT} / \mathrm{yr} \text { ) } \\
\text { Hydrogen generation from SMRs estimated for future ammonia production is capped at } \\
4 \mathrm{MMT} / \mathrm{yr}\end{array}$} \\
\hline $\begin{array}{l}\text { Capital } \\
\text { Cost }\end{array}$ & \multicolumn{5}{|c|}{$\begin{array}{l}\$ 53 \mathrm{M} \text { for } 380 \mathrm{MT} / \text { day plant } \\
\text { Future Central H2A Case Study }\end{array}$} \\
\hline Yield & \multicolumn{5}{|c|}{$\begin{array}{l}0.156 \mathrm{mmBtu} / \mathrm{kg} \mathrm{H} \\
\text { Future Central H2A Case Study }\end{array}$} \\
\hline
\end{tabular}

The 2017 industrial natural gas price in AEO 2018 is $\$ 3.95 / \mathrm{mmBtu}$ (EIA 2018a).

Current total annual SMR capacity is around 10 MMT hydrogen (IHS Markit 2015; Elgowainy et al. 2020).

Current SMR capital costs are $\$ 70 \mathrm{M}$ for $380 \mathrm{MT} /$ day plant and the current yield is $0.156 \mathrm{mmBtu} / \mathrm{kg}$ based on the $\mathrm{H} 2 \mathrm{~A}$ case study "Current Central Hydrogen Production from Natural Gas without $\mathrm{CO}_{2}$ Sequestration version 3.2018" (DOE 2018a). 
Table A-10. Low-Temperature Electrolysis Assumptions

\begin{tabular}{|c|c|c|c|c|c|}
\hline & Reference & $\begin{array}{l}\text { Current R\&D } \\
\text { Trajectory }\end{array}$ & $\begin{array}{l}\text { Low NG } \\
\text { Resource/ } \\
\text { High NG } \\
\text { Price }\end{array}$ & $\begin{array}{l}\text { Aggressive } \\
\text { Electrolysis } \\
\text { R\&D }\end{array}$ & $\begin{array}{l}\text { Lowest-Cost } \\
\text { Electrolysis }\end{array}$ \\
\hline Capital Cost & $\begin{array}{l}\$ 900 / \mathrm{kW} \\
\text { Current } \\
\text { Central H2A } \\
\text { Case Study }\end{array}$ & \multicolumn{2}{|c|}{$\begin{array}{l}\$ 400 / \mathrm{kW} \\
\text { Current technology at scale, } \\
\text { Future Central H2A Case } \\
\text { Study }\end{array}$} & $\begin{array}{l}\text { \$200/kW } \\
\text { Additional R\&D } \\
\text { improvements }\end{array}$ & $\begin{array}{l}\$ 100 / \mathrm{kW} \\
\text { Optimistic R\&D } \\
\text { improvements }\end{array}$ \\
\hline Yield & $\begin{array}{l}54.3 \mathrm{kWh} / \mathrm{kg} \\
\mathrm{H}_{2} \\
\text { Current } \\
\text { Central H2A } \\
\text { Case Study }\end{array}$ & \multicolumn{4}{|c|}{$\begin{array}{l}50.2 \mathrm{kWh} / \mathrm{kg} \mathrm{H} \\
\text { Future Central H2A Case Study }\end{array}$} \\
\hline $\begin{array}{l}\text { LDE Market } \\
\text { and } \\
\text { Availability }\end{array}$ & \multicolumn{2}{|c|}{$\begin{array}{l}\text { Available at retail prices } \\
80 \mathrm{TWh} \text { at } \$ 20 / \mathrm{MWh} \\
180 \mathrm{TWh} \text { at } \$ 30 / \mathrm{MWh}\end{array}$} & $\begin{array}{l}\text { Available at } \\
\text { retail prices } \\
200 \mathrm{TWh} \text { at } \\
\text { \$20/MWh } \\
410 \mathrm{TWh} \text { at } \\
\text { \$30/MWh }\end{array}$ & $\begin{array}{l}\text { Available at retail } \\
\text { with services } \\
\text { prices } \\
410 \mathrm{TWh} \text { at } \\
\text { \$20/MWh } \\
\text { 1,000 TWh at } \\
\text { \$30/MWh }\end{array}$ & $\begin{array}{l}\text { Available at } \\
\text { wholesale } \\
\text { prices } \\
1,000 \mathrm{TWh} \text { at } \\
\text { \$20/MWh } \\
4,500 \mathrm{TWh} \text { at } \\
\text { \$30/MWh }\end{array}$ \\
\hline $\begin{array}{l}\text { Natural Gas } \\
\text { Price }\end{array}$ & \multicolumn{2}{|c|}{$\begin{array}{l}\text { \$6.60/MMBtu } \\
2050 \text { Industrial price from AEO } \\
2017 \text { Reference case }\end{array}$} & \multicolumn{3}{|c|}{$\begin{array}{l}\text { \$11.30/MMBtu } \\
2050 \text { Industrial price from AEO } 2017 \text { LOGR case }\end{array}$} \\
\hline $\begin{array}{l}\text { Renewable } \\
\text { Energy } \\
\text { Costs }\end{array}$ & \multicolumn{5}{|c|}{$\begin{array}{l}2017 \text { ATB Low Cost Projections } \\
\text { Key parameters included in figures below and additional information can be found at } \\
\text { https://atb.nrel.gov/electricity/2017/index.html }\end{array}$} \\
\hline $\begin{array}{l}\text { Utility Scale } \\
\text { Battery } \\
\text { Costs }\end{array}$ & \multicolumn{5}{|c|}{$\begin{array}{l}\$ 500 / \mathrm{kWh} \text { in } 2050 \text {, decreasing to } \$ 220 / \mathrm{kWh} \text { in } 2050 \\
\text { Cole et al. (2016) }\end{array}$} \\
\hline $\begin{array}{l}\text { Nuclear and } \\
\text { Coal } \\
\text { Lifetime }\end{array}$ & \multicolumn{2}{|c|}{$\begin{array}{l}\text { Economic retirement, or } 60-80 \\
\text { year nuclear and } 65-75 \text { year } \\
\text { coal lifetimes }\end{array}$} & \multicolumn{3}{|c|}{$\begin{array}{l}\text { 80-year nuclear lifetime, accelerated coal retiremen } \\
\text { (10 years earlier) }\end{array}$} \\
\hline
\end{tabular}

The 2017 industrial natural gas price in AEO 2018 is $\$ 3.95 / \mathrm{mmBtu}$ (EIA 2018a).

The figures below show the wind and utility-scale PV capital cost and capacity factor assumptions from the 2017 ATB. Additional parameters can be found at https://atb.nrel.gov/electricity/2017/index.html. 


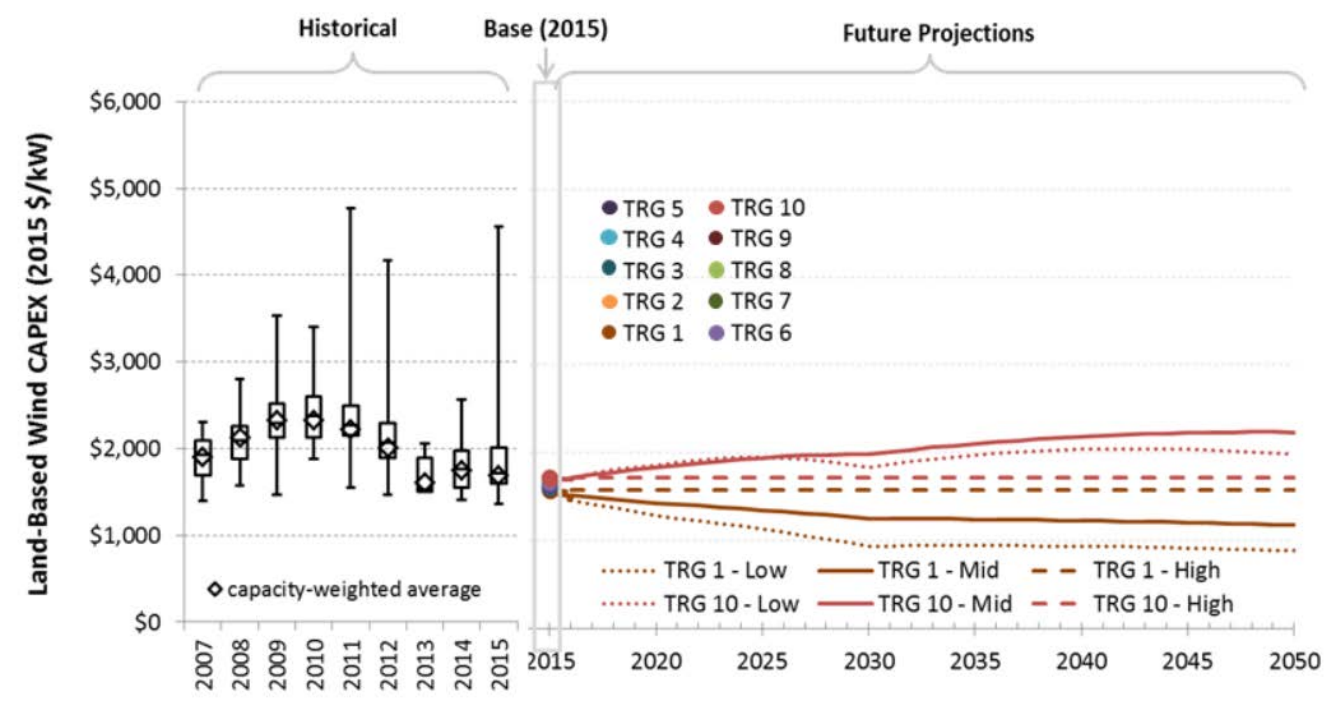

CAPEX (CAPital EXpenditures) historical trends, current estimates, and future projection for land-based wind Source: National Renewable Energy Laboratory Annual Technology Baseline (2017), http://atb.nrel.gov

Figure A-1. Capital expenditures trajectory for land-based wind from the 2017 ATB (NREL 2017a) The Low value is used in the present analysis.

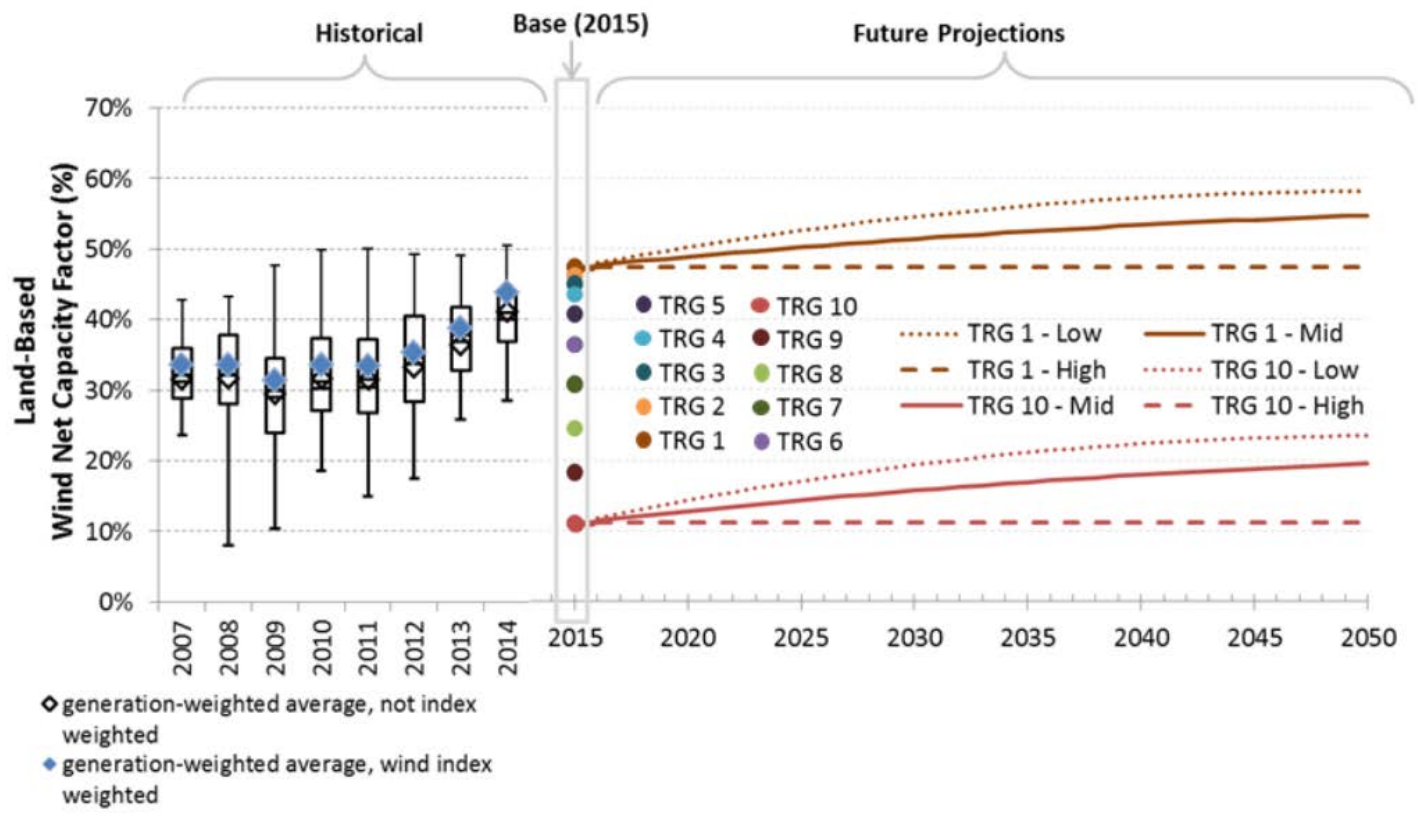

Land-based wind net capacity factor

Source: National Renewable Energy Laboratory Annual Technology Baseline (2017), http://atb.nrel.gov

Figure A-2. Capacity factor trajectory for land-based wind from the 2017 ATB (NREL 2017a)

The Low value is used in the present analysis. 


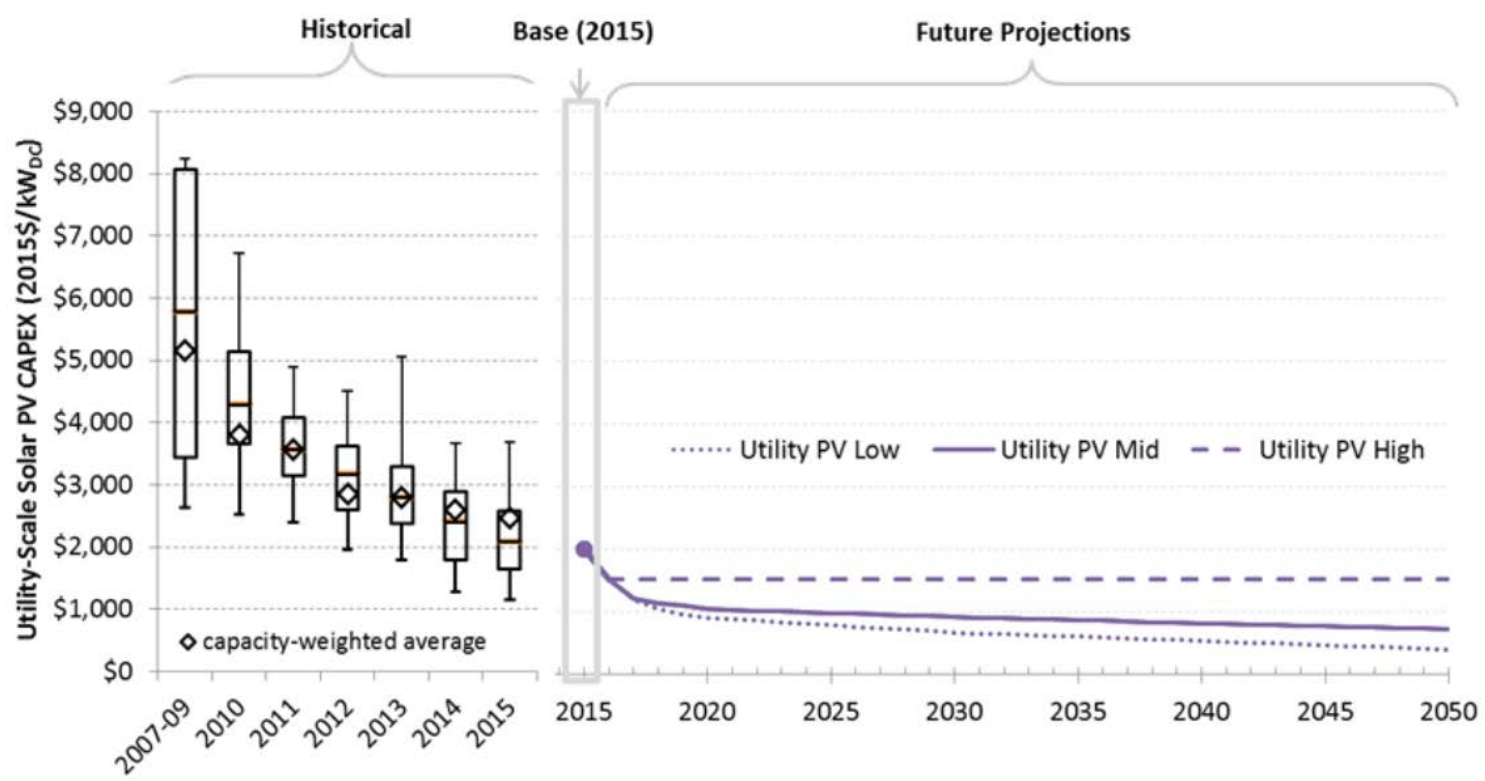

CAPEX (CAPital EXpenditures) historical trends, current estimates, and future projection for utility PV (DC) Source: National Renewable Energy Laboratory Annual Technology Baseline (2017), http://atb.nrel.gov

Figure A-3. Capital expenditures trajectory for utility-scale PV from the 2017 ATB (NREL 2017a) The Low value is used in the present analysis.

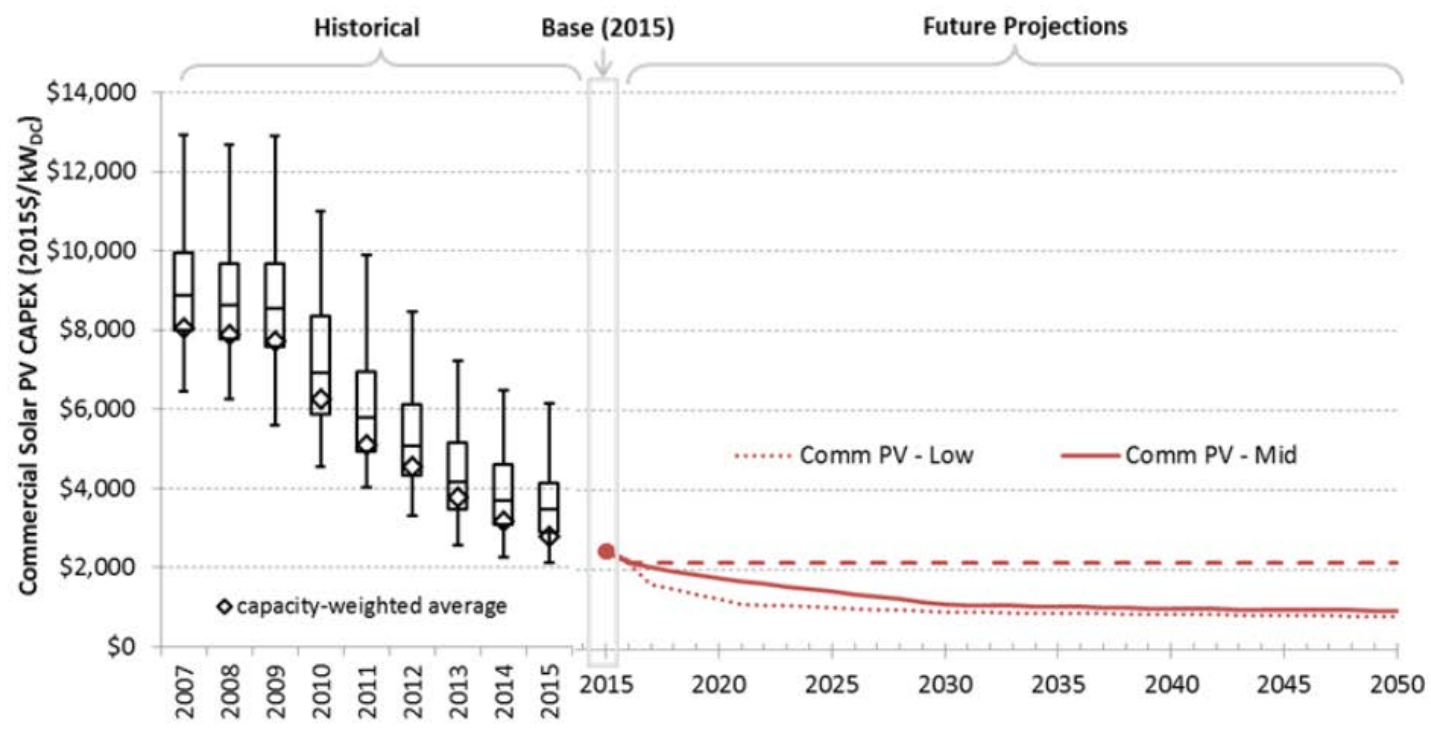

CAPEX (CAPital EXpenditures) historical trends, current estimates, and future projection for commercial PV Source: National Renewable Energy Laboratory Annual Technology Baseline (2017), http://atb.nrel.gov

Figure A-4. Capital expenditures trajectory for utility-scale PV from the 2017 ATB (NREL 2017a) The Low value is used in the present analysis. 
Table A-11. High-Temperature Electrolysis Using Nuclear-Generated Heat Assumptions

\begin{tabular}{|c|c|c|c|c|c|}
\hline & Reference & $\begin{array}{l}\text { Current } \\
\text { R\&D } \\
\text { Trajectory }\end{array}$ & $\begin{array}{l}\text { Low NG } \\
\text { Resource/ } \\
\text { High NG } \\
\text { Price }\end{array}$ & $\begin{array}{l}\text { Aggressive } \\
\text { Electrolysis } \\
\text { R\&D }\end{array}$ & $\begin{array}{l}\text { Lowest-Cost } \\
\text { Electrolysis }\end{array}$ \\
\hline $\begin{array}{l}\text { Capital Cost } \\
\text { of SOEC }\end{array}$ & $\begin{array}{l}\$ 820 / k W \\
\text { Current Central } \\
\text { H2A Case Study }\end{array}$ & \multicolumn{4}{|c|}{$\begin{array}{l}\text { \$423/kW } \\
\text { INL: Epiney et al. 2017; Rabiti et al. } 2017\end{array}$} \\
\hline Yield & $\begin{array}{l}36.8 \mathrm{kWhe} / \mathrm{kg} \mathrm{H} \mathrm{H}_{2} \\
14 \mathrm{kWh} \text { thermal/kg } \\
\mathrm{H}_{2} \\
\text { Current Central } \\
\text { H2A Case Study }\end{array}$ & \multicolumn{4}{|c|}{$\begin{array}{l}35.3 \mathrm{kWhe} / \mathrm{kg} \mathrm{H} \text {; } 9.5 \mathrm{kWh} \text { thermal } / \mathrm{kg} \mathrm{H}_{2} \\
\text { INL Epiney et al. 2017; Rabiti et al. } 2017\end{array}$} \\
\hline $\begin{array}{l}\text { Availability of } \\
\text { Nuclear Fleet } \\
\text { and Price of } \\
\text { Electricity }\end{array}$ & $\begin{array}{l}20 \% \text { of fleet } \\
\text { available at low cost } \\
(20 \mathrm{GW}, 3.8 \mathrm{MMT} \\
\left.\mathrm{H}_{2} / \mathrm{yr}\right) \text {, with } \\
\$ 25 / \mathrm{MWh} \text { electricity } \\
40 \% \text { of fleet } \\
\text { available at high } \\
\text { cost }(40 \mathrm{GW}, 7.7 \\
\left.\text { MMT } \mathrm{H}_{2} / \mathrm{yr}\right) \text {, with } \\
\$ 40 / \mathrm{MWh} \text { electricity } \\
\text { New builds with } \\
\$ 80 / \mathrm{MWh} \text { electricity }\end{array}$ & \multicolumn{4}{|c|}{$\begin{array}{l}20 \% \text { of fleet available at low cost }\left(20 \mathrm{GW}, 4.2 \mathrm{MMT} \mathrm{H}_{2} / \mathrm{yr}\right) \text {, } \\
\text { with } \$ 25 / \mathrm{MWh} \text { electricity } \\
40 \% \text { of fleet available at high cost }\left(40 \mathrm{GW}, 8.4 \mathrm{MMT} \mathrm{H}_{2} / \mathrm{yr}\right) \text {, } \\
\text { with } \$ 40 / \mathrm{MWh} \text { electricity } \\
\text { New builds with } \$ 80 / \mathrm{MWh} \text { electricity }\end{array}$} \\
\hline
\end{tabular}




\section{Appendix B. Methodology and Data for Estimating U.S. Energy Use and Emissions Impacts}

In this analysis, we estimate the energy use and emissions impacts of various hydrogen economic potential scenarios. Section 2.3 summarizes the overall methodology for these estimates, and Section 6.6 presents the results. In this appendix, we provide additional detail on the methodology and references used to develop energy use and emissions impact estimates for sources of both hydrogen production and hydrogen demand. All energy use estimates are provided on an HHV basis. We use heating value and emissions factors from GREET 2018 (ANL 2017).

\section{B.1 Energy Use Impacts Estimates for Hydrogen Production}

Energy use and emissions from hydrogen production depend on the production feedstock and assumed use rate. In this analysis, we consider hydrogen production from SMR of natural gas, LTE using LDE, HTE using nuclear-generated heat, and biomass gasification. The energy requirements for each production technology are described below and summarized in Table B-1.

For SMR of natural gas, we assume a use rate of $0.156 \mathrm{mmBtu}$ of natural gas per $1 \mathrm{~kg}$ of hydrogen on an LHV basis $(0.173 \mathrm{mmBtu}$ of natural gas per $1 \mathrm{~kg}$ of hydrogen on an HHV basis). Using HHV, we estimate that 1.28 Btu of natural gas are required to produce 1 Btu of hydrogen.

We assume hydrogen production from LTE uses only LDE, at a use rate of $50.2 \mathrm{kWh}$ of electricity per $1 \mathrm{~kg}$ of hydrogen (171,289 Btu/kg HHV). Following the methodology employed by EIA, which reports primary energy as fossil fuel equivalent (EIA, n.d.), we assume electricity generation has a $37 \%$ average efficiency factor. ${ }^{67}$ The resulting Btu of electricity required to produce 1 Btu of hydrogen via LTE is 3.44 .

For hydrogen production from HTE using nuclear-generated heat, we assume a use rate of 9.5 $\mathrm{kWh}$ of heat and $35.3 \mathrm{kWh}$ of electricity per $1 \mathrm{~kg}$ hydrogen. Assuming a $32 \%$ thermal efficiency, the total electricity requirement is $38.3 \mathrm{kWh} / \mathrm{kg}$ hydrogen (or $120 \mathrm{kWh}$ heat $/ \mathrm{kg}$ ). This results in a total HTE input to output energy ratio of 3.04 .

Biomass gasification requires $13.03 \mathrm{~kg}$ of woody biomass per $1 \mathrm{~kg}$ of hydrogen. We assume poplar to be the primary feedstock, which has an HHV of $19,380 \mathrm{~kJ} / \mathrm{kg}(18,367 \mathrm{Btu} / \mathrm{kg})(\mathrm{DOE}$ 2010). ${ }^{68}$ The biomass requirement on an energy basis is then estimated as $1.78 \mathrm{Btu}$ of biomass per 1 Btu of hydrogen. Biomass gasification also requires $0.945 \mathrm{kWh}$ of electricity and 0.003 mmBtu of natural gas (LHV), resulting in a total input to output energy ratio of 1.87 .

\footnotetext{
${ }^{67}$ The efficiency factor is calculated from the projected 2050 energy consumption and electricity generation of the power sector in the AEO 2017 Reference case.

68 The value of $19,380 \mathrm{~kJ} / \mathrm{kg}$ is calculated as the average of the range of provided values $(19,022-19,737 \mathrm{~kJ} / \mathrm{kg})$.
} 
Table B-1. Energy Use Required for Hydrogen Production

\begin{tabular}{|c|c|c|c|}
\hline $\begin{array}{l}\text { Production } \\
\text { Technology }\end{array}$ & $\begin{array}{l}\text { Primary Energy } \\
\text { Source }\end{array}$ & $\begin{array}{l}\text { Btu of Primary } \\
\text { Energy Source } \\
\text { per Btu Hydrogen }\end{array}$ & References \\
\hline SMR & Natural gas & 1.28 & $\begin{array}{l}\mathrm{H} 2 \mathrm{~A} \text { case study "Future Central Hydrogen } \\
\text { Production from Natural Gas without } \mathrm{CO}_{2} \\
\text { Sequestration version } 3.2018 \text { " (DOE 2018a) }\end{array}$ \\
\hline LTE & $\begin{array}{l}\text { Wind and solar } \\
\text { resource }\end{array}$ & $3.44^{a}$ & $\begin{array}{l}\text { H2A case study "Future Central Hydrogen } \\
\text { Production from PEM Electrolysis version } \\
\text { 3.2018" (DOE 2018a); } 2017 \text { AEO (EIA 2017a) }\end{array}$ \\
\hline HTE & Nuclear & 3.04 & Epiney et al. (2017); Rabiti et al. (2017) \\
\hline $\begin{array}{l}\text { Biomass } \\
\text { gasification }\end{array}$ & Biomass & 1.87 & $\begin{array}{l}\text { H2A case study "Future Central Hydrogen } \\
\text { Production via Biomass Gasification version } \\
\text { 3.2018" (DOE 2018a) }\end{array}$ \\
\hline
\end{tabular}

a Energy is reported as a fossil fuel equivalent.

\section{B.2 Energy Use Impacts Estimates for Hydrogen Demand}

The impact of hydrogen demand on national energy use and emissions depends on the source of hydrogen production, as described above, and on if and how the hydrogen demand displaces use of another fuel or feedstock. Here we describe the methodology used for each demand application, and Table B-3 summarizes the assumed energy displacement factors. In the case of petroleum, we only consider impacts from direct fuel substitution and do not calculate impacts from lifecycle petroleum use (e.g., from the harvesting and delivery of biomass).

For oil refining, ammonia, and synthetic methanol, end-use energy is determined only by the assumed market growth, and there is no change in energy end use due to displaced energy (although total energy can change based on the hydrogen production mix). Demand for oil refining is allocated to the transportation sector, and demand for ammonia and synthetic methanol is allocated to the industrial sector.

We assume hydrogen demand for metals refining is due to reshoring of metals production to the United States. Therefore, while iron refining using DRI can decrease energy use and emissions in steel production on a global level, here we only the show the changes of increased hydrogen production on a national level, which results in increased energy use and emissions with market growth.

Growth in biofuels demand affects the energy in the transportation sector coming from biomass, as well as the energy coming from petroleum. The energy required for the biofuel production is calculated assuming a mix of hydrotreating of FOGs and catalytic fast pyrolysis (Elgowainy et al. 2020). We assume FOGs require no biomass use. The catalytic fast pyrolysis production process uses 1 dry MT of biomass (assumed to be woody biomass) to produce 65.9 gasoline gallon equivalents (GGE) of biofuel (1 dry ton produces 59.5 GGE), based on Dutta et al. (2020). We use a woody biomass HHV of $18,367 \mathrm{Btu} / \mathrm{kg}$ (DOE 2010), along with the assumed hydrogen use of $490 \mathrm{~g} / \mathrm{gal}$, to calculate the total energy use required for the corresponding estimated hydrogen demand for biofuels production. We estimate 4.17 Btu of biomass are required per Btu of hydrogen (2.29 Btu of biomass are required per Btu of biofuel), based on the weighted average of FOG and catalytic fast pyrolysis penetrations (1.8 billion gal/yr from FOGs and 17.5 
billion gal/yr from catalytic fast pyrolysis, as described in Section 3.4). In addition to the increased energy use for biofuels production, we also estimate the displaced energy from petroleum use in the transportation sector. We assume 1 Btu of jet fuel is displaced per Btu of biofuel. Using a lifecycle petroleum multiplier for jet fuel of 1.04 (calculated from GREET 2018), we calculate that 1.92 Btu of petroleum are displaced per Btu of hydrogen required for biofuel production.

FCEVs can displace petroleum use in the transportation sector, and - depending on vehicle fuel efficiency - may also decrease overall energy use. We rely on fuel economy, vehicle stock, and VMT estimates from Elgowainy et al. (2020) (Table B-2) and the market sizes of our scenarios to project energy use impacts from FCEVs in LDV and medium- and heavy-duty truck applications. We assume the projected VMT from FCEVs displace VMT from internal combustion engine vehicles; LDVs displace gasoline use, and medium- and heavy-duty vehicles displace diesel.

Table B-2. Fuel Economy and VMT Estimates for 2075 (Elgowainy et al. 2020)

\begin{tabular}{lccc}
\hline & $\begin{array}{l}\text { Internal Combustion } \\
\text { Engine Vehicle Fuel } \\
\text { Economy in 2075 (mpgge) }\end{array}$ & $\begin{array}{l}\text { FCEV Fuel Economy } \\
\text { in 2075 (mpgge) }\end{array}$ & $\begin{array}{l}\text { FCEV VMT in 2075 } \\
\text { (million miles) }\end{array}$ \\
\hline Light-duty cars & 43 & 100 & 438,000 \\
Light-duty trucks & 30 & 64 & 480,000 \\
Medium-duty trucks & 16 & 33 & 46,000 \\
Heavy-duty trucks & 12 & 15 & 55,000 \\
\hline
\end{tabular}

Elgowainy et al. (2020) assume constant fuel economy from 2050-2075.

Synthetic fuel, specifically MTG, also has the potential to displace petroleum use in the transportation sector. We estimate that 0.90 Btu of gasoline can be displaced per Btu of hydrogen used for synthetic fuel; this equates to 0.91 Btu of petroleum displacement assuming a lifecycle petroleum multiplier of 1.013 for gasoline. ${ }^{69}$ While growth in synthetic fuels may increase overall energy use, it can lead to reductions in overall emissions.

For injection into natural gas pipelines, hydrogen displaces natural gas on an energy basis. In other words, we assume that the energy efficiency of using hydrogen and natural gas is constant. We assume natural gas to be displaced proportionally to the split between the natural gas use in the residential, commercial, industrial, and transportation sectors. ${ }^{70}$

We assume hydrogen for seasonal energy storage for the electric grid would displace coal and natural gas used by conventional generators. The energy displaced can be calculated from the

\footnotetext{
${ }^{69}$ This value is based on the following parameters: $1 \mathrm{~kg}$ of MTG fuel requires $0.43 \mathrm{~kg}$ of hydrogen (based on the requirement of 3 moles of hydrogen to reduce oxygen and carbon dioxide), 1 gallon of MTG fuel equates to 2.819 $\mathrm{kg}$ of MTG fuel, and the HHV of MTG fuel is $124,340 \mathrm{Btu} / \mathrm{gal}$ (assumed to be the same as gasoline blendstock).

${ }^{70}$ The residential, commercial, industrial, and transportation sectors account for $23 \%, 18 \%, 53 \%$, and $5 \%$ of natural gas end use in the AEO 2017 Low Oil \& Gas Resource and Technology scenario in 2050.
} 
estimated electricity generation from these sources (see Appendix C), with an assumed generation efficiency of $37 \%$, as described above.

Table B-3. Energy Displacement from Each Hydrogen Demand Application

\begin{tabular}{|c|c|c|c|}
\hline Demand Application & $\begin{array}{l}\text { Displaced Energy } \\
\text { Source }\end{array}$ & $\begin{array}{l}\text { Btu of Energy } \\
\text { Displaced per } \\
\text { Btu Hydrogen }\end{array}$ & References \\
\hline Biofuela & Petroleum & 1.92 & $\begin{array}{l}\text { Internal calculations based on } \\
\text { Dutta et al. (2020) }\end{array}$ \\
\hline MTG & Petroleum & 0.91 & Internal calculations \\
\hline Light-duty car FCEV & Petroleum & 2.32 & Internal calculations \\
\hline Light-duty truck FCEV & Petroleum & 2.14 & Internal calculations \\
\hline Medium-duty FCEV & Petroleum & 2.09 & Internal calculations \\
\hline Heavy-duty FCEV & Petroleum & 1.21 & Internal calculations \\
\hline $\begin{array}{l}\text { Injection into natural } \\
\text { gas pipelines }\end{array}$ & Natural gas & 1.00 & Internal calculations \\
\hline
\end{tabular}

We assume no energy displacement occurs for hydrogen demand in oil refining, ammonia, methanol, or metals refining.

a We estimate that 4.17 Btu of biomass are required per Btu of hydrogen demanded.

\section{B.3 Emissions Impacts Estimates for Hydrogen Production and Demand}

Emissions and fuel use reductions are calculated using the displacement factors above and the emissions factors for each respective energy source. The emissions factors for hydrogen and other fuels used in this analysis, from GREET (ANL 2017), are listed in Table B-4. The grid electricity emissions factors used to estimate emissions impacts are shown in Table B-5.

Table B-4. Emissions Factors Used to Estimate Emissions Impacts (ANL 2017)

\begin{tabular}{|c|c|c|c|c|}
\hline Fuel Type & $\begin{array}{l}\mathrm{CO}_{2} \mathrm{e} \\
(\mathrm{g} / \mathrm{mmBtu})\end{array}$ & $\begin{array}{l}\mathrm{NO}_{\mathrm{x}} \\
\text { (g/mmBtu) }\end{array}$ & $\begin{array}{l}\mathrm{SO}_{\mathrm{x}} \\
\text { (g/mmBtu) }\end{array}$ & $\begin{array}{l}\mathrm{PM}_{10} \\
\text { (g/mmBtu) }\end{array}$ \\
\hline SMR hydrogen & 82,687 & 33 & 15 & 2 \\
\hline LTE hydrogena & - & - & - & - \\
\hline HTE hydrogen & 1,845 & 2 & 1 & 0 \\
\hline Biomass gasification hydrogen & 12,538 & 42 & 26 & 3 \\
\hline Biofuel $^{b}$ & 15,866 & 321 & 6 & 21 \\
\hline Gasoline & 89,017 & 60 & 19 & 8 \\
\hline Diesel & 90,818 & 61 & 13 & 8 \\
\hline
\end{tabular}

All values are per mmBtu HHV based on the 2050 generation mix from AEO 2017 (EIA 2017a). Hydrogen emissions factors for each scenario are calculated from the factors above and the hydrogen production mix. a We assume LTE uses only LDE from wind and solar resources as described in Section 4.2.

${ }^{b}$ Biofuel emissions are based on a mix of hydrotreating of FOGs and catalytic fast pyrolysis, as described in Section 3.4. 
Table B-5. Grid Electricity Emissions Factors Used to Estimate Emissions Impacts

\begin{tabular}{|c|c|c|c|c|}
\hline Grid Mix Scenario & $\mathrm{CO}_{2} \mathrm{e}(\mathrm{g} / \mathrm{kWh})$ & $\mathrm{NO}_{\mathrm{x}}(\mathrm{g} / \mathrm{kWh})$ & $\mathrm{SO}_{\mathrm{x}}(\mathrm{g} / \mathrm{kWh})$ & $P M_{10}(g / k W h)$ \\
\hline AEO 2050 Reference & 399 & 0.28 & 0.53 & 0.06 \\
\hline ReEDS Low RE Cost & 239 & 0.17 & 0.31 & 0.05 \\
\hline ReEDS High Curtailment & 91 & 0.07 & 0.14 & 0.03 \\
\hline Reference & 239 & 0.17 & 0.31 & 0.05 \\
\hline $\begin{array}{l}\text { R\&D Advances + } \\
\text { Infrastructure }\end{array}$ & 239 & 0.17 & 0.31 & 0.05 \\
\hline $\begin{array}{l}\text { Low NG Resource/ } \\
\text { High NG Price }\end{array}$ & 91 & 0.07 & 0.14 & 0.03 \\
\hline $\begin{array}{l}\text { Aggressive Electrolysis } \\
R \& D\end{array}$ & 92 & 0.07 & 0.14 & 0.03 \\
\hline Lowest-Cost Electrolysis & 83 & 0.06 & 0.14 & 0.03 \\
\hline
\end{tabular}

AEO Reference grid electricity is based on the 2050 generation mix from AEO 2017 (EIA 2017a). 


\section{Appendix C. Estimate of Serviceable Consumption Potential and Economic Potential for Seasonal Electricity Storage}

Hydrogen has the potential to provide seasonal energy storage to the electric grid. Current grid operations are based primarily on central generation supplying distributed loads. That central generation includes baseload generators, such as nuclear and coal generation, which operate almost all the time. It also includes intermediate and peaking generators, which often have higher operating costs but are designed to be flexible - they ramp generation up and down and can be turned on and off relatively inexpensively. Generation by VRE generators such as wind and PV is limited by the availability of wind or solar resource at any given time, so it is neither constant nor able to follow load. Currently, the grid uses dispatchable intermediate and peaking generation to match generation and load and buffer intermittencies in VRE generation (Chang et al. 2013).

Although the current demand for electrical energy storage is low, analysis suggests its role will increase as VRE penetration increases, especially at VRE penetrations of greater than $80 \%$ of annual load (Scholz, Gils, and Pietzcker 2017). Storage to manage diurnal cycles in load and generation likely will be provided by batteries, because they are well suited for 1-10 hours of storage (Dufo-López, Bernal-Agustín, and Domínguez-Navarro 2009). Hydrogen may be the most cost-effective method to provide longer-term, or seasonal, storage - as shown in Figure 5 and discussed in Korpas and Greiner (2008) and Cebulla, Naegler, and Pohl (2017).

We estimate the technical potential for hydrogen storage as the quantity of hydrogen that would be required annually to replace electricity generation from natural gas in a scenario with very high penetrations of renewable and nuclear generation. At high penetrations of renewable and nuclear generation, natural gas generation could provide power when renewable resources are not available in particular areas - power that could be provided instead by hydrogen produced from LDE. To estimate the technical and economic potential for seasonal storage, we calculate the quantity of hydrogen necessary to replace natural gas generation, and we estimate the price points necessary for hydrogen to compete with several electricity-generation technologies using fossil energy.

We base our serviceable consumption potential estimate on the minimum amount of electricity generated from coal and natural gas in the ReEDS High Curtailment grid scenario described in Section 4.2 and Ruth et al. (forthcoming), with natural gas prices from the AEO LOGR scenario and an LDE price of $\$ 25 / \mathrm{MWh}$. We use an LDE price of $\$ 25 / \mathrm{MWh}$ because it is the price in the ReEDS High Curtailment grid scenarios with the lowest fossil electricity generation. Scenarios with lower prices result in less renewable capacity, so more generation is provided by fossil energy. Our scenario with a higher LDE price $(\$ 30 / \mathrm{MWh})$ results in more fossil generation, because fossil generators run slightly more often to generate electricity for the LDE market. At an LDE price of $\$ 25 / \mathrm{MWh}$, the 2050 annual generation is $14 \mathrm{TWh} / \mathrm{yr}$ from NGCTs and 252 $\mathrm{TWh} / \mathrm{yr}$ from NGCCs, totaling $266 \mathrm{TWh} / \mathrm{yr}$ (5\% of the annual load). This $266 \mathrm{TWh} / \mathrm{yr}$ requires 14.8 MMT/yr hydrogen for conversion to electricity via a stationary fuel cell with a $60 \%$ direct current efficiency (FCTO 2017) and a 93\% inverter efficiency (Wei et al. 2014). Thus, the serviceable consumption potential for hydrogen for energy storage is $14.8 \mathrm{MMT} / \mathrm{yr}$. 
We estimate the hydrogen threshold prices for seasonal storage to compete by calculating the cost of hydrogen necessary to generate electricity at the same LCOE as each fossil generator modeled (NGCT and NGCC). To estimate the threshold price, we calculate the necessary hydrogen cost for stationary $\mathrm{H}_{2}-\mathrm{FCs}$ and $\mathrm{H}_{2}-\mathrm{CTs}$ and use the larger of those hydrogen costs. Table C-1 reports the overnight capital cost, heat rate, and efficiency of $\mathrm{H}_{2}-\mathrm{FCs}$ and $\mathrm{H}_{2}-\mathrm{CTs}$ that we use, along with references. Capital and operating costs and efficiencies for the fossil generators are from NREL's Annual Technology Baseline (NREL 2017a). We estimate the national-average threshold price for each generator instead of a higher fidelity (i.e., each generator in each region in ReEDS) to be consistent with the overall structure of this analysis, which focuses on national supply and demand curves.

Table C-1. Stationary Hydrogen Fuel Cell and Combustion Turbine Assumptions and References

\begin{tabular}{lrl}
\hline Parameter & Value & Reference \\
\hline Stationary PEM Fuel Cell $\left(\mathbf{H}_{2}-\mathrm{FC}\right)$ & & \\
Overnight capital cost $(\$ / \mathrm{kW})$ & 1,000 & (FCTO 2017), Table 3.4.12 \\
Heat rate (mmBtu/MWh electricity) & 6.12 & Calculated from overall efficiency \\
Fuel cell efficiency & $60 \%$ & (FCTO 2017), Table 3.4.12 \\
Inverter efficiency & $93 \%$ & (Wei et al. 2014) \\
Overall Efficiency & $55.8 \%$ & Calculation \\
\hline
\end{tabular}

\section{Hydrogen Combustion Turbine $\left(\mathrm{H}_{2}-\mathrm{CT}\right)$}

Overnight capital cost $(\$ / \mathrm{kW})$

833 Based on $10 \%$ addition to projected cost of natural gas turbine generator; $10 \%$ addition is from personal communication with an industrial representative

Heat rate (mmBtu/MWh electricity) $\quad 8.2$ Equivalent to natural gas turbine efficiency

The resulting hydrogen threshold prices and key factors in their calculation for seasonal dispatch are reported in Table C-2 and Table C-3 under the AEO LOGR scenario and the AEO Reference scenario, respectively. Each table reports the annual generation from each specific technology as estimated in 2050 using ReEDS. The capacity factors are calculated as the annual generation divided by the maximum potential generation based on each technology's 2050 national capacity as calculated by ReEDS. Each table also reports the LCOE for the fossil technology, the most cost-effective hydrogen technology to replace each, the quantity of hydrogen required annually, and the hydrogen price required for that technology to have an equivalent LCOE. $\mathrm{H}_{2}$-CTs have a higher hydrogen threshold price at very low capacity factors because they have low capital costs compared with $\mathrm{H}_{2}-\mathrm{FCs}$, whereas $\mathrm{H}_{2}-\mathrm{FCs}$ have higher hydrogen threshold prices at higher capacity factors because their efficiency is higher. We use the resulting hydrogen quantities and threshold prices to develop the electricity storage portion of the demand curves. 
Table C-2. Hydrogen Prices Necessary to Compete with Fossil Generation for Seasonal Dispatch under the AEO LOGR Scenario

\begin{tabular}{lrr}
\hline & NGCT & NGCC \\
\hline Annual generation using the technology (TWh/yr) & 14 & 252 \\
Capacity factor & $0.7 \%$ & $11 \%$ \\
LCOE of the fossil generator (\$/MWh) & $\$ 1,330$ & $\$ 160$ \\
Technology to replace fossil generation & $\mathrm{H}_{2}-\mathrm{CT}$ & $\mathrm{H}_{2}-\mathrm{FC}$ \\
Hydrogen quantity required to replace electricity generation $(\mathrm{MMT} / \mathrm{yr})$ & 0.8 & 14 \\
Hydrogen price required to compete with fossil generation $(\$ / \mathrm{kg})$ & $\$ 0.26$ & $\$ 1.10$ \\
\hline
\end{tabular}

Table C-3. Hydrogen Prices Necessary to Compete with Fossil Generation for Seasonal Dispatch under the AEO Reference Scenario

\begin{tabular}{lrr}
\hline & NGCT & NGCC \\
\hline Annual generation using the technology (TWh/yr) & 82 & 897 \\
Capacity factor & $2.7 \%$ & $36 \%$ \\
LCOE of the fossil generator (\$/MWh) & $\$ 370$ & $\$ 67$ \\
Technology to replace fossil generation & $\mathrm{H}_{2}-\mathrm{CT}$ & $\mathrm{H}_{2}-\mathrm{FC}$ \\
Hydrogen quantity required to replace electricity generation $(\mathrm{MMT} / \mathrm{yr})$ & 4.4 & 48 \\
Hydrogen price required to compete with fossil generation $(\$ / \mathrm{kg})$ & $\$ 0.55$ & $\$ 0.57$ \\
\hline
\end{tabular}

Figure C-1 shows the serviceable consumption potential of hydrogen demand for seasonal energy storage by county. 


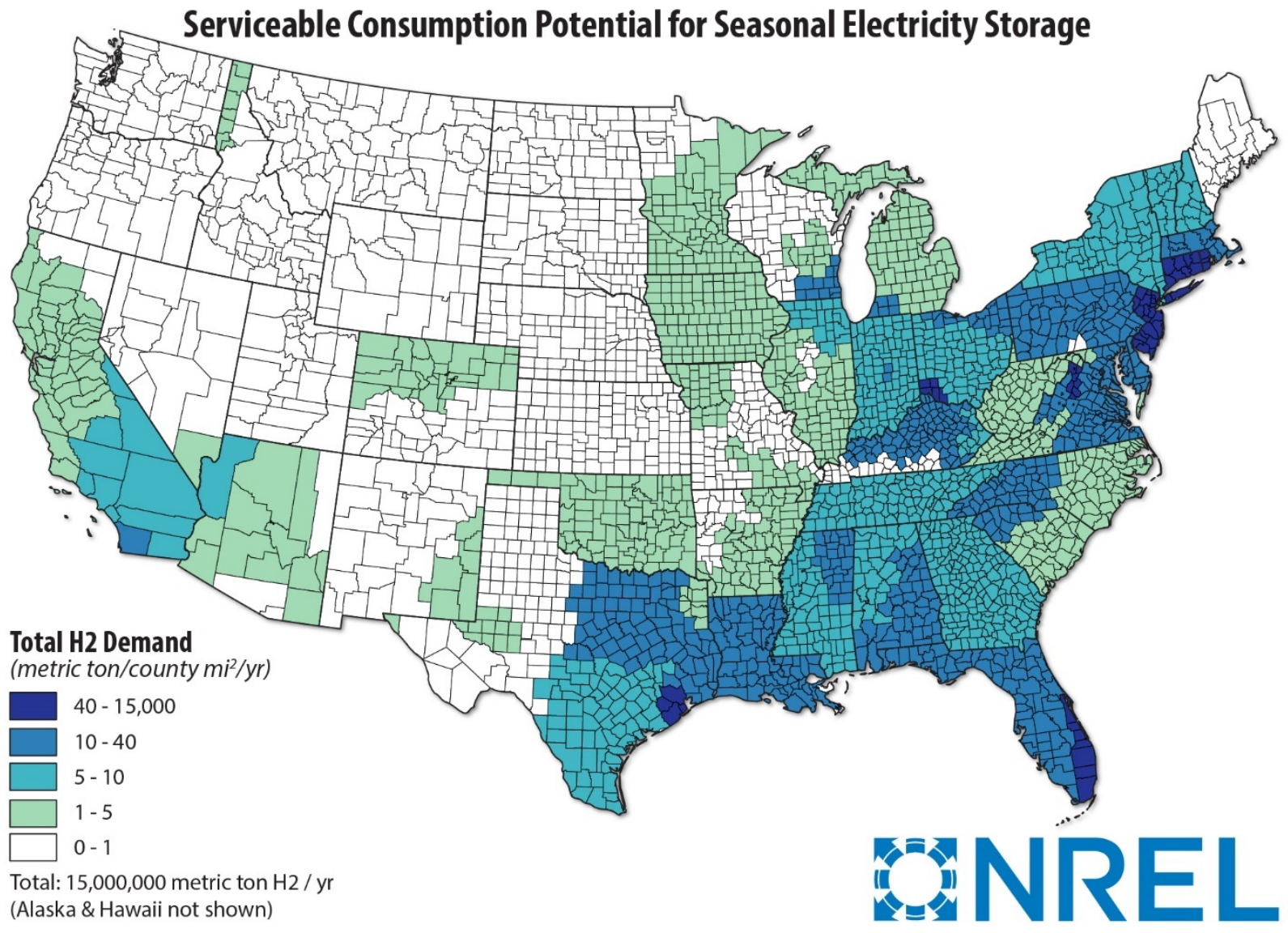

Figure C-1. Locations of aggregated serviceable consumption potentials for seasonal energy storage for the electric grid under the AEO LOGR scenario 


\section{Appendix D. Summary of Methods for Serviceable Consumption Potential, Technical Potential, and Economic Potential Regionalization}

The methods used to map supply and demand levels are summarized in Table D-1. For the serviceable consumption potential size maps, we allocate demand to the county level to compare to the geographically detailed resource technical potential estimates. For the scenario supply and demand (economic potential) comparisons, we map to a more aggregated level. Locations are specified to represent an aggregation of counties and to represent major metro areas, current SMR and nuclear plant sites, and all ReEDS balancing areas.

In most cases, as shown in Table D-1, the same data source is used for county- and node-level mapping. However, we use separate data sources for transportation owing to the assumed penetration of FCEVs in the serviceable consumption potential compared with the economic potential. The economic potential assumes lower adoption of FCEVs; therefore, we rely on estimates from the H2USA study to allocate demand to the locations most likely to adopt FCEVs in an aggressive adoption scenario. In contrast, VMT by county is used to allocate the serviceable consumption potential, which is based on more widespread adoption of FCEVs.

Table D-1. Summary of Methods Used to Determine Demand and Production Locations for Serviceable Consumption Potential, Technical Potential, and Economic Potential Estimates

\begin{tabular}{|c|c|c|}
\hline & $\begin{array}{l}\text { Hydrogen } \\
\text { Demand or } \\
\text { Production } \\
\text { Technology }\end{array}$ & $\begin{array}{l}\text { Serviceable Consumption } \\
\text { Potential (Demand) or Technical } \\
\text { Potential (Production), County } \\
\text { Level }\end{array}$ \\
\hline \multirow{4}{*}{ 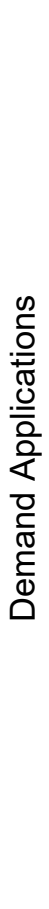 } & Oil refining & $\begin{array}{l}\text { Located at existing refinery locations } \\
\text { from EIA }(2017 \text { e) refinery capacity } \\
\text { data }\end{array}$ \\
\hline & Metals refining & $\begin{array}{l}\text { Demand split evenly between three } \\
\text { primary regions for metals refining } \\
\text { based on communication with } \\
\text { experts from Idaho National } \\
\text { Laboratory (January } 25,2017 \text { ): } \\
\text { Minnesota, Lake Michigan and Lake } \\
\text { Erie, and Birmingham, Alabamaa }\end{array}$ \\
\hline & $\begin{array}{l}\text { Ammonia } \\
\text { production }\end{array}$ & $\begin{array}{l}\text { Allocated to existing and projected } \\
\text { ammonia plants within each county, } \\
\text { from ammonia industry as analyzed } \\
\text { in Elgowainy et al. (2020) }\end{array}$ \\
\hline & $\begin{array}{l}\text { Biofuels } \\
\text { production }\end{array}$ & $\begin{array}{l}\text { Allocated to state using resource } \\
\text { availability from BTS (DOE 2016); } \\
\text { state-level demand allocated evenly } \\
\text { to industrial locations within each } \\
\text { region (industrial locations are those } \\
\text { previously identified as refinery, } \\
\text { ammonia, metals, or SMR locations) }\end{array}$ \\
\hline
\end{tabular}

\section{Economic Potential, Major Metro Area Level}

Same method as for serviceable consumption potential, but demand is mapped to major metro areas

Same method as for serviceable consumption potential, but demand is mapped to major metro areas

Same method as for serviceable consumption potential, but demand is mapped to major metro areas

Same method as for serviceable consumption potential, but demand is mapped to major metro areas 


\begin{tabular}{|c|c|c|c|}
\hline & $\begin{array}{l}\text { Hydrogen } \\
\text { Demand or } \\
\text { Production } \\
\text { Technology }\end{array}$ & $\begin{array}{l}\text { Serviceable Consumption } \\
\text { Potential (Demand) or Technical } \\
\text { Potential (Production), County } \\
\text { Level }\end{array}$ & $\begin{array}{l}\text { Economic Potential, Major } \\
\text { Metro Area Level }\end{array}$ \\
\hline & $\begin{array}{l}\text { Synthetic } \mathrm{HC} \\
\text { (methanol) }\end{array}$ & $\begin{array}{l}\text { Allocated to largest carbon dioxide } \\
\text { resources from ethanol plants based } \\
\text { on Elgowainy et al. (2020) }\end{array}$ & $\begin{array}{l}\text { Same method as for serviceable } \\
\text { consumption potential, but demand } \\
\text { is mapped to major metro areas }\end{array}$ \\
\hline & $\begin{array}{l}\text { Synthetic HC } \\
\text { (MTG) }\end{array}$ & $\begin{array}{l}\text { Allocated to top carbon dioxide } \\
\text { resources from refining and ammonia } \\
\text { plants based on Elgowainy et al. } \\
(2020)\end{array}$ & $\begin{array}{l}\text { Same method as for serviceable } \\
\text { consumption potential, but demand } \\
\text { is mapped to major metro areas }\end{array}$ \\
\hline & $\begin{array}{l}\text { Injection into } \\
\text { the natural gas } \\
\text { system }\end{array}$ & $\begin{array}{l}\text { Allocated evenly to counties based } \\
\text { on the } 2015 \text { AEO report of national } \\
\text { natural gas use by census division } \\
\text { (EIA 2015a) }\end{array}$ & Not mapped \\
\hline & $\begin{array}{l}\text { Light-duty } \\
\text { FCEVs }\end{array}$ & $\begin{array}{l}\text { Allocated to each county proportional } \\
\text { to county-level VMT using an internal } \\
\text { NREL database of county-level VMT, } \\
\text { developed as part of the Cities } \\
\text { Leading through Energy Analysis and } \\
\text { Planning project (DOE n.d.) }\end{array}$ & $\begin{array}{l}\text { Allocated to each major metro area } \\
\text { proportional to the hydrogen } \\
\text { demand in the H2USA National } \\
\text { Expansion scenario (M. Melaina et } \\
\text { al. 2017) }\end{array}$ \\
\hline & Other transport & $\begin{array}{l}\text { Allocated to each county proportional } \\
\text { to county-level VMT using an internal } \\
\text { NREL database of county-level VMT, } \\
\text { developed as part of the Cities } \\
\text { Leading through Energy Analysis and } \\
\text { Planning project (DOE n.d.) }\end{array}$ & $\begin{array}{l}\text { Allocated to each major metro area } \\
\text { proportional to the hydrogen } \\
\text { demand in the H2USA National } \\
\text { Expansion scenario (M. Melaina et } \\
\text { al. 2017) }\end{array}$ \\
\hline & $\begin{array}{l}\text { Seasonal } \\
\text { electricity } \\
\text { storage }\end{array}$ & $\begin{array}{l}\text { Located at site of displaced natural } \\
\text { gas generation, determined by } \\
\text { ReEDS scenarios in Ruth et al. } \\
\text { (forthcoming); quantity in each } \\
\text { ReEDS balancing area allocated by } \\
\text { spatial area to counties within that } \\
\text { area }\end{array}$ & Not mapped \\
\hline \multirow{3}{*}{ 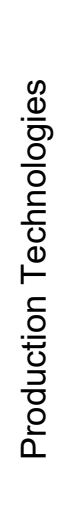 } & $\begin{array}{l}\text { SMR of natural } \\
\text { gas }\end{array}$ & Not mapped & $\begin{array}{l}\text { Supply from each census division } \\
\text { mapped proportionally to current } \\
\text { production locations from IHS (2015) }\end{array}$ \\
\hline & LTE using LDE & $\begin{array}{l}\text { Technical potential of utility PV and } \\
\text { wind from Connelly et al. (2020) }\end{array}$ & $\begin{array}{l}\text { Supply allocated to major metro } \\
\text { areas within each ReEDS balancing } \\
\text { area based on the amount of LDE } \\
\text { available (Ruth, Jadun, and Cole } \\
\text { forthcoming) }\end{array}$ \\
\hline & $\begin{array}{l}\text { HTE using } \\
\text { nuclear energy }\end{array}$ & Not mapped & $\begin{array}{l}\text { Supply allocated to nuclear plant } \\
\text { locations selected in the low- } \\
\text { extension-cost and high-extension- } \\
\text { cost categories }\end{array}$ \\
\hline
\end{tabular}




\begin{tabular}{lll}
\hline $\begin{array}{l}\text { Hydrogen } \\
\text { Demand or } \\
\begin{array}{l}\text { Production } \\
\text { Technology }\end{array}\end{array}$ & $\begin{array}{l}\text { Serviceable Consumption } \\
\text { Potential (Demand) or Technical } \\
\text { Potential (Production), County } \\
\text { Level }\end{array}$ & $\begin{array}{l}\text { Economic Potential, Major } \\
\text { Metro Area Level }\end{array}$ \\
\hline Biomass & Technical potential of biomass from & $\begin{array}{l}\text { Supply allocated to state using } \\
\text { resource availability from BTS (DOE } \\
\text { gasification } \\
\text { evenly to industrial locations within } \\
\text { each region (industrial locations are } \\
\text { those previously identified as } \\
\text { refinery, ammonia, metals, or SMR } \\
\text { locations) }\end{array}$ \\
\hline
\end{tabular}

a Demand for Minnesota is allocated to Minneapolis and Duluth. Demand for Lake Michigan and Lake Erie is distributed evenly to Gary, IN; Toledo, OH; Cleveland, OH; Erie, PA; Buffalo, NY; and Rochester, NY. Demand for Birmingham is distributed to counties with metro areas within a 250-mile radius of the city. 


\section{Appendix E. Maps of Hydrogen Serviceable Consumption Potentials and Hydrogen Production Technical Potentials}

Figure E-1 and Figure E-2 show the geographic distribution of U.S. natural gas resources, indicating the distribution of hydrogen's technical potential from natural gas SMR. Figure E-3 through Figure E-7 map the technical potential for hydrogen production options, corresponding to the analysis in Connelly et al. (2020). Figure E-8 through Figure E-15 show the serviceable consumption potentials for each demand application described in Section 3. Lastly, Figure E-16 shows a county-by-county comparison between the technical potential for hydrogen production from onshore wind and PV resources and serviceable consumption potential for all demands in relation to existing nuclear plants.

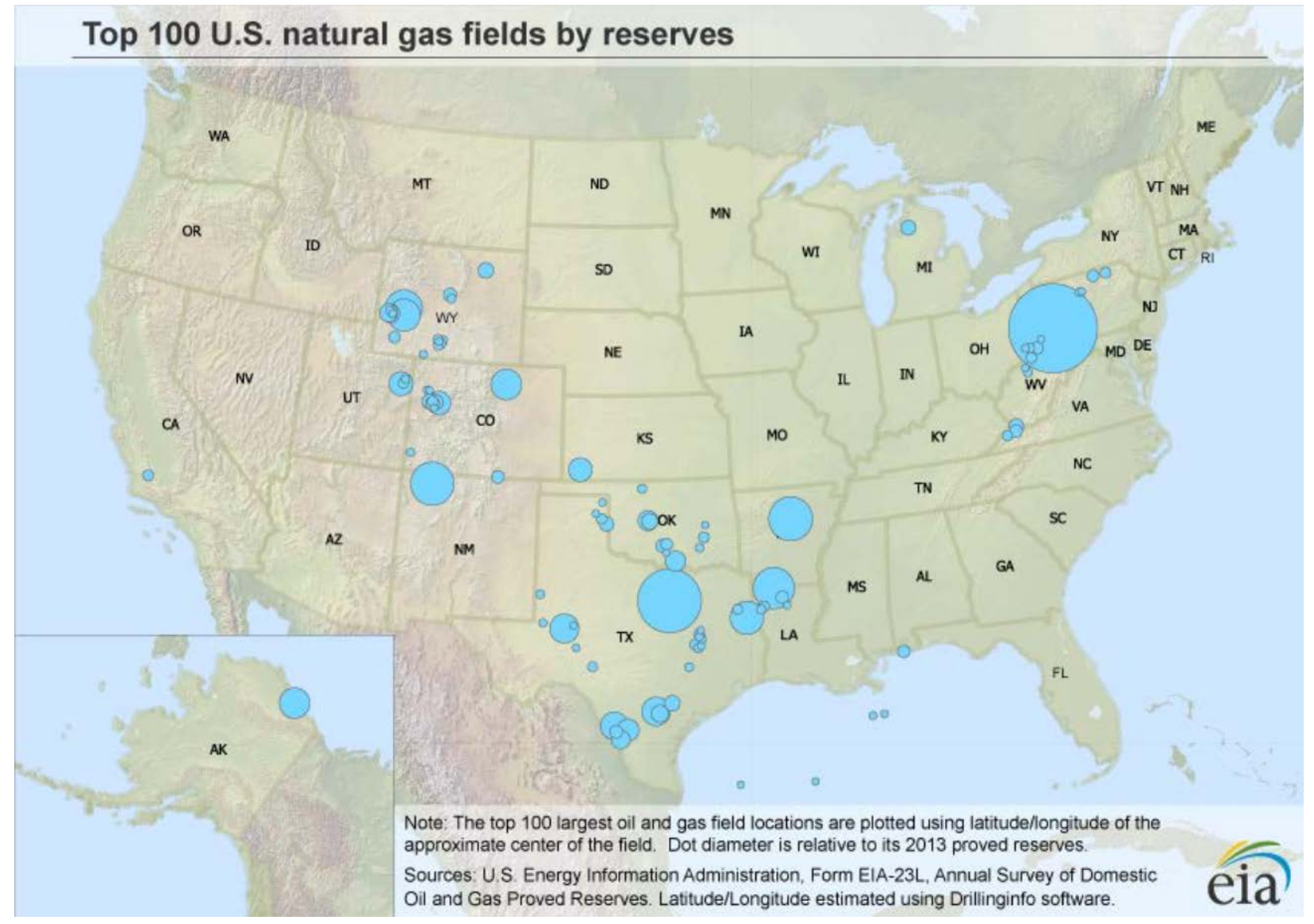

Figure E-1. Geographic distribution of the top 100 U.S. natural gas fields

Source: EIA (2015b) 


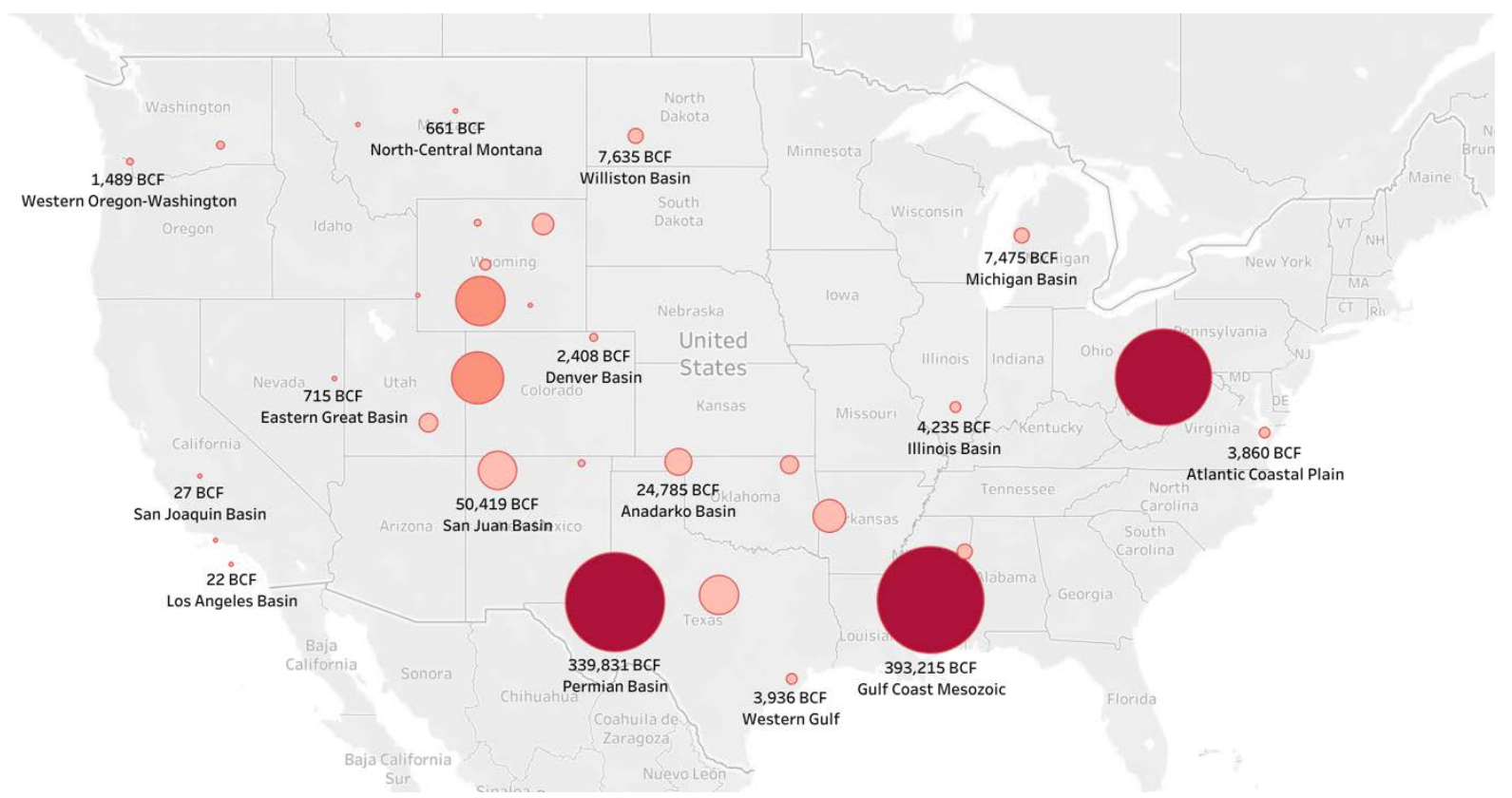

Figure E-2. Geographic distribution of U.S. continuous unconventional natural gas resources Source: U.S. Geological Survey (2020)

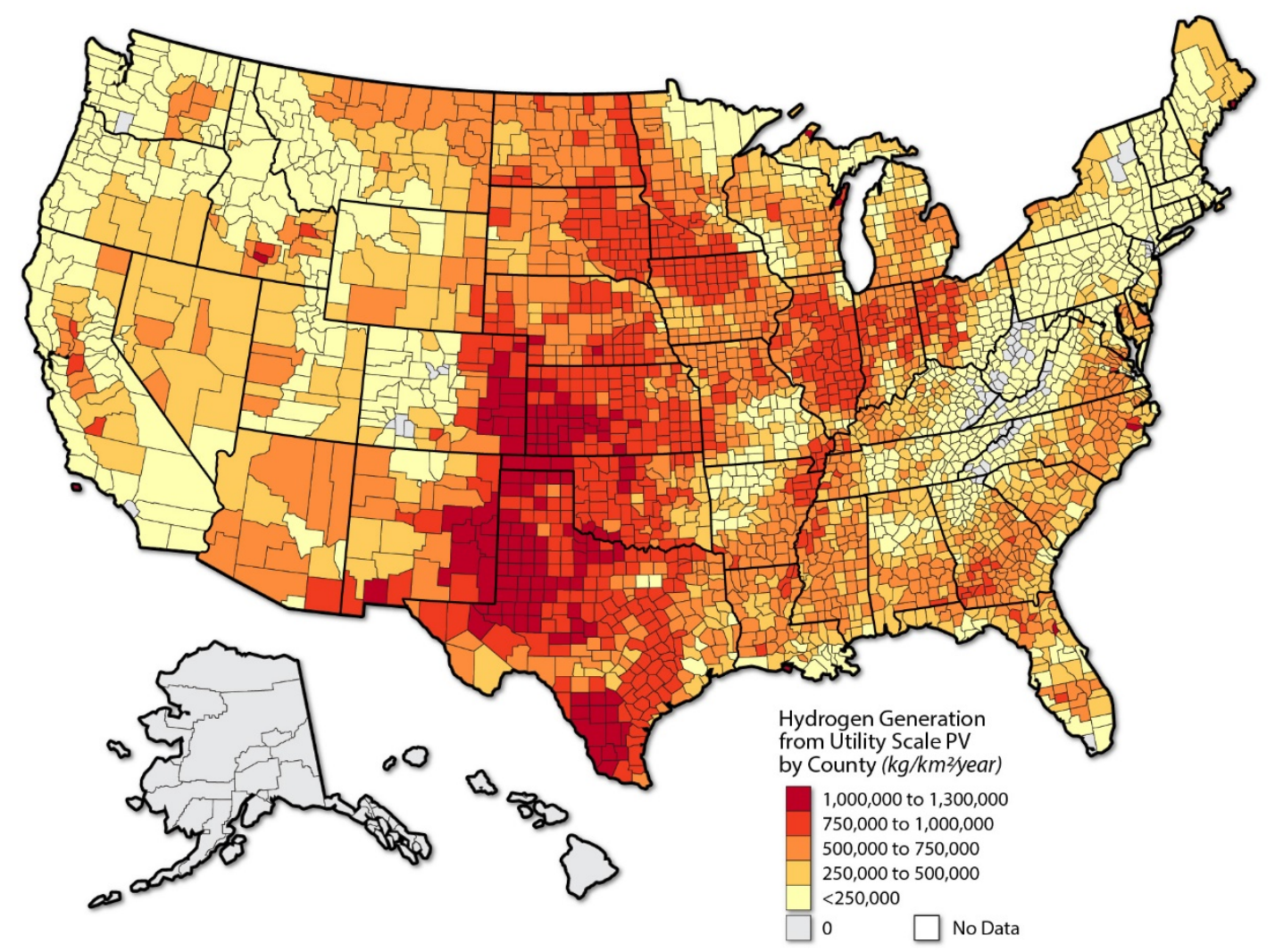

Figure E-3. Hydrogen production potential from utility-scale PV resources, by county land area Source: Connelly et al. (2020) 


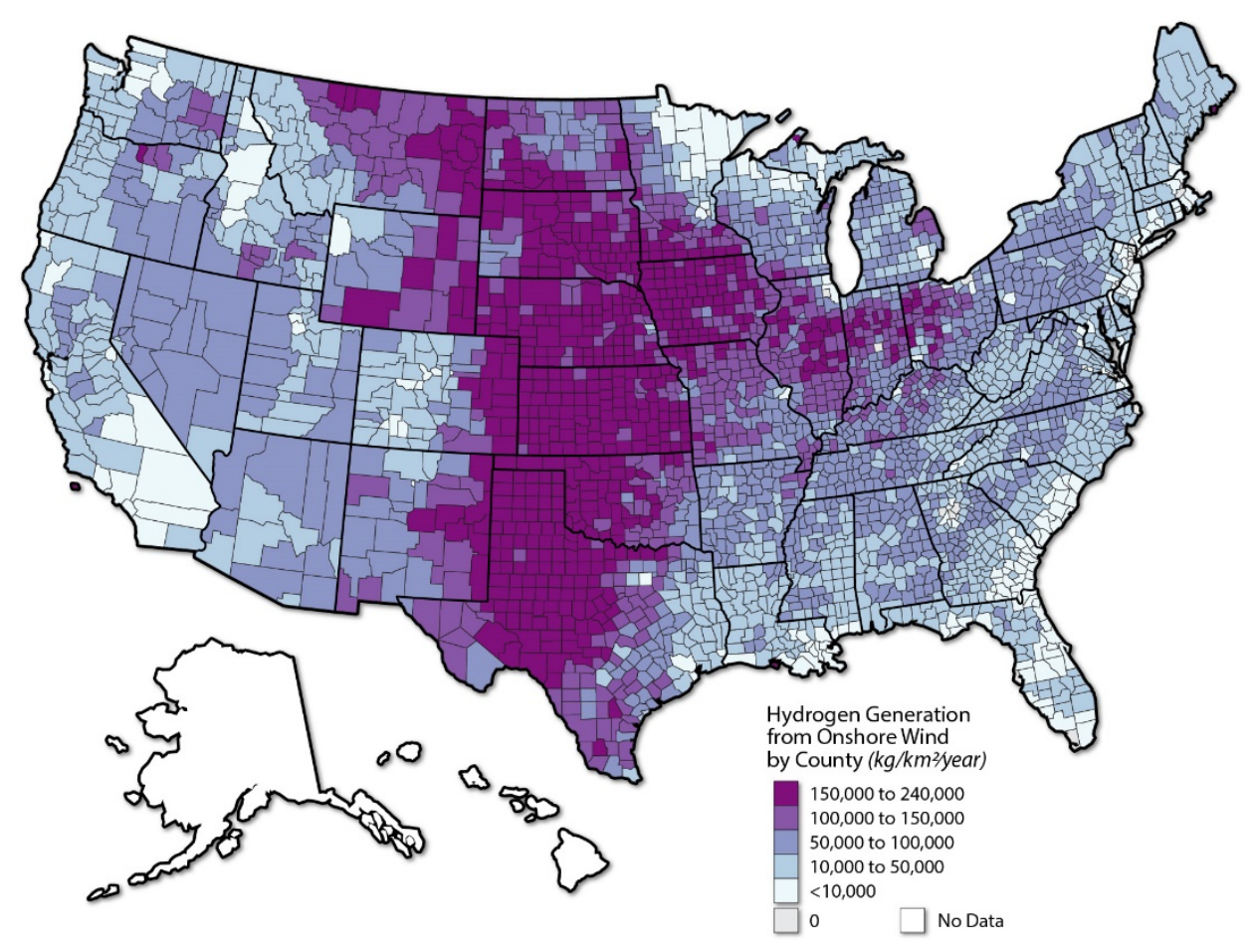

Figure E-4. Hydrogen production potential from onshore wind resources, by county land area Source: Connelly et al. (2020)

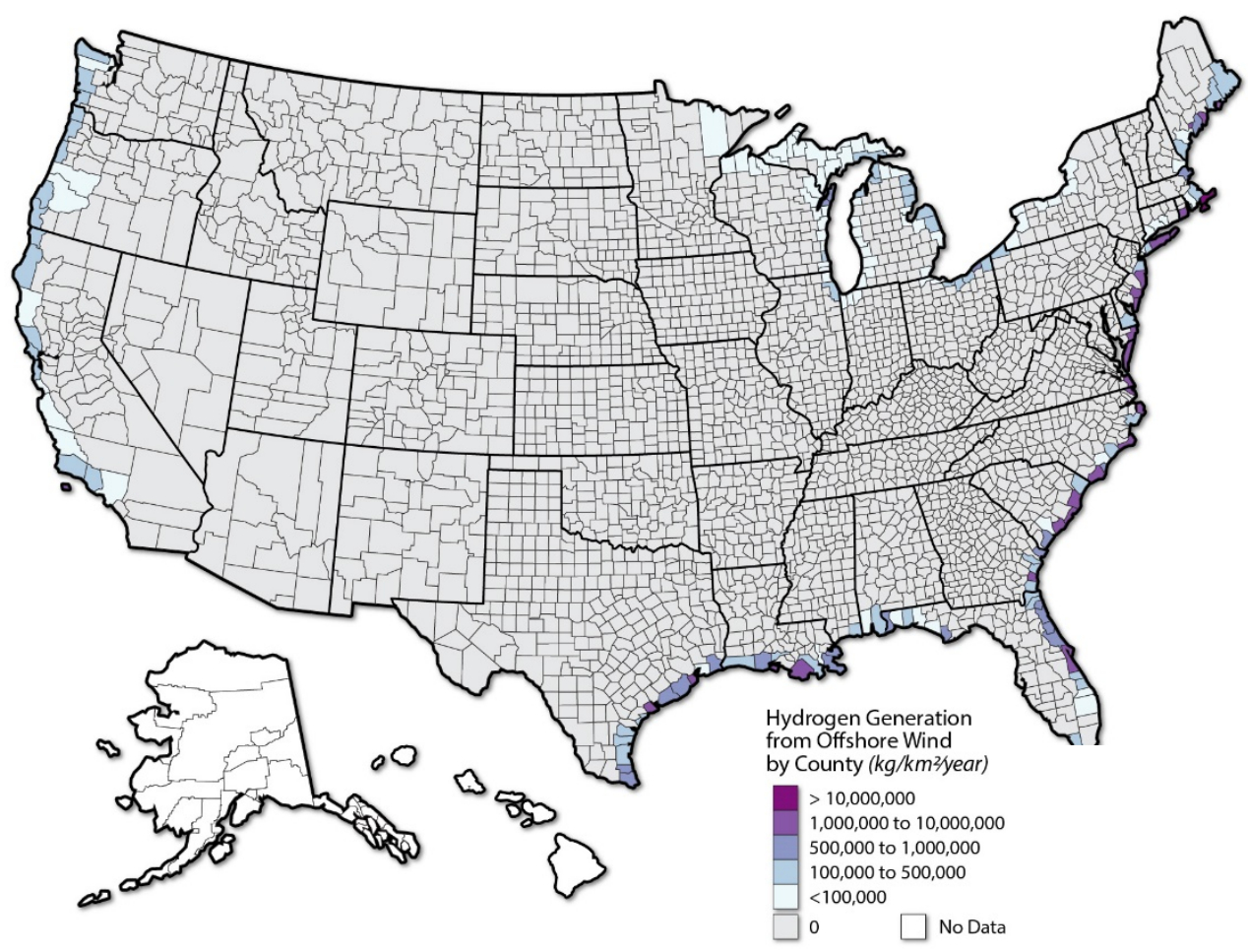

Figure E-5. Hydrogen production potential from offshore wind resources, by county land area Source: Connelly et al. (2020) 


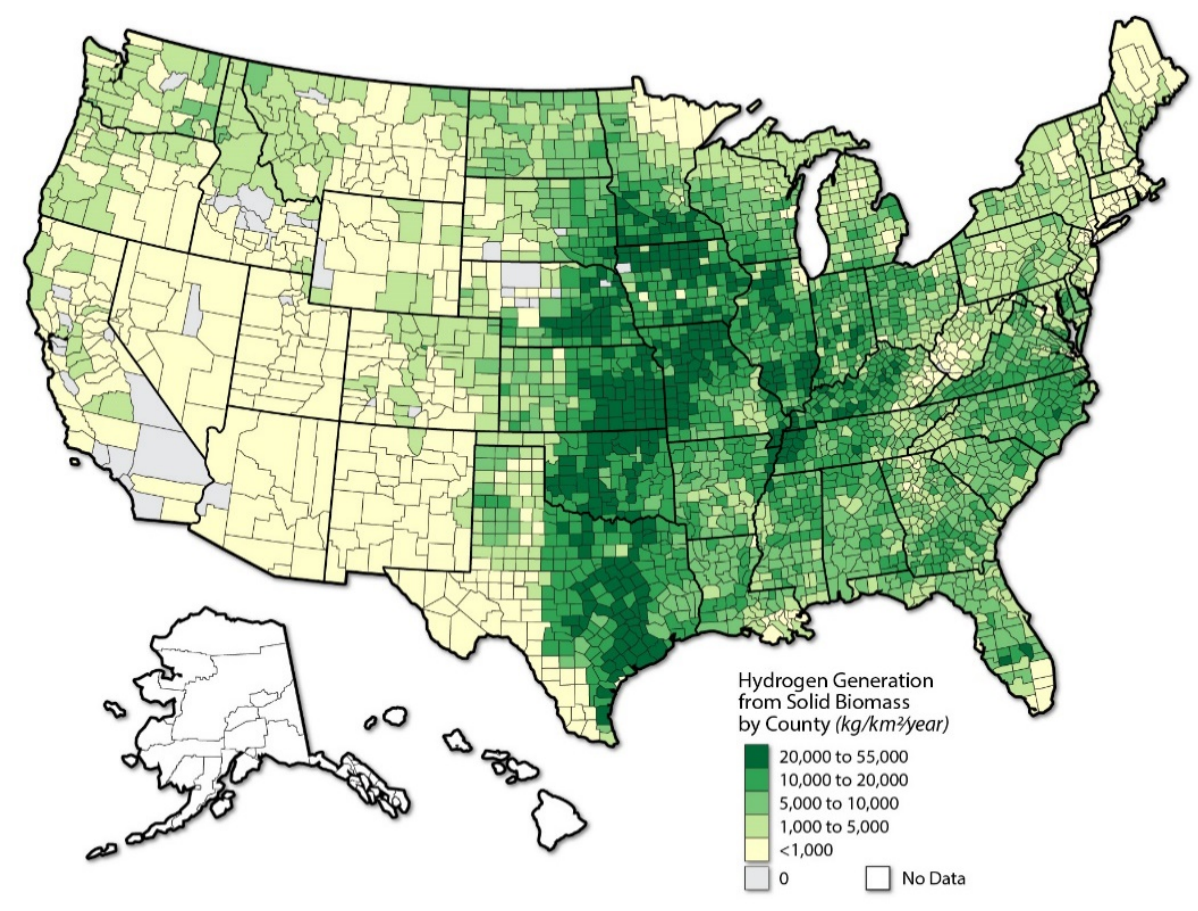

Figure E-6. Hydrogen production potential from solid biomass resources, by county land area Source: Connelly et al. (2020)

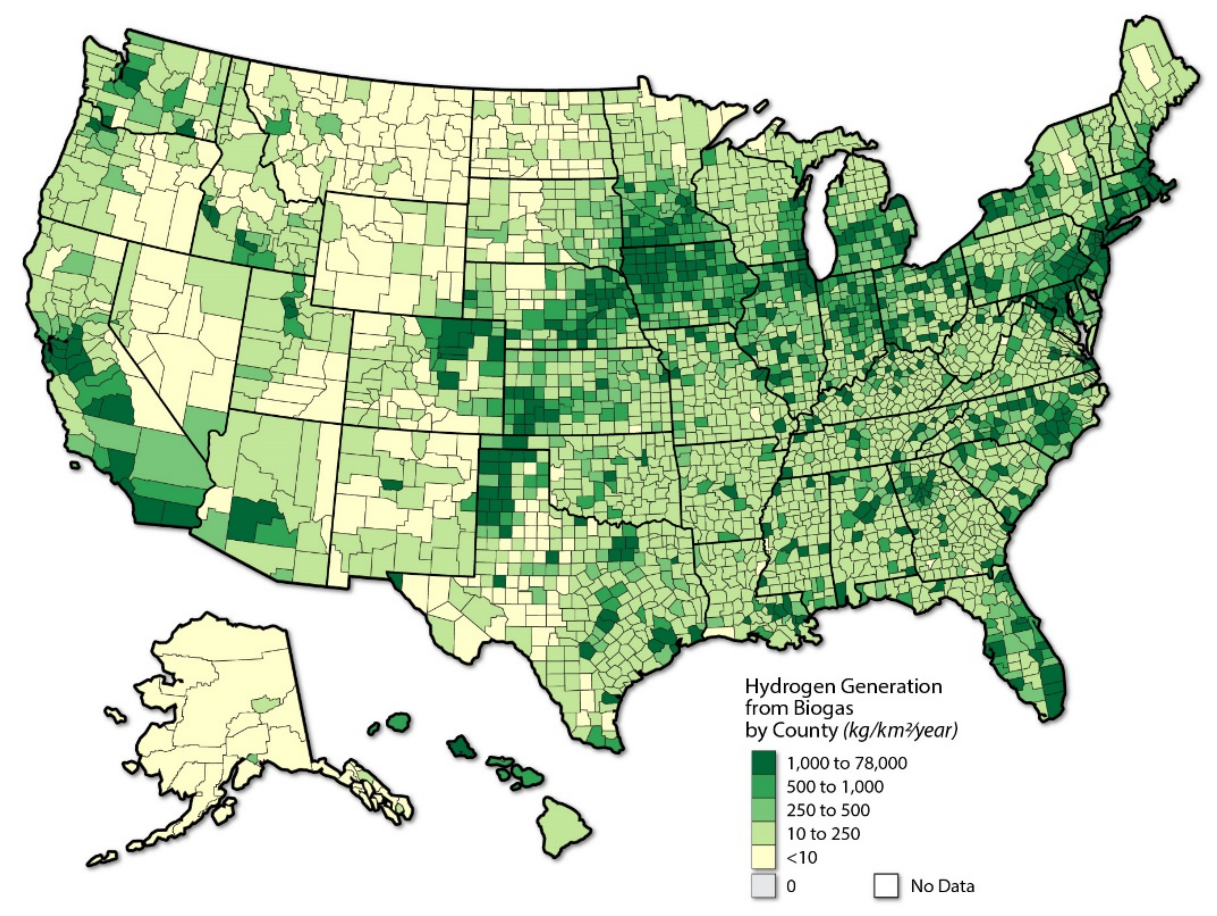

Figure E-7. Hydrogen production potential from biogas resources, by county land area

Source: Connelly et al. (2020) 


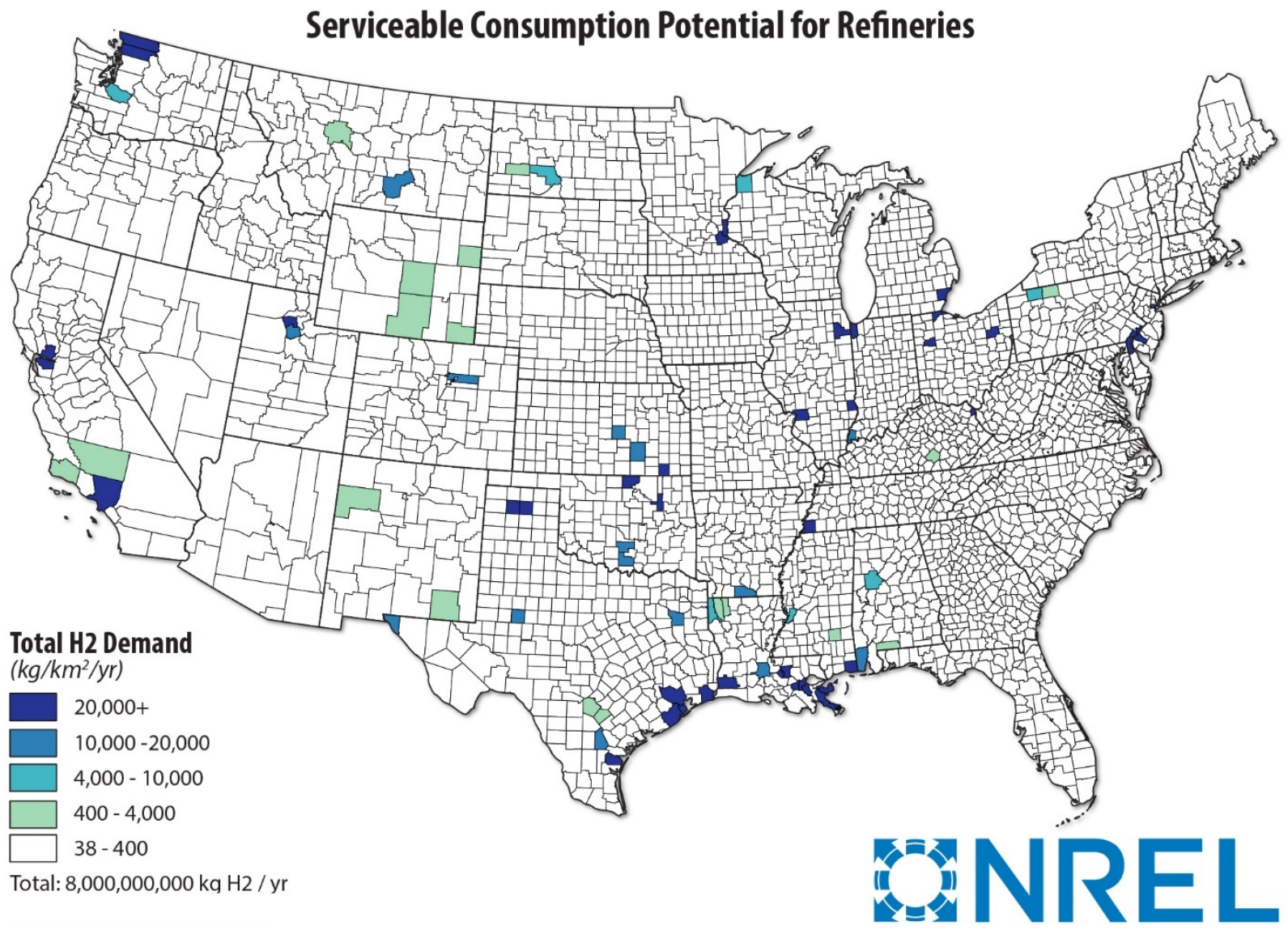

Figure E-8. Serviceable consumption potential of hydrogen for oil refining 


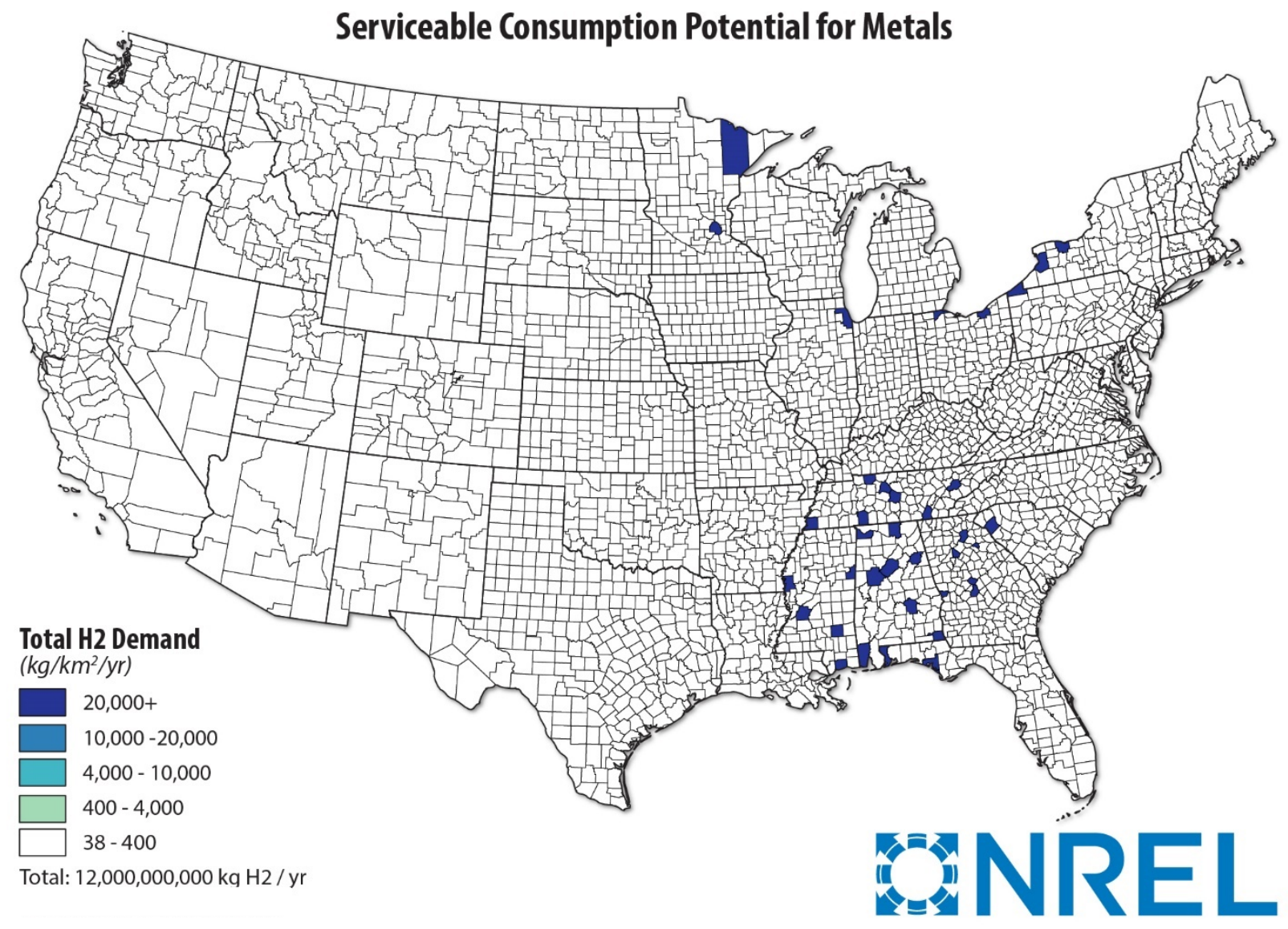

Figure E-9. Serviceable consumption potential of hydrogen for metals production 


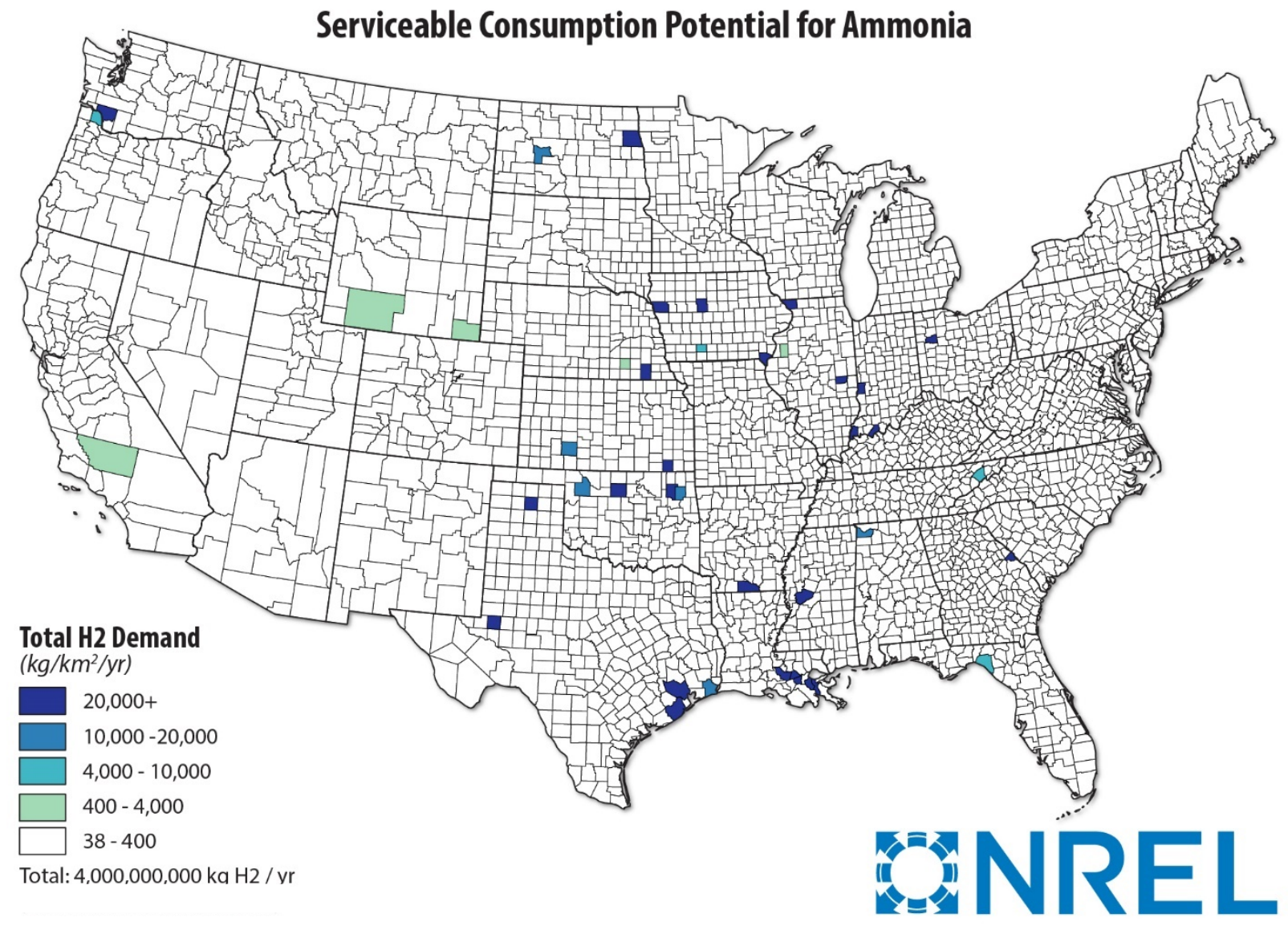

Figure E-10. Serviceable consumption potential of hydrogen for ammonia 


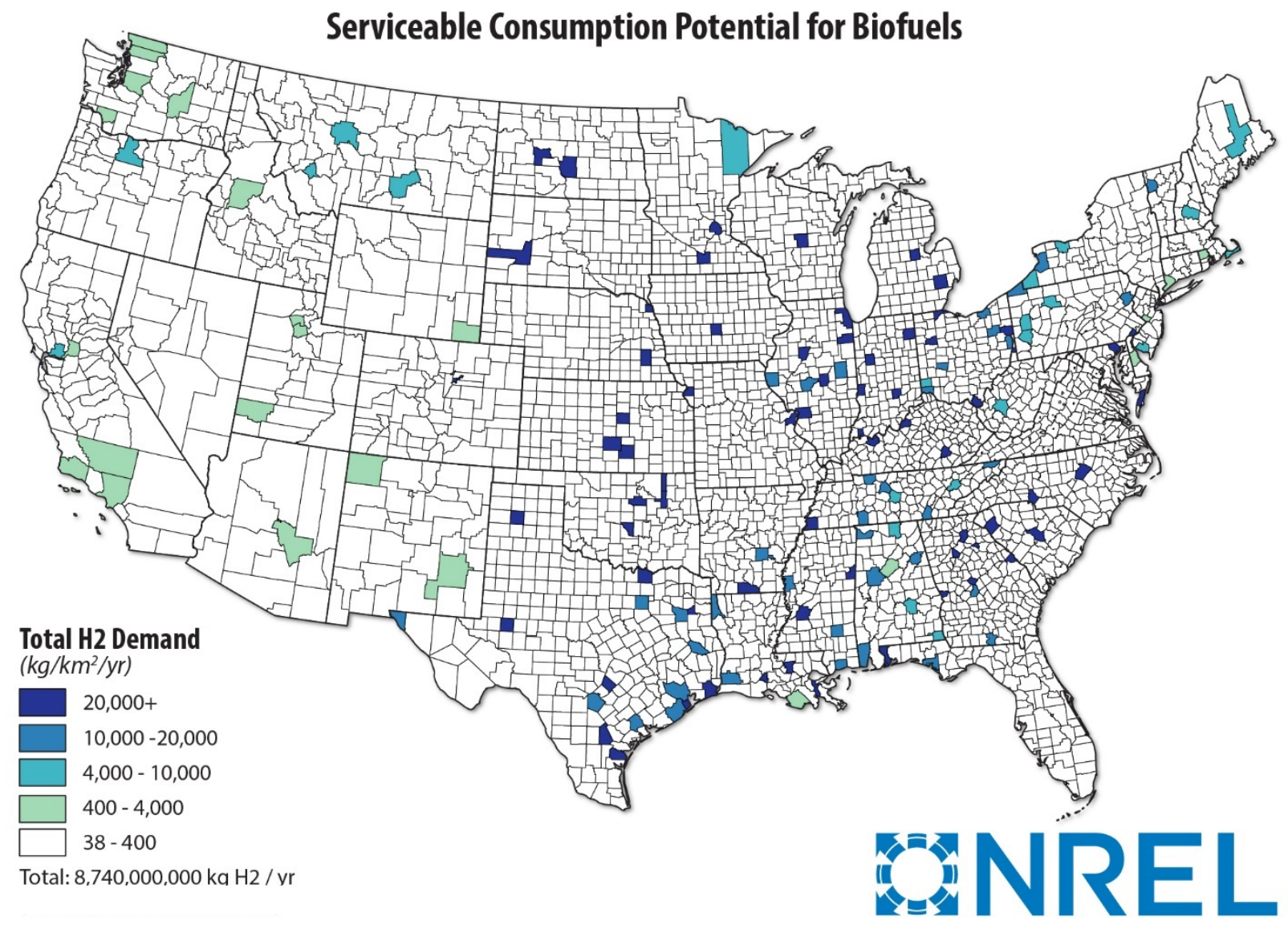

Figure E-11. Serviceable consumption potential of hydrogen for biofuels 


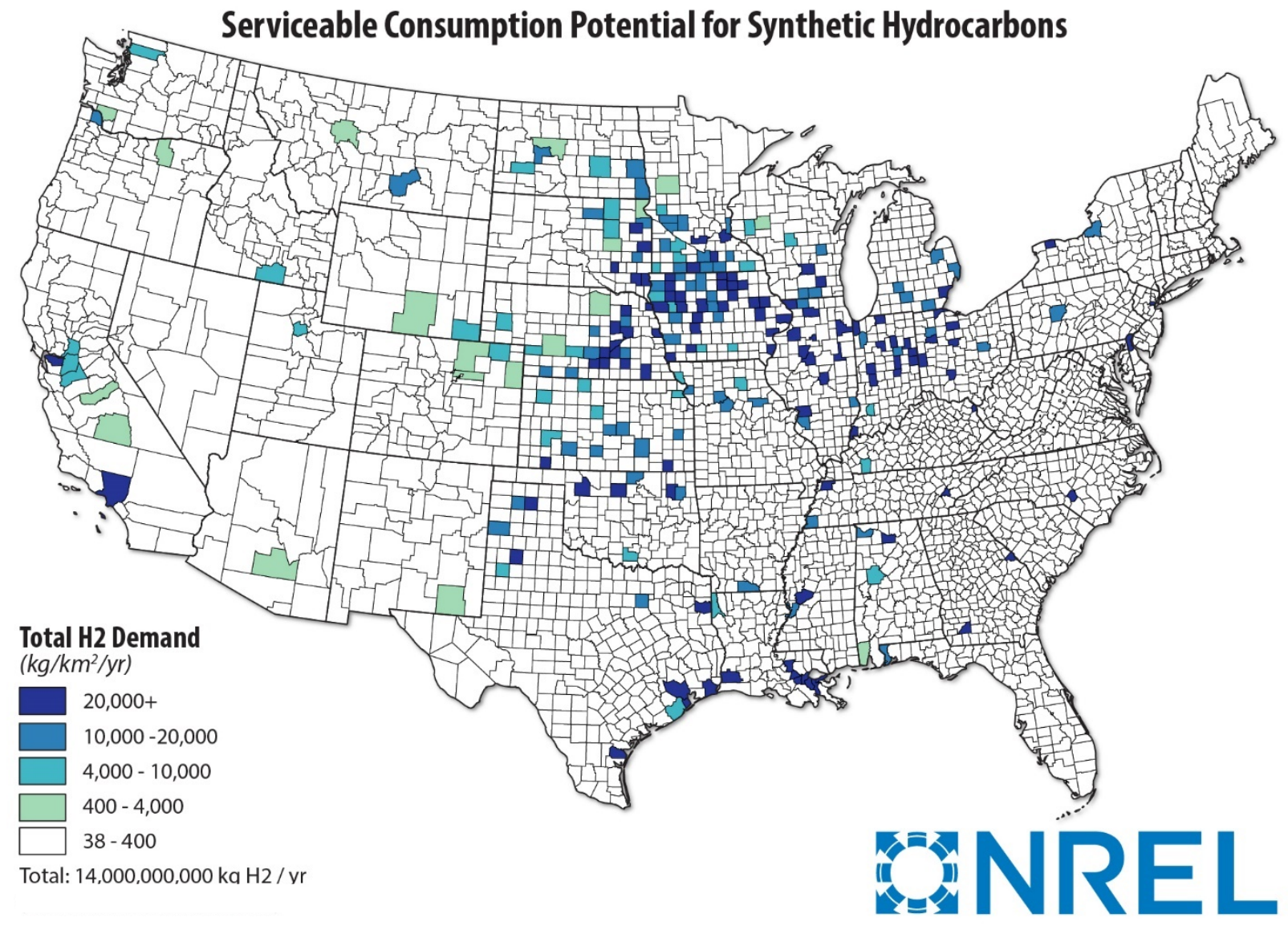

Figure E-12. Serviceable consumption potential of hydrogen for synthetic HC 


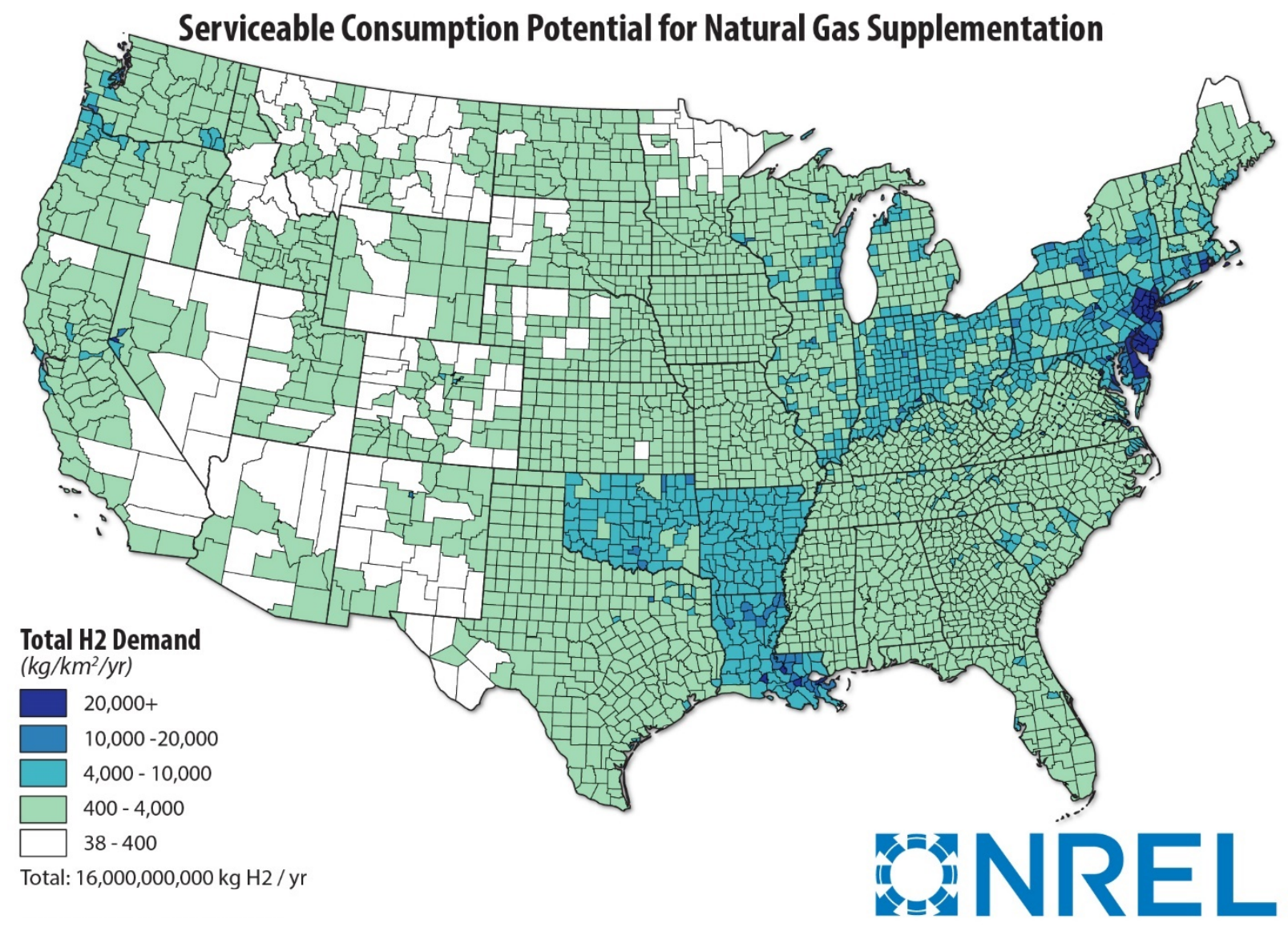

Figure E-13. Serviceable consumption potential of hydrogen for injection into the natural gas infrastructure 


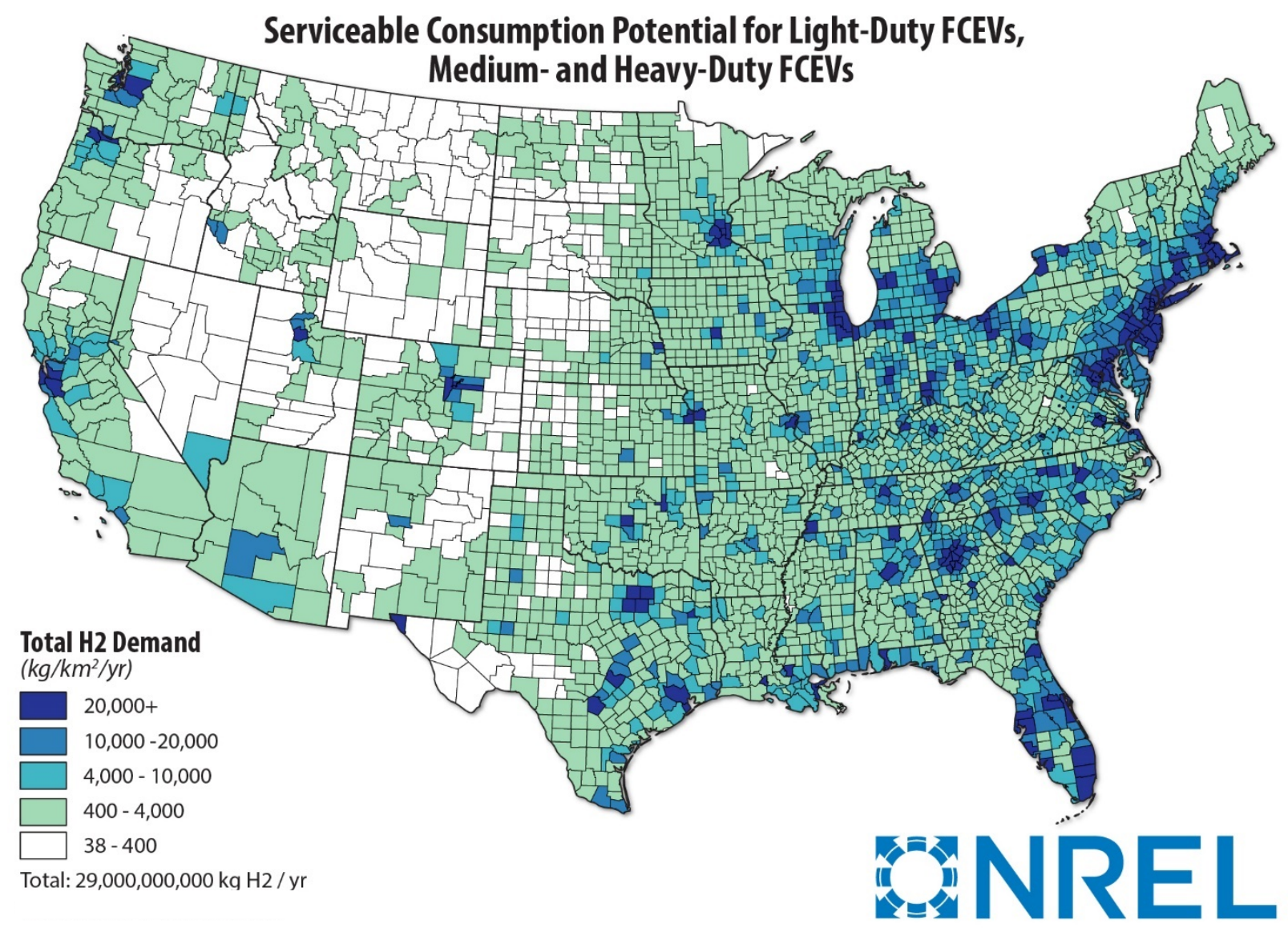

Figure E-14. Serviceable consumption potential of hydrogen for light-duty FCEVs and mediumand heavy-duty FCEVs 


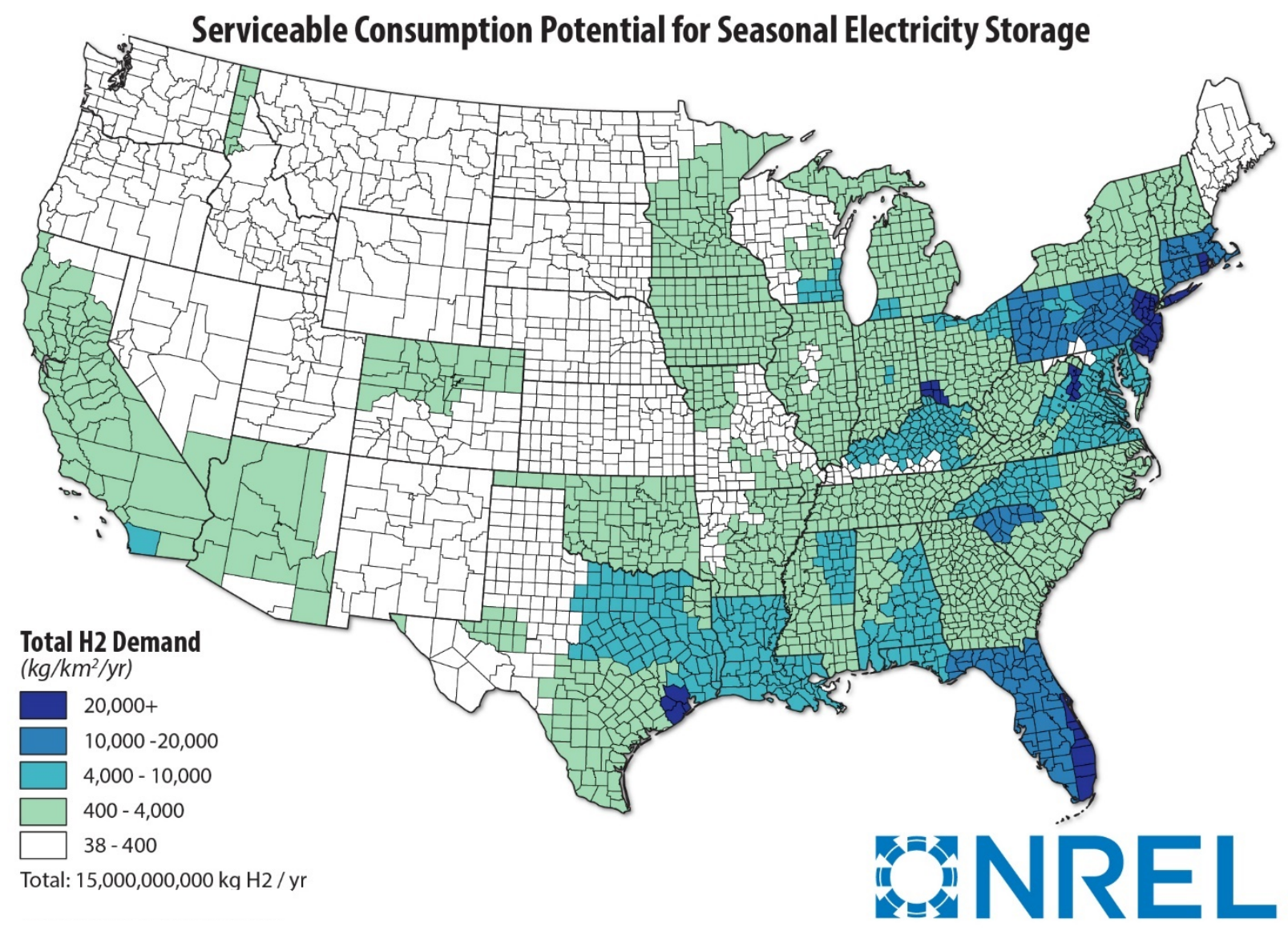

Figure E-15. Serviceable consumption potential of hydrogen for seasonal energy storage for the electric grid 


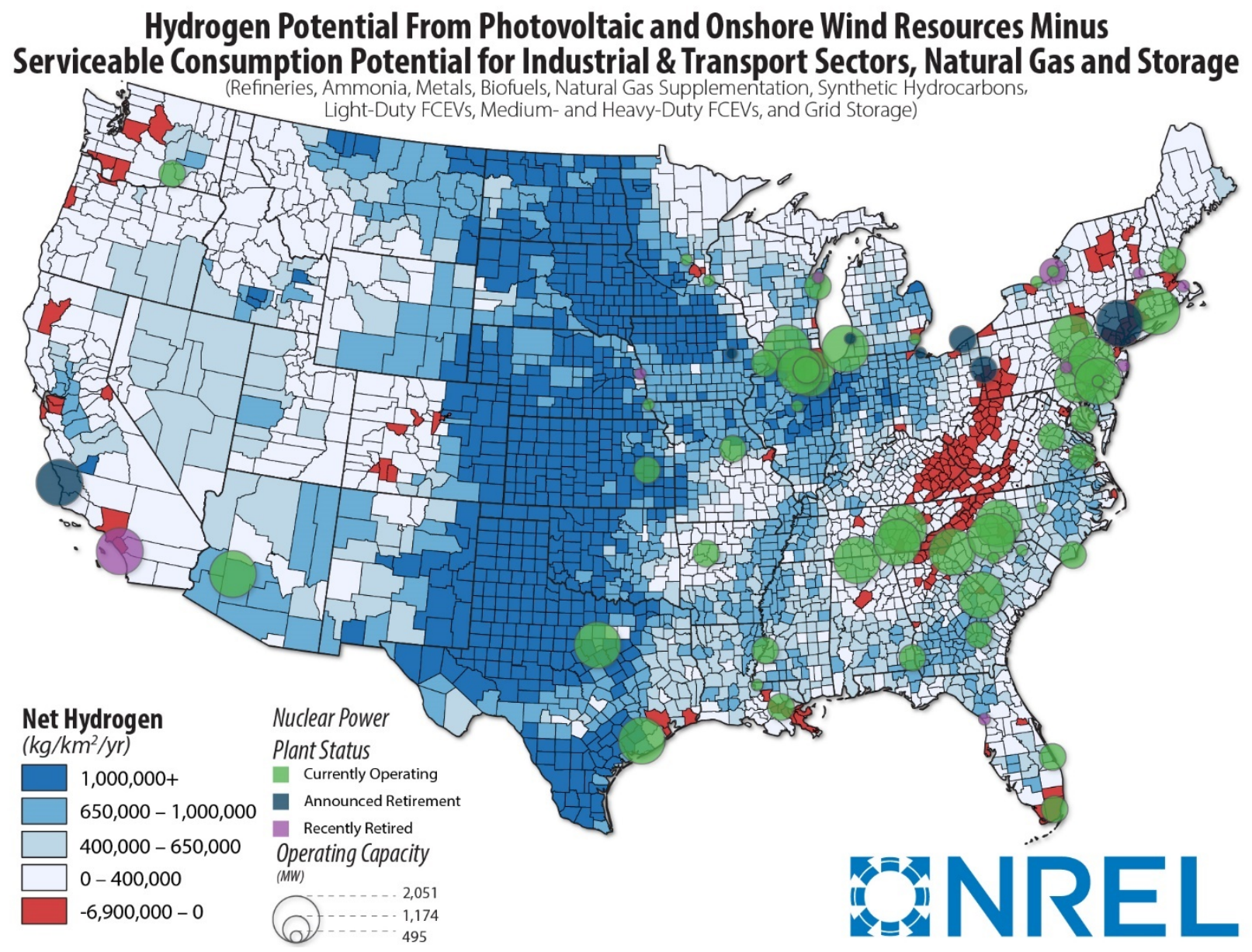

Figure E-16. County-by-county comparison between the technical potential for hydrogen production from onshore wind and PV resources and serviceable consumption potential for all demands, with current nuclear plants 


\section{Appendix F. Serviceable Consumption Potential and Economic Potential Scenario Results in Alternative Units}

The hydrogen market sizes of the serviceable consumption potential and economic potential estimated in Section 5 and Section 6 are presented in MMT/yr of hydrogen. For reference, Table F-1 shows these market size in alternative energy units. All LHVs and HHVs used in calculations come from GREET 2018 (ANL 2017) and are consistent with Appendix A.

Table F-1. Annual Hydrogen Market Sizes for Serviceable Consumption Potential and Economic Potential Scenarios in Alternative Units

\begin{tabular}{|c|c|c|c|c|c|c|}
\hline & $\begin{array}{c}\text { Serviceable } \\
\text { Consumption } \\
\text { Potential }\end{array}$ & Reference & $\begin{array}{c}\text { R\&D } \\
\text { Advances + } \\
\text { Infrastructure }\end{array}$ & $\begin{array}{c}\text { Low NG } \\
\text { Resource/ } \\
\text { High NG Price }\end{array}$ & $\begin{array}{l}\text { Aggressive } \\
\text { Electrolysis } \\
\text { R\&D }\end{array}$ & $\begin{array}{l}\text { Lowest-Cost } \\
\text { Electrolysis }\end{array}$ \\
\hline MMT & 106 & 22 & 31 & 23 & 23 & 41 \\
\hline $\begin{array}{l}\text { Quads } \\
\text { (HHV basis) }\end{array}$ & 14 & 3.0 & 4.2 & 3.1 & 3.1 & 5.5 \\
\hline $\begin{array}{l}\text { Exajoules } \\
\text { (HHV basis) }\end{array}$ & 15 & 3.1 & 4.4 & 3.3 & 3.3 & 5.8 \\
\hline $\begin{array}{l}\text { Billion TWh } \\
\text { (HHV basis) }\end{array}$ & 49 & 10 & 14 & 11 & 11 & 19 \\
\hline $\begin{array}{l}\text { Billion GGE } \\
\text { (LHV basis) }\end{array}$ & 107 & 22 & 31 & 23 & 23 & 42 \\
\hline $\begin{array}{l}\text { Billion barrels } \\
\text { crude oil } \\
\text { (HHV basis)a }\end{array}$ & 2.5 & 0.51 & 0.72 & 0.53 & 0.53 & 0.95 \\
\hline
\end{tabular}

a The HHV is used for crude oil to be consistent with EIA reporting. 


\section{Appendix G. Scenario Electricity Generation and Capacity}

This section includes ReEDS capacity (Figure G-1 and Table G-1) and generation (Figure G-2 and Table G-2) results for our H2@Scale scenarios. ReEDS was run for our two grid scenarios (ReEDS Low RE Cost and ReEDS High Curtailment) at LDE price increments of \$5/MWh (from $\$ 0-\$ 30 / \mathrm{MWh}$ ). For the scenarios below, we linearly interpolate capacity and generation from ReEDS runs based on weighted-average LDE prices for each scenario (see Table 25).

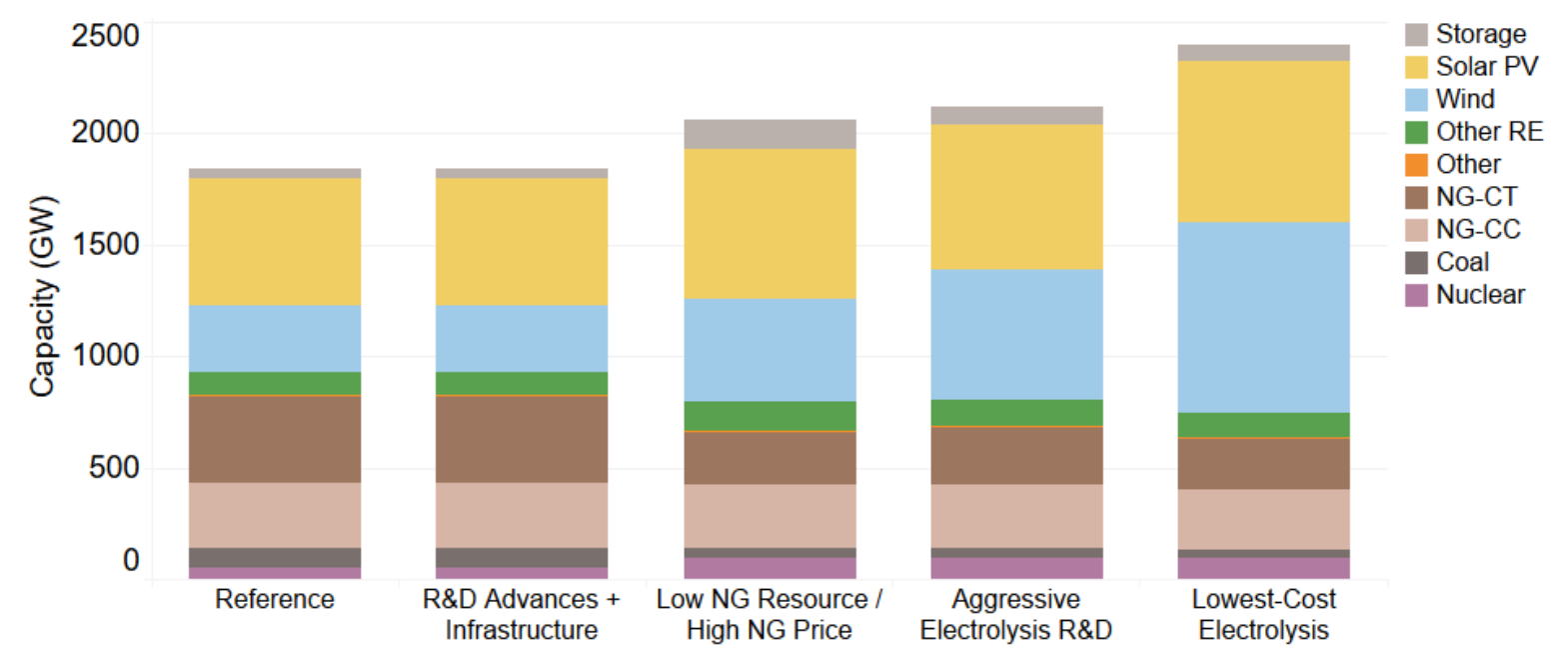

Figure G-1. Electricity generation capacity from ReEDS for H2@Scale scenarios

Other RE includes hydropower, geothermal, biopower, CSP, and landfill gas. Other includes oil-gas-steam and imports. Reference and R\&D Advances + Infrastructure assume the ReEDS Low RE Cost grid scenario. The other scenarios assume the ReEDS High Curtailment grid scenario.

Table G-1. Electricity Generation Capacity (GW) from ReEDS for H2@Scale Scenarios

\begin{tabular}{lrrrrr}
\hline Reference & $\begin{array}{c}\text { R\&D } \\
\text { Advances + } \\
\text { Infrastructure }\end{array}$ & $\begin{array}{c}\text { Low NG } \\
\text { Resource/ } \\
\text { High NG Price }\end{array}$ & $\begin{array}{c}\text { Aggressive } \\
\text { Electrolysis } \\
\text { R\&D }\end{array}$ & $\begin{array}{c}\text { Lowest-Cost } \\
\text { Electrolysis }\end{array}$ \\
\hline Storage & 42 & 42 & 132 & 80 & 68 \\
PV & 570 & 570 & 680 & 650 & 720 \\
Wind & 300 & 300 & 460 & 580 & 860 \\
Other RE & 100 & 100 & 130 & 120 & 110 \\
Other & 5 & 5 & 5 & 5 & 5 \\
NGCT & 390 & 390 & 240 & 260 & 230 \\
NG-CC & 290 & 290 & 290 & 290 & 270 \\
Coal & 90 & 90 & 50 & 50 & 40 \\
Nuclear & 50 & 90 & 90 & 90 & 90 \\
\hline
\end{tabular}

Other RE includes hydropower, geothermal, biopower, CSP, and landfill gas. Other includes oil-gas-steam and imports. Reference assumes the ReEDS Low RE Cost grid scenario, and other scenarios assume the ReEDS High Curtailment grid scenario. 


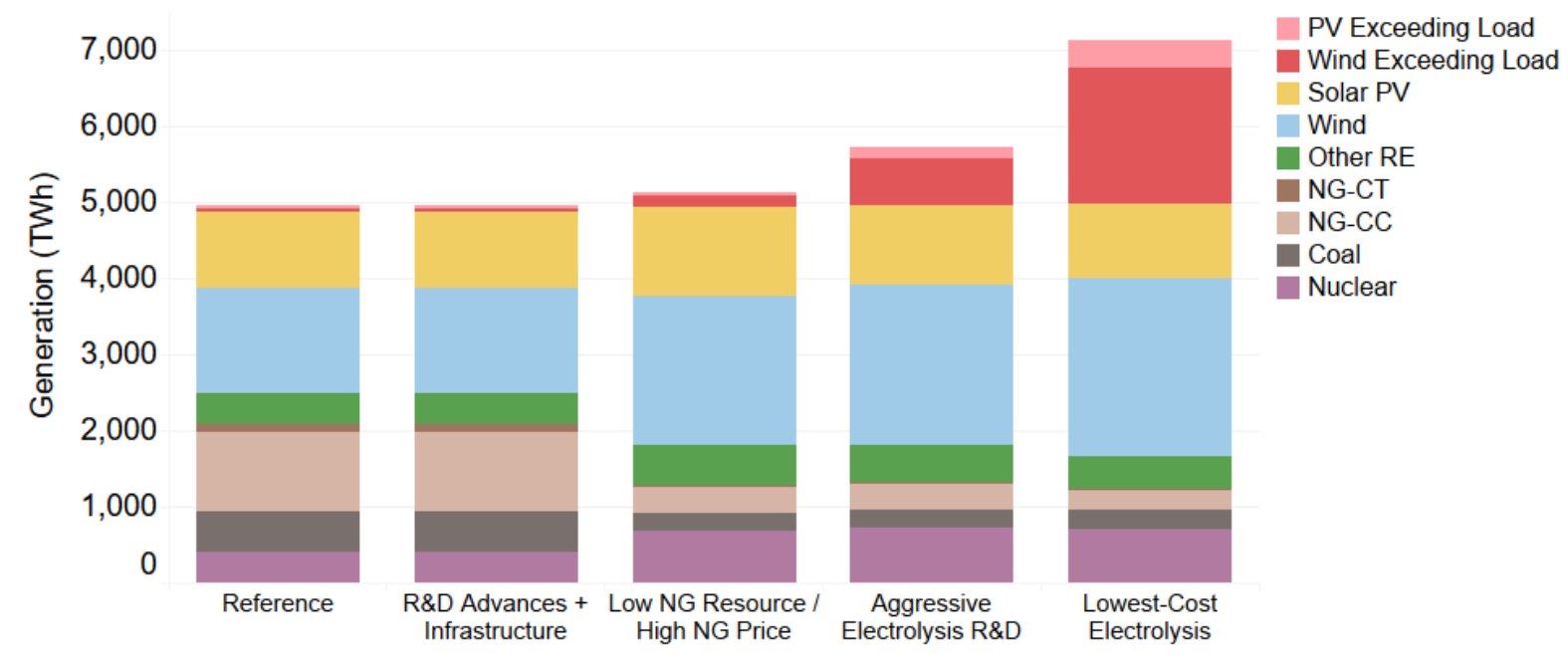

Figure G-2. Electricity generation from ReEDS for H2@Scale scenarios by technology

NG-CT is natural gas combustion turbine, NG-CC is natural gas combined cycle. Other RE includes hydropower, geothermal, biopower, CSP, and landfill gas. Other includes oil-gas-steam and imports. Reference and R\&D Advances + Infrastructure assume the ReEDS Low RE Cost grid scenario. The other scenarios assume the ReEDS High Curtailment grid scenario.

Table G-2. Electricity Generation (TWh) from ReEDS for H2@Scale Scenarios by Technology

\begin{tabular}{lrrrrr}
\hline & Reference & $\begin{array}{c}\text { R\&D } \\
\text { Advances + } \\
\text { Infrastructure }\end{array}$ & $\begin{array}{c}\text { Low NG } \\
\text { Resourcel } \\
\text { High NG Price }\end{array}$ & $\begin{array}{c}\text { Aggressive } \\
\text { Electrolysis } \\
\text { R\&D }\end{array}$ & $\begin{array}{c}\text { Lowest-Cost } \\
\text { Electrolysis }\end{array}$ \\
\hline $\begin{array}{l}\text { PV Exceeding } \\
\text { Load }\end{array}$ & 30 & 30 & 50 & 150 & 370 \\
$\begin{array}{l}\text { Wind Exceeding } \\
\text { Load }\end{array}$ & 50 & 50 & 140 & 620 & 1,800 \\
PV & 1,000 & 1,000 & 1,200 & 1,000 & 970 \\
Wind & 1,400 & 1,400 & 2,000 & 2,100 & 2,400 \\
Other RE & 400 & 400 & 520 & 490 & 430 \\
NGCT & 90 & 90 & 6 & 11 & 14 \\
NG-CC & 1,100 & 1,100 & 360 & 340 & 250 \\
Coal & 540 & 540 & 240 & 250 & 250 \\
Nuclear & 400 & 400 & 680 & 720 & 710 \\
\hline
\end{tabular}

Other RE includes hydropower, geothermal, biopower, CSP, and landfill gas. Other includes oil-gas-steam and imports. Reference and R\&D Advances + Infrastructure assume the ReEDS Low RE Cost grid scenario. The other scenarios assume the ReEDS High Curtailment grid scenario. 


\section{Appendix H. Energy Use Sankey Diagrams}

This appendix includes Sankey diagrams for each ReEDS grid scenario and H2@Scale scenario. Diagrams showing the difference between each H2@Scale scenario and its respective ReEDS scenario are also included. Section 6.6 describes these figures in more detail.

Figure H-1 shows the ReEDS Low RE Cost scenario, Figure H-2 and Figure H-3 show the Reference and R\&D Advances + Infrastructure scenarios, and Figure H-4 and Figure H-5 show the differences from the ReEDS Low RE Cost scenario.

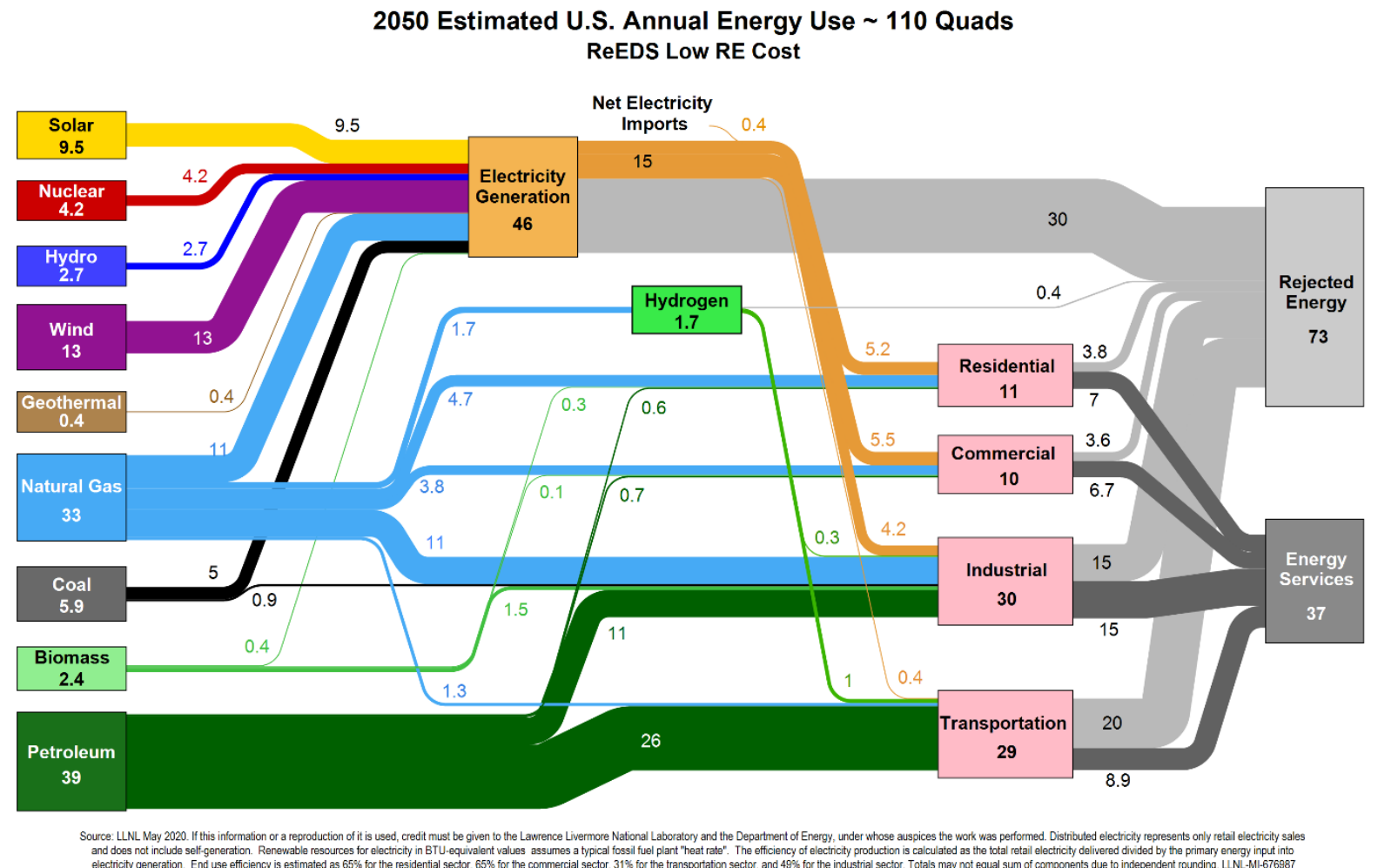

Figure H-1. Energy-use Sankey diagram for the ReEDS Low RE Cost scenario 
2050 Estimated U.S. Annual Energy Use 115 Quads Reference

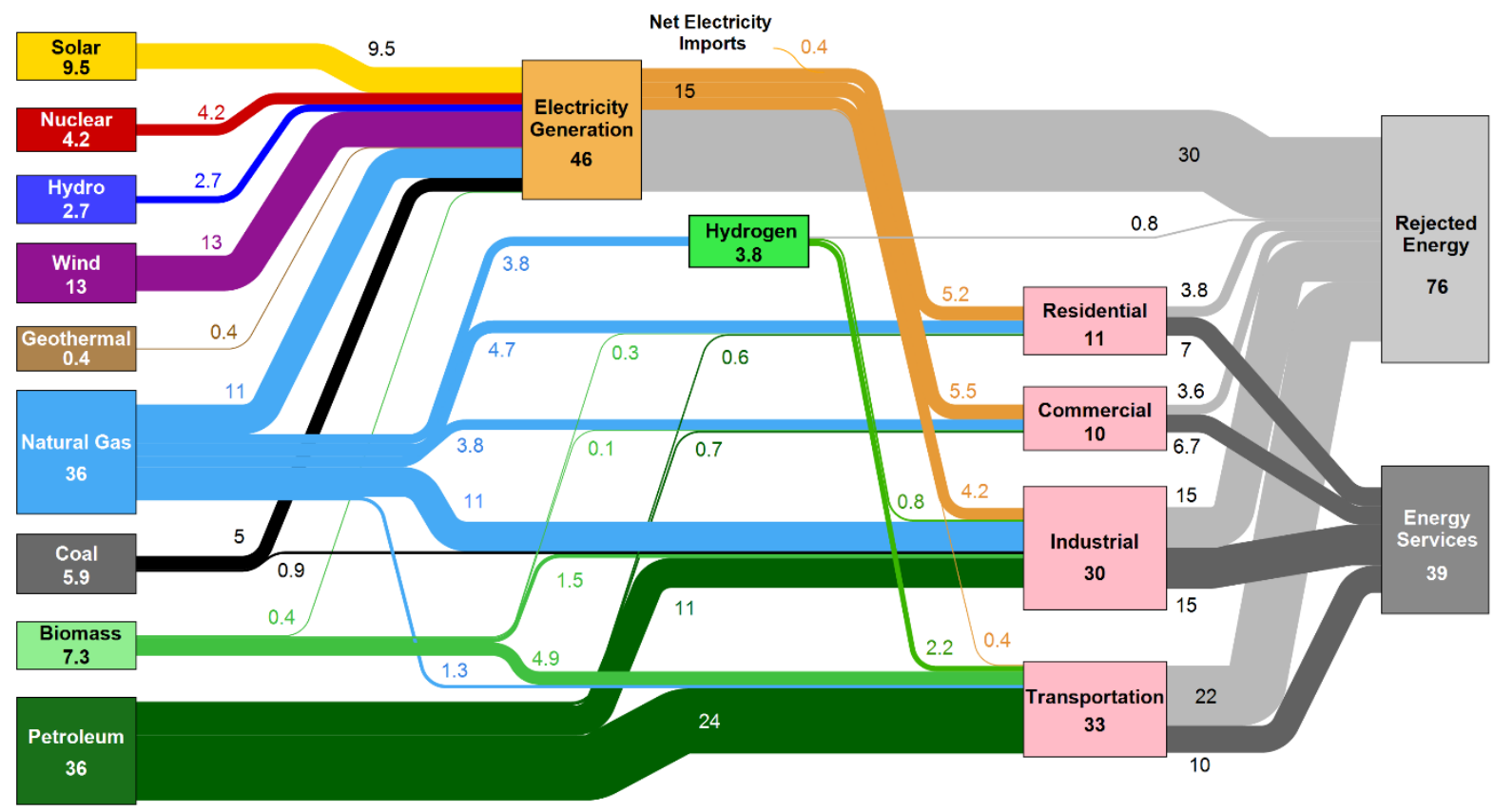

Source: LLNL May 2020 . If this information or a reproduction of ti is used, credit must be given to the Lawrence Livertmore National Laboratory and the Department of Energy, under yinsese auspices sthe work was performed. Distributed electricity represents only retail electricity sales

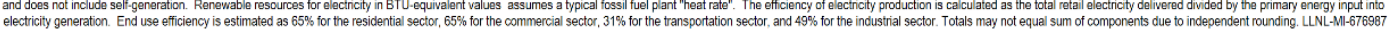

Figure H-2. Energy-use Sankey diagram for the Reference scenario

2050 Estimated U.S. Annual Energy Use $~ 115$ Quads R\&D Advances + Infrastructure

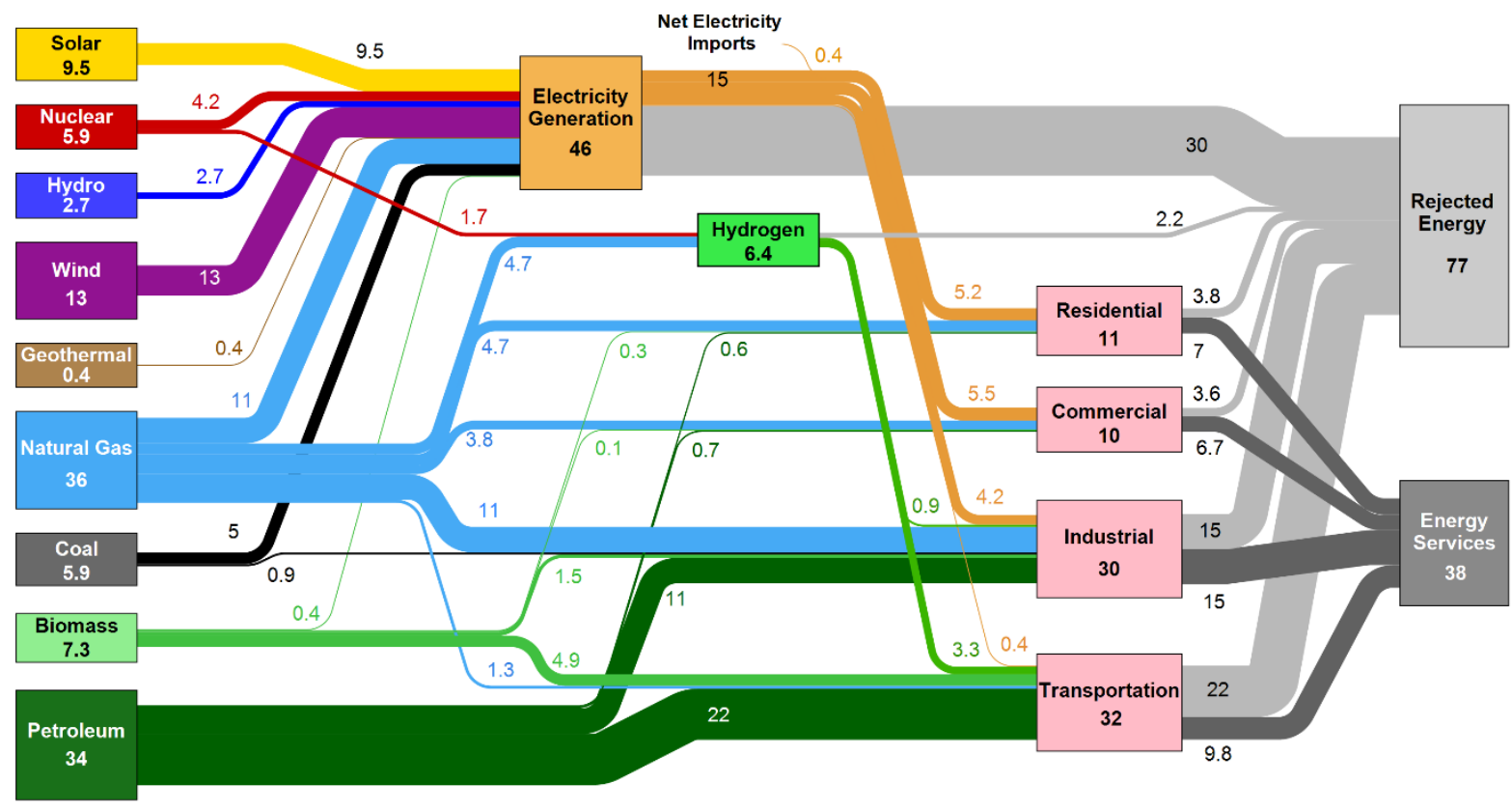

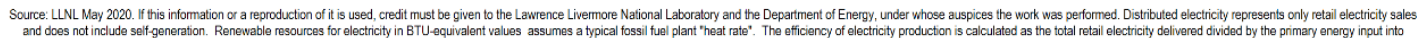

Figure H-3. Energy-use Sankey diagram for the R\&D Advances + Infrastructure scenario 
2050 Energy Use Difference Between 'Reference' and 'ReEDS Low RE Cost'

(Quadrillion BTUs)

Note: Boxes represent Reference values

Black Flows indicate Reference uses more energy than ReEDS Low RE Cost

Red Flows indicate ReEDS Low Cost uses more energy than Reference

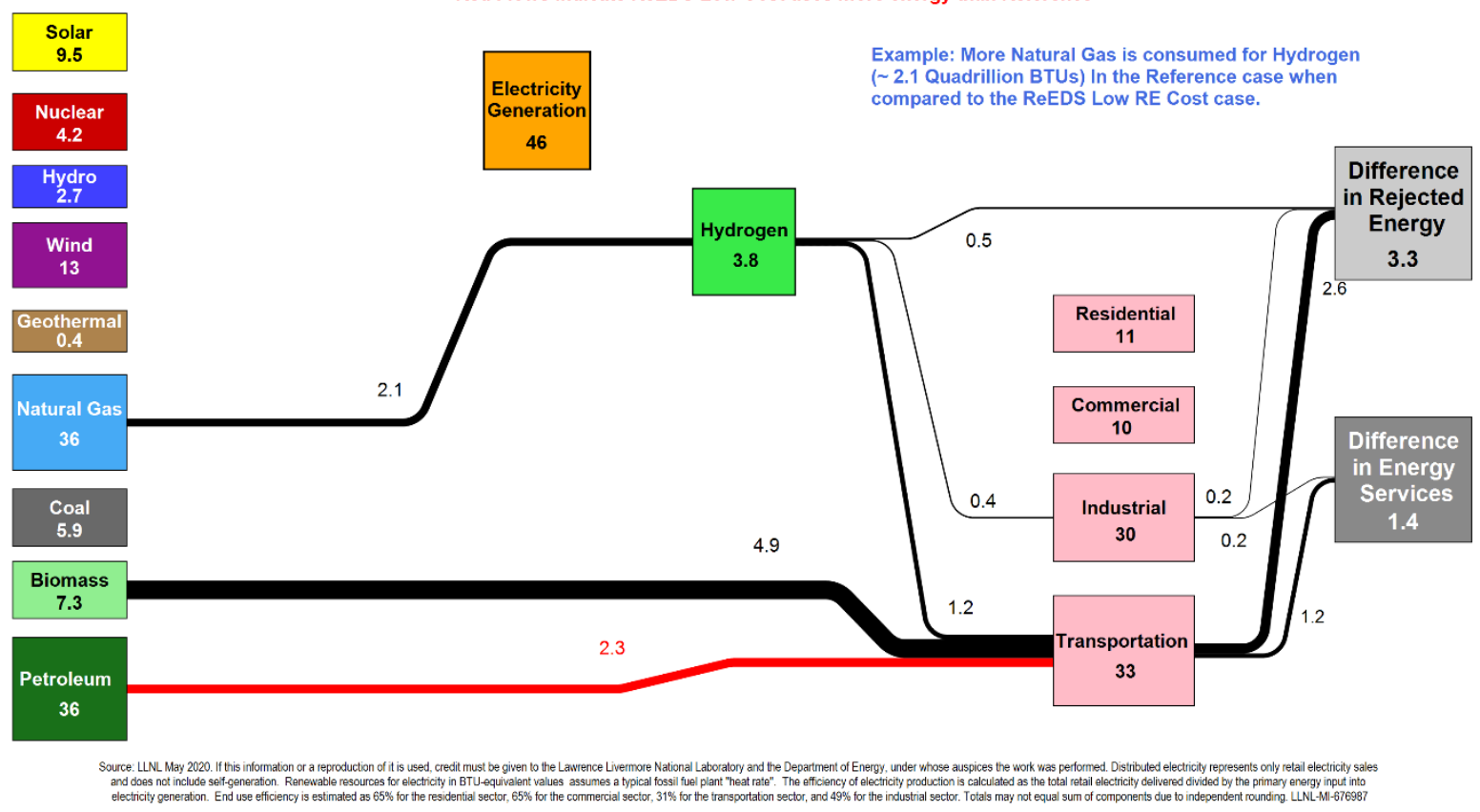

Figure H-4. Difference in energy use between the ReEDS Low RE Cost and Reference scenarios

2050 Energy Use Difference Between 'R\&D Advances + Infrastructure' and 'ReEDS Low RE Cost'

(Quadrillion BTUs)

Note: Boxes represent R\&D Advances + Infrastructure values

Black Flows indicate R\&D Advances + Infrastructure uses more energy than ReEDS Low RE Cost

Red Flows indicate ReEDS Low RE Cost uses more energy than R\&D Advances + Infrastructure

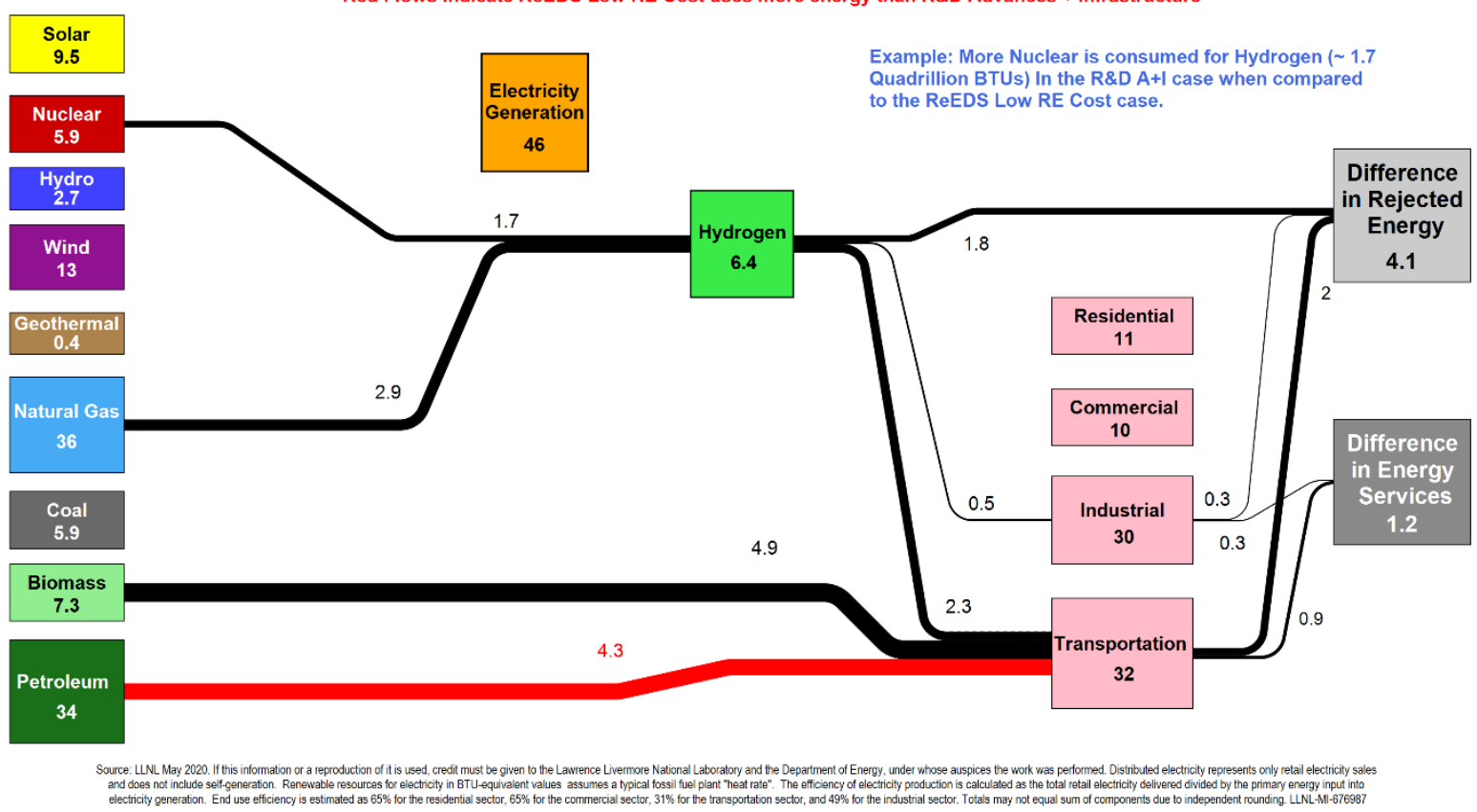

Figure H-5. Difference in energy use between the ReEDS Low RE Cost and R\&D Advances + Infrastructure scenarios 
Figure H-6 shows the ReEDS High Curtailment scenario; Figure H-7, Figure H-8, and Figure H9 show the Low NG Resource/High NG Price, Aggressive Electrolysis R\&D, and Lowest-Cost Electrolysis scenarios; and Figure H-10, Figure H-11, and Figure H-12 show the differences from the ReEDS High Curtailment scenario.

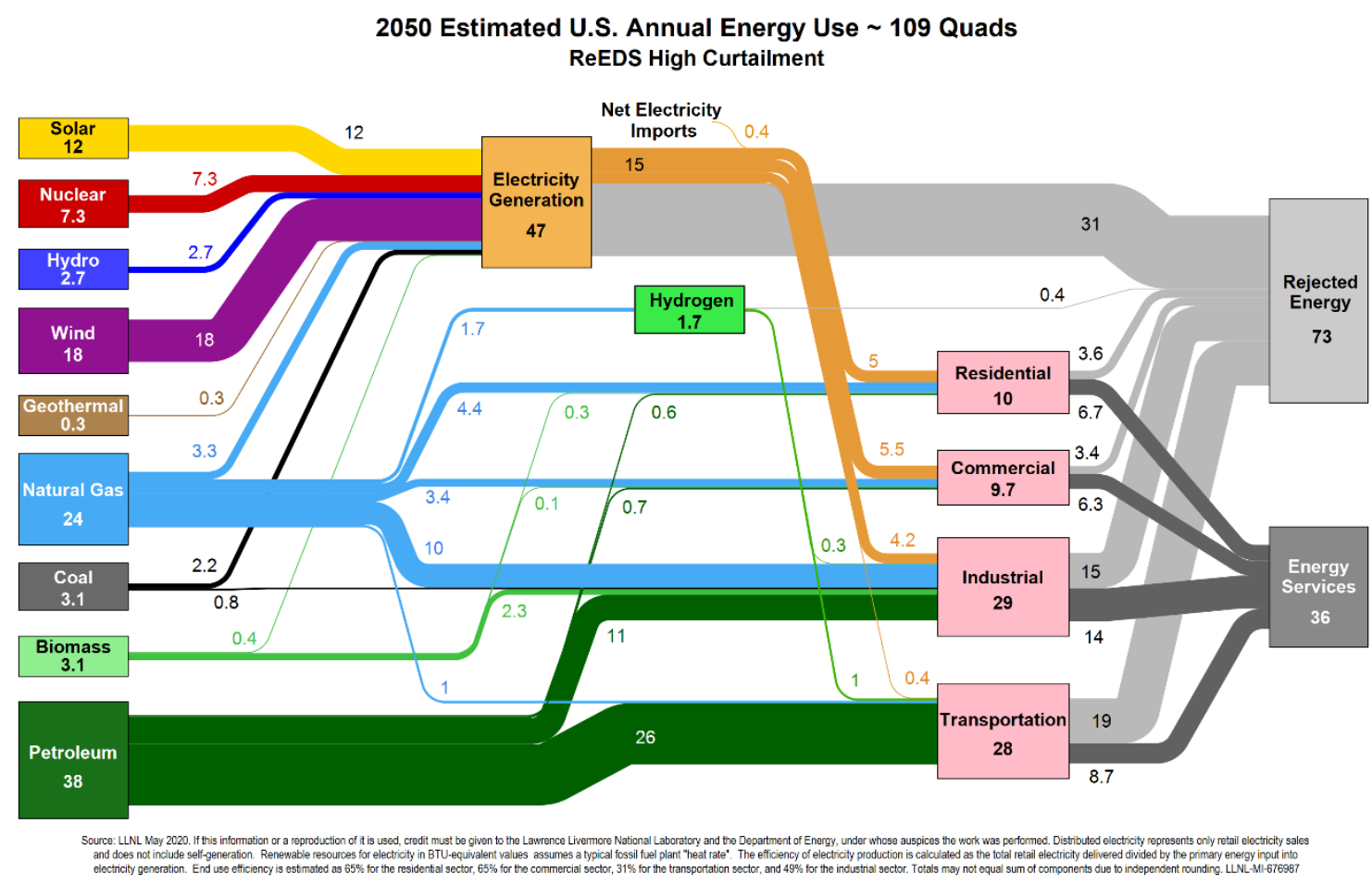

Figure H-6. Energy-use Sankey diagram for the ReEDS High Curtailment scenario 


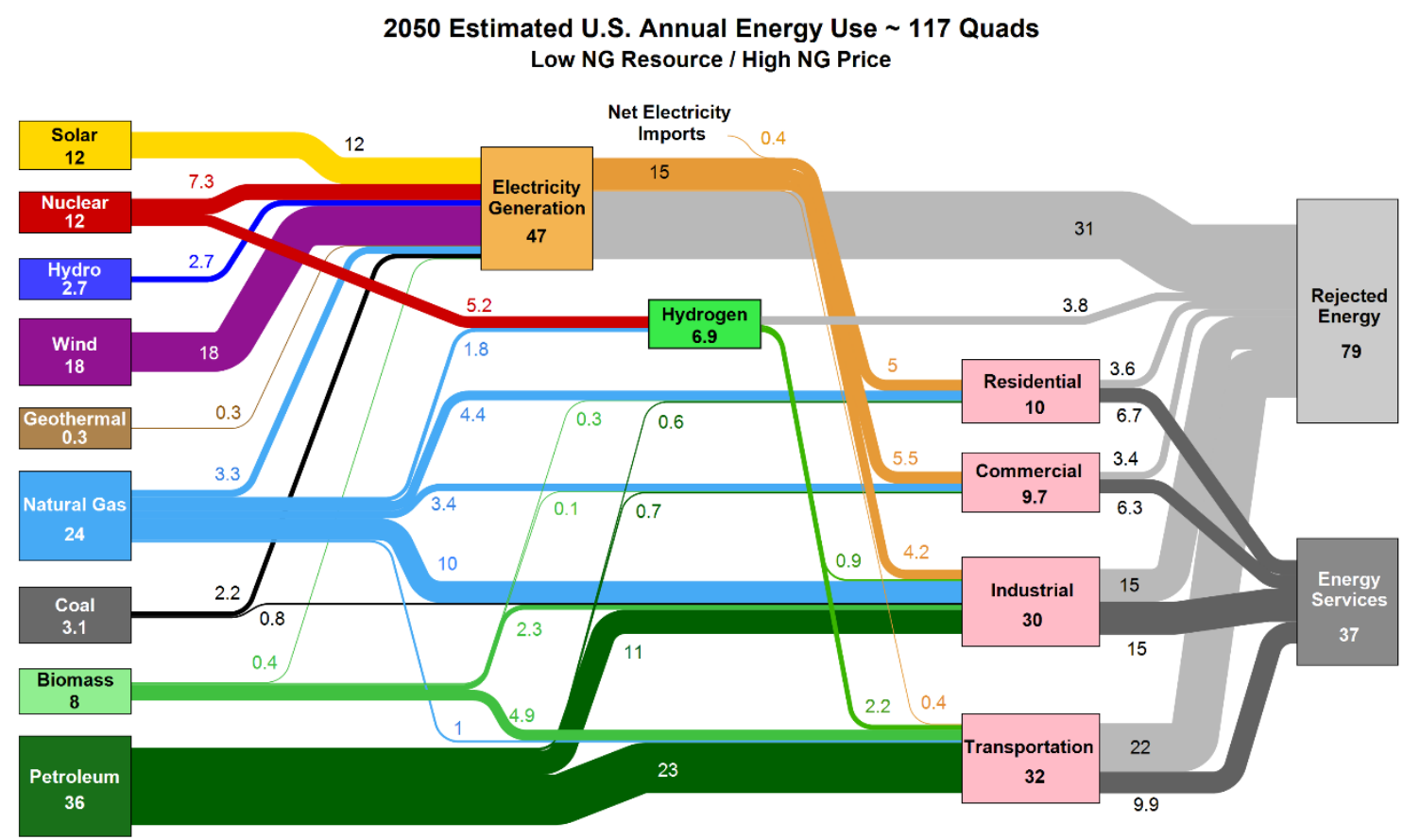

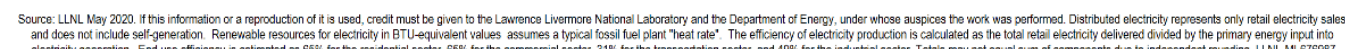

Figure H-7. Energy-use Sankey diagram for the Low NG Resource/High NG Price scenario 2050 Estimated U.S. Annual Energy Use 119 Quads Aggressive Electrolysis R\&D

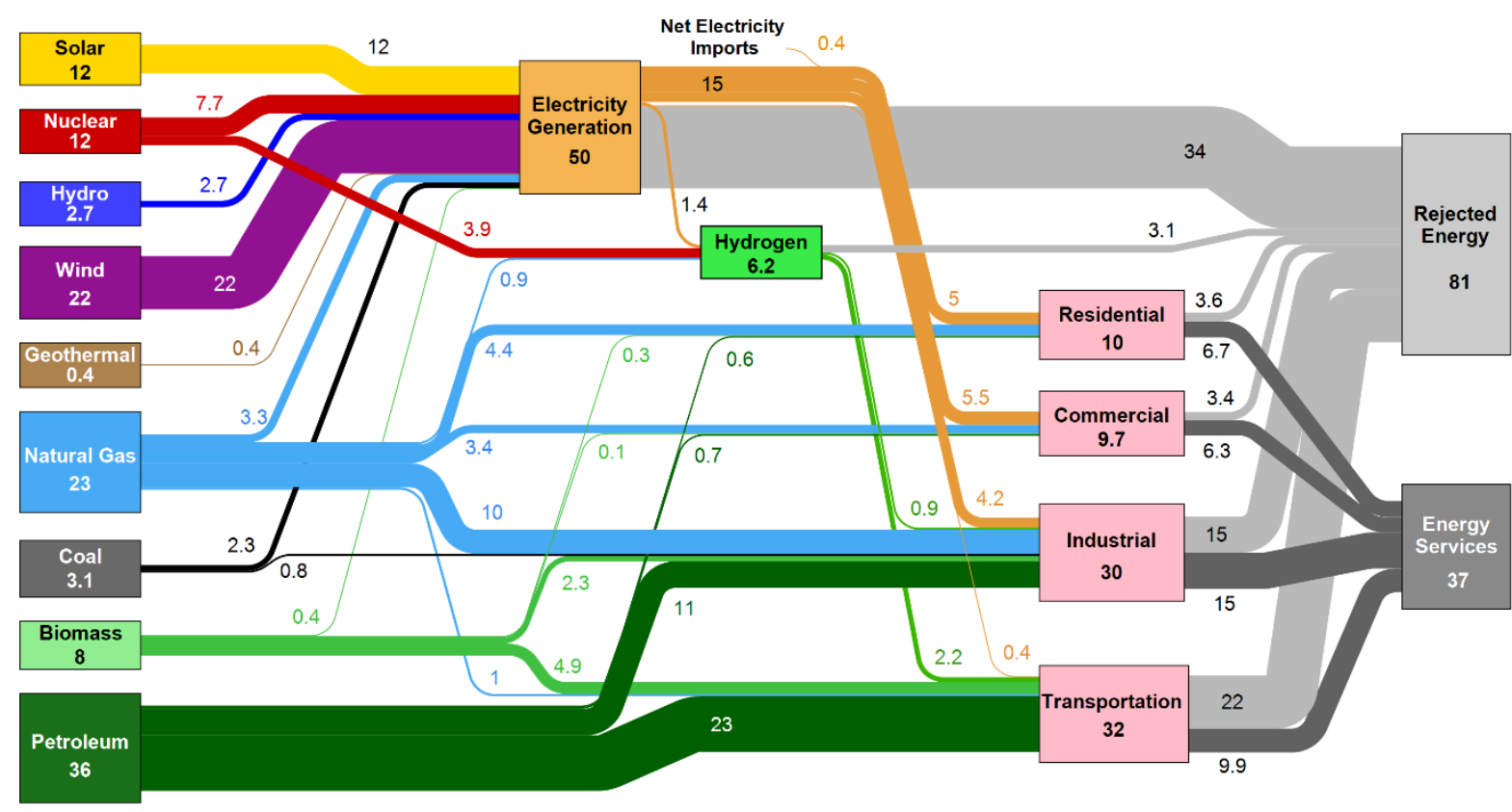

Source: LNLL May 2020. If this information or a reproduction ofit is used, credit must be given to the Lawrence Livermore National Laboratory and the Department of Energy, under whose auspices the vork was performed. Distributed electricity represents only retal electricity sales

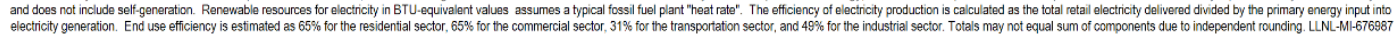

Figure H-8. Energy-use Sankey diagram for the Aggressive Electrolysis R\&D scenario 
2050 Estimated U.S. Annual Energy Use 125 Quads Lowest-Cost Electrolysis

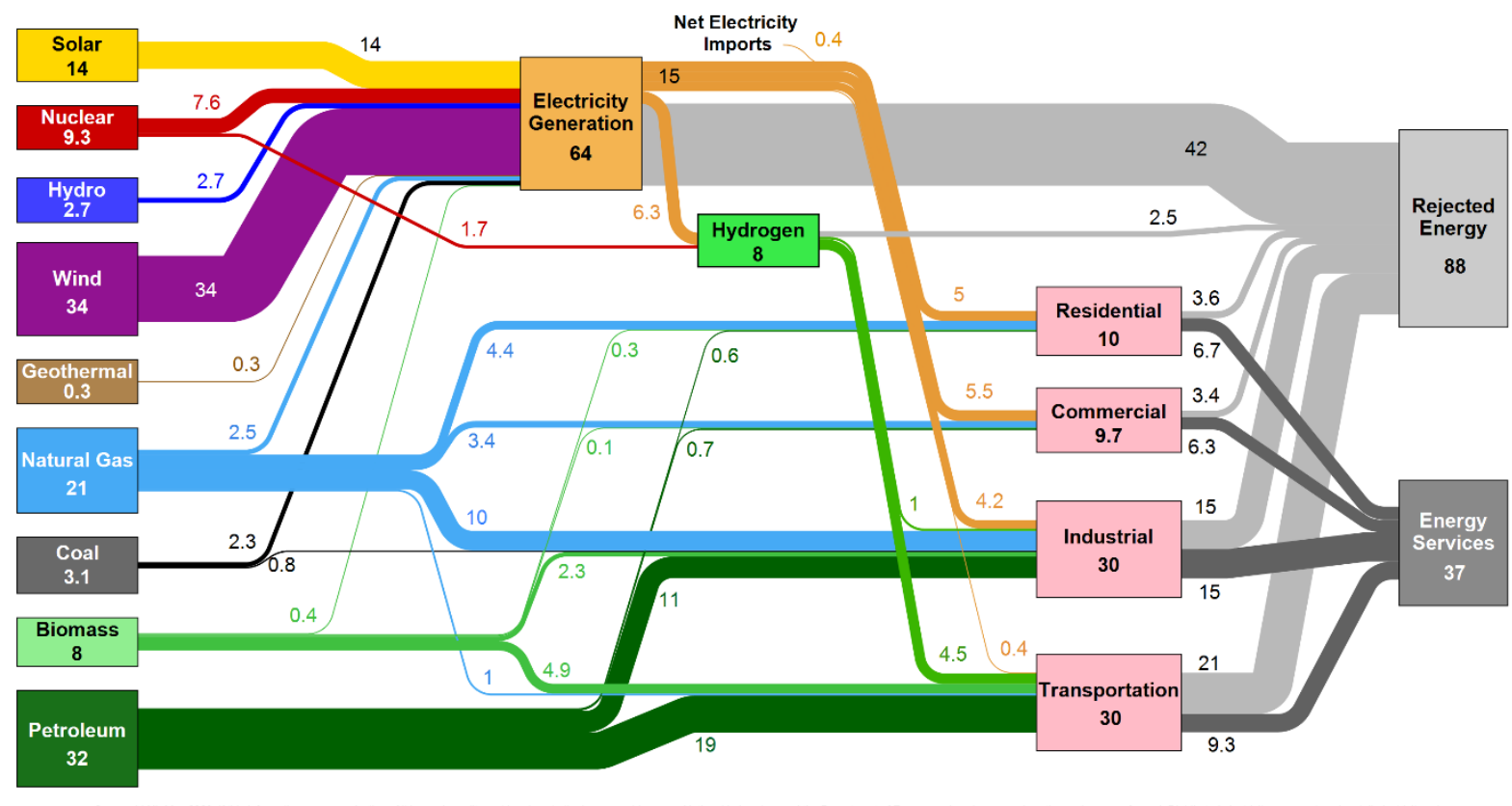

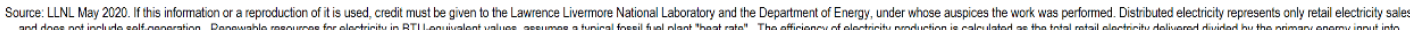

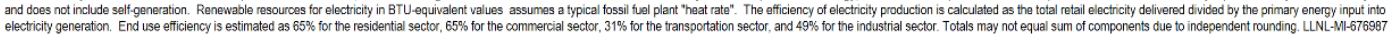

Figure H-9. Energy-use Sankey diagram for the Lowest-Cost Electrolysis scenario

2050 Energy Use Difference Between 'Low NG Resource/High NG Price' and 'ReEDS High Curtailment' (Quadrillion BTUs)

Note: Boxes represent Low NG Resource / High NG Price values

Black Flows indicate Low NG Resource / High NG Price uses more energy than ReEDS High Curtailment Black Flows indicate Low NG Resource/High NG Price uses more energy than ReEDS High Curtailment
Red Flows indicate ReEDS High Curtailment uses more energy than Low NG Resource / High NG Price

Figure H-10. Difference in energy use between the ReEDS High Curtailment and Low NG Resource/High NG Price scenarios 
2050 Energy Use Difference Between 'Aggressive Electrolysis R\&D' and 'ReEDS High Curtailment' (Quadrillion BTUs)

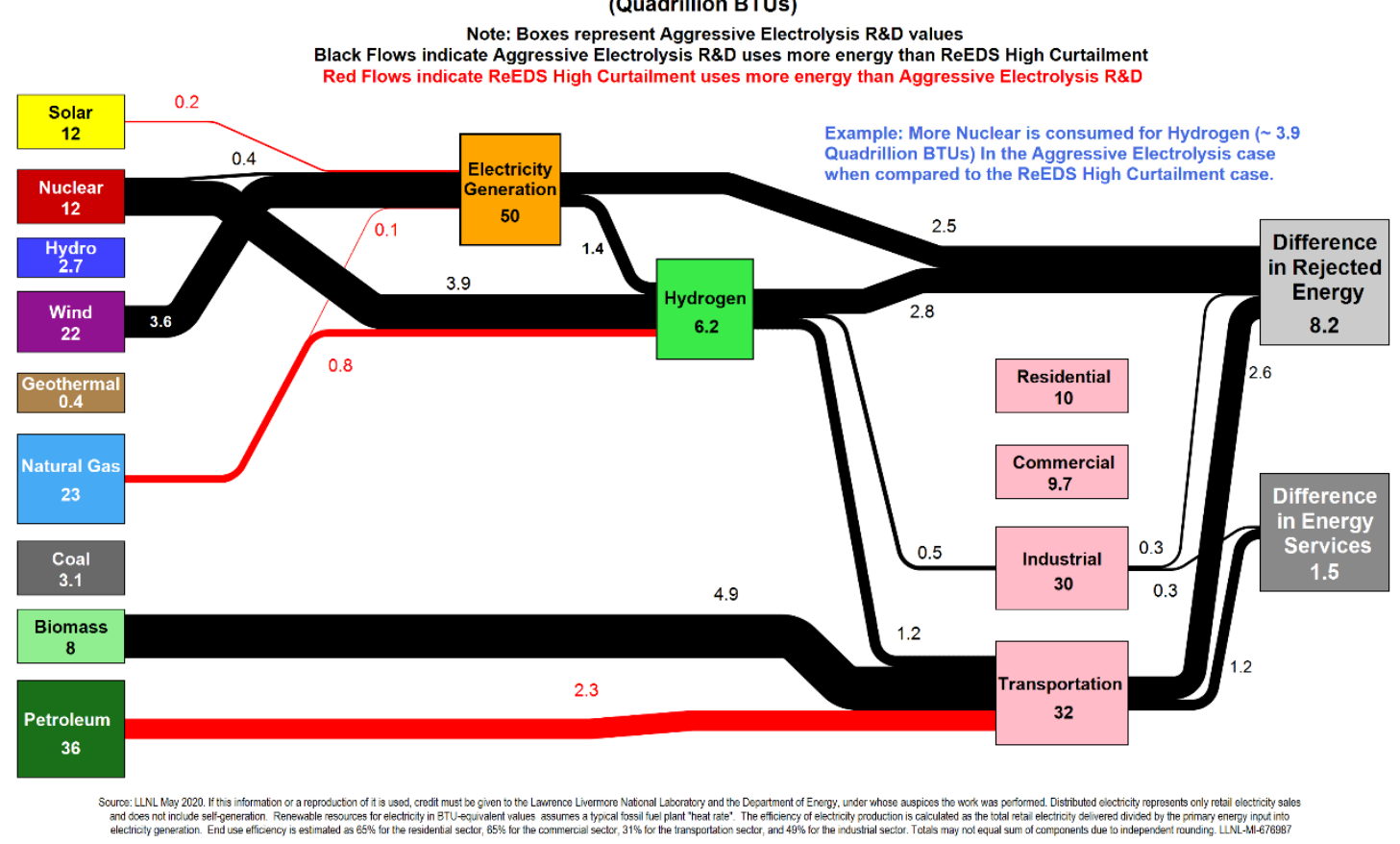

Figure H-11. Difference in energy use between the ReEDS High Curtailment and Aggressive Electrolysis R\&D scenarios

2050 Energy Use Difference Between 'Lowest-cost Electrolysis' and 'ReEDS High Curtailment'

(Quadrillion BTUs)

Note: Boxes represent Lowest-Cost Electrolysis values

Black Flows indicate Lowest-Cost Electrolysis uses more energy than ReEDS High Curtailment

Red Flows indicate ReEDS High Curtailment uses more energy than Lowest-Cost Electrolysis

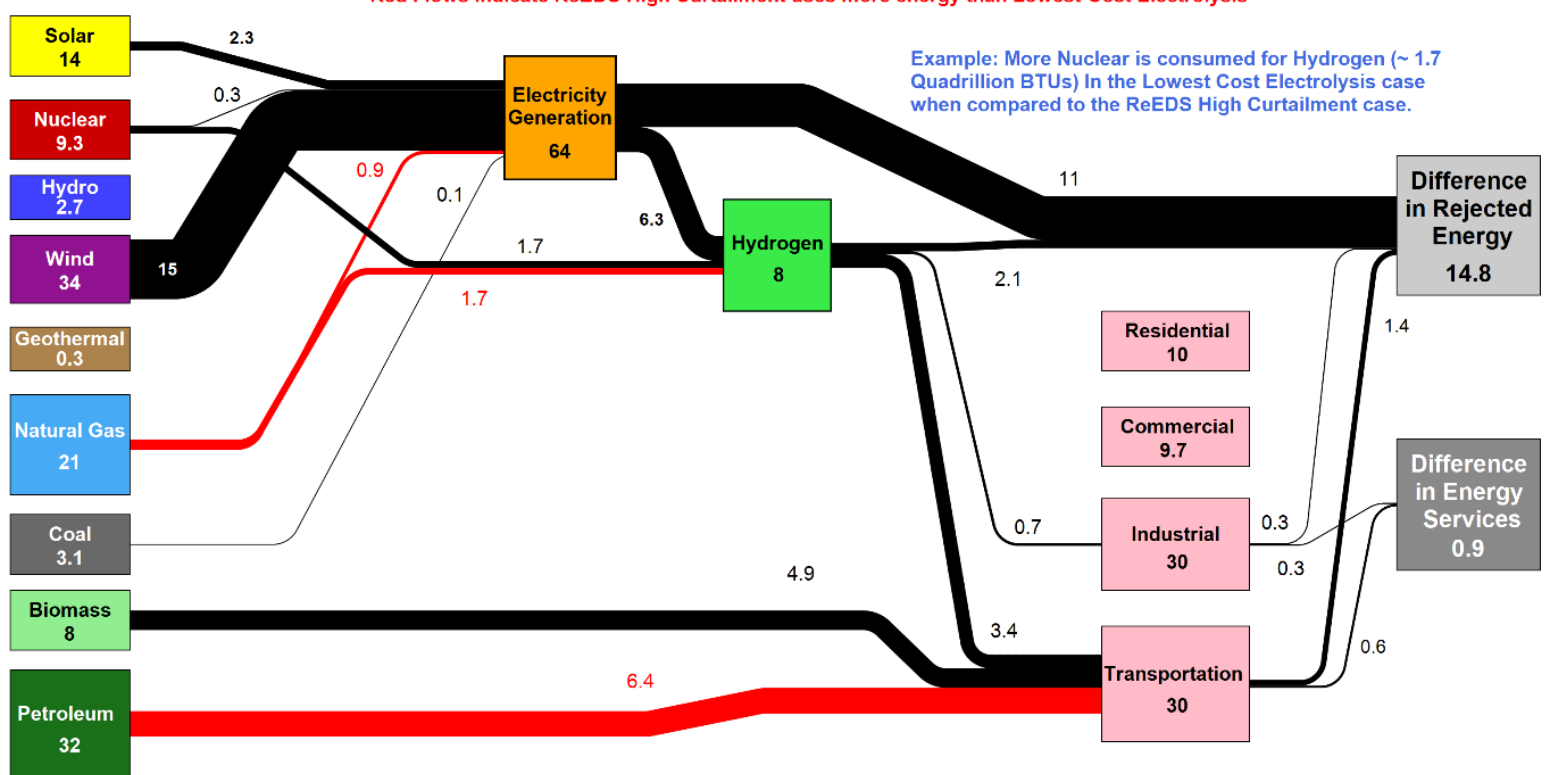

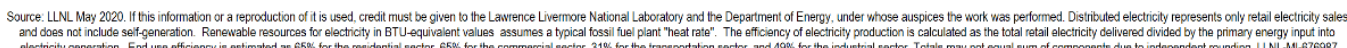

Figure H-12. Difference in energy use between the ReEDS High Curtailment and Lowest-Cost Electrolysis scenarios 


\section{Appendix I. Biomass Heating Value Assumptions}

The biomass gasification process assumed in this study-based on the H2A "Future Central Hydrogen Production via Biomass Gasification version 3.2018" case study (DOE 2018a) — uses a woody biomass feedstock. We estimate biomass resource availability from the 2016 BTS, which includes various resource estimates across herbaceous, waste, and woody biomass (DOE 2016). For consistency with the H2A case study, we convert all resource estimates in the BTS to a poplar energy equivalent using HHVs.

Table I-1 shows the HHVs assumed for each resource in the BTS, based on estimates from the Biomass Energy Data Book (DOE 2010) and the Ontario Ministry of Agriculture, Food, and Rural Affairs (2011). The "Resource Used to Estimate HHV" column lists the resource used in the given reference to estimate the HHV if data for the specific resource from the BTS were not available. The HHV is calculated as the average of the minimum and maximum values if a range is provided in the reference.

Table I-1. Assumptions for Biomass HHVs

\begin{tabular}{|c|c|c|c|c|}
\hline $\begin{array}{l}\text { Resource } \\
\text { Type }\end{array}$ & Resource in BTS & $\begin{array}{l}\text { Resource Used To } \\
\text { Estimate HHV }\end{array}$ & HHV (kJ/kg) & Reference \\
\hline \multirow{14}{*}{ Herbaceous } & Barley straw & Wheat straw & 17,564 & \multirow{13}{*}{$\begin{array}{l}\text { Biomass } \\
\text { Energy Data } \\
\text { Book (DOE } \\
\text { 2010) }\end{array}$} \\
\hline & Corn stover & & 18,078 & \\
\hline & Cotton gin trash & Hulls, shells, prunings & 18,187 & \\
\hline & Cotton residue & Hulls, shells, prunings & 18,187 & \\
\hline & Energy cane & Sugarcane bagasse & 17,918 & \\
\hline & Miscanthus & & 18,840 & \\
\hline & Oats straw & Wheat straw & 17,564 & \\
\hline & Rice hulls & Hulls, shells, prunings & 18,187 & \\
\hline & Rice straw & Wheat straw & 17,564 & \\
\hline & Sugarcane bagasse & & 17,918 & \\
\hline & Sugarcane trash & Sugarcane bagasse & 17,918 & \\
\hline & Switchgrass & & 18,581 & \\
\hline & Wheat straw & & 17,564 & \\
\hline & Biomass sorghum & Biomass sorghum & 17,000 & $\begin{array}{l}\text { Ontario Ministry } \\
\text { of Agriculture, } \\
\text { Food, and } \\
\text { Rural Affairs } \\
\text { (2011) }\end{array}$ \\
\hline \multirow{3}{*}{ Waste } & Citrus residues & Hulls, shells, prunings & 18,187 & \multirow{3}{*}{$\begin{array}{l}\text { Biomass } \\
\text { Energy Data } \\
\text { Book (DOE } \\
\text { 2010) }\end{array}$} \\
\hline & Non-citrus residues & Hulls, shells, prunings & 18,187 & \\
\hline & Tree nut residues & Hulls, shells, prunings & 18,187 & \\
\hline Woody & Eucalyptus & & 19,300 & \\
\hline
\end{tabular}




\begin{tabular}{|c|c|c|c|c|}
\hline $\begin{array}{l}\text { Resource } \\
\text { Type }\end{array}$ & Resource in BTS & $\begin{array}{l}\text { Resource Used To } \\
\text { Estimate HHV }\end{array}$ & HHV (kJ/kg) & Reference \\
\hline & $\begin{array}{l}\text { Hardwood, lowland } \\
\text { logging residues }\end{array}$ & Hardwood wood & 19,685 & \multirow{17}{*}{$\begin{array}{l}\text { Biomass } \\
\text { Energy Data } \\
\text { Book (DOE } \\
2010 \text { ) }\end{array}$} \\
\hline & $\begin{array}{l}\text { Hardwood, lowland whole } \\
\text { trees }\end{array}$ & Hardwood wood & 19,685 & \\
\hline & $\begin{array}{l}\text { Hardwood, upland } \\
\text { logging residues }\end{array}$ & Hardwood wood & 19,685 & \\
\hline & $\begin{array}{l}\text { Hardwood, upland whole } \\
\text { trees }\end{array}$ & Hardwood wood & 19,685 & \\
\hline & $\begin{array}{l}\text { Mixedwood logging } \\
\text { residues }\end{array}$ & Softwood wood & 17,564 & \\
\hline & Mixedwood whole trees & Softwood wood & 18,187 & \\
\hline & Other forest residue & Softwood wood & 19,857 & \\
\hline & Other forest thinnings & Softwood wood & 19,857 & \\
\hline & Pine & \multirow[t]{2}{*}{ Softwood wood } & 19,857 & \\
\hline & Poplar & & 19,380 & \\
\hline & Primary mill residue & Softwood wood & 18,187 & \\
\hline & Secondary mill residue & Softwood wood & 19,857 & \\
\hline & $\begin{array}{l}\text { Softwood, natural logging } \\
\text { residues }\end{array}$ & Softwood wood & 19,857 & \\
\hline & $\begin{array}{l}\text { Softwood, natural whole } \\
\text { trees }\end{array}$ & Softwood wood & 19,857 & \\
\hline & $\begin{array}{l}\text { Softwood, planted logging } \\
\text { residues }\end{array}$ & Softwood wood & 19,857 & \\
\hline & $\begin{array}{l}\text { Softwood, planted whole } \\
\text { trees }\end{array}$ & Softwood wood & 19,857 & \\
\hline & Willow & & 19,153 & \\
\hline
\end{tabular}

The "Resource used to estimate HHV" column lists the resource used in the given reference to estimate the HHV if data for the specific resource from the BTS were not available. 